\title{
Organizing Aid: \\ Exploring Aid Agency Structure and Change Across OECD-DAC Donors
}

by

\section{Rachael Calleja}

A thesis submitted to the Faculty of Graduate and Postdoctoral Affairs in partial fulfillment of the requirements for the degree of

\section{Doctor of Philosophy}

in

International Affairs

Norman Paterson School of International Affairs

Carleton University

Ottawa, Ontario

(C) 2017

Rachael Calleja 


\section{Abstract}

This study provides the first systematic inquiry into the determinants of aid agency structure and change across the five organizational models used by OECD-DAC donors from 1962-2015. In recent years, several donors have reorganized their bilateral aid agencies, sparking debate on the efficacy of different organizational models. Despite such interest, little is known about aid agency structure and the reasons why donors adopt various organizational models and engage in organizational change.

This study develops a multidisciplinary theoretical framework for understanding the factors that contribute to the choice of aid agency structure and change. Using a mixed-method, sequential explanatory research design, this framework is tested in two parts. First, this study conducts a multinomial logit and rare-events logit estimation to identify the main determinants of aid agency structure and change across all OECD-DAC donors since the emergence of aid programs. Using a unique dataset, I find that the purpose of aid programs, political ideology of donor governments, size and structural factors contribute to the choice of aid agency structure, while changes in ODA budget size and structural changes within donors typically precede organizational change. Second, findings from the quantitative analysis are supplemented with six in-depth case studies, which explore organizational choices and changes in Ireland, Iceland, the Netherlands, Australia, Japan and Germany. Building on results from the prior section, the case studies highlight the importance of political factors, administrative efficiency, and substantive purposes as determinants of structural choice and change.

A key finding from this thesis is that the size of aid agencies influences structural choice and change through efficiency, showing that smaller donors have tended to adopt, 
and may be better suited, to merged organizational models. This finding represents a first step towards identifying optimal organizational models based on donor characteristics and has the potential to inform the organizational decisions of new and current OECDDAC members. Overall, this study sheds light on the concept of aid agency structure and provides a starting point for future analysis. 


\section{Acknowledgements}

This thesis was completed with the help of a very supportive village.

To my committee - I am deeply grateful for your time, valuable comments and support throughout this process. This thesis is the result of your collective effort and insight. In particular, this work would not have been possible without the guidance provided by Dr. Yiagadeesen Samy. I greatly benefitted from his perspective and advice throughout this process. This thesis also benefitted from the valuable insight and support of Dr. Stephen Brown and Dr. Robert Sauder. Your comments and viewpoints improved the quality of this thesis. Thank you also to Dr. Dane Rowlands who spent three months in early 2017 patiently answering many inane questions about multinomial logits.

A special thank you to every one of my interviewees, who graciously lent their time and insight to this thesis. The findings presented here are thanks to your knowledge, perspective, and willingness to assist a random Canadian $\mathrm{PhD}$ Candidate.

Thank you to the faculty and staff at NPSIA for the lessons, advice and opportunities over the last six years. I have learnt from every course, paper and exam, and look forward to taking my new skills into the world.

To every friend and family member I've been "too busy" for over the course of this thesis - thank you for your patience, love, and support. I look forward to making up for all the missed silliness in the months to come.

Sean - Throughout this writing process you listened to every problem, celebrated every success, and weathered every thesis-related meltdown (and there were many). I cannot thank you enough for your patience, love and unwavering confidence that I would actually graduate. 


\section{TABLE OF CONTENTS}

CHAPTER 1 - INTRODUCTION

1.1 Scope and Limitations

1.2 Five Models of Aid Agency Organization 8

1.3 Data and Methodology $\quad 11$

1.4 Going Forward 13

CHAPTER 2 - TOWARDS A THEORETICAL FRAMEWORK OF AID AGENCY STRUCTURE $\quad 15$

$\begin{array}{ll}\text { 2.1 Determinants of Organizational Structure: A Literature Review } & 17\end{array}$

2.1.1 Organizational Theory 17

2.1.2 Perspectives from the Public Sector 20

2.1.3 Mergers and Hybrid Forms in the Public Sector 28

2.1.4 Aid Agencies: Understanding Structure

2.1.5 The Research Gap: A Summary 38

2.2 Cunningham in the 21st Century 41

2.2.1 Do Substantive Choices Influence Organizational Design?

2.2.2 Are donors still reactive? $\quad 45$

2.2.3 Summary 58

2.3 Towards a Theory of the Determinants of Aid Agency Structure

2.3.1 What are the substantive choices made by donors? $\quad 60$

2.3.2 Which choice is the most significant for organizational form? 68

2.3.3 What purposes do aid agencies pursue?

$\begin{array}{ll}\text { 2.3.4 Summary and Findings } & 79\end{array}$

$\begin{array}{ll}2.4 \text { Discussion and Hypotheses } & 80\end{array}$

\begin{tabular}{l}
2.5 Conclusion \\
\hline
\end{tabular}

CHAPTER 3 - ANALYZING TRENDS IN AID AGENCY STRUCTURE 93

$\begin{array}{ll}3.1 & \text { Mapping Aid Agency Structure }\end{array}$

3.2.1 Moving Away from Model 5 99

3.2.2 Who Uses Which Model and Why? 104

3.2.3 Convergence to Models 2 and $3 \quad 106$

$\begin{array}{ll}3.3 \text { Conclusion } & 108\end{array}$

CHAPTER 4 - WHAT FACTORS DETERMINE ORGANIZATIONAL STRUCTURE?: A QUANTITATIVE MODEL 111

4.1 Towards a Model of Aid Organization $\quad 113$

$\begin{array}{lr}4.2 \text { Variables } & 114\end{array}$

4.3 The Model $\quad 126$

4.4 Results

$\begin{array}{ll}\text { 4.5 Sensitivity Test } & 137\end{array}$

$\begin{array}{ll}\text { 4.6 Discussion } & 138\end{array}$

4.6.1 Key Results - Significant Variables 138

4.6.2 Key Results - Differences Across Models 140 
5.1 Understanding Organizational Change

5.4 Results

5.5 Discussion

5.6 Conclusion

CHAPTER 6 - DETERMINANTS OF AID AGENCY STRUCTURE IN IRELAND, ICELAND AND THE NETHERLANDS

6.1 Case Selection and Data

6.1.1 Extreme "match" - Ireland

167

6.1.2 Extreme "mismatch" - Iceland

170

6.1.3 Average "match" - Netherlands

6.2 Data and Methodology

172

6.2.1 Data Collection and Interviews

174

6.2.2 Limitations

175

6.3.1 History of Irish Aid

177

6.3.2 Determinants of Ireland's aid agency structure

6.3.3 Discussion

192

6.3.4 Conclusion

6.4 Iceland

196

6.4.1 History of Iceland's Aid Management System

6.4.2 Determinants of Iceland's aid agency structure

6.4.3 Discussion

208

6.4.4 Conclusion

6.5 The Netherlands

6.5.1 History of Dutch Aid Management

6.5.2 Determinants of Dutch Aid Agency Structure

6.5.3 Discussion

6.5.4 Conclusion

6.6 Contemplations and Main Findings

230

6.7 Conclusion

CHAPTER 7 - DETERMINANTS OF AID AGENCY CHANGE IN AUSTRALIA, JAPAN AND GERMANY

7.1 Case Selection

7.1.1 Case Diversity

7.1.2 Data and Methodology

7.2.1 History of Australian Aid Management System

7.2.3 Discussion

7.2.4 Conclusion 
$\begin{array}{ll}7.3 \text { Japan } & 273\end{array}$

7.3.1 History of Japan's Aid Management System 273

7.3.2 Determinants of Organizational Change 282

$\begin{array}{ll}7.3 .3 \text { Discussion } & 286\end{array}$

$\begin{array}{lr}\text { 7.3.4 Conclusion } & 288\end{array}$

7.4 Germany
289

7.4.1 History of Germany’s Aid Management System 289

$\begin{array}{ll}\text { 7.4.2 Germany and the Absence of Change } & 298\end{array}$

$\begin{array}{ll}\text { 7.4.3 Discussion } & 307\end{array}$

$\begin{array}{lr}\text { 7.4.4 Conclusion } & 309\end{array}$

7.5 Contemplations and Main Findings $\quad 310$

$\begin{array}{ll}7.6 \text { Conclusions } & 312\end{array}$

CHAPTER 8 - CONCLUSIONS 314

8.1 Taking Stock of Key Findings: The Determinants of Organizational Choice 319

8.2 Taking Stock of Key Findings: The Determinants of Organizational Change 321

8.3 Importance and Implications $\quad 323$

$\begin{array}{ll}\text { 8.4 Future Research } & 325\end{array}$

$\begin{array}{ll}\text { REFERENCES } & 328\end{array}$ 


\section{LIST OF TABLES}

Table 1: Summary of Findings from Literature Review........................................... 41

Table 2: Donor Role based on Presence of Country Programming ................................ 52

Table 3: Estimatstion 1: Multinomial Logit (Annual Model) ..................................... 129

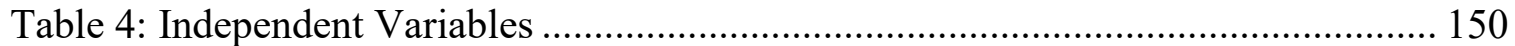

Table 5: Estimation 4: Results of Rare Events Logit.................................................. 157

Table 6: Frequency of Extreme Match Results.......................................................... 169

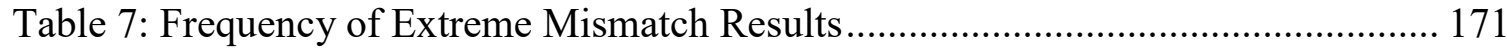

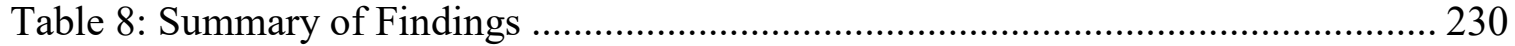

Table 9: CDI Rank for Model 1 Donors ....................................................................... 234

Table 10: Determinants of Organizational Choice - Summary of Findings .................. 319 


\section{LIST OF FIGURES}

Figure 1: Organizational Models ...................................................................... 9

Figure 2: Average ODA/GNI across all OECD-DAC donors from 1960-2015 .............. 47

Figure 3: Average ODA as a proportion of Central Government Expenditure across all

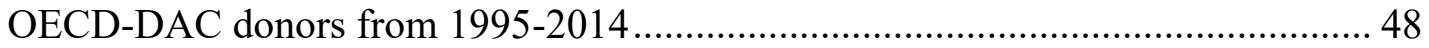

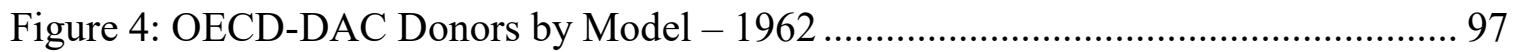

Figure 5: 'Mismatch' between actual and predicted organizational models as $\%$ of

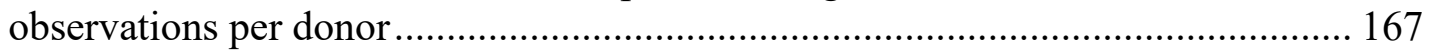

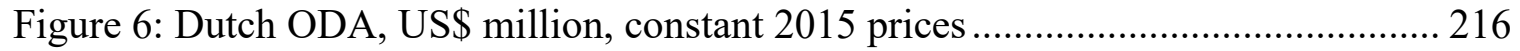

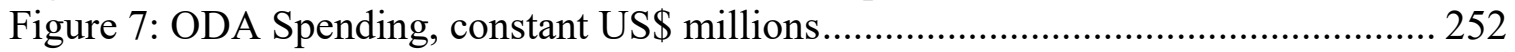

Figure 8: Predicted Likelihood of Australia Adopting the Actual Model Chosen ......... 256

Figure 9: Administrative Costs as a \% of ODA........................................................... 260

Figure 10: Japanese ODA \$US Millions, Constant ................................................. 278

Figure 11: Germany's Total Gross ODA (US\$ millions, constant 2015)...................... 298

Figure 12: Likelihood of Germany Selecting Model 3 Structure ................................. 299 


\section{LIST OF APPENDICES}

APPENDIX 1: OECD-DAC Donor Organization by Year ....................................... 352

APPENDIX 2: OECD-DAC Donor Organization by Year ......................................... 360

APPENDIX 3: OECD-DAC Aid and Peer Review Schedule .................................... 363

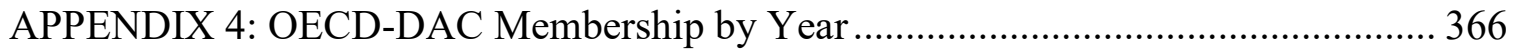

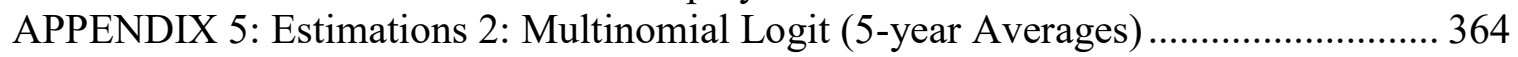

APPENDIX 6: Estimation 3: Annual Model, no outliers ......................................... 365

APPENDIX 7: Correlation of Variables for Multinomial Logit .................................. 369

APPENDIX 8: Correlation of Variables for Rare-events Logit .................................. 370 
CHAPTER 1

INTRODUCTION 
In 2013, the Canadian government merged its bilateral aid agency, the Canadian International Development Agency (CIDA), with the Department of Foreign Affairs and International Trade (DFAIT). The merger resulted in the creation of a new mega bureaucracy called Global Affairs Canada (GAC), ${ }^{1}$ which situates a semi-autonomous aid structure within the mandate of Canada's foreign ministry. While the possibility of a merger had been rumored within Canadian aid circles since the 1990s (see Morrison, 1998), its announcement in the back-pages of the 2013 budget was met with concern from the Canadian development community which feared that the new institutional arrangement would subordinate development to foreign policy interests managed by the larger and more powerful DFAIT (see Brown, 2013; CBC News, 2013).

Such concerns represent conventional wisdom on the relationship between aid agency structure and performance, which extolls the potential value of aid agency autonomy for enhancing the effectiveness of donor actions. At its core, the argument is based on the understanding that "governance structures that entrust a development ministry with robust authorities for policy-setting and execution are better able to protect the global public goods aspects of aid effectiveness" than foreign ministries, which are also responsible for pursuing political and commercial objectives (Gulrajani, $2014 \mathrm{p}$. 102). Greater autonomy between foreign ministers and aid agencies is seen to increase "the capacity [an aid agency] has to pursue its mission without having to negotiate with other government agencies or direct its resources towards supporting their mission" (Lancaster, 2008 p. 52).

Despite this conventional wisdom, the number of traditional donors that manage their development programs through a separate department has actually declined over the

\footnotetext{
${ }^{1}$ Previously called the Department of Foreign Affairs, Trade and Development (DFATD).
} 
last 15 years. While four donors used separate aid agencies for policy formation and implementation in 2000 (Canada, Australia, US and UK), the only donor that still adopts this structure today is the UK, which has been considered one of the best bilateral aid agencies throughout the past decade (see Easterly and Pfutze, 2008; Knack, Rogers and Eubank, 2010). Given the perceived benefits of autonomy, the declining use of autonomous aid agencies suggests that donors are increasingly selecting models that are considered less well aligned with achieving development outcomes. In this context, an important question concerns the determinants of organizational choices, or put differently, why donors select the organizational models that they adopt?

Importantly, the rationale surrounding the adoption of particular aid agency structures has largely been ignored by the academic literature. The most relevant attempt to understand the drivers of aid organization was conducted by George Cunningham in 1974. Writing soon after the emergence of aid agencies as actors in international relations, Cunningham suggests that donors adopt organizational structures that match their substantive preferences, where aid programs are organized to achieve a specific purpose (1974, p. 2). Importantly, Cunningham's thesis was neither tested nor verified against other possibilities, raising questions concerning the credibility of his argument in practice. Since Cunningham, most studies of aid agency structure have tended to focus on the relationship between structure and effectiveness (Faure, Long and Prizzon, 2015; Gulrajani, 2012; Gulrajani, 2014, 2015a), seeking to understand whether and how organizational factors, including structural autonomy, influence the effectiveness of aid programs. Although these studies provide some insight into the behaviour of donors in 
relation to particular structures, they overlook questions pertaining to the determinants of structural forms in the first instance.

Limited scholarly engagement with factors that determine aid agency structure has created a gap in the literature. Indeed, no study has ever systematically explored questions of aid agency structure, including whether there is a theory or model for explaining structural choices. This study intends to narrow that gap by addressing the primary research question: why do donors adopt different structural forms? Recognizing that in many cases the structural models currently used by donors are rooted in past reorganizations, answering this research question will require examining the impetus for organizational change as well as the factors that determine the new structure chosen. These issues will be addressed though answering two sub-questions: Why do donors reorganize aid agencies? What factors determine the new structural form?

Understanding the reasons why donors adopt various organizational models is an important first step towards more meaningful conversations on the relationship between structure and donor effectiveness. At the most basic level, the typical narrative around aid agency autonomy implies that autonomous agencies are more likely to deliver aid in alignment with aid effectiveness principles. ${ }^{2}$ There are however, two key problems with this logic. First, the logic itself is largely untested. Any meaningful assessment of the relationship between structure and effectiveness requires systematic analysis of donor effectiveness in relation to the structures used by multiple donors over time. While previous studies have begun to explore the linkage by grouping donors according to the organizational models used (for example, Faure et al., 2015), such studies have only

\footnotetext{
${ }^{2}$ As far as I am aware, there is no convincing evidence that autonomous structures cause or enhance aid effectiveness.
} 
presented organizational groupings at snapshots in time and do not allow for meaningful time-series analysis. Through understanding the determinants of aid agency structure, this study will compile the most comprehensive data on aid agency structure across donors and time, to date.

Second, implicit in the theoretical linkage between autonomy and effectiveness is the assumption that autonomous structures will be equally effective for donors seeking to maximize development impact. The trouble however, is that this logic does not account for differences between donors that may limit the effects of an autonomous structure in certain contexts. For instance, differences in donor size may alter the practicality of adopting autonomous structures in the first place. By seeking to understand the determinants of aid agency structure, this study is a first attempt to take stock of the gamut of reasons for adopting specific organizational structures including the reasons why donors do (and do not) adopt autonomous agencies. Doing so is a necessary first step towards understanding the conditions under which autonomy may be a viable structural form for donors seeking to enhance effectiveness, marking a clear contribution to an underdeveloped literature.

The remaining sections of this introductory chapter outline the parameters and methodology that will be used throughout this study. The next section provides a brief account of the scope of the study, clearly outlining the main limitations of the sample used. The second section outlines the main typology of aid agency structures that will frame the study and serve as the main dependent variable throughout. The third section highlights the main data sources and methodology used in conducting this study. A final section provides a brief outline of the study by chapter. 


\subsection{Scope and Limitations}

This study will focus exclusively on bilateral agencies to ensure meaningful comparison across the sample population. While bilateral agencies are responsible to donor governments, which give them their mandates and cues, multilateral agencies are likely to be influenced by the competing interests of member states. As a result, the factors influencing aid agency structure are likely to differ between bilateral and multilateral donors.

The time period covered in this study will extend from the 1960 s to the present day. While many aid programs officially began in the late 1940s as part of the Marshall Plan and efforts to reconstruct Europe following the Second World War, aid agencies as they are known today find their roots in the early 1960s. According to the International Development Association (IDA) (2007), the 1960s was a decade of "economic development assistance" following a period concerned by post-war security and reconstruction. During this period, "most donors established separate, in some cases independent, development cooperation structures" (IDA, 2007 p. 28) with nine countries (Canada, Germany, Japan, Sweden, Belgium, Switzerland, Norway, Denmark and the Netherlands) establishing "ministries or agencies to manage their development cooperation programs between 1960 and 1963" (IDA, 2007 p. 29). Prior to the 1960s, only three donors (France, the UK and the US) allocated aid through specialized ministries or agencies (IDA, 2007). In essence, the large-scale emergence of aid agencies as structures to manage aid programs in the early 1960s, justifies the use of 1960s as the historical time period in which aid agencies emerged. As a result, the historical scope of this study extends from 1960 to the present day. 
Additionally, this study will exclusively examine OECD-DAC donors in order to ensure meaningful comparison across a reasonably similar sample population. It is well established that OECD-DAC donors subscribe to similar standards and principles; such standards are not necessarily consistent with the practices and standards of other groups of bilateral donors. According to Zimmerman and Smith (2011) and Waltz and Ramachandran (2011), there are several categories of "donors" that currently provide bilateral aid spending: OECD-DAC donors, "emerging donors", providers of SouthSouth Cooperation, and Arab donors.

Importantly, Arab donors and providers of South-South Cooperation have notoriously avoided adopting international standards for aid programming, using markedly different models of aid giving and operating well outside typical OECD-DAC defined standards of practice (Zimmerman and Smith, 2011). In addition, various forms of government found within Arab and South-South donor countries suggest that different formal and informal links between government ministries, executive powers, and donor agencies, are likely to alter relations and may influence aid agency structure. Indeed, differences in the purposes, preferences and practices of Arab and South-South donors render these groups distinct from OECD-DAC donors.

Of the other groupings, "emerging" donors are the most similar to the OECDDAC category. Zimmerman and Smith (2011) note that donors in the "emerging donor" category, which tend to be Eastern European countries, are remarkably similar to OECDDAC donors in their propensity to actively report aid data. However there remain clear differences between OECD-DAC and "emerging donors", as "emerging donors" tend to channel aid through multilateral institutions rather than through bilateral programs. 
The point here is not to suggest that OECD-DAC donors are uniform in their behaviour or policies. Even among OECD-DAC donors, clear differences exist in terms of budget size, share of bilateral/multilateral spending, implementation of Paris aid effectiveness principles, etc. However, OECD-DAC donors are uniform in terms of their compliance with DAC data reporting standards, which ensures that close to full data is available for donors throughout their tenure as OECD-DAC members. Prior to joining the DAC, data availability and quality is less reliable. Similarly, the consistent preparation and participation of OECD-DAC donors in Peer Reviews ensures that information on aid management is available and accessible in English for each donor. Without such reviews, tracing aid management in a consistent manner across donors from the 1960s would be virtually impossible given language barriers. The ability to ensure comparable and accessible data is a key justification for restricting the sample to OECDDAC donors.

Lastly, due to the first limitation, which restricts the sample to bilateral donors only, the European Union will be the only OECD-DAC donor not included in this study. While the European Union acts as a bilateral donor, its multilateral composition suggests that the factors influencing the organizational structure of the EU aid agency may differ from those that are significant for single-country bilateral donors. Limiting the study to bilateral OECD-DAC donors will enhance the comparability of the population.

\subsection{Five Models of Aid Agency Organization}

The first step towards understanding the determinants of aid agency structure is identifying the range of organizational models typically used by OECD-DAC donors. 
According to the OECD, DAC donors have tended to adopt one of five distinct models (Figure 1) to organize aid programs (Chang et al., 1999; OECD 2009). The first model, used by Norway and Denmark, places development cooperation within the ministry of foreign affairs, rendering foreign affairs responsible for development policy and implementation. In this structure, responsibility for development is grouped with political and trade relations by country or region. The second model provides a greater role for "Development Cooperation Directorates" or semi-autonomous agencies within the ministry of foreign affairs, where development actors maintain responsibility for development policy and implementation. Countries using this model include Ireland, New Zealand, Canada (following the recent merger of CIDA with DFAIT) and Australia (following the integration of AusAID into DFAT). A third model, associated with France, Germany, Sweden, and Japan uses separate executing agencies for the implementation of development programming, where policy decisions are made by responsible ministries (typically, but not exclusively foreign affairs). The fourth model places a separate ministry or agency, which is not foreign affairs, as responsible for creating and implementing development policy. The only country currently using this model is the United Kingdom (OECD, 2009a). A fifth model uses multiple ministries which each take responsibility for various aspects of aid programming. While this model became obsolete in the early 2000 s, it had previously been used by a number of countries including Japan, France, Austria, Portugal and Spain (Chang et al., 1999).

\section{Figure 1: Organizational Models}


Model 1

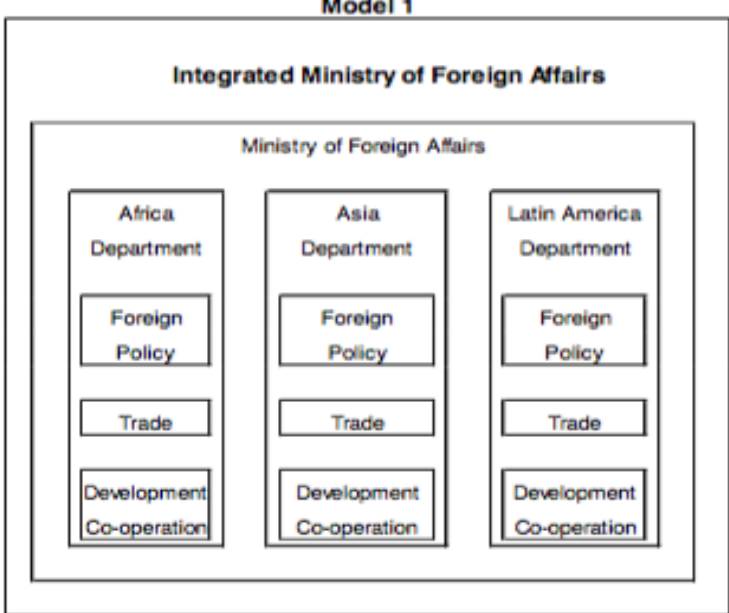

Model 3

Policy Ministry with Separate Implementing Agency

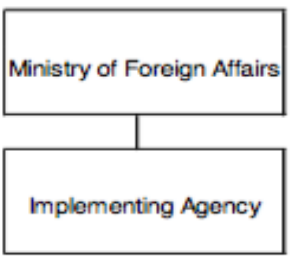

Model 2

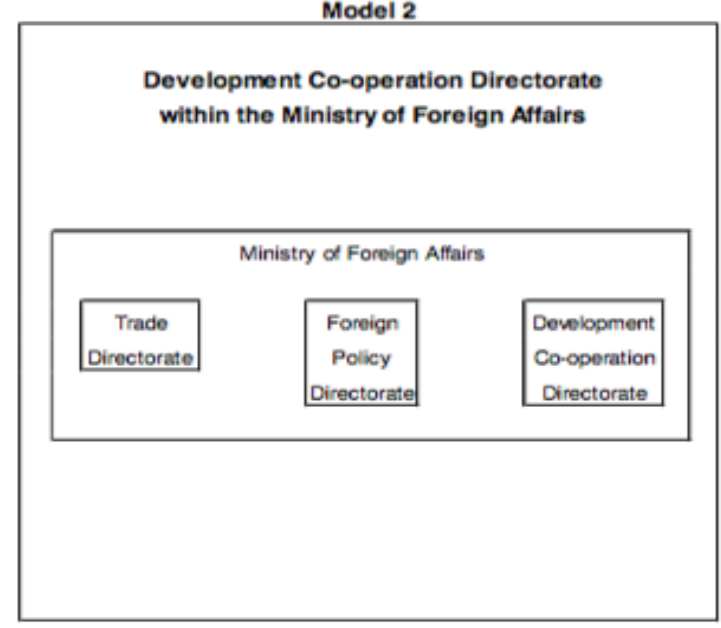

Model 4

Autonomous Aid Agency

Ministry/Agency for Development Co-operation

Model 5

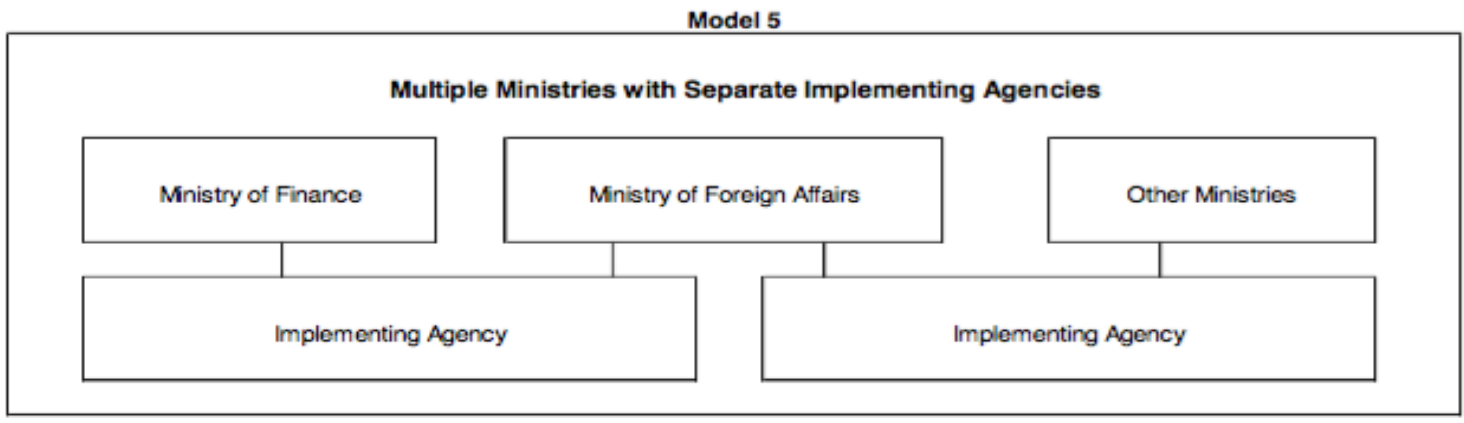

Source: Chang et al. (1999). A Comparison of Management Systems for Development Cooperation in OECD/DAC Members. Paris: Organisation for Economic Cooperation and Development.

This study utilizes the OECD-DAC's typology of aid agency structure throughout its discussion and analysis. This is done for two main reasons. Firstly, the OECDDAC's typology has formed the basis of most current studies that seek to engage with questions of aid agency structure (see Gulrajani, 2015a; Faure at al., 2015) rendering its 
use consistent with the broader academic literature. Secondly, the majority of the data used throughout this study to understand and trace organizational models is taken from OECD-DAC Peer Reviews. Using the OECD's typology ensures that analysis of these reviews is consistent with the OECD's understanding of the main organizational types used by DAC donors.

\subsection{Data and Methodology}

This study employs a mixed methods research design in efforts to generate a holistic answer to the proposed research questions. Mixed methods research provides many methodological benefits. For instance, mixed methods approaches offset the weaknesses of both quantitative and qualitative evidence by building on the strengths of both approaches (Cresswell and Plano Clark, 2006). In doing so, it is possible to obtain more comprehensive evidence for studying a research problem by using multiple tools for data collection and analysis, and presenting answers to questions that cannot be adequately addressed by either quantitative or qualitative methods alone (Cresswell and Plano Clark, 2006). Combining quantitative techniques with case studies promises to capture a more holistic understanding of aid agency determinants by accounting for both the statistical relationship between variables theorized to explain organizational structure across the entire donor sample, as well as context specific factors that may determine structural form in individual cases.

A mixed methods research design is ideal for the research question posed in this study for two main reasons. Firstly, in order to provide an adequate response to understanding the determinants of organization across OECD-DAC donors, it is 
necessary to conduct cross-comparative research on the largest sample of donors possible. Given the exploratory nature of this research, and the numerous theoretical explanations for organizational design that should be considered, quantitative analysis provides a strong methodological tool for testing numerous independent variables across OECD-DAC donors and over a long period of time.

After developing the theoretical framework to guide analysis, two quantitative models are used to test the determinants of aid agency structure, and changes in aid agency structure, across OECD-DAC donors from 1962 to 2015. The first model uses a multinomial logit technique to understand the determinants of the choice between organizational models, while the second model uses a rare-events logit to test the determinants of organizational change in aid programs. Both models utilize an original dataset that combines proxy variables for organizational determinants with a categorical dependent variable to capture the organizational model used by donors over time.

While quantitative methods provide a good picture of general trends in the relative importance of key independent variables as determinants of organizational form, such methods are not able to capture the unique context of individual donors and qualitative nuances that undoubtedly influence organizational choices. In order to ensure that this study accounts for the subtleties and contextual factors that contribute to donor decisions regarding organizational structure, the quantitative analysis is followed by six case studies presented over two chapters. The first three cases complement the statistical model designed to assess the determinants of structural form by conducting a focused, structured comparison of structural determinants in the case of Ireland, Iceland and the Netherlands. The remaining cases build on the rare events model used to understand the 
determinants of organizational change and provides a more in-depth analysis of reorganizations in the cases of Australia, Japan and Germany. These cases were selected using post-estimation techniques derived from the quantitative findings and are a representative cross-section of donors in terms of size, OECD-DAC membership and organizational model used.

Taken together, the case studies aim to further explain findings from the quantitative models. The cases rely heavily on desk research as well as interviews with 2-3 key individuals from each of the six countries used as cases. The interviews played a key role in the qualitative analysis, providing significant insight into the main factors and contexts, which contributed to determining aid agency structures and reorganizations. More specific information on the case selection and interview methodology is provided in Chapter 6.

\subsection{Outline}

The remainder of this study proceeds as follows. Chapter 2 lays out the theoretical framework that will provide the basis for the remainder of the study. Chapter 3 provides a descriptive analysis of trends in aid agency structure over time and outlines the methodology and data used to map aid agency structures across donors and time. Chapter 4 presents a multinomial logit model used to examine the determinants of aid agency structure. Chapter 5 presents a rare-events model used to understand the determinants of reorganization in aid programs. Chapter 6 presents the first three crosscomparative case studies of the Icelandic, Irish and Dutch cases to provide a deeper exploration of the determinants of aid agency structure, while Chapter 7 presents the 
second set of cross comparative cases, looking at Australia, Japan and Germany, to identify the main drivers of organizational change. The dissertation closes with Chapter 8, which explores the policy implications, insights for future research and concluding remarks. 
CHAPTER 2

TOWARDS A THEORETICAL FRAMEWORK OF AID AGENCY STRUCTURE 
This chapter develops a theoretical framework for understanding the determinants of aid agency structure and to guide analysis presented in the rest of the study. To do so, this chapter begins by conducting a detailed, extensive and multidisciplinary literature review. Through exploring the literature from organizational studies, public administration and international development, this chapter identifies the main variables for understanding the choice of aid agency structure and outlines a clear gap in the current knowledge which will be narrowed throughout the course of this study.

This literature review includes an in-depth discussion of the study most closely related to the current one, namely George Cunningham's 1974 book which argues that aid agencies are structured to match substantive priorities. While Cunningham's work provides an important basis for considering questions of aid agency structure, his study is both outdated and untested. In order to be relevant to the current discussion, I update Cunningham's theory to account for changes to the development landscape and literature that have implications for his understanding of the substantive priorities that underlie aid management decisions.

This chapter closes by outlining the main hypotheses to be tested throughout the remaining chapters of this study. The hypotheses are based on key variables related to aid agency structure highlighted throughout the literature review and discussion of Cunningham's theory. In effect, these hypotheses act as the foundations for this study and provide the theoretical framework that guides the analysis presented in the following chapters. 


\subsection{Determinants of Organizational Structure: A Literature Review}

\subsubsection{Organizational Theory}

The literature on structural determination can generally be divided into two main categories. The first suggests that organizational structure is driven by efforts to increase efficiency (Taylor, 1947; Weber, 1947; Woodward, 1965; Hage and Aiken, 1967; Hall, 1962; Pugh et al., 1963, 1969; Chandler, 1962). Within this stream, the most prevalent explanation suggests that organizational structure is determined by the contextual factors that constrain individual organizations (Donaldson, 2001; Pennings, 1992; Child, 1972). Proponents argue that organizational effectiveness stems from "fitting" organizational structure to the contextual factors or "contingencies" that constrain operations. The theory suggests that certain contextual variables, such as agency size (Blau, 1970) organizational strategy (Chandler, 1962), and environmental change (Pennings, 1992), have the potential to limit output by constraining organizational functioning. As a result, the most effective structures are those that best "fit" organizational contexts. According to Donaldson, organizations in "fit" with contingencies are likely to enjoy higher performance, which in turn generates surplus and facilitates expansion - growth in size, innovation, diversification, etc. As organizations grow, their contingencies change. These changes cause organizational structures to be out of "fit" with new contingencies where reorganization becomes a way to adapt structures to new structural contingencies and ensure continued "fit".

An important potential source of misfit is organizational size. Rooted in Weber's (1947) classic analysis of bureaucracy, contingency theorists find that organizational size influences the type of organizational structure best suited to maximize efficiency. For 
instance, small organizations are more efficient with highly centralized decision-making and low intra-organizational specialization, which allows top managers to control the organization directly. Alternatively, larger organizations maximize efficiency through decentralizing decision-making and formalizing separate divisions for task specialization (Donaldson, 2001). Other key contingencies include external (or environmental) contingencies, which pertain to contextual factors that can constrain organizational leadership and design (see Donaldson, 2001; Sadler and Barry, 1970; Pennings, 1992), as well as strategic contingencies that impact the internal structure needed to meet agency goals (see Chandler, 1962; Galbraith, 1973).

While contingency theory remains a prominent perspective for understanding organizational structure, it has been criticized for being overly deterministic. For Child (1972; 1997), determinism inherent in contingency theory, where structures are created and defined by organizational contingencies, causes the theory to ignore political processes that allow power-holders within organizations to choose structural forms based on strategic preferences. Child's criticism gives rise to the theory of strategic choice, where power-holders, who aim to maximize firm efficiency and profit, are afforded the agency to influence organizational design. Moreover, Child's theory extends to the environment in which organizations operate, where power-holders choose the environment, and subsequently the constraints, that influence organizational forms.

In contrast, a second branch of the organizations literature offers an institutional perspective for understanding organizational design, where legitimacy is deemed to be the fundamental driver of structural design and change (Clegg, Kornberger, and Pitsis, 2011; Donaldson, 2006; DiMaggio and Powell, 1991). Institutional theorists argue that 
organizations adapt to their institutional context by adopting features that are recognized as legitimate within the larger institutional environment, where organizational structure is determined by the prevailing institutional norms within a field. As a result, the source of organizational change is exogenous to organizations themselves (Wooten and Hoffman, 2008) and the environment containing organizations becomes a socially constructed context that molds the processes of organizational decision-making and structural change (Scott, 2001; Heugens and Lander, 2009).

Within this literature, several competing ideas are presented to address how and why the institutional environment influences organizational form (Scott, 1987). DiMaggio and Powell (1983) suggest that in any given field, organizations undergoing structural change will tend to adopt (or morph into) the characteristics of similar firms. Such isomorphic change occurs through three main mechanisms: coercion, mimicry, and normative processes. Coercive isomorphism is caused by the exertion of pressures on organizations by actors on which they are dependent, such as resource providers (Bridges and Villemez, 1991; Teo, Wei and Benbasat, 2003) or governments with formal legislative power (Provan, 1987). The second form of isomorphism is mimicry, where uncertainty from poorly understood technologies, ambiguous goals, or environmental factors urge firms to model themselves on other organizations (DiMaggio and Powell, 1983). Haunschild and Miner (1997) explain that organizational templates for mimicry are those of highly visible organizations, successful counterparts, or those used by many organizations within a field. Finally, normative isomorphism stems from the professionalization of fields, where members gain collective control over membership and operational forms (DiMaggio and Powell, 1983). The new norms created by 
professionalization diffuse through professional networks (Lee and Pennings, 2002) or key legitimizing institutions (Honig and Karlson, 2004).

While the organizational studies literature offers insight for understanding the general determinants of organizational structure, it is important to recognize that this literature largely focuses on the organizational structure of firms. Understanding that the incentives and priorities of profit-seeking businesses are largely different from those of aid agencies, or public organizations more generally (see Perry and Rainey, 1988; Bozeman and Bretschneider, 1994; Rainey and Bozeman, 2000, Christensen et al., 2007), it is important to look beyond this literature to identify additional factors that are relevant in the public sphere. The next section explores the determinants of organizational form from a public sector perspective.

\subsubsection{Perspectives from the Public Sector}

At the most basic level, the literature on public sector organization can be divided into two broad categories. The first explores facets of internal relations and behaviours within government agencies (see Denhardt, 2008; Argyris, 1973), such as managerial techniques (see Berry, 1994; Rainey, 1983; Khojasteh, 1993) and employee attitudes (DeSantis and Durst, 1996) to understand the impact of such behaviour on internal organizational development. The second provides broader theoretical perspectives for understanding the factors that contribute to the organizational features of government bodies themselves. Given that this study is interested in exploring the determinants of aid agency organization in relation to other government structures, notably foreign ministries, discussions of internal staffing/managerial relations found within the first group of studies offers little explanatory power for addressing the proposed research question. 
Indeed, these studies appear to take organizational location and structure as given, focusing instead on the individual and group dynamics within organizational entities. As a result, this study will focus on public sector organizational theories that speak directly to the broader questions of the organizational determinants of government agencies. Such theories appear to fall under three main perspectives for understanding the determinants of organizational form in the public sector: structural-instrumental, cultural, and environmental perspectives.

\section{Structural-Instrumental Perspective}

The structural-instrumental perspective posits that public organizations are tools (or instruments) designed to achieve particular goals (Christensen et al., 2007; Christensen and Læfreid, 2011). From this perspective, organizational structure and change are determined through choices based on perceived consequences in relation to stated goals (Christensen et al., 2007 p. 20). As such, decision-makers in public organizations are seen as instrumentally rational actors who choose to design structures that offer the best approach for reaching desired goals.

The emphasis on calculated decision-making highlights the central role of leaders as drivers of organizational structure and change, where leaders are seen to "have a relatively large degree of control over reform processes” (Christensen and Læfreid, 2011 p. 411). However, the actions of leaders are constrained by the structural, constitutional and polity factors that inform and compose the broader context in which organizations operate. While the degree and effect of such constraints vary, where tight constraints may give leaders hierarchical control but limited space for action and looser constraints may provide discretionary influence with limited direction (Christensen and Læfreid, 
2011), both cases suggest that the influence of public sector leaders is limited by the features of the broader political-administrative regime.

The structural-instrumental perspective is grounded in the broader literature on rational choice institutionalism. In particular, transaction-cost and principal-agent theories have been readily applied to the public sector to explain organizational structure. The transactions-cost approach, which is commonly traced to Coase (1937), and later Williamson $(1979 ; 1981)$, suggests that organizational structure is designed to reduce the transaction costs (or enhance efficiency) of particular activities. While some contend that public institutions cannot be presumed to structure agencies based on efficiency (Moe, 1984; 1989; North, 1990b), Williamson (1999) finds evidence that public bureaucracies are particularly well suited to reduce the costs of sovereign transactions, such as those conducted in foreign affairs, defense, intelligence, and development assistance.

The rational choice perspective has also employed principal-agent theory to understand organizational form in the public sector. At the most basic level, principalagent theory "deals with the design and control problems a principal has when delegating a task to a specialized and autonomous agent", such as the problems government (principals) face when engaging with autonomous public bodies (agents) (Læfreid and Verhoest, 2010 p. 7). In brief, principal-agent theory focuses on institutions within a framework of contractual relations between a principal and agent (Verhoest et al., 2012). Underlying this relationship are incongruent goals and information asymmetry, where the principal is able to observe the outcomes of agent processes but is unable to monitor the day-to-day actions of its agent (Miller, 2005). In the policy setting, these challenges can 
lead to deviant policy execution and low performance with respect to the principal's goals (Verhoest et al., 2012).

In the public sphere, principal-agent theory has been readily applied to the relationship between executive powers and government agencies (Schillemans, 2013), where political principals monitor the actions of bureaucratic agents, like aid agencies. In these cases, information asymmetries between political principals and bureaucratic agents force principals "to decide how much discretion should be delegated to bureaucrats and how policy implementation can be controlled to ensure that outcomes will be as intended" (Christensen et al., 2016, p. 213). In part, how this relationship is managed is linked to organizational structures (government departments, statutory bodies, and stateowned foundations or corporations) used to arrange bureaucratic functions. Of these organizational forms, Christensen et al. (2016) suggest that government "agencies" are more autonomous and provide fewer opportunities for intervention by political principals.

Over the last three decades, many changes to the organizational structures of Western governments involved the formation of government agencies, where governments separated executive units from central control to create new and autonomous structures (Van Thiel and Yesilkagit, 2011; Pollitt and Bouckaert, 2004; Pollitt et al., 2001). According to Pollitt et al. (2001), such separation was modeled on the principal-agent dynamic, where the creation of agencies permitted greater transparency by creating performance criteria and budgetary limitations for government agents. In this sense, Van Thiel and Yesilkagit (2011) suggest that new agencies are sometimes created to resolve problems with public sector performance, where governments contract functions to arms-length agencies that can be held accountable in 
instances of poor performance. Alternatively, Christensen et al. (2016) suggest that the creation of agencies, or "agencification", can be used to de-politicize specific tasks by locating functions in autonomous units to limit political interference. In part, the principal-agent dynamics imply that reorganizations are likely to occur when principals seek to tighten control over opportunistic agents (Lane, 2005; Donaldson, 1990). Based on the understanding that agents are expected to pursue their own interests, reorganizations can be viewed as an attempt to curb opportunistic behavior and align agent action with principal priorities through vertical integration and mergers (Dunleavy, 1991).

\section{Cultural Perspective}

The cultural perspective suggests that over time, public organizations develop informal norms that evolve into distinct cultures within organizations (Christensen and Læfreid, 2011). Such values inform the structural progression of institutions in the years that follow, where future reforms are shaped by pre-existing cultural norms. As such, organizational form is influenced by culture through path dependency, where the historical-cultural roots of countries and government institutions shape current organizational design. In essence, the cultural perspective accounts for the norms and values which reside "in the walls" of organizations.

At the most basic level, path dependency theory suggests that historical realities shape the outcomes of events occurring later in time, where historical contexts and processes define the evolution of organizations (Pierson, 2000; Sewell, 1996). In terms of agency structure, path dependency implies that the organizational form of donor agencies is linked to historical process and contexts, which shape structural choices and 
inform the outcome of reorganizations. Speaking specifically about path dependence in determining organizational form, Sydow, Schreyogg, and Koch (2009) suggest that organizational path dependence occurs in three stages: 1. Path dependence is triggered by a critical event (decision, accident etc.) that forces actors to take a decision and leads to a "critical juncture" (the point where organizational path dependence begins); 2. An organizational "path" forms as positive feedback reinforces a pattern of practices that gain predominance against alternatives through continual use reinforcement; 3 . The new structure is "locked-in" as organizational forms and processes are solidified to a point where deviations from the path are strategically inefficient.

In comparing experiences of public sector organizational reform, Hood (2000) suggests that path-dependence may explain findings of non-convergence towards a single global model of public sector management. Indeed, Hood (1996) and Olsen (1996) suggest that differences in the speeds at which governments pursue the same reforms, where some are tortoises while others resemble hares, could be viewed as evidence of path dependencies on the adoption of reforms. While variation in the processes of similar reforms suggests that the direction and pace of organizational change is likely to be shaped by individual historical contexts, challenges in measuring the influence of path dependency make it difficult to properly assess its role in determining organizational forms and the processes of organizational change (Peters, Pierre, and King, 2005).

\section{Environmental Perspective}

The environmental perspective suggests that organizational structure is determined by the broader institutional context surrounding public organizations. According to Christensen and Læfreid (2011), the environment of public organizations 
can be divided into two parts - technical and institutional. The technical environment is concerned with issues of efficiency, exchange and production, and exerts strong external determinism over organizations to adapt to environmental demands (Christensen and Læfreid, 2011). For instance, the technical environment "may direct attention towards certain problems and pressures, such as the need to lower unemployment and to make the existing apparatus for employment and welfare more effective and efficient" (Askim et al., 2008, p. 6). In some circumstances, these changes may be witnessed at the organizational level through structural adaptation.

In contrast, the "institutional environment has a less instrumental character and is more about assumptions concerning the appropriate organizational structure, internal culture, recruitment, policy, demography, etc." (Christensen and Læfreid, 2011 p. 412). The logic surrounding the influence of the 'institutional environment' on organizational form follows the institutional isomorphic perspective presented in the preceding section. The basic idea is that "institutions operate within institutional environments where they are confronted with socially created norms for how they should be designed and how they should function" (Christensen et al., 2007). As a result, organizations may reflect such norms in organizational structures in order to exemplify institutional principals deemed legitimate by the broader community.

In the public sector, there are many such institutional norms, or "myths" concerning organizational structure. Perhaps the most prominent is found in the theory of New Public Management (NPM). Emerging in 1970s the NPM has become one of the most popular paradigms informing the organizational form of public sector organizations in OECD countries (Hood, 1991). In essence, the NPM model is associated with four 
trends in organizational design: a reduction in government size, the privatization and quasi-privatization of government functions, the automation of service production and distribution, and an increased focus on the international agenda and norms concerning public management styles (Hood, 1991). The primary organizational objectives associated with NPM are decentralization, a focus on processes (such as strengthening internal cross-boundary collaboration and faster decision-making), and the standardization and formalization of strategic operational management (Diefenbach, 2009). After several decades of paradigmatic dominance within public administration, evidence suggests that NPM has guided organizational reforms within a variety of countries (Diefenbach, 2009; Kirkpatrick, Ackroyd and Walker, 2005), and enjoyed support from all major political parties in Anglo-Saxon and European countries (Hood, 1991). While some challenge the assertion that countries converged through NPM reforms (Pollitt and Bouckert, 2004), others warn that the NPM paradigm is becoming increasingly obsolete, pointing to the emergence of a new post-NPM model (Dunleavy et al., 2006).

The post-NPM agenda has been viewed as a reaction to the effects of NPM reforms (Christensen and Læfreid, 2008), that seeks to address two challenges associated with NPM: 1. The loss of direct control experienced by politicians over functions that were decentralized to new agencies; and 2. The challenges of cross-sectoral engagement created through the proliferation of specialized silos (Christensen and Læfreid, 2008). As a result, the post-NPM reforms include efforts to enhance vertical reintegration through dissolving agencies and integrating their functions into ministries or imposing greater constraints on existing structures to allow executive politicians to "take back some of that 
control and increase their own capacity to solve societal problems" (Christensen and Læfreid, 2008, p. 5). Importantly, the recent mergers of some aid agencies with foreign ministries mirror the reforms identified in the post-NPM agenda; however, it is unclear whether such reforms were motivated by the post-NPM logic.

Recently, Verhoest et al. (2012) explored the trends in the supposed "agencification" and "de-agencification" associated with the NPM and post-NPM agenda across 29 countries. Drawing conclusions from this edited volume, Van Thiel (2012) find that NPM has not been the only important driver of agencification in most regions. For instance, government expansion and restructuring were important drivers of agency formation in Eastern European countries, while in Latin countries "agency-like bodies have been set up, or hived off from departments, to free or exempt specific units or services from strict regulations and procedures regarding the use of resources and management that apply to core departments" (Van Thiel et al., 2012 p. 415). Moreover, the types of agencies used by governments tends to differ across regions, with Scandinavian, Northern and Central European countries preferring semi-autonomous structures and statutory bodies, while federal countries from Mid-Europe (Germany, Switzerland) and Non-European countries (Australia, US) preferring independent ministries or decentralizing tasks to local or regional units (Van Theil, 2012).

\subsubsection{Mergers and Hybrid Forms in the Public Sector}

While the public administration literature presents a perspective on the creation and "de-agencification" there is a small but separate literature that speaks to the uses of mergers in the public sector that is worth reviewing. The rationale for merging within the public sector is somewhat distinct to the logic of mergers presented in the business 
literature. For instance, mergers in the private sphere tend to be motivated by a search for shareholder value, increased competition, attempts to gain market power, and efforts towards empire-building by corporate leaders (Frumkin, 2003). In the public sector, mergers are motivated by: 1. calculation-based optimizations designed to achieve service improvement, cost efficiency, and greater cooperation between previously separate structures (Talbot and Talbot, 2011), or 2. strategic factors including efforts to build stronger management structures and more flexible pools of resources (Harman, 2000). For Frumkin (2003), this difference means that mergers in the public sector are understood as cooperative arrangements rather than hostile takeovers, where public sector mergers can be viewed as "strategic alliances" or "collaborative missions" (Harman and Harman, 2003).

Harman (2000) shows that public sector mergers can take a number of forms. In discussing mergers in Australia's education system, Harman (2000) distinguishes between voluntary and involuntary mergers, where voluntary mergers involve two or more institutions that initiate a merger themselves, versus involuntary mergers, which are initiated by government. Additionally, Harman differentiates between "consolidation" mergers and acquisitions, understanding consolidations as a coming together of institutions to create a new organization, while acquisitions involve the absorption of one (or many) institution by another.

The proliferation of mergers in the public sphere has led to preliminary discussions surrounding the potential for "de-merging" or "de-amalgamating". At this point, most of the literature on de-amalgamation has been used to describe instances of de-merging after the forced creation of large municipal regions (see Dollery, Kortt and 
Grant, 2012; Miljan and Spicer, 2015). In these cases, de-amalgamation is framed as a response to consolidations that failed to generate the desired, and often promised, results (Miljan and Spicer, 2015). While Miljan and Spicer (2015), find that de-amalgamation can further complicate matters in regional governance, Dollery et al. (2012) note that almost no analytical work has been conducted on de-amalgamation, its uses and effects in other cases.

\subsubsection{Aid Agencies: Understanding Structure}

The literature referencing the organizational structure of bilateral donor agencies can be divided into two parts. The first is a series of studies that explore the internal processes and incentives that underlie bilateral aid organizations (Quarles et al., 1988; Ostrom et al., 2001; Martens et al., 2002; Martens, 2005). This literature tends to be slightly older and is concerned with the role and function of aid agencies as managers of development programming. For instance, Quarles et al. (1988) explore the interaction between the bureaucratic processes of aid organizations and development results. Using a series of case studies from the donor and recipient perspective, Quarles et al. (1988) seek to understand the intermediary administrative processes, across administrative levels and between development actors, which influence the translation of donor intentions into development outcomes. In doing so, Quarles et al. offer three main findings: 1) the lack of focus on inter-relations between bureaucratic levels and actors means that problem solving typically involves passing challenges to the next bureaucratic level; 2) basic contradictions within the policy process limit the effectiveness of development policy; and 3) that skewed incentive structures render donors more accountable to domestic authorities that fund development programs than to recipients and outcomes. 
Incentive problems in the aid system are further explored in Ostrom et al.'s (2001) study of how adverse incentives nested in the chain of aid delivery affect the potential for programming to achieve sustainable development outcomes. Ostrom et al. (2001) highlight motivational and informational incentive problems in the aid system, analyzing the potential impact of these challenges in relation to particular aid characteristics (grants, credits, tied, etc.) and modalities. Focusing specifically on the Swedish International Development Agency (SIDA), Ostrom et al. (2001) adopt an institutional approach to explore SIDA's internal organization, finding that a number of institutional processes within SIDA, such as budget processes that encourage moving money, can foster incentives that undermine SIDA's ability to achieve its goal of sustainable development.

Also using an institutional approach, Martens et al. (2002) explore how institutions affect the outcomes of organizations that undertake aid delivery. The authors find that for bilateral aid agencies, outcomes are inherently affected by two incentive problems: multiple principals and competing objectives. For any given project, Martens et al. (2002) report that aid agencies are accountable to a number of political principals, including parliamentarians, domestic interest groups, commercial aid service suppliers, charitable organizations and environmental groups, where multiple interests threaten to weaken or blur the formulation of project objectives. Combined with a broken feedback loop, whereby donor interest groups have more political leverage over development programs than recipients, Martens et al. (2002) contend that such incentive structures cannot be neutralized "without eliminating the organizations in which they are embedded" (p. 182). 
Martens (2005), probes deeper into agency organization by exploring the need for aid agencies in the first instance. Using a transaction-cost approach, Martens (2005) explores the value of organizing aid activities through organizations including NGOs, development banks, and bilateral and multilateral aid agencies, rather than transferring funds directly to recipients. Martens (2005) finds that the primary role of aid agencies is to reduce transaction costs associated with aid delivery, such as collecting information on potential recipients, and monitoring project implementation and ex-post uncertainties that stem from divergent preferences between donors and recipients. While Martens' study does not comment on the determinants of organizational structure per se, the idea that aid agencies reduce the transaction costs of aid delivery could have implications for design if different organizational models reduce costs to different degrees.

A second branch of the literature has begun to explore the relationship between donor organization and effectiveness. Lundsgaarde's (2013) recent study probes the relationship between organizational structure and effectiveness by examining the role of line ministries as providers of development cooperation in OECD donors. Lundsgaarde (2013) explores the use of line ministries within the context of actor proliferation and donor fragmentation to uncover potential coordination challenges associated with allocating responsibility for development across multiple government departments or actors. For Lundsgaarde, such challenges are likely to affect donors by generating inefficiencies and monetary costs to donor governments (and recipients) by limiting the ease of inter-donor harmonization and increasing the administrative burden for recipients.

Lundsgaarde's analysis stands in contrast to other studies focusing on the organizational structure used by individual donors. For instance, Barder (2005) provides 
a history of reforms to the UKs development program leading to the creation of the Department for International Development (DFID). For Barder, one of the "main ingredients" for successful reforms, which rendered the UK one of the best performing bilateral donors, was the creation of a single department responsible for development policy and implementation. Barder (2005) contends that, "Establishing an integrated development ministry, with influence over a range of government policies that affect development, has had a significant effect on the conduct of policy" (p. 31). IglesiaCaruncho (2011) conducts a comprehensive analysis of Spanish aid programming and organization, concluding that the current organizational structure contains too many actors and the potential for tensions between actors charged with various roles and responsibilities. In response, Iglesia-Caruncho (2011) suggests that the budget and overall responsibilities for aid policy should be centralized into a single development ministry, mirroring the structure used by DFID. Similarly, Lancaster (2008) provides a brief discussion of recent aid agency organizational changes in Japan, US, and France. While Lancaster (2008) shows that the creation of the Millennium Challenge Corporation in the US weakened USAID and made it more vulnerable to control by the State Department, a 1998 merger between the French Ministry of Cooperation and Ministry of External Affairs enhanced the coherence and development focus of French aid.

The call for donors to adopt autonomous aid agencies is not new. Gulrajani (2012) notes that the creation of "a strengthened CIDA with unquestioned and primary responsibility for development policy formulation and its implementation across government" (p. 54) was one of the key structural options discussed for the reform of CIDA prior to the 2013 merger. More recently, Gulrajani (2015a) argued that 
autonomous aid agencies are important to ensure donor effectiveness in the context of the "beyond aid" agenda, where greater autonomy is perceived to enhance donor guardianship over the global development agenda within donor governments. Others have explored structural differences between donors to analyze the relationship between aid agency structure and donor effectiveness (OECD, 2008a, 2009; Gulrajani, 2012; Gulrajani, 2015b; Faure et al., 2015; Gavas et al., 2015). For instance, Gulrajani (2012) examines Canadian donor and aid effectiveness in comparison to the UK and Norway. Based on the understanding that the British and Norwegian models are commonly discussed as alternatives to Canada's aid structure, Gulrajani explores variation in donor performance across the three cases. Gulrajani finds that structural forms may be less important for donor effectiveness than the presence of clear development mandates and strong leadership (see also Prizzon, 2012).

Similarly, Faure et al. (2015) explore the relationship between aid quality and quantity indicators in relation to various organizational models. Using the OECD's typology of donor models as the basis for analysis, they find that Model 1 and Model 4 structures tend to be more effective than other structural forms. In addition, they suggest that the presence of a "sufficiently senior and publicly accountable figure matters for the effectiveness of development cooperation" (p. 20), lending further support for Gulrajani's (2012) finding on the relative importance of leadership for development outcomes.

More recently, research has focused on the organizational factors that contribute to making a development agency capable of addressing the challenges of the future (Gavas et al., 2015; Gulrajani, 2015a). Based on the understanding that the development landscape is changing and that aid is unlikely to remain the primary response to the 
challenges of the sustainable development era, Gavas et al. (2015) explore the implications of this change for bilateral government agencies responsible for development policy and programs. They suggest that preparing bilateral donor agencies to meet the demands of the beyond aid agenda is likely to require: 1) new government mandates that clearly articulate agency purpose and support the capacity for working across government towards a common goal; 2) senior political leadership for development such as cabinet level representation; 3) the relationships and structures to support collaboration across government; and 4) the skills and competencies to address new partnerships and challenges.

Perhaps the most systematic attempt to engage with aid agency structure has been undertaken by the OECD. Based on the understanding that the organizational structures of donor agencies are important for donor action, a 2009 report on aid management by the OECD discussed structural forms, changes, and challenges within the realm of aid management. The report discussed recent changes to the structural forms of donor agencies, suggesting that structural changes are often prompted by political phenomena, such as changes in government or leadership with the ministry of foreign affairs, by decisions to increase foreign assistance, by an attempt to deepen policy coherence, or as a means of centralizing control to focus on results.

While the literature on aid agency structure has begun to explore differences in structural form, and how such differences affect donor performance, only one study has examined the factors that influence the selection and use of various structural forms in the first instance. In The Management of Aid Agencies, George Cunningham (1974) examines the different organizational choices made by newly formed donor agencies. 
Cunningham starts from the understanding that organizational form is determined by the substantive, or policy, preferences of donors, stating that:

The decisions which an aid donor has to take can be divided between substantive aid decisions and organisational ones. The answers to the substantive questions should determine the answers to the others. The substantive decisions relate to: the distribution of funds between potential recipients; the choice of programme or project aid; the adoption of an active or reactive role on aid application; the option of country programming; the selection of projects; the form of committing funds; the terms of aid; the total volume. (p. 4)

Of these substantive choices, Cunningham suggests that "the policy choice having greatest relevance to administration is whether donors wish to play an active or reactive role" in recipient countries $(1974$, p. 2). An "active" role is one where donors "take the initiative in deciding which countries to assist, in examining the economies and obstacles to development in each recipient, and in suggesting projects to recipient governments" ( $\mathrm{p}$. 2). Alternatively, a "reactive" role is one where donors "sit back and wait" passively for recipients to ask for assistance and fund projects with little regard for whether proposals reflect the best use of resources (p. 13). Whether donors adopt an active or reactive policy is, for Cunningham, a choice "determined by a donor's conception of the essential purpose of having an aid programme" (p. 3).

Importantly, Cunningham suggests that the difference between active and reactive preferences become embodied in the organizational design of donor agencies. Indeed, Cunningham states that:

A donor who chooses the active role will find itself driven to set up an ambitious aid agency with specialists on each country and each economic sector. The supreme illustration of this choice is of course the United States: the Agency for International Development in Washington as it operated in the late 'sixties will probably prove to have been the ultimate in ambitious aid agencies, large enough and competent enough to duplicate the economic planning work of at least the smaller recipient states. At the 
other end of the spectrum is Austria, which uses the specialist government ministries like Education and Agriculture to react to proposals with a minimum of interministerial co-ordinating machinery (Cunningham, 1974 p. 3).

Despite broadly linking donor roles to structural preferences to facilitate active or reactive programming, Cunningham does not associate donor role directly to specific organizational structures. For instance, while Cunningham praises USAID as the quintessential active donor, and despite USAID adopting an autonomous aid agency structure at the time of writing, Cunningham does not suggest that active donors will necessarily tend towards autonomous structures. Nor does Cunningham provide potential rationale for explaining differences amongst organizational structures (Model 1-4) between OECD-DAC donors that adopt active policies, or which donor models are associated with the pursuit of active donor roles. In essence, it is unclear which organizational models beyond autonomous structures can be associated with active donor roles and which models other than Model 5 (the model used by Austria in Cunningham's example) can be associated with reactive donor roles.

While Cunningham's theory offers an explanation for understanding variation in the organizational structure of aid agencies, the theory suffers from a number of weaknesses. Firstly, Cunningham's theory does not explain differences in the types of organizational structures used by active or reactive donors. Cunningham's theory suggests that donors will adopt different structures according to the role they choose to pursue however, he does not hypothesize about differences between the models used by active or reactive donors. While it could be argued that differences in the models used by active or reactive donors could be linked to degrees of activity, Cunningham does not 
suggest or explore ways that levels of donor activity could be measured to account for such variation.

In addition, it is important to acknowledge that Cunningham's theory was developed in the 1970s at the early stages of aid agency development and assistance programming. As a result, there is the potential that Cunningham's theory may be outdated and unable to account for the factors that influence aid agency structure in the $21^{\text {st }}$ century, or structural changes in the development landscape that changed donor behaviour. A key point, for instance, is whether the distinction between active and reactive donors can still be meaningfully made among current OECD-DAC donors. Moreover, Cunningham's understanding that substantive choices influence organizational structures suggests that any changes to the relative importance or type of substantive decisions that face donor agencies would also change the organizational structures which donors utilize.

Perhaps most significantly, a glaring weakness of Cunningham's theory is that it does not engage with or consider alternate hypotheses for explaining aid agency structure. Cunningham's study is primarily descriptive and based on observations from a number of short case studies. As a result, Cunningham does not acknowledge or test other theoretical explanations for organizational structure. This not only calls the validity of his theory into question, but highlights a clear gap for further exploration.

\subsubsection{The Research Gap: A Summary}

This literature review has sought to identify the research gap surrounding the determinants of aid agency structure. It began by exploring general theories of organizational structure taken from the business literature. This literature outlined two 
key theories, contingency and institutional theory, which suggest that organizational structure is designed to maximize a firm's efficiency and legitimacy. While these theories are useful for providing initial insight into structural determinants, this literature does not speak specifically to the determinants of organizational form in the public sector.

To account for this challenge, the review then focused on theories of organizational structure and change taken from the public sector organization literature. This literature highlighted three main groups of theories for understanding organizational structure in the public sphere - structural-instrumental, cultural, and environmental. The structural-instrumental perspective contends that organizational structures are deliberately designed to serve a particular purpose or goal and is linked to rationalinstitutional theories related to transaction-costs and principal-agent dynamics. The cultural perspective points to the importance of organizational culture and path dependency as determinants of structural organization and the path of organizational change. The environmental perspective suggests that popular norms or myths about organization, such as new public management, influence the types of structures governments use and the types of organizational changes they consider. In addition, a small literature on mergers in the public sector highlights the use of organizational mergers to enhance collaboration between agencies, enhance efficiency, and increase strategic management of resources. Although the literature on public sector organization highlights motivations and explanations for organizational choices and changes in the public sector, it does not speak specifically to organizational forms or changes concerning aid agencies. 
The final section of this literature review explored the development literature for potential insights into the determinants of organizational structure and aid management. The literature tended to fall into two main categories. The first discussed the role and functions of aid bureaucracies as agents responsible for aid programming and delivery. This literature tended to discuss the organizational structures present, without questioning the determinants or rationale for particular organizational forms. The second group of studies explored structure as a variable related to donor and aid effectiveness, pointing to differences in the relative performance of donors that adopt different organizational structures. However, this literature did not question or explore the determinants of organizational form in the first instance. The only study that engaged with the determinants of aid agency structure was conducted by Cunningham in the early 1970s. However, several key challenges with the rigour and assumptions made throughout this study calls its ability to explain aid agency organizational design and changes into question.

The result of this review is a clear gap in the literature exemplified by the absence of theorizing around the determinants of aid agency structure. This gap justifies the current research, which develops and tests a framework for the understanding organizational choices of donor governments regarding their aid programs. To do so, the next section will unpack and explore Cunningham's study in greater detail in effort to build a theory for understanding aid agency structure. Table 1 below provides a summary of the major literatures, their main contributions, and any gaps/limitations discussed during the review. 
Table 1: Summary of Findings from Literature Review

\begin{tabular}{|c|c|c|}
\hline Literature & Main Contributions & Gaps/Limitations \\
\hline Organizational studies & $\begin{array}{l}\text { 1. Contingency Theory } \\
\text { 2. Institutional Theory }\end{array}$ & $\begin{array}{l}\text { Draws primarily on findings } \\
\text { from the private sector. } \\
\text { Highlights the importance of } \\
\text { efficiency and institutional } \\
\text { legitimacy as determinants of } \\
\text { organizational structure. While } \\
\text { these findings are important } \\
\text { and may be applicable in the } \\
\text { public sector, this literature } \\
\text { cannot speak specifically to } \\
\text { determinants of organizational } \\
\text { structure in government. }\end{array}$ \\
\hline $\begin{array}{l}\text { Public Sector } \\
\text { Organization }\end{array}$ & $\begin{array}{l}\text { 1. Structural-instrumental } \\
\text { - Transaction-cost } \\
\text { - Principal-agent } \\
\text { 2. Cultural } \\
\text { - Path dependency } \\
\text { 3. Environmental } \\
\text { - New Public } \\
\text { Management } \\
\text { 4. Public sector mergers }\end{array}$ & $\begin{array}{l}\text { The literature on public sector } \\
\text { organization highlights a } \\
\text { number of determinants of } \\
\text { organizational structure within } \\
\text { the public sector. However, } \\
\text { this literature does not speak to } \\
\text { the specific determinants of the } \\
\text { structure of aid agencies and } \\
\text { requires more specific sectoral } \\
\text { insight. }\end{array}$ \\
\hline $\begin{array}{l}\text { Development } \\
\text { literature }\end{array}$ & $\begin{array}{l}\text { 1. The role and function of } \\
\text { aid bureaucracies } \\
\text { 2. The role of structure as a } \\
\text { determinant of aid and } \\
\text { donor effectiveness }\end{array}$ & $\begin{array}{l}\text { The two main groups of studies } \\
\text { in this literature speak about } \\
\text { aid agency structure in terms of } \\
\text { the role and function of aid } \\
\text { agencies, and as a determinant } \\
\text { of aid effectiveness. The only } \\
\text { study which offers insight into } \\
\text { the determinants of aid agency } \\
\text { structure was conducted by } \\
\text { Cunningham in 1974. It is } \\
\text { unclear whether the findings of } \\
\text { this study remain valid. }\end{array}$ \\
\hline
\end{tabular}

\subsection{Cunningham in the 21st Century}

As the only theory that offers an explanation for aid agency organization, Cunningham's perspective warrants careful consideration. However, the aforementioned challenges raise questions concerning the capacity for Cunningham's theory to explain 
aid agency structure and change in the $21^{\text {st }}$ century. The following sections engage with Cunningham's theory to explore its continued relevance and applicability for understanding the organizational choices of aid agencies. This is done through critically engaging with the two main assumptions that underlie Cunningham's theory. The first section explores Cunningham's assumption that substantive choices influence organizational structures. By exploring this relationship in light of other theories for understanding organizational structure, the validity of this assumption is clarified. The second section explores Cunningham's assertion that the main substantive decision that drives donor organization is the choice between adopting an active or reactive role by questioning whether this distinction remains valid in the $21^{\text {st }}$ century. Through analyzing current trends in donor size, standards and practices, it is clear that the choice between active and reactive donor roles is no longer a meaningful choice facing donors, as all current OECD-DAC donors appear to adopt active roles. In light of this finding, a third section explores current debates surrounding aid activities to identify key choices made by donors today.

\subsubsection{Do Substantive Choices Influence Organizational Design?}

Cunningham's theory of aid organization is built on the understanding that substantive choices influence organizational design. For Cunningham, substantive choices refer to the policy decisions made by donors regarding their aid activities, i.e. decisions pertaining to the role of donors (active vs. reactive), aid allocation, programming, volume, terms, etc. However, Cunningham provides little evidence to support the relationship between substantive policy and organizational choices in aid agency structure, raising questions concerning the causal mechanisms at play. In order to 
understand the capacity for Cunningham's theory to explain the organizational structure of aid agencies, it is firstly necessary to explore this linkage in terms of theories of organizational structure.

Both contingency theories and structural-instrumental perspectives appear grounded in the understanding that the substantive choices facing organizations determine organizational structures and provide theoretical support for this aspect of Cunningham's argument. For contingency theory, the design of organizational structure is determined by the environmental or structural constraints of an organization, where failing to conform to contingencies reduces organizational efficiency. Understanding that contingency theory stems from the business literature, where profit maximization is considered the main goal of firm activities, and such profit is presumed to arise through enhancing efficiency, the notion that organizational structures are determined by efforts to fit contingencies and maximize efficiency becomes a product of the pursuit of profit maximization. As a result, contingency theory is grounded in the same assumption articulated by Cunningham, where substantive choices pertaining to firm efficiency and profit determine structural designs.

Similarly, the structural-instrumental perspective within the public sector literature explicitly links structure to agency goals. According to structuralinstitutionalists, organizational structure is understood as an instrument for the pursuit of a specific goal. In this sense, organizational design is seen as a deliberate attempt to adopt structures that offer the best capacity to achieve an organization's desired outcomes. In doing so, organizational design is explicitly linked to the substantive policies that organizations seek to pursue. Indeed, the relationship between substantive 
and organizational choices is further emphasized in the two main theories that underlie this perspective. From a transaction-cost perspective, organizational structure is designed to reduce the costs of meeting the goals of a given organization. While this perspective assumes that organizations seek to enhance efficiency, such efficiency is not necessarily associated with profit, particularly in the public sector, but could also be related to generating better outcomes with fewer resources. In this case, organizational structures are viewed as attempts to attain substantive outcomes at the lowest possible cost, where the specific policy pursued determines the type of structure needed to enhance efficiency. Similarly, from a principal-agent perspective, the substantive ends of the principal are likely to determine the type of structural design and management of agencies charged with carrying out the wishes of the principal. Indeed, it is in the interest of principals to design agencies or agent relations that offer the best potential for achieving desired results. In this case, the type of policy given to agents is likely to determine the structural design of agencies and principal-agent relations.

Discussion of the relationship between substance and structure highlights a key assumption about the actors responsible for organizational determination; namely, that decision-makers exert control over organizational structure. Importantly, theory suggests that such decisions are made by political actors rather than bureaucratic agents. Indeed, both the structural-institutional and principal-agent perspectives link substantive choices to the overall mission of aid agencies, which are determined by political actors. By accepting the assumed link between substantive questions and organizational structure, it 
follows that the locus of organizational decision-making is likely to stem from political actors, and raises important questions surrounding the politics of aid agency structure. ${ }^{3}$

Assuming the validity of the relationship between substantive choices and organizational structure, the question becomes one of identifying and understanding the substantive questions facing donors that are most likely to influence the organizational structure of aid agencies. For Cunningham, the primary substantive choice for donors is whether they seek to adopt an active or reactive role in their development programs. As a result, assessing the degree to which Cunningham's theory can be used to understand the organizational structure of donors today begins by asking whether the decision to adopt an active or reactive role is still the most important substantive choice facing donors?

\subsubsection{Are donors still reactive?}

For Cunningham, the choice between adopting active or reactive roles is tied to a number of donor characteristics. Firstly, Cunningham suggests that active donors tend to have larger aid budgets, stating that "the greater the aid provided, the more thoroughly a donor will find itself compelled to investigate proposals and the economic policies which lie behind them" (p. 13). Conversely, the logic implies that donors with small aid budgets are more likely to adopt a reactive role, as there is less incentive to actively utilize or employ resources to ensure that aid is well spent. In this case, one way to explore whether differences between active and reactive donors remain relevant is to examine changes to the size of donor budgets over time.

Essentially, Cunningham's theory suggests that the mechanism linking size to active and reactive roles is connected to the incentive for donors to actively program aid

\footnotetext{
${ }^{3}$ The influence of politics on aid organization will be explored in greater depth in the next two chapters.
} 
based on ODA budget size. ${ }^{4}$ Understanding that donors come from economies of different sizes, the amount of aid needed to provide an adequate incentive for action is likely to differ across donors. For instance, the amount needed to provide an incentive for Austria to actively program is likely to be significantly smaller than that of the US based on differences in the relative sizes of their economy and government expenditures. As a result, comparing these countries in terms of absolute values would not capture the relative importance of aid budgets in their individual contexts and thus could not provide a clear indication of the incentive connected to spending. Looking at aid spending as a proportion of GNI or as a proportion of government expenditure avoids this challenge by equalizing the significance of aid relative to donor contexts.

Interestingly, both of the proposed indicators show an increase in average proportional aid spending over time for OECD-DAC donors. Figure 2 (below) shows that the level of aid spending across OECD-DAC donors as a proportion of GNI has increased (on average) since the 1960s. In 1960, the average aid effort was $0.35 \%$ of GNI across OECD-DAC donors at the time, increasing to $0.39 \%$ in $1980,0.45 \%$ in 1990 and $0.50 \%$ by 2010 (see Figure 2). ${ }^{5}$

\footnotetext{
${ }^{4}$ Cunningham does not provide guidance on a specific threshold of donor size where the incentive to engage in active programming can be expected to change.

${ }^{5}$ Own calculation of average ODA/GNI across donors; includes DAC-members from year of joining. ODA/GNI data taken from OECD Creditor Reporting System database.
} 
Figure 2: Average ODA/GNI Across OECD-DAC Donors 1960-2015

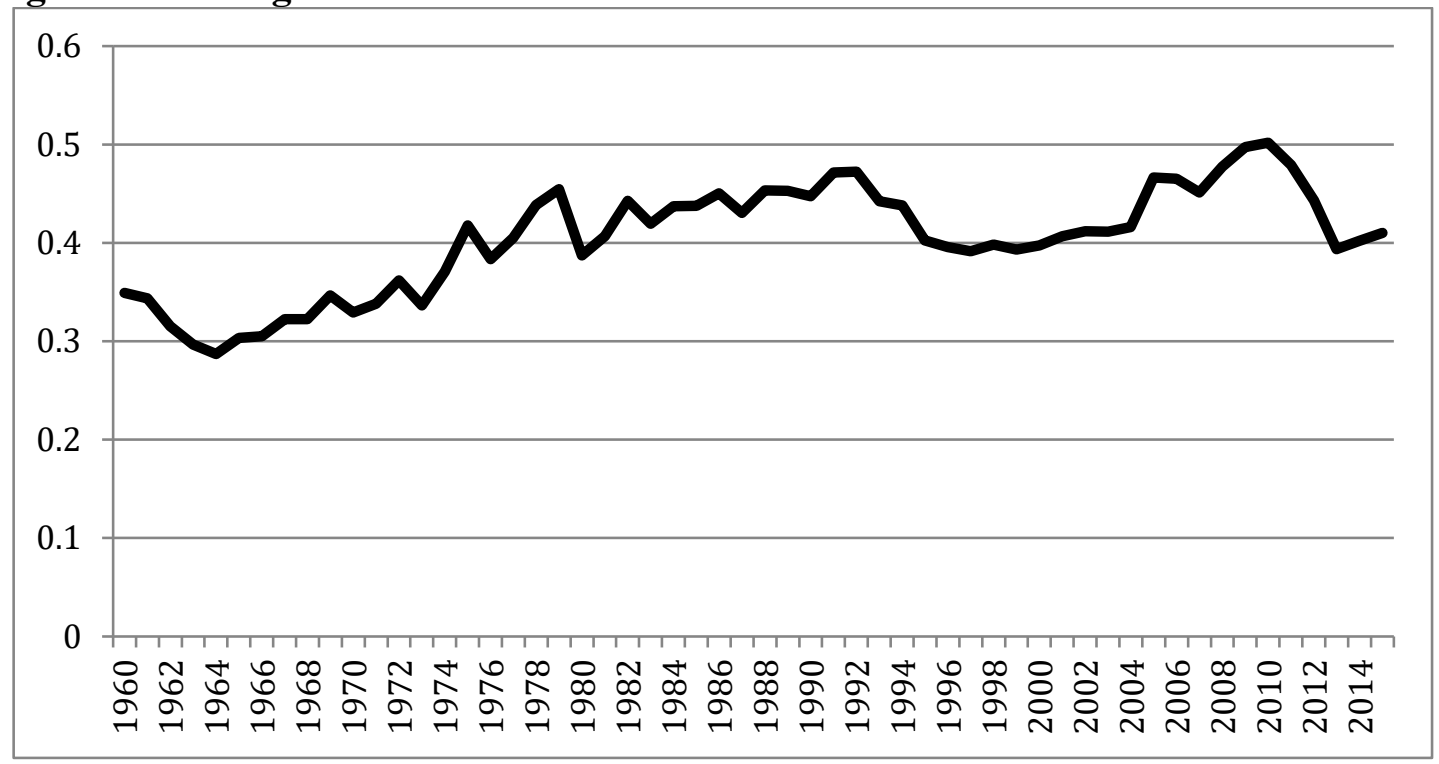

However, in 2013, average ODA to GNI across OECD donors fell to a forty-year low of $0.39 \%$. While part of the decline is likely the effect of the 2008 financial crisis, the drop can also be attributed to relatively low ODA to GNI in five countries (Czech Republic, Iceland, Poland, Slovak Republic and Slovenia), which joined the OECD-DAC in 2013. Indeed, excluding these new donors, average ODA to GNI in 2013 is several points higher at $0.45 \%$. This discrepancy could suggest that while more established OECD-DAC donors are increasing ODA/GNI proportions, potentially indicating the adoption of increasingly active donor roles, lower than average ODA/GNI proportions by new OECD members suggests that donors may be more likely to adopt reactive roles in the early stages of aid program development. Indeed, the trend towards lower ODA spending at the early stages of aid agency development mirrors lower spending trends by original OECD-DAC donors in the 1960s and 1970s. For long-term OECD-DAC donors, higher average ODA/GNI proportions over time could provide evidence of an increasing incentive to actively program aid funds, due to higher financial engagement, than existed at the time of Cunningham's study. 
Since 1995, ODA as a proportion of government spending increased from $0.85 \%$ to a peak of $1.17 \%$ in 2005 before declining in the years following the financial crisis (see Figure 3). ${ }^{6}$ As with ODA/GNI, recent declines in ODA/Central Government Expenditure are driven by low levels of spending in new OECD-DAC donors. While the proportion of government expenditure spent on ODA across all donors in 2014 was $0.9 \%$, when new donors are removed from the sample proportional ODA spending for 2014 is much higher at $1.08 \%$. This discrepancy suggests that on average, more established donors have increased their level of ODA spending over the last two decades, while newer donors tend to allocate much smaller amounts to aid activities. This again could point to differences in the donor roles adopted by established versus new donors, suggesting that while longer-term donors theoretically have greater incentive to adopt active donor roles due to increasing budgets, smaller budgets for newer donors make them more likely to adopt reactive roles.

Figure 3: Average ODA as a Proportion of Central Government Expenditure Across OECD-DAC Donors 1995-2014

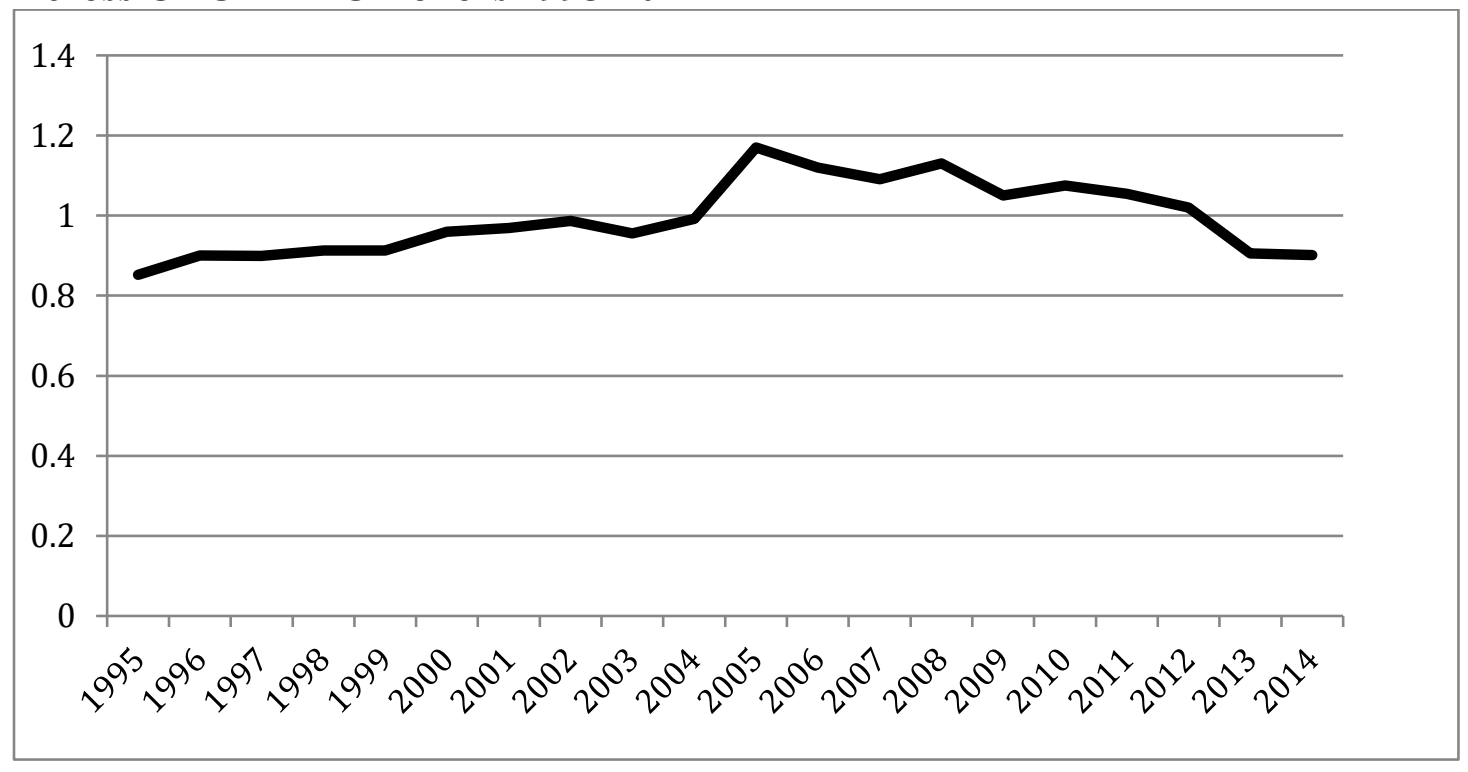

${ }^{6}$ Compiled data on central government expenditure is not available prior to 1995. 
Curiously, Cunningham's understanding of the relationship between ODA budget size and aid organization does not account for the institutionalization of the $0.7 \%$ of GNI spending target for ODA. The target was first adopted in 1970, urging donors to raise aid spending to a minimum net amount of $0.7 \%$ by the middle of the decade (OECD, 2016). While only one donor, Sweden, had reached the $0.7 \%$ spending target by the time of Cunningham's study, several others including Norway, the Netherlands, Luxembourg and recently, the UK and Germany, followed suit.

In the context of the target, which continues to be institutionalized through international agreements including the 2002 International Conference on Financing for Development in Monterrey and calls for donors to increase spending in support of the 2015 Millennium Development Goals and 2030 Sustainable Development Agenda, donors are consistently called to adopt a level of spending that would presumably provide the incentive to adopt an active role. To the degree that donors buy in to international standards and norms surrounding aid, evidenced by more donors reaching or pledging to reach the $0.7 \%$ spending target, it is likely that established donors, as a group, have moved away from reactive roles through increased development spending. For newer donors, the question is whether they too will increase aid expenditure and move towards active roles in the future.

The shift towards active donor roles by established donors is perhaps most clearly evidenced through the increasing use of country programs by OECD donors. According to Cunningham, "Country programming is a term increasingly used by donors which opt for an active role, to suggest that their operations in each country are designed as a cohesive whole and are not a haphazard collection of individual projects" (1974, p. 16). 
As an example of active country programming, Cunningham cites USAID's annual preparation of "country sub-missions" which "cover the economic condition of the recipient country and assesses obstacles to development" (1974, p. 16). In essence, these documents outline the development goals of partner countries and the corresponding use of aid as determined through discussions between USAID and recipients (Cunningham, 1974). In contrast, reactive donors are presumed to have less incentive to invest the time and resources into developing country-level programming strategies, opting instead to fund project proposals received.

The connection between country programming and active donor roles suggests that one way to identify the continued relevance of the active/reactive distinction is by examining changes to the use of country programming by OECD-DAC donors over time. Using evidence from OECD Aid Reviews, the use of country programming for each OECD-DAC donor is examined in two snapshots in time. The first is taken from 1975, slightly after the time of Cunningham's study, and aims to capture the prevalence of reactive donors at the early stages of OECD-DAC development activity. The second snapshot is taken from 2015 in order to examine whether there are still reactive donors in the present day. For these purposes, any donor that adopts country programming, defined as the use of long-term planned interventions that consider the contexts and needs of partner countries, is termed "active". Alternatively, donors that do not develop country programs, opting instead to use "a haphazard collection of individual projects" in partner countries are considered reactive (Cunningham, 1974 p. 13).

The full results of this research are available in Appendix 1, while a summarized version is provided in Table 2 below. The comparison of donor activities shows that in 
1975, 9 out of the 17 OECD-DAC donors at the time did not use country program approaches to development, favouring reactive approaches instead. By 2015, all but three (Greece ${ }^{7}$, Poland and Slovenia) OECD-DAC donors developed long-term country programs with partner countries. Two of the donors that remain reactive, Poland and Slovenia, are relatively new OECD-DAC members, while Greece joined the OECD-DAC in 1999. None of the original 17 OECD-DAC members still use reactive policies for development planning.

\footnotetext{
${ }^{7}$ The most recent Peer Review of Greece (2011) called on the country to make multi-annual country programs with partner countries a priority for its aid program. There is no clear evidence on whether these recommendations have been implemented.
} 
Table 2: Donor Role based on Presence of Country Programming

\begin{tabular}{ccc}
\hline Country & 1975 & 2015 \\
\hline Australia & Reactive & Active \\
\hline Austria & Reactive & Active \\
Belgium & Reactive & Active \\
\hline Canada & Active & Active \\
Czech Republic & N/A & Active \\
\hline Denmark & Active & Active \\
\hline Finland & Active & Active \\
\hline France & Reactive & Active \\
\hline Germany & Active & Active \\
\hline Greece & N/A & Reactive \\
\hline Iceland & N/A & Active \\
\hline Ireland & N/A & Active \\
Italy & Reactive & Active \\
\hline Japan & Reactive & Active \\
\hline Korea & N/A & Active \\
\hline Luxembourg & N/A & Active \\
\hline Netherlands & Reactive & Active \\
\hline New Zealand & Reactive & Active \\
\hline Norway & Active & Active \\
\hline Poland & N/A & Reactive \\
\hline Portugal & N/A & Active \\
\hline Slovak Republic & N/A & Active \\
\hline Slovenia & N/A & Reactive \\
\hline Spain & N/A & Active \\
\hline Sweden & Active & Active \\
\hline Switzerland & Reactive & Active \\
\hline United Kingdom & Active & Active \\
\hline & Active & Active \\
\hline & \\
\hline & & \\
\hline Untes & & \\
\hline
\end{tabular}

The shift towards active programming is perhaps unsurprising in light of calls for donors to adopt country programs as early as the 1970s. For instance, the 1977 OECD Development Cooperation Report notes that donors had been urged to adapt aid programs to the needs of least developed countries (LDCs) following resolutions made in 1972 and 1976 UNCTAD Conferences in Santiago and Nairobi respectively (OECD, 1977b p. 129). Indeed, building on the need for aid adaptation, the 1977 OECD Report suggests that, "An effective way of adapting aid programmes to the special needs of individual 
LDCs is via multi-year country programmes. These programmes are drawn up for the whole, or at least as essential part, of the aid activities of a donor in a given country and are normally based on a detailed and comprehensive analysis of the development situation and prospects for the recipient" (p. 129). In a sense, the OECD's call for donors to adopt country programs could indicate that such programming was becoming best practice within the international donor community. Indeed, the 1985 OECD Development Cooperation Review provides further evidence of an institutional level shift towards country programming as best practice, stating:

In the 1960s donors had a tendency to say that projects were financed only in response to a request from the recipient. The assumption was that the recipient would organise his requests in accordance with his own priorities and would retain responsibility for bringing coherence to the whole.

It soon emerged that this assumption was unsustainable. Few recipients had the capacity to maintain control over the complex flow of resources that had become available, and their task was rendered more difficult by differences in the priorities and preferences of individual donors. Country programming evolved as a means of clarifying the relationship of a recipient country's plans, policies and resources with the proposed uses of aid. (OECD, 1985c p. 185).

More recently, principles associated with longer-term country programming, such as predictability of aid spending, alignment with recipient priorities, and developing timelines and indicators to measure progress or "manage for results", were presented as best practice in the 2005 Paris Declaration and reaffirmed at the 2011 Fourth High Level Forum on Aid Effectiveness in Busan. Indeed, recent OECD Peer Reviews have used these principles to assess the budgeting and programming processes of donors, citing that "The member's approach to how it delivers its programme...as defined in Paris, Accra and Busan" as one of the seven dimensions of analysis undertaken in all Peer Reviews (OECD, 2014a). In this sense, the trend towards adopting country program approaches is 
perhaps unsurprising given the institutional push towards using programs to enhance predictability, alignment and effectiveness of aid activities.

Despite such institutionalization, the presence of three donors without country programming is curious. In part, the reactive polices of Poland, Slovenia and Greece could be explained by the small scale of their development programs. In 2015, each of these three donors disbursed ODA valued at or below $0.15 \%$ of GNI $(0.1 \%, 0.15 \%$ and $0.14 \%$ respectively). To the degree that Cunningham's theory of the relationship between budget size and organizational preferences is correct, it could be suggested that the small scale of these three donor programs provides little incentive for governments to invest in the resources necessary to engage in active programming, favouring humanitarianism, multilateral spending and reactive programs instead. Alternatively, it seems prudent to suggest that reactive policies may be more prevalent at the early stages of developing donor aid programs, where new donors may prefer reactive policies until institutional capacity is developed. Indeed, Cunningham pointed to this trend, suggesting that, "Every aid programme began as responses to requests..." (Cunningham, $1974 \mathrm{p} \mathrm{13).}$

However, even at the time of writing, Cunningham had observed that donors were moving towards the pursuit of active policy. Led by the influence of the US, Cunningham (1974) states that, "The early desire to give aid from a distance and with only half an eye on its application suffered a prolonged setback during the sixties when the US made deep country involvement the conventional wisdom of donors" (p. 14). While in the early 1970s the Nixon Government sought to revert back to reactive policies, Cunningham noted that, "Other donors show no sign of going back on the trend of the 
sixties. Sweden, Canada and Germany in particular have moved towards deeper country involvement" (Cunningham, 1974 p. 14).

Taken together, the continued use of reactive policies by new donors and Cunningham's assertion of a trend from reactive to active programming, points to a potential path of aid agency development. This is not to say that donors may not return to reactive roles in the future, nor that all donors are equal in terms of their adoption of active tendencies. For instance, use of the multilateral system could be seen as a form of reactive aid policy, as providing aid through multilaterals shifts the responsibility for programming from donors to multilateral institutions. In this case, donors that provide more funding through multilateral systems could be seen as relatively more reactive than donors that prefer bilateral programming. However, in the context of the evidence provided regarding current norms and standards of the aid system, such differences would reflect differing degrees of reactivity rather than suggesting that donors are primarily reactive in their approach to development.

While the fact that three countries remain reactive suggests that such policies may be preferable to new donors, the overall increase in the use of country programming and active roles by OECD-DAC donors suggests that the choice of donor role may be losing relevance as a determinant of organizational structure. According to Cunningham, the choice of active or reactive donor role determines the organizational structure donors choose to adopt. However, in order for this theory to be valid, there must be enough variation in the roles adopted by donors to explain differences in organizational form. The finding that most donors use country programming, and can subsequently be categorized as active, suggests that there is less variation in the roles adopted by current 
OECD-DAC donors to explain continued differences in the organizational structure of donor agencies. ${ }^{8}$ As a result, it seems that Cunningham's distinction between reactive and active donors is unlikely to explain all variation in organizational form.

Lastly, evidence of donors' shift away from reactive roles can be seen through changes to the way donor preferences and interests are understood in relation to the roles they adopt. According to Cunningham (1974), donors that use aid for strategic interests are more likely to adopt an active role to ensure that aid is allocated in a manner that fosters results not only for recipients, but also for donors (p. 13-14). Alternatively, Cunningham suggests that some donors, typically with small budgets, may prefer to "sit back and wait for recipients to ask for assistance for specified projects" (p. 13), presumably as budget size reduces the incentive for active programming and the purposive allocation of aid funding. In these cases, donors are not seen to use aid to satisfy domestic purposes, but rather to respond to the requests of developing countries.

In essence, Cunningham suggests that the difference between reactive and active donors is not necessarily related to the specific purpose that donors seek to pursue (i.e. strategic interests vs. poverty reduction), but rather to the presence of a clearly defined purpose for aid spending in the first instance. Cunningham readily admits that some active donors have a stated interest in using aid for poverty reduction; Sweden is a clear example. According to Cunningham, Sweden's earliest aid policies, which date back to 1962 and 1967, stated that Swedish development assistance should be concentrated on "countries which are pursuing policies which Sweden believes will assist social equality" (Cunningham, 1974, p. 157).

\footnotetext{
${ }^{8}$ While it could be argued that differences in the degree to which donors use country programming could show variation in donor role, and in theory, structural choices, Cunningham's theory does not provide insight into why or how differences across "active" donors are likely to influence structural choice.
} 
Based on this understanding, the proportion of donors that adopt reactive versus active roles can be seen through examining whether current donors adopt a clear purpose for aid activities. Aside from a range of studies which seek to distinguish between the main purposes of donors, all of which appear to assume that donors consciously seek to use aid for specific ends (see Alesina and Dollar, 2000; Hoeffler and Outram, 2008; Berthelemy and Tichit, 2004), analysis by the OECD (2009) shows that almost all OECD donors have a high-level policy statement or legislation which outlines the main purpose of development programs. Indeed, the OECD (2009) states that while more than twothirds of OECD-DAC donors have high-level policy statements for development, "All DAC members but one (France) have legislation and/or a high-level policy statement” (p. 18). In 2011, France also published a Framework Document on development cooperation, which "establishes the objectives of the development policy that France intends to pursue over the next ten years to address international challenges" (OECD, 2011 p. 37). The finding that all current donors utilize policy statements or legislation to articulate a clear purpose of aid programs suggests that OECD-DAC donors can currently be considered active according to Cunningham's criteria. As a result, the absence of meaningful variation between the role of donors, as evidenced by increasing aid budgets, near uniform use of country programs, and consistent presence of clear policy statements for development by OECD donors, suggests that the choice between the active and reactive donor roles may no longer be a relevant determinant of aid agency structure.

In essence, the point is that contrary to Cunningham's theory, the last 50 years has increasingly shifted donors towards active roles. This convergence has rendered the choice between adopting an active or reactive role less prevalent and has reduced the 
variation that Cunningham suggests underlies differences in organizational structure. However, if all current OECD-DAC donors adopt a primarily active role, then persistent variation across donor organizational structures raises questions concerning the source of such variation. Building on Cunningham's first assumption, that substantive choices influence organizational forms, the next section looks beyond the choice of donor role to explore alternative substantive choices for explaining variation across aid agency structures.

\subsubsection{Summary}

This section engaged with Cunningham's early theory of aid management and questioned the on-going applicability of Cunningham's thesis for explaining the structural choices made by donors in the $21^{\text {st }}$ century. In doing so, this section found continued theoretical evidence to support Cunningham's assertion that substantive choices can reasonably be considered drivers of organizational choice.

With this finding in mind, this section explored whether donors still adopt the practices and preferences, which Cunningham associates with reactive donor roles. Through exploring donor size and use of country program, this section highlights a notable shift towards donors adopting more active roles. Importantly, the dichotomous division between active and reactive roles presented by Cunningham does not provide the necessary insight in order to understand variation across all five organizational models presented in Chapter 1. Based on the relationship between substance and structure presented by Cunningham, the next section will explore the range of substantive choices made by donors in efforts to identify the types of substantive preferences which present the greatest theoretical ability to explain variation in the adoption of different aid 
management structures. Doing so will highlight the key substantive variables linked to structural choice will inform the theoretical framework that underlies the remainder of this study.

\subsection{Towards a Theory of the Determinants of Aid Agency Structure}

This section builds on the above logic to present a preliminary theory of aid agency organization. To do so, it begins by highlighting some basic criteria that underlie the capacity of substantive choices to explain variation in organizational structure. This is followed by an exploration of the range of substantive choices faced by donors in order to identify the choice most likely to influence aid agency structure.

Any substantive choice capable of contributing to a theory of aid agency structure must meet two basic criteria. First, for the choice to be capable of explaining variation in aid agency structure, there must be variation across donor responses to the choice. Variation must be present throughout the entire sample period. In theory, the absence of variation would suggest that the choice was irrelevant to explaining differences in organizational structure by suggesting uniform action/preferences by donors.

Second, any substantive choice capable of explaining organizational structure must be a decision that is similarly relevant to all donors. Efforts towards theory development require that the substantive choice identified is not only made by all donors, but of similar significance to donors to ensure generalizability. In the event that some donors prioritized the choice more significantly than others, then the capacity of the choice to be a reasonable driver of agency structure would vary by the weight that donors gave to the choice. Such variation would limit the explanatory power of the choice by 
reducing its relative significance in some cases and increasing the potential that organizational structure follows the logic of other substantive choices in some cases.

With these two conditions in mind, the next section identifies the range of substantive choices made by donors in order to explore possible alternative choices for understanding variation in aid agency structure. To do so, relevant academic and grey literature is initially explored. Once the range of substantive choices has been established, the choices will be reviewed in efforts to answer the question: Which substantive choice is the most important determinant of organizational form?

\subsubsection{What are the substantive choices made by donors?}

According to Cunningham, substantive choices are the policy decisions related to all aspects of development programming. In addition to the choice between active and reactive donor roles, Cunningham identifies several substantive choices facing donors including the geographic distribution of aid funds, volume of aid funds, the choice between program or project aid, the use of country programming, project selection, the form of committing aid funds, and terms of aid. In essence, these choices are related to how donors allocate and spend aid funds. Cunningham's list of substantive choices provides a starting point for analysis. This section provides a review of the academic and grey literature on major substantive choices facing donor agencies. In doing so, this section pays particular attention to the theoretical capacity for each choice to influence organizational form in order to identify the substantive choice with the greatest potential to explain variation in organizational structures.

Perhaps the most notable and well-studied substantive policy choice facing donors concerns the geographic allocation of development funds. In general, this literature links 
geographic spending patterns to efforts to promote poverty reduction (Faust, 2011), pursue geo-strategic interests (Collier and Dollar, 2002; Alesina and Dollar, 2000; Maizels and Nissanke, 1984; McKinlay and Little, 1977; Schraeder, Hook and Taylor, 1998), or a combination of both (Berthelemy, 2005; Hoeffler and Outram, 2008). As a result, geographic allocation decisions are conceptualized as proxies for donor preferences, interests, and ultimately, the purpose of bilateral aid programs.

Differences between patterns of allocation across donors point to the use of development resources to promote varying donor interests. Such interests are not static and are likely to change with domestic conditions, or international contexts. Domestically, there is some evidence that the ideology of government influences allocation patterns, where conservative governments are seen as more likely to provide aid to support geo-strategic and commercial interests (Fleck and Kilby, 2006). Similarly, changes to the international environment have historically influenced the geographic distribution of aid spending. For instance, during the Cold War, the US used aid to support allied countries (Maizels and Nissanke, 1984). More recently, the post-2001 period has seen the securitization of aid and the provision of aid to help alleviate terrorrelated activities (Bandyopadhyay and Vermnann, 2013).

The relationship between donor preferences and allocation trends, where donor interests and priorities are said to drive spending towards countries of diplomatic interest or developmental need, is relevant for discussions of aid organization. To the degree that the substantive purpose of aid programs can influence the structure of aid agencies, as discussed above, the choice of geographic allocation may act as a proxy for understanding the purpose that agencies are designed to pursue. Such purposes are, at 
least anecdotally, linked to outcomes derived from the adoption of various organizational forms. For instance, following the 2013 merger of Canada's aid agency with its foreign ministry, commentators suggested that the new organizational arrangement reflected a shift in Canada's developmental priorities towards the use of aid for strategic and commercial purposes, and expressed concern that the new institutional arrangement would "dilute Canadian development commitments so that it serves the interests of private constituencies rather than the poor" (Gulrajani, 2013). While it should be noted that others came out in support of the merger (see Stein, 2013), the important point for this study is the connection between organizational structure and the presumed priorities of the government.

Similarly, there is evidence that autonomous aid agencies have been used by donors seeking to signal a commitment to poverty reduction. In the case of the UK, controversy over the use of aid funds to pursue geopolitical and commercial interests resulted in calls to separate aid from the Foreign Office (Barder, 2005). While the creation of DFID itself cannot be held solely responsible for the UK's development focus, strong leadership for instance certainly helped to place DFID on a particular path, Gulrajani (2013) states that "evidence points to the value of empowering independent development ministries to achieve real development results".

As a result, the capacity for geographic choices to highlight the priorities of donors makes it an important substantive choice in terms of understanding organizational structure. This is not to say that the choice of geographic allocation itself relates to structural issues, but rather that the relationship between allocation decisions and 
underlying donor interests, preferences, and ultimately, purpose, suggests that allocation choices may serve as a proxy for understanding the purpose of aid programs.

Once geographic choices are made, donors face the decision of whether, and to what degree, to use different channels to deliver aid spending. The choice between allocating aid through bilateral or multilateral channels has generated a substantial literature focusing on questions of why bilateral donors allocate aid through multilateral institutions (see Milner and Tingley, 2013; Powell and Bobba, 2006; OECD, 2011; Dietrich, 2012). This literature finds that multilateral institutions are used due to their relative efficiency as a result of resource pooling (OECD, 2011), and capacity to enhance coordination (Powell and Bobba, 2006) and effectiveness of aid in certain regions (Dietrich, 2012). Importantly, the choice to use the multilateral system may be linked to questions concerning donor role, where higher proportions of aid channeled to or through multilaterals may signify a donor's desire to adopt more reactive policies by transferring the programming burden. If the use of multilateral institutions is connected to the choice of donor role, then the choice of channel for allocating aid acts as a proxy for understanding donor role and is peripherally linked to structure. However, beyond this connection, there is no clear literature or rationale to suggest that the choice of channel would reasonably influence the organizational structure of aid agencies.

Following allocation decisions, donors are faced with decisions concerning funding modality. Specifically, there has been some debate surrounding the choice of project versus program aid, particularly with regards to the relative effectiveness of each modality. These discussions typically associate project aid with high transaction costs (Camara, 2004) while program aid has been linked to high fiduciary risks and budgetary 
fungibility (Leiderer, 2012). More recently, concern over the effectiveness of aid modalities has led to the exploration of budget support, where un-earmarked contributions are made to recipient governments to support poverty reduction or domestic reform, as a modality for enhancing aid effectiveness. In essence, budget support (both general budget support and sector budget support) is expected to improve the effectiveness of aid by increasing the potential for aid to be spent in harmonization with recipient priorities, increase recipient ownership over aid spending, and reduce transaction costs by limiting fragmentation and increasing the effectiveness of recipient government systems (Jelovac and Vandeninden, 2008; Leiderer, 2012; Bandstein, 2007).

The question of modality appears to have little logical or theoretical connection to the organizational structure of aid agencies. At most, the choice of modality has been linked to donor efforts to sustain domestic support for aid by selecting modalities that best allow donors to demonstrate results (Bandstein, 2007). In these cases, donors are more likely to select project or results-based modalities over programs or budget support, as such mechanisms allow for donors to monitor outcomes more clearly. Additionally, Bandstein (2007) notes that aid modalities may also be used to support political preferences, where budget support allocations can signal pleasure or displeasure with partner governments. Despite the potential for donors to use modalities as political tools for managing donor-recipient relations, the choice of modality is primarily related to the terms of aid in individual relationships and does not appear to connect directly to structural decisions. Indeed, the choice of modality is likely to come after choices of geographic allocation. 
Similarly, the choice of country programming is linked to the decision between project and program spending. According to Cunningham (1974, p. 16), country programming is marked by a choice to design operations in recipient countries that complement each other and act as a cohesive whole. Importantly, the literature on the choice of country programming is thin. When available, it tends to focus on the number of country programs maintained by donors as part of broader questions of aid fragmentation and concentration (see Klingebiel, Mahn and Negre, 2016; Brown and Swiss, 2013) rather than the reasons for using country programs in the first instance. Other literature provides practical guidance for donors seeking to engage in country programming (Jones et al., 2012; FAO, 2012). An exception is Cunningham's assertion that the choice to use country programs is connected to donors seeking to pursue active roles, which are associated to the choice of organizational structure. Indeed, Cunningham makes an explicit link between country programming and the choice of organizational structure, stating that, "The real case for a separate agency, however, arises when a donor wishes to direct his aid at the long-term expansion of the economy of recipient countries" (1974, p. 33).

However, Cunningham's logic suggests that it is not the choice to adopt country programming itself that is important for organizational structure, but rather what the choice represents. The choice to use country programming is linked to the pursuit of active policies, where such policies require structures that allow donors to develop expertise commensurate to working cooperatively with recipients to program effectively. Taken one step further, the pursuit of an active role through country programming is important because it signifies a commitment to long-term development with partner 
countries; in essence, it speaks to the intended purpose of aid programs that organizational structures are designed to support. Indeed, Cunningham points to the link between purpose and structure by stating, that "even if a donor chooses a more reactive role, so long as it wishes to secure long-term development rather than short-term political and economic objectives, it will be necessary to take aid work away from traditional departments" (Cunningham, 1974 p. 34), arguing that foreign and trade ministries tend to be concerned with short-term political or commercial objectives. The point then, is that while the choice to program aid is important due to its capacity to act as a proxy for active door roles, for Cunningham, the choice to adopt country programming also, and perhaps more importantly, acts as a proxy for the developmental purpose of donors. ${ }^{9}$

Beyond country programming, the choice of modality is explicitly linked to questions concerning the terms of aid. Key debates tend to center around questions of the effectiveness of conditionality (Leandro, Schafer and Frontini, 1999; Adam et al., 2003; Dijkstra, 2002) and the potential for ex-post conditionality, or selectivity, to enhance aid effectiveness (see Burnside and Dollar, 2000; Chhotray and Hulme, 2009). While the terms of aid spending have undergone significant change over the past few decades, particularly with donors agreeing to untie aid from trade interests, the choice of terms do not appear to be meaningfully connected to questions of agency structure. Indeed, questions pertaining to the terms of aid spending appear more technical in nature than other choices reviewed.

\footnotetext{
${ }^{9}$ It should be noted that while country programming is an appropriate proxy for purpose at the time of Cunningham's study, the institutionalization of country programming as best practice has led to its adoption by almost all aid agencies as of 2015 (see Annex 1). Persistent variation in organizational structure despite this convergence towards the use of country programmes suggests that the presence or absence of country programs no longer speaks to unique purposes of aid programs that contribute to the adoption of different organizational forms.
} 
The literature on the choice of providing aid as grants or loans is similarly technical and unrelated to issues of organizational structure. This literature tends to explore the incentive effects of modality in recipient countries (Clements et al., 2004; Odedokun, 2004; Djankov, Montalvo and Reynal-Querol, 2004) and the capacity of each modality option to support economic growth (Djankov et al., 2004; Sawada, Kohama and Kono, 2004; Bandyopadhyay, Lahiri and Younas, 2013). However, this choice provides little insight into issues related to organizational form and is rather concerned with the specifics of conducting aid programming after modality and geographic choices are made.

Perhaps one of the most fundamental choices made by donor agencies concerns the volume of domestic resources allocated to development spending in each budgetary cycle. While the academic literature has produced relatively few studies of the choice of aid volume, such issues are highly relevant in domestic policy and international discourses. Discussions surrounding the donor aid effort are notably connected to calls for donors to reach the UN's $0.7 \%$ of GNI spending target. The few studies available have found that the choice of aid volume is often linked to donor income, pro-poor tendency, donor's military adventurism (Round and Odedokun, 2003), as well as political ideology of donor governments (Tingley, 2010). While the choice of budget size is consistently negotiated by all donors and is significant for gauging the relative prioritization of development assistance as a function of government, the theoretical relationship between questions of volume and aid agency structure is limited.

Most notably, the relationship between aid volume and organizational structure is grounded in Cunningham's assertion that size is linked to the incentive for donors to 
adopt active roles, where active roles are associated with more ambitious agency structures. In this case, similar to country programming, the size of donor agencies appears significant not because size itself informs structural preferences, but because the choice of size is viewed as a proxy for active donor roles. Indeed, Cunningham finds no evidence of a relationship between size and structure, stating that:

An examination of aid statistics does not suggest that the existence of an aid agency is accompanied by any particular characteristics in the programme...Among the seven aid agency donors four were above average [in ODA spending as a proportion of GNP] and three below. Among the nine non-aid agency donors six were above and three below...All this suggests that whatever else the creation of a separate aid agency means it does not seem to achieve or reflect a particularly generous attitude to aid allocations (Cunningham, 1974 p. 31-32).

However, size remains a significant choice facing donors to the degree that it serves as a proxy for active donor roles, where size does not dictate the presence of a separate agency, but is likely to signify a greater incentive for donors to actively program aid. While donors can actively program for a range of purposes, the point is that larger budgets provide greater incentive for donors to use aid to pursue a specific purpose. Similar to the choice of country programming then, the choice of budget size is important not because size is related to organizational structure, but because size signifies a commitment to active or purposeful aid allocation.

\subsubsection{Which choice is the most significant for organizational form?}

While Cunningham suggests that each of the above choices represent substantive decisions made by donors that could influence the choice of aid agency structure, the above review finds that some choices are more likely to influence structural form than others. Based on the theoretical linkages between the reviewed substantive choices and 
their connection to organizational structure, the choice of geographic allocation and aid effort size appear to be most significant for organizational form. However, in both cases, these decisions do not present an explicit connection to organizational form, but rather appear to influence organizational structure through their potential to act as proxies for the purpose of aid programs.

In the case of aid volume, the relationship between volume size and organizational form is predicated on the relative incentive for donors to engage in active donor roles, defined by the pursuit of purposeful aid programming. In this sense, volume becomes an indicator for the likelihood that donors have an incentive to develop policies and structures for the purposeful use of aid. Despite this link between the substantive choice of aid volume and the choice of organizational structure, the choice of volume is incapable of explaining variation in organizational structure in two ways.

Firstly, while volume may have historically acted as an indicator for active or reactive donor roles, the degree to which volume is linked to active donor roles appears to be declining. Indeed, newer donors with relatively small aid volumes appear to be active as shown through the use of country programs (see Slovak Republic, Greece, and Czech Republic). As a result, the capacity for this choice to explain the current organization preferences of donors is limited.

A further challenge with the choice of aid volume is that any variation between active and reactive donor roles identified through aid volume is not disaggregated enough to account for variation across the multiple organizational models used by active donors. Indeed, consider that reactive donors tend to adopt Model 5 structures; this suggests that Models 1-4 are the most commonly associated with active donor roles. The problem 
then, becomes one of differentiating between Model 1-4 structures based on aid volume, as Cunningham provides no theoretical relationship between aid effort and organizational form across models used by active donors. The point then, is that while the choice of aid volume is theoretically linked to organizational structures, theory is limited to understanding the difference between two donor roles, limiting the capacity of such theory to account for variation across five organizational models used by aid agencies.

The second choice of interest is that of geographic allocation. The review above found that the allocation choices of donors appear to be clear substantive decisions that relate to the organizational choices of aid agencies. However, similar to the choice of aid volume, the significance of allocation choices is linked to its capacity to act as a proxy for donor interest, preferences, and ultimately, the purpose of aid programs as defined by donor governments.

Indeed, the literature review provided in the prior section shows clear linkages between particular organizational forms and allocation preferences, where popular discourses suggest that organizational structures are adopted to allow donors to pursue specific interests or purposes through allocation. Autonomous aid structures, for instance, are theorized to be adopted by donors that seek to allocate aid to the poorest countries in support of developmental purposes, where institutional separation reduces the likelihood that aid becomes subsumed by foreign or domestic interests witnessed through the allocation of spending to strategic recipients.

Similar to the discussion of aid volume, the importance of the choice of geographic allocation is what the choice represents - i.e. in theory, allocation is the implementation of a donor's development policy and the intended purpose of aid 
programs. However, unlike the choice of aid volume, the choice of geographic allocation is not constrained by limited variation. Numerous potential choices for aid allocation, and ultimately, aid purpose, suggests that in theory, there is enough variation to explain differences across five organizational models. Moreover, the capacity for geographic choices influence organizational decisions through acting as a proxy for donor intentions or purpose does not appear to change over the sample period. Indeed, through the current reading of the literature, there is no theoretical reason to expect differences in the capacity for geographic choices to measure donor purpose, and subsequently influence organizational form, over time.

The finding that the substantive questions with the greatest potential to influence organizational structure (donor role and geographic allocation) relate to the capacity of choices to serve as proxies for understanding the purpose of aid programs, suggests that the most substantive choice facing donors is the choice of program purpose itself. Indeed, the significance of agency purpose as the main substantive question facing donors is supported by Lancaster (2008), who suggests that when taken together, the substantive choices facing donors serve as proxies for understanding decisions made by donors concerning the purpose of aid programs. Assuming that the purpose of aid agencies underlies the main choices identified, then the choice of aid volume, and more importantly geographic allocation, become proxies for the purpose of aid activities as defined by donor governments.

Theories from the organizational literature also suggest that the purposes of aid agencies are the most important substantive decisions for organizational structure. In the business literature, this understanding underlies the logic of contingency theory, where 
"The choice of goals and strategy influences how an organization should be designed" (Daft, 2013 p. 54), clearly linking organizational structure to its substantive purpose. Similarly, the structural-institutional perspective suggests that organizational structure is consciously designed to achieve policy goals. In many cases, such policy goals are dictated by the purpose or mandate of a given agency.

In particular, the principle-agent relationship between citizens and government draws further attention to the significance of the choice of purpose of aid programs. Aid agencies, like other line ministries, are branches of government that spend taxpayer resources (Martens, 2005). While aid agencies spend domestic tax revenues abroad, the understanding that such resources are provided and owned by citizens of donor countries necessitates that aid agencies are ultimately accountable to domestic taxpayers (Martens, 2005). As a result, governments responsible for pursuing the interest of its citizens are theoretically directed to develop aid programs that reflect the will of the public, where differences in aid policies across donors should reflect variation in the interests of citizens regarding aid programs. These interests, in theory, become the public purpose which aid agencies are used to pursue. ${ }^{10}$ While the specific purpose preferred by agencies is likely to change over time relative to the domestic context, the point is that the principal-agent relationship between government and citizens underlies the purpose of aid programs and becomes the basis on which 'substantive' policy choices are made. ${ }^{11}$

\footnotetext{
${ }^{10}$ Pursuing the public interest does not mean that aid programs are necessarily used aid for economic or strategic ends. In some countries, the Nordics for example, a socially minded population may prefer aid agencies to use taxpayer spending to pursue developmental ends.

${ }^{11}$ It is perhaps important to mention that the capacity of citizen interest to determine the purpose of aid agencies is based on the assumption that citizens have the ability to hold government accountable in cases of misuse. However, the degree to which citizens engage in such behaviour requires a citizenry that is actively interested in and capable of monitoring donor agents. Unfortunately, information asymmetries between citizen principles and government agents, or public apathy towards foreign affairs, reduces the ability or willingness for citizens to hold government accountable. While it is recognized that apathy on the
} 
Such evidence suggests that the most important substantive choice capable of forming the basis of organizational decisions is the choice of the purpose of aid programs. Having established the link between aid agency purpose as the key substantive choice and organizational structure, a next step is to clearly identify the types of purposes pursued by aid agencies in efforts to devise clear hypotheses surrounding the link between purpose and organizational form.

\subsubsection{What purposes do aid agencies pursue?}

This section explores the range of purposes pursed by donors through aid programs in order to begin theorizing about the relationship between each purpose and the organizational structures that may best fit their pursuit. Indeed, understanding that substantive choices influence organizational forms, it follows that each option within a substantive choice should coincide with a structural model. However, prior to exploring variation across the types of purposes used by donors, it is necessary to derive a clear definition of purpose as it applies to aid donors.

While the purpose of aid programs may be central to the form and function of aid agencies, there are few clear definitions for understanding the purpose of aid programs. In general, the term purpose is used to denote challenges which aid is intended to address. While some use the term in relation to sectoral challenges to which aid is allocated (Van de Sijpe, 2012), others describe purpose as the broader, overarching intentions behind aid programs in an aggregate sense (Christansen and Rogerson, 2005; Lancaster, 2007). Perhaps one of the clearest definitions of the purpose of aid programs is presented by

part of the public may limit the degree to which the purpose of aid programs is actively aligned with explicit citizen interests, the significance of the principal-agent relationship between government and citizens as a foundational component of democracy makes it necessary to meaningfully account for it when discussing the purpose of any government agency. 
Lancaster (2007), who defined purpose as "the broad goals that donor governments sought to achieve with their aid, evident not only in what they said the goals of their aid were but in the decisions they made on its amount, country allocation, and use" (p. 13).

Having defined the purpose of aid programs, it is necessary to explore the range of purposes identified throughout the literature. In general, Lancaster (2007) suggests that there are four main purposes of foreign aid, each of which is adopted by donors to varying degrees: diplomatic, development, humanitarian and commercial. Diplomatic purposes are perhaps some of the most well documented throughout the development literature. These purposes include aid intended to promote international security, democracy promotion, international political goals, and manage relations between governments (Lancaster, 2007). As such, diplomatic purposes are associated with the use of aid to pursue geostrategic interests. The literature related to the diplomatic purposes of aid tends to be composed of empirical studies of aid allocation, which find evidence that the diplomatic interests of donor countries influence aid allocation decisions. This finding is robust across a range of diplomatic proxy variables including security alliances (Meernik, Krueger and Poe, 1998; Berthelemy and Tichit, 2004; Bueno de Mesquita and Smith, 2009), UN votes and or Security Council seats (Alesina and Dollar, 2000) and geographic distance (Neumayer, 2005; Bueno de Mesquita and Smith, 2007). Moreover, the types of diplomatic interests pursued by donors are likely to change with international contexts. For instance, the end of the Cold War was coupled with a reduction in aid to former colonies (Berthelemy and Tichit, 2004), while the post-911 era saw a spike in aid to Afghanistan and Iraq as part of efforts to promote stability. 
In contrast, the development purpose uses aid to support economic and social efforts towards poverty reduction and improving livelihoods. This purpose is central to the idea of aid giving, which finds its roots in the 1945 UN Charter, where members committed to "promote social progress and better standards of life in larger freedom...[and] employ international machinery for the promotion of the economic and social advancement of all peoples" (UN, 1945). Moreover, in the OECD's 1961 Resolution for the Common Aid Effort, OECD-DAC donors made explicit commitments to pursue the developmental purposes of aid by increasing aid volume, ensuring that “assistance [is] provided on an assured and continuing basis" (Führer, 1996 p. 11 quoting OECD, 1961), provide aid on favourable terms based on the mutually agreed "need to help the less-developed countries help themselves by increasing economic, financial and technical assistance and by adapting this assistance to the requirements of the recipient countries" (OECD, 2006a p. 10). In this sense, the developmental purpose, perhaps more so than the others identified, is inherent in the notion of aid programming itself, and is necessarily adopted by all OECD-DAC donors. However, the degree to which donors have and continue to prioritize the development purpose over diplomatic, commercial and humanitarian considerations remains open for debate. ${ }^{12}$

The humanitarian purpose of aid programs refers to donor efforts to provide support to natural and manmade crises. Unlike traditional development assistance, which attempts to encourage long-term development and economic growth, humanitarian aid is generally seen as a shorter-term transfer intended to provide basic needs - foods, shelter, health care - in response to acute stressors, whether natural or man-made. While in

\footnotetext{
${ }^{12}$ This study intends to identify the purposes donors pursue in practice and does not seek to engage with or comment on normative questions of what the purpose of aid programs should be.
} 
theory, understanding the humanitarian purpose as a response to crisis suggests that donors engaging in humanitarian intervention are those that prioritize supporting basic needs over other considerations, where the allocation of humanitarian aid is seen as apolitical, several studies suggest that in practice humanitarian allocation is subject to the same political determinants as traditional spending. Indeed, a study of US disaster assistance, Drury, Olsen and Van Belle (2005) find that the decision to allocate disaster funds is inherently political, with democratic or allied countries more likely to receive disaster assistance, while others have found links between humanitarian spending and geographic proximity of recipients (Fink and Redaelli, 2011) and donor election cycles (Annen and Strickland, 2016). In spite of these findings, the distinct intentions of humanitarian spending and theoretical differences with traditional development assistance render the humanitarian purposes of aid distinct to other categories. However, the possible links between humanitarian spending and political interests raise questions for the interpretation and linkage between the pursuit of humanitarian purposes and organizational structures.

Lastly, the commercial purpose of aid programs involves using aid to create financial incentives for trade between donors and recipients. Similar to the diplomatic purpose of aid, donors that prioritize the commercial purposes of aid are said to allocate aid in order to enhance trade linkages (Meernik et al., 1998; Schraeder et al, 1998; Berthelemy and Tichit, 2004; Younas, 2008) and foreign direct investment (Alesina and Dollar, 2000; Berthelemy and Tichit, 2004). While part of donor commercial interests was perhaps more explicitly targeted through aid terms and tying aid spending to 
procurement from donor countries, the commercial purposes of aid remain prevalent and require consideration.

In addition, to the four purposes noted above, Lancaster notes that donors may also use aid to support cultural purposes, where aid is allocated in support of language training in former colonies. Traditionally, this purpose has been adopted to a lesser degree (Lancaster, 2007), as the association of this purpose with former colonial powers suggests that it is not likely to be relevant to countries without colonial pasts. As a result, the cultural purpose of aid will not be considered throughout this study. Similarly, additional purposes include the use of aid to promote economic and social transitions, promoting democracy, addressing global issues such as environmental security and global health, and to mitigate conflicts or manage post-conflict transitions, fulfilling historical obligation and establishing a particular international reputation/presence (Lancaster, 2007; Van der Veen, 2011). While the emergence of new purposes is interesting and important to understand, these purposes can broadly be related to the diplomatic purpose already identified, where aid allocated to furthering democracy, global health, or global security, can be considered in the best interest of donor countries. Moreover, the emergence of these more specific purposes in the late 1990s suggests that they were not significant determinants of aid throughout the entire sample period, but rather emerged due to changing global circumstances. As a result, these purposes will be considered within the broader diplomatic purpose, but will not be assessed at an individual level.

Having described the main purposes of aid programs utilized by donors, it is necessary to ensure that the choice of purpose satisfies the two criteria outlined at the 
beginning of this section. The first criterion is ensuring that there is adequate variation in both the possible responses to the substantive questions identified, as well as in terms of the actual purposes donors select in practice. To demonstrate variation, one need only to venture as far as the aid allocation literature, which uses proxy variables to assess the degree to which donors allocate aid towards recipients that represent commercial interests, act as geostrategic allies, face natural or manmade strife, or are the most impoverished (see Alesina and Dollar, 2000; Collier and Dollar, 2002; Berthelemy, 2005; Hoeffler and Outram, 2008; Berthelemy and Tichit, 2004; Faust, 2011; Younas, 2008). Indeed, many of these studies confirm the presence of variation between the relative prioritization of the identified purposes used by donors. The US, for instance, has long been thought to provide aid to pursue diplomatic interests (see McKinlay and Little, 1977; 1979; Alesina and Dollar, 2000) while the Nordic countries have been shown to prioritize development concerns over other interests (Gates and Hoeffler, 2004).

In addition to differences in the adoption of priorities across donors, there is some evidence to suggest that the degree to which donors provide aid in support of each purpose differs over time. For instance, by comparing the pre- and post-Cold War period, Berthelemy and Tichit (2004) show that aid in the post-Cold War period was more targeted towards commercial versus strategic interests, suggesting shifting purposes with the decline in international tensions. The presence of variation in donor purposes across time is significance as it suggests that if donor purposes are found to be primary determinants of organizational structure, then temporal changes could be linked to reorganizations. 
The second criterion suggests that any substantive decision capable of informing a theory of aid organization must be one that is made by all donors to facilitate comparison. Firstly, the presence of an aid program itself necessitates the presence of a purpose. Once aid programs are established, the purpose of aid programs remains subject to debate and changes based on domestic and international conditions. While such changes may not be explicit each year, changing government priorities, even changes to government, are likely to cause donors to rethink the purpose of their aid programs.

By meeting the above criteria, the choice of aid program purpose appears to provide the necessary variation and consistent relevance across donors to be considered a key factor for influencing organizational structure. Having critically engaged with Cunningham's theory, this section sought to build on Cunningham's initial logic, while identifying a new substantive question capable of explaining organizational structure since the early 1960s. The next section will build on the proposed theoretical framework by identifying several key hypotheses.

\subsubsection{Summary and Findings}

This section sought to identify the substantive choice that is the most important for determining aid agency structure. In doing so, this section explored a range of typical substantive choices made by donors including geographic allocation, aid channel, and aid volume. Of the choices reviewed, the substantive purpose pursued by aid agencies was shown to be the most likely determinant of structural choice, partly due to its capacity explain variation across multiple organizational models.

This section then identified the main purposes that donors tend to pursue. Drawing specifically from Lancaster (2008), four key aid agency purposes were 
highlighted - diplomatic, commercial, humanitarian and developmental. The choice of aid agency purpose was then shown to be applicable to all donors over time, making it a viable potential driver of structural choice. In essence, this section highlighted the importance of aid agency purpose as a substantive choice with the potential to influence structural design.

The next section builds further on the theoretical linkage between purpose and the choice of structure by outlining the proposed theoretical relationship and hypotheses between certain types of structures and purposive choices. These hypotheses, and the theory outlined in this chapter, provide the theoretical framework to be tested throughout the remainder of this study.

\subsection{Discussion and Hypotheses}

This section outlines the hypotheses that will be tested throughout the remaining chapters of this dissertation. The main hypotheses are drawn from the theory developed in the preceding section. Alternative hypotheses are taken from the literature reviewed at the beginning of this chapter. To ensure that this study accounts for all possible theoretical determinants of aid agency structure, the next chapter will develop and test quantitative models that account for all identified hypotheses.

The main hypothesis of this study is that the purpose of aid programs is a key determinant of aid agency structure. Based on the understanding that the key substantive choices facing donors are likely to influence the organizational choices made, where the choice of purpose is considered the main substantive decision facing donors, the purpose of aid programs is seen as a key determinant of organizational structure as donors are said 
to adopt organizational forms that offer the greatest potential for achieving donor purposes. In theory, this would also mean that donors with similar purposes are likely to adopt similar structures, suggesting that groups of donors adopting similar structural models should seek to derive similar purposes from aid programs. Inherent in this logic is the understanding that aid agency structures are expected to remain the same over periods in which they maintain the same purposes. Put differently, changes to the main purpose of aid programs identified by donors are expected to be followed by changes to the organizational structures of aid agencies.

H1: If aid agency structure is determined by 'purpose', then aid agencies with similar purposes should adopt similar structures.

As a result, it is prudent to explore the types of organizational choices that are theoretically linked to the purposes selected by aid agencies. At the most basic level, the five organizational models used by donors employ varying degrees of policy autonomy enjoyed by aid agencies. The most autonomous aid agencies are those that adopt a Model 4 structure. These agencies retain control over policy decisions and implementation related to development functions. At the other end of the spectrum, Model 1 structures are the most integrated, with policy and implementation decisions made by foreign ministries. Models 2 and 3 tend to fall somewhere in between. Model 2 agencies are semi-autonomous and generally maintain development directorates that oversee aid policies and implementation. However, the location of such directorates within foreign ministries renders them accountable to the interests of the larger agency. Alternatively, 
in Model 3 structures, policy is typically generated in foreign ministries, ${ }^{13}$ while implementation is the responsibility of separate agencies.

The degree of autonomy and source of policy authority is less clear in donors using the Model 5 structure. The OECD states that such donors use a range of ministries to "take responsibility for a particular aspect of the programme" (Chang et al., 1999 p. 39), without specifying whether such ministries act as policy makers or takers regarding their portion of the aid budget. Moreover, for reactive donors adopting Model 5 structures, it would seem that donors are not responsible for implementation and do not need institutional structures to support such functions.

Theory suggests that donors that prioritize diplomatic or commercial purposes relative to developmental concerns are more likely to adopt less autonomous organizational structures. Such structures institutionally link aid programs to foreign policy by rendering foreign ministries responsible for aid policy. Recognizing that foreign policy is a central concern of governments, often requiring close oversight from the political executive (see Wildavsky, 1966), governments that seek to use aid to further foreign interests are likely to prefer organizational forms that prioritize institutional closeness to allow for greater political oversight and ensure that bureaucratic actions support government priorities (Arel-Bundock, Atkinson and Potter, 2015). In this sense, governments that prioritize diplomatic and commercial purposes of aid programs are likely to adopt organizational structures that place responsibility for aid policy within the foreign ministry - Models 1, 2 or 3.

\footnotetext{
13 Perhaps a notable exception is Germany, which is assigned a Model 3 structure according to the OECD categorization, yet takes policy from a development ministry rather than a ministry responsible for foreign policy (BMZ, 2016). The difference between the use of a foreign and development ministry suggests that Germany may possess more policy autonomy than other Model 3 donors.
} 
Alternatively, donors that prioritize the developmental purpose of aid over strategic interests are more likely to use 'autonomous' organizational structures - Model 4 - to organize aid programs. If institutional closeness is used to improve government oversight and ensure that aid agencies align development efforts to broader diplomatic and strategic objectives, then agency independence is used to safeguard agencies from political interference. Indeed, there is some evidence of this in the organizational design of two independent aid structures. Firstly, the separation of the UK's DFID from the Foreign Office in the 1990s was a direct response to controversy over the political uses of aid in prior years. Similarly, in 2004, the American Millennium Challenge Corporation (MCC) "was established as an independent agency in large part because of concerns that its development focus would be compromised if it were housed within an executive branch agency" (Lancaster 2007, 106-107, cited in Arel-Bundock et al., 2015 p. 546). Indeed, the fact that the MCC was not placed within the US State Department "may have been a concern that it would be located too close to the center of the US foreign policy apparatus and would limit the program's immunity from strategic and political interference" (Nowels, 2003 p. 20, cited in Arel-Bundock et al., 2015 p. 546). In both cases, efforts to sustain the developmental purpose of aid are associated with the use of autonomous aid agency structures.

In addition, it seems prudent to suggest that Model 5 donors are also likely to support developmental purposes. While Model 5 donors tend to be 'reactive', suggesting the absence of clear policy for aid allocation and programming, the presence of aid programs themselves suggest that donor either consider development assistance something that they should, or want, to engage in. Either way, in the absence of clear 
policy of purposeful allocation, the purpose that seems the most likely to be pursued by Model 5 agencies is the developmental, as it speaks to the fundamental purpose or normative understanding of aid programs. In essence, the point is that in the absence of clear policy or efforts to develop coherent aid programs, the purpose pursued by Model 5 donors should be the same as the justification for developing aid programs in the first instance; presumably, this purpose is to support the development of the Global South.

The connection between the humanitarian purpose and corresponding organizational structures is perhaps the least obvious. At the most basic level, it seems prudent to suggest that all donors are likely to support the humanitarian purposes of aid. However, the presence of institutional structures capable of mobilizing human and financing resources quickly in the face of humanitarian crises may be better placed to support humanitarian purposes than reactive donors without clear institutional structures for responding to international incidents. Indeed, the disaggregated structure of Model 5 organizational forms, in conjunction with a reliance on developing countries to submit proposals for funding, suggests that there is low institutional capacity to plan, or mobilize resources effectively in multiple-ministry structures. In this sense, it appears that the humanitarian purpose is more likely to be adopted by 'active' donors, such as those using Model 1, 2, 3 and 4, while Model 5 donors are the least likely to use aid for humanitarian purposes.

H1(A): If aid agency structure is determined by agency 'purpose', then aid agencies with the purpose of pursuing strategic interests are likely to adopt merged organizational structures.

H1(B): If aid agency structure is determined by agency 'purpose', then aid agencies with the primary purpose of pursuing long-term poverty reduction are likely to adopt autonomous or multiple ministry organizational structures. 
H1(C): If aid agency structure is determined by agency 'purpose', then aid agencies with the purpose of pursuing commercial interests are likely to adopt merged organizational structures.

H1(D): If aid agency structure is determined by agency 'purpose', then aid agencies with the purpose of pursuing humanitarian interests are less likely to adopt multiple ministry organizational structures.

A further question related to the purpose of aid programs concerns the underlying determinants of differences in the motivations for aid giving identified by donors i.e. poverty reduction and strategic interests. Perhaps most significantly, the political ideology of donor governments has been shown to influence the types of aid policies pursued by donors (Tingley, 2010; Fleck and Kilby. 2006; Goldstein and Moss, 2005). For instance, Fleck and Kilby (2006) find partisan politics are important for aid allocation, arguing that US aid preferences are linked to the partisan control of Congress. In particular, they find that a Republican held Congress is more likely to allocate aid based on export markets and economic strategy, while Democratic held Congresses tend to distribute aid based on a more "development-oriented and humanitarian approach to aid" (2006, p. 21). While Goldstein and Moss (2005) and Moss (2007) find that Republican governments tend to have higher aid budgets than their Democratic counterparts, this finding could be explained based on the understanding that for Republicans, poverty reduction is seen as a means for improving international security. More specifically, Tingley (2010) suggests that conservative governments may be more likely to organize aid agencies in a way that promotes the alignment of aid spending with broader foreign policy interests.

These cases suggest that there appears to be a partisan connection to the purposes parties pursue in regards to aid, where conservative governments may prioritize the 
strategic purpose of aid while liberal parties appear less likely to use aid for political or strategic purposes. As a result, it seems prudent to suggest that conservative governments may seek to design aid structures that would maximize the opportunity for aid to be allocated in alignment with other foreign interests (Models 1 and 2), while leftleaning governments may be more inclined to prioritize the poverty reduction capacity of aid and adopt structures that best support this function (Models 3 and 4).

The degree to which political ideology influences the likelihood of adopting Model 5 structures is questionable. Despite the aforementioned potential for Model 5 donors to pursue developmental purposes, the relatively small amount allocated to aid spending by Model 5 donors suggests that aid programs may be viewed as inconsequential or beyond ideological preference. In this sense, it seems prudent to suggest that ideology may have limited effect on the choice to adopt Model 5 structures.

H1(E): If aid agency structure is determined by agency 'purpose' and the political ideology of donor governments determines the purpose of aid, then right-leaning governments are likely to prioritize the strategic purpose of aid and adopt merged organizational models (1 and 2), left-leaning governments are likely to prioritize the poverty reduction capacity of aid and adopt more autonomous structural forms (Models 3 and 4), while ideology is assumed to have no effect on the choice to adopt Model 5 structures.

In addition to the purpose of aid programs, the capacity for aid agencies to achieve desired outcomes at the lowest cost may also influence the organizational form of aid agencies. In the organizational literature, contingency theory suggests that organizations are designed to maximize efficiency by adopting organizational forms that 'fit' the contextual and functional contingencies that confine any given agency (Weber, 1947; Pugh et al., 1963, 1969; Child 1972; Donaldson, 2001). In this case, agencies not achieving the desired outcomes/outputs at appropriate costs are seen as out of "fit", 
necessitating reorganization to improve the capacity for organizations to achieve particular goals.

Similarly, the structural-instrumental perspective forwarded in the literature on public sector organization suggests that organizational form is a tool for achieving specific goals. Based on the understanding that structures influence behaviour, organizational forms are seen as important sources of efficiency. As a result, it seems that organizational structures that do not contribute to desired behaviour and outcomes, are likely to face re-organization in the efforts to find a better tool for achieving the specified goals. Moreover, the transaction-cost perspective included within the structuralinstrumental approach suggests that organizations may be designed to reduce the transactions costs involved in an organization's activities. In this case, the choice of organizational structure is again considered a deliberate effort to enhance the efficiency of the organization in terms of reducing costs and achieving results.

In the foreign aid literature, the efficiency of aid agencies is rarely addressed from the donor perspective. More commonly discussed are questions concerning the effectiveness of aid programs and donors themselves (Gulrajani, 2012). Recently, some have sought to apply a transaction cost perspective to aid activities (Paul and Vandeninden, 2012), however such analysis focuses on the costs of various modalities for aid delivery rather than overall donor functions. When efficiency is mentioned in relation to donors, it tends to be understood in terms of administrative costs, and is used to compare such costs across donors (see Easterly and Pfutze, 2008; Knack et al., 2012).

Despite the absence of efficiency theorizing in the aid sector, the organizational and public sector literatures suggest that efficiency could be a determinant of 
organizational structure in aid agencies. Based on the contingency theory perspective that organizations are most efficient when they are in "fit" and efficiency losses are likely to be met with organizational change to restore fit, the second major hypothesis (below) identifies efficiency as a potential determinant of structural form. ${ }^{14}$

H2: If aid agency structure is determined by efficiency, then donors should select organizational structures that allow them to maximize efficiency.

According to the institutional theory, organizations seek to enhance their institutional legitimacy by adopting structural forms that conform to dominant norms of the broader institutional environment (Clegg et al., 2011; Donaldson, 2006; DiMaggio and Powell, 1991). Similarly, the environmental perspective forwarded in the public sector literature points to the significance of the external environment as a determinant of organizational structure in public agencies. In essence, both theories suggest that organizational structures within a similar field are likely to converge towards structures that best support institutional norms and contribute to institutional legitimacy.

In aid, 'best practices' tend to focus on donor level principles designed to enhance the capacity of aid, such as the Paris Principles (OECD, 2005), or enhance the levels of aid spending to meet the UN target of $0.7 \%$ of GNI. In both cases, legitimacy is associated with the capacity of agencies to act in ways that advance key principles. Recent cross-country comparisons of donor behaviour have pointed to the UK as one of the best performing donors in terms of its capacity to embody and exemplify the Paris principles (Gulrajani, 2012), linking such performance to the strengths of its autonomous

\footnotetext{
${ }^{14}$ It should be noted that for the purpose of this study, it will be assumed that structures are initially in fit. Seeing as baseline efficiency is likely to differ across donors based on fund size and project type, and the understanding that donors can only be meaningfully assessed against themselves, this hypothesis assumes initial fit and proposes that if efficiency is a determinant of structure, then structural change should follow changes to efficiency.
} 
organizational design (Carment et al., 2013). However, understanding that there are a variety of potential organizational structures that could allow for the maximization of institutional legitimacy, this hypothesis suggests that if aid agency structure is determined by legitimacy, then donors should adopt the structures used by "best performers".

H3: If aid agency structure is determined by legitimacy, then donors should adopt the structures of best performers.

In addition to enhancing institutional legitimacy, the public administration literature suggests that many organizational reforms taken by government have been influenced by the NPM agenda. Based on the understanding that the NPM agenda was influential in restructuring public sector institutions throughout OECD countries for multiple decades during the existence of aid agencies (Hood, 1991), it is likely that the organizational structure of aid agencies may be influenced by the NPM agenda. Underlying the NPM paradigm is the understanding that the efficiency of government can be improved through adopting a style of government that is grounded in market-oriented principles, where efficiency is believed to be achieved through the decentralization, privatization, and automation of government via 'contracting out' government functions (Hood, 1991).

Based on this logic, the organizational structures that best conform to the principles of NPM are found in Model 2, 3 and 4 structures, each of which embody decentralization and specialization by using separate agencies to perform specific tasks. In Model 2, semi-autonomous structures suggest some movement towards the specialization of tasks within units that possess some autonomy for specialized functioning. For Model 3, separate agencies are used for the implementation of aid programs, where policies made by central government are 'contracted out' to 
implementing structures. Similarly, in Model 4, aid agencies are autonomous from foreign ministries and are able to specialize in development programming and delivery. In this sense, if the NPM agenda has contributed to the organizational forms of aid agencies, it is expected that organizational changes to aid agencies would lead donors to adopt Model 2, 3 or 4 structures. Conversely, organizational shifts that lead to the formation of merged agency structures, such as those found in Model 1 would represent a break with the NPM agenda through relocating development programming under centralized control.

H4: If the organizational structure of aid agencies is influenced by the NPM paradigm, then donors should adopt decentralized organizational structures (Model 2, 3 or 4) following the emergence of the NPM paradigm.

While the NPM agenda implies that organizational structure is determined by institutional forces outside donor governments, path dependency theory suggests that structure is linked to the cultural and historical roots of public administration within donor governments themselves (Christensen and Læfreid, 2011). For path-dependency, historical realities shape the outcomes that occur later in time, where agency structure links organizational form to the historical process and contexts that lead donors to adopt specific organizational forms and shape the outcome of reorganizations. In essence, the argument suggests that aid agency structures are likely to be determined by pre-existing internal structures, such as the type of government system, which informs the further development of government structures (Verhoest et al.'s, 2012). Indeed, path dependence not only suggests that organizational structures are based on preexisting domestic institutions and organizational preferences, but that countries with shared histories or similar structures are likely to develop similar institutional forms. 
H4(A): If aid agency structure is determined by path-dependency, then it is expected that donors with similar histories and governing structures will converge around similar organizational models.

H4(B): If aid agency structure is determined by path-dependency, then donors will utilize organizational models for extended periods of time due to structural inertia.

\subsection{Conclusion}

This chapter developed a theoretical framework for understanding the determinants of aid agency structure. It began with a multi-disciplinary review of literature from organizational studies, public administration, and international development to identify key theories for understanding why donors select particular organizational models. The review found few studies that focus specifically on issues related to aid agency structure, highlighting a clear gap in the academic literature.

An important exception is George Cunningham's in 1974 work on aid management, which highlights the importance of substantive choices as key drivers of structural form. In particular, Cunningham points to differences between active and reactive donor roles as central to organizational choices. Taking Cunningham's theory as a starting point, this chapter explored whether the active/reactive distinction can reasonably be seen to drive organizational choices forty years after Cunningham's initial thesis. I argue that since the time of Cunningham's work, the division between active and reactive donors has become less stark, with more donors moving towards active donor roles. While some newer OECD-DAC donors still adopt more reactive models, general convergence towards active engagement with partner countries suggests that the choice of donor role is unable to explain current variation in the organizational models used by donors. 
With this in mind, this chapter reviewed a range of substantive choices faced by donors that could inform structural choices. Of these, the choice found most likely to influence aid agency structure is that of aid agency purpose; specifically four purposes are deemed to drive organizational choices - developmental, commercial, diplomatic and humanitarian. The theoretical linkage between substantive preferences and organizational structure is a main hypothesis tested throughout this study.

The final section of this chapter outlines the key hypotheses related to the drivers of aid agency structure as identified through the literature review. These variables compose the main theoretical framework that will be tested in the remainder of this study. Indeed, the chapters that follow used quantitative and qualitative techniques to test the identify the factors that contribute to organizational choices and change. 


\section{CHAPTER 3}

ANALYZING TRENDS IN AID AGENCY STRUCTURE 
A necessary first step towards understanding reasons why donors adopt various aid agency structures is identifying the models donors use, and have used, over time. This requires mapping the donor organizational landscape to capture the full range of structural choices and changes undertaken by donor governments since the OECD-DAC was formed in the early 1960s. Doing so will highlight key trends in the usage of models and allow for an analysis of organizational structure across all OECD-DAC donors. This analysis is the first of its kind and is one of the key contributions of this study.

Using data from the OECD-DAC Peer Reviews dating to 1962, this chapter introduces a new variable that maps aid agency structure over time and provides a descriptive analysis of the organizational development of OECD-DAC donors from 1962 to present day. In doing so, this chapter contributes to the literature on aid organization by constructing a variable for aid agency structure and mapping main trends in organizational choices and changes over time.

This analysis highlights a few important findings. First, the descriptive analysis shows that donors stopped using the Model 5 organizational structures in the early 2000s. This finding appears to mirror the decline in the adoption of "reactive" donor roles, and provides initial support for Cunningham's thesis presented in Chapter 2. Moreover, the use of Model 1 by primarily Nordic donors, and the use of Model 4 by Anglophone countries, suggests that historical and cultural similarities are likely to influence the choice of donor role. Third, in recent years, there has been a clear convergence towards the adoption of Model 2 and Model 3 structures. While further analysis into the determinants of such structures is necessary to understand such convergence, there is 
some evidence to suggest that this convergence may highlight the role of legitimacy as a determinant of aid agency structure.

\subsection{Mapping Aid Agency Structure}

To map the organizational structure adopted by donors over time, information on aid agency "organization and management" sourced from OECD-DAC Peer Reviews was compiled and analyzed for each donor from 1962 to 2015. The OECD-DAC began conducting Peer Reviews (formerly called Aid Reviews) in 1962, two years after the DAC was established (Führer, 1996). The Reviews assess the development assistance policies and programs of each DAC member, offering advice to improve program quality and effectiveness (OECD, 2014). As part of this assessment, the Reviews consistently

examine the administration and management of aid programs by capturing current organizational forms and reviewing organizational changes occurring since the previous Review. As a result, the Reviews provide a consistent source of information on aid agency structure across all OECD-DAC donors as far back as the 1960 s.

To obtain the full range of information on aid agency structure, primary research was conducted at the OECD Library and Archives in Paris in June 2015. While recent Peer Reviews (since the late 1990s) are freely available via the OECD's E-Library, backissues of Aid Reviews for all donors from the 1960s to the mid-1990s are available on microfilm and microfiche at the OECD Library and Archives in Paris. During this period, copies of Aid Reviews for each OECD donor from 1962 to the present were consulted. 
Descriptions of donor organization and changes were compiled for each donor in each year that data was available. ${ }^{15}$ In some cases, such as Australia in 1989, aid reviews were missing in the OECD archives. While the presence of missing data is unfortunate, it does not impact the ability to trace aid program development over time. Aid Reviews not only report current structures, but also outline any changes to structures that occurred in recent years. In instances where data was missing from OECD archives, aid agency structures were deduced by examining reviews from the years prior to and after those with missing information. Recognizing that aid agency structures do not exhibit regular change, there is reasonable certainty that this method captured all major organizational changes and allowed for the correct identification of aid models in each year.

Once the data was compiled, descriptions of the organizational structures used by donors were coded as Model 1, 2, 3, 4, or 5 for each year according to the typology of donor organizational models developed by the OECD and presented in Chapter 1 (OECD, 2009a; see also Chang et al., 1999).

\subsection{Trends and Changes in Organizational Structure ${ }^{16}$}

Over time, the administrative units adopted by donors have been subject to various organizational changes, with many countries shifting between aid agency models at various junctures. Figure 4 (below) identifies the organizational model used by OECDDAC donors at four snapshots in time - 1962, 1980, 1995, and 2015. Snapshot years

\footnotetext{
${ }^{15}$ Importantly, the frequency of the Aid Reviews has changed over time. From 1962 to 1975, Aid Reviews were conducted every year for each OECD-DAC member active at the time. From 1976 to 1990, the Aid Reviews were conducted bi-annually for all active members, and since 1990, OECD Peer Reviews have been conducted every four years. A full list of the Aid Reviews and Peer Reviews by donor and year can be found in Appendix 3.

${ }^{16} \mathrm{~A}$ full list of models associated with each donor in each year can be found in Appendix 2.
} 
were chosen at approximately equal points between 1962 and 2015 (1962 is selected as the starting point as this is when the OECD-DAC began issuing Aid Reviews). Seeing as organizational change tends to occur infrequently, examining changes as snapshots efficiently captures organizational shifts and highlights movement over time. It should be noted that donors appear across the snapshots as they join the OECD-DAC. ${ }^{17}$ These donors are italicized.

Figure 4: OECD-DAC Donors by Model - 1962
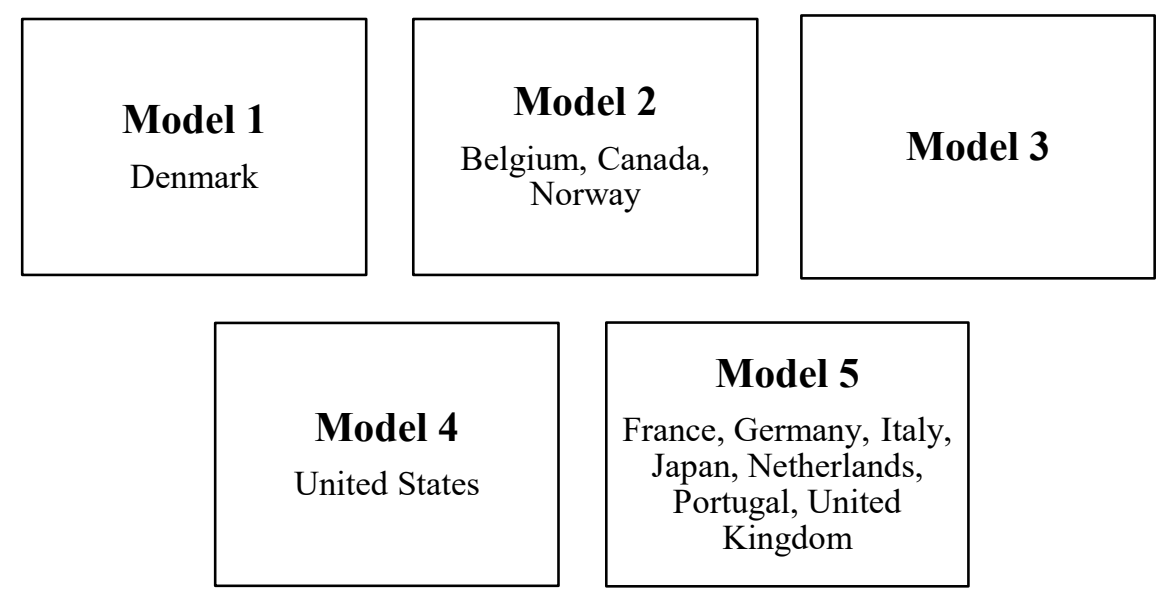

\section{OECD-DAC Donors by Model - 1980 ${ }^{18}$}
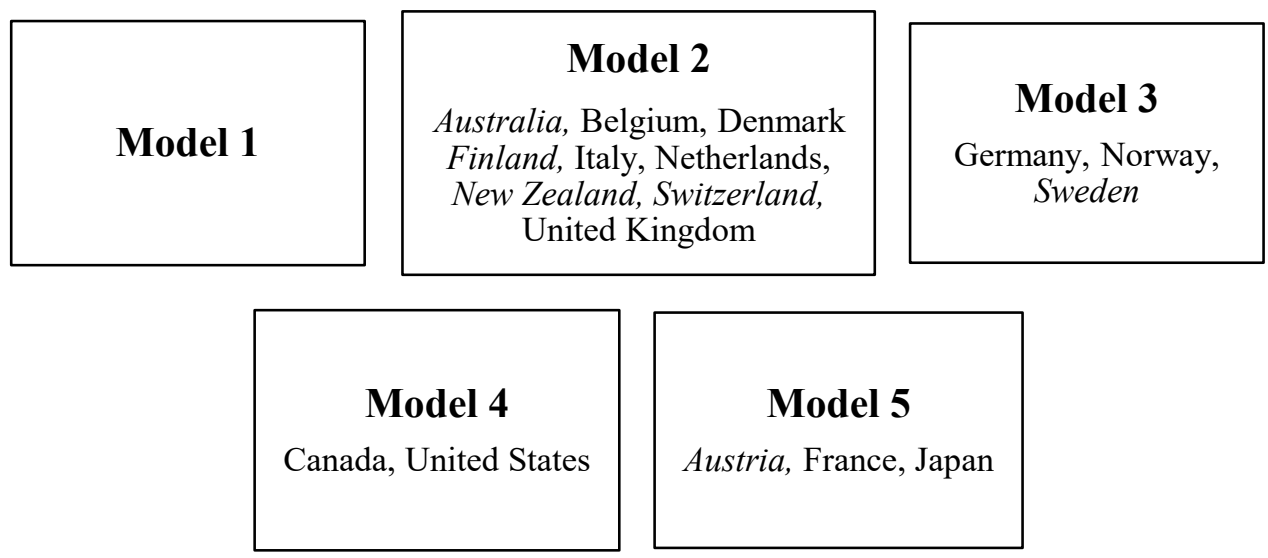

\footnotetext{
${ }^{17}$ A full list of dates at which donors joined the OECD-DAC can be found in Appendix 4.

${ }^{18}$ Portugal does not receive an aid review from 1969 to 1991.
} 


\section{OECD-DAC Donors by Model - 1995}

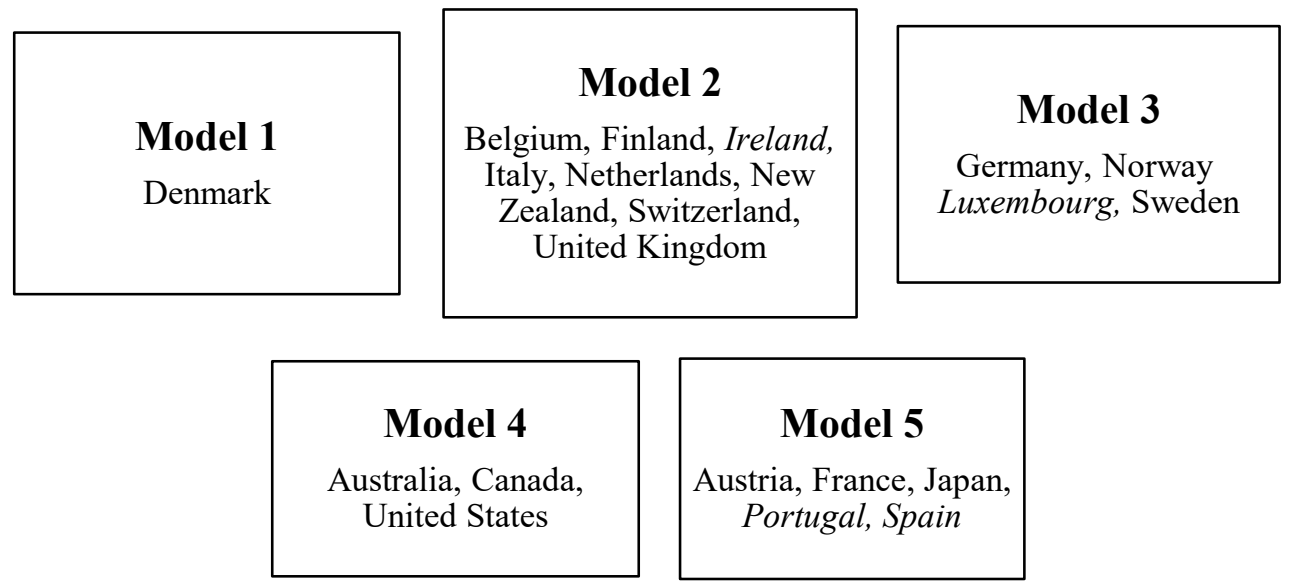

\section{OECD-DAC Donors by Model - 2015 ${ }^{19}$}
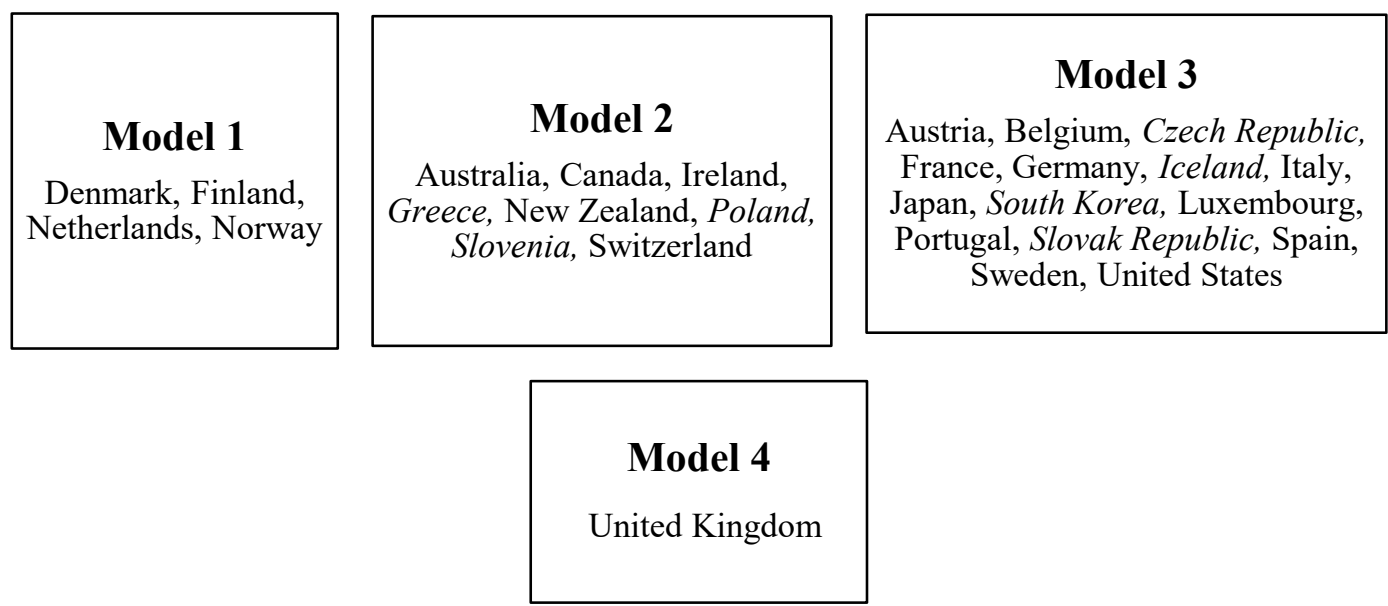

${ }^{19}$ It should be noted that while most of the Model classifications match those identified by the OECD in both Chang et al. (1999) and OECD (2009), my analysis differs in two instances. In the case of Finland and the Netherlands, Chang et al. (1999) note that both countries had recently undergone organizational changes that resulted in a change to Model 1 structures. A decade later, the OECD (2009) recoded both countries as using Model 2 structures despite the absence of major organizational changes in either case.

For the purpose of this study, my coding matches the findings of Chang et al. (1999) and considers both the Netherlands and Finland to use Model 1 structures in each year following their organizational changes which took place in 1996 and 1998, respectively. In both cases, these changes amounted to a reorganization of the Ministry of Foreign Affairs (MFA) towards a more "integrated" approach between aid, trade, and foreign policy. Organizationally, this change saw regional units became responsible for developing country-specific strategies that considered all foreign policy efforts (aid, trade, political). In both cases, "directorates" for development cooperation are used to provide policy direction.

Although the retention of "directorates" for development cooperation is a feature of the Model 2 structure, the "integrated" function played by geographic units responsible for developing strategies that account for all foreign policy priorities is definitive of the Model 1 structure. While the presence of both directorates and integrated geographic units could make both cases "hybrid" structures, I contend that the integration of aid, trade and political considerations in geographical units renders both countries closer to a Model 1 structure than a Model 2 form, which clearly delineates responsibility for the programming and implementation of "development cooperation" in a separate unit or directorate. 
The snapshots highlight three key trends, each of which is discussed in greater detail below. Firstly, the snapshots show that over time, Model 5 has become obsolete as a structure for organizing aid programs among OECD-DAC donors. Second, there seems to a clear convergence by donors with similar historical and culture features towards the same organizational structures. Third, in recent years, donors have moved towards Models 2 and 3 in particular.

\section{$\underline{\text { 3.2.1 Moving Away from Model } 5}$}

In 1962, Model 5 was one of the most used organizational structures for aid management, with $58 \%$ (or 7/12) OECD-DAC donors using this structure to organize aid programming. By the early 2000s, Model 5 was no longer in use.

There appear to be two main trends in the usage of Model 5 across donors. First, a number of donors used the Model 5 structure for a short period in the early stages of aid program development prior to adopting a different structural form. This is the case for Germany, the UK, the Netherlands, Italy, and Australia. ${ }^{20}$ In each case, Model 5 appears to act as a "starter" model in the early period of aid programs and aid management.

It is possible that the usage of Model 5 in the early stages of aid programs could be linked to the fact that this model does not require donors to invest heavily in aid administration, and rather uses current ministries and structures to share the burden of aid programming by taking ownership of tasks they already perform. Indeed, in the Australian case for instance, aid was seen as a temporary commitment in alignment with the Colombo Plan. In this case, the Model 5 was used in a period where the government had not anticipated that aid would become a long-term feature of its foreign policy. Once

\footnotetext{
${ }^{20}$ Australia is not shown to use Model 5 in the snapshots as it only becomes an OECD member in 1966. However, Australia adopts the Model 5 structure from 1966 to 1974. For more, please see Appendix 2 and Chapter 7 for full history of Australia's aid program.
} 
it became clear that development spending was here to stay, Australia began to explore other options of aid management. ${ }^{21}$

Second, early analysis of the management of aid programs linked multiple ministry structures to donors that pursued a "reactive" donor role. Recall Cunningham's (1974) theory that reactive donors may be inclined to use "specialist government ministries like Education and Agriculture to react to proposals with a minimum of interministerial coordinating machinery" (p. 3). Indeed, there is some evidence to support the relationship between reactive roles and Model 5 structures, where the declining usage of Model 5 mirrors the shift towards the adoption of more active donor roles as argued in Chapter 2.

Taking the use of country programming as an indication of "active" donor roles, OECD-DAC Reviews suggest that Austria, Japan and France, the donors which used Model 5 over the longest period, were not "active" until at least the mid-1980s. In the case of Austria, a 1999 Peer Review states that its Department of Development Cooperation (DDC) began engaging in country programming with the drafting of country strategies for its 19 partner countries in 1993 (OECD, 1999a). In Japan, the creation of five-year country strategies for 11 major recipients was first reported in the 1999 OECD Review (OECD 1999d). For France, the shift towards a more active donor role began as early as 1985, when it first developed "medium-term orientations" (MTOs) for some recipients. ${ }^{22}$ France further expanded the use of country strategies to cover all

${ }^{21}$ See Chapter 7 for more details.

${ }^{22}$ France's development assistance was historically divided into "ambit" and "non-ambit" partner countries, which were managed by different organizational branches. "Ambit" countries were former colonies and other (mostly) African partners. Development assistance for ambit countries was managed by the former Ministry for Cooperation. For "non-ambit" recipients, which included all other developing countries, aid was managed by the Treasury Department of the Ministry of Economic Affairs (see OECD, 1993a). 
development partners by 2004. In each case, the shift towards the use of country programming suggests movement towards the adoption of a more active donor role. Moreover, various phases of France's engagement in country programming could also suggest a distinction between active and reactive is likely to be relative rather than absolute.

While the adoption of country programming in the years prior to reorganizations away from Model 5 structures provides some initial evidence towards Cunningham's theory of the relationship between structure and donor role, it provides little insight as to why Model 5 donors chose to reorganize to Model 3 structure. Indeed, all donors that used Model 5 in the 1990s adopted Model 3 upon changing their structure. Of these donors, three cite greater coordination as the purpose of reorganization (France, Portugal and Japan), while two donors (Spain and Austria) frame the adoption of Model 3 as an effort to support a rapid and planned scale-up of aid spending. While coordination challenges are undoubtedly a problem with multiple-ministry structures, the common choice to use Model 3 instead of other organizational designs raises questions as to why this model was consistently chosen over other organizational forms.

The shift from Model 5 to 3 structures across the entire sample of long-term Model 5 donors could suggest a degree of path dependence, potentially related to institutional similarities between the two models. Recall that Model 3 structures use an autonomous executing agency to implement aid programs while receiving policy direction from the foreign ministry. In four of the five countries that once used the Model 5 structure (France, Japan, and Spain), the "executing agency" selected upon transformation to Model 3 was part of the initial Model 5 design. 
For instance, in the Japanese case, the Japanese International Cooperation Agency (JICA) became the main executive agency of Japan's aid program upon reorganization in the early 2000s (see OECDc, 2004). JICA had a long history as part of Japan's aid management system and had been responsible for Japan's technical cooperation since its creation in 1974. By 1999, JICA had developed a strong field presence with "330 employees posted in 55 overseas offices, covering 151 countries" (OECD, 1999d p. 33) and played a central role as one of two main arms responsible for the implementation of Japanese aid. ${ }^{23}$ As the only actor in Japan's aid management system that was solely focused on development activities, and given the large field presence, the elevation of JICA to the status of "Independent Administrative Institution" in 2001 could be considered part of its institutional path in Japan's aid administration.

Similarly, the French Agency for Development (AFD) and Spain's Agency for International Cooperation (AECI), which were chosen as executing agencies upon transforming from Model 5 to Model 3, were central parts of their respective multiple ministry designs. Both also possessed a strong field presence and expertise in technical cooperation at the time of reorganizations to Model 3 structures. The strong field presence and institutionalized processes of managing and coordinating field staff suggests that the choice to adopt a Model 3 structure in the French and Spanish cases could be the product of path dependence, where pre-existing experience managing and working in the field meant that these agencies possessed the expertise necessary to act as the main implementing arm of their respective aid programs

\footnotetext{
${ }^{23}$ The other, the Overseas Economic Co-operation Fund (later called the Japan Bank for International Cooperation (JBIC)), was primarily responsible for ODA loans.
} 
In Portugal, two pre-existing agencies, the Institute for Portuguese Co-operation (IPC) and the Portuguese Agency for Development Support (APAD) were merged to form Portugal's new executing agency called the Portuguese Institute for Development Support (IPAD). Prior to the merger, IPC served as the main coordinating unit for Portugal's development system while APAD was responsible for promoting private sector development and supporting social and economic infrastructure projects in partner countries. While neither IPC nor APAD had field staff or particular expertise in technical cooperation, both were significant actors within Portugal's development landscape. Indeed, IPC was crucial in terms of coordination, and APAD managed a relatively large proportion of Portugal's financial cooperation with funding scaling-up prior to the merger. In this case, the merger of two agencies central to the Portuguese aid management system could again indicate path dependence in the choice to move towards the Model 3 structure, as the structures chosen to serve as implementing agency not only managed a large portion of Portuguese bilateral assistance, but had experience coordinating development activities across a disaggregated development system of 17 ministries and several agencies (OECD, 2001b).

However, path dependence appears to have a lesser role in the reorganization of the Austrian aid program. The Austrian transition from Model 5 to Model 3 led to the creation of a new implementing agency, called the Austrian Development Agency (ADA), which had no clear roots in a pre-existing organizational structure. The ADA was essentially created as a new administrative structure to address three main challenges faced by Austria's aid program - expected increases in ODA, to advance cooperation with the EU for development, and promoting private sector activities for development 
(OECD, 2004b). The creation of a new implementing structure, rather than using preexisting elements, suggests that the reorganization of Austria's aid program did not appear to follow the path-dependent logic as in the other cases. ${ }^{24}$ While Austria's choice to adopt a Model 3 structure upon reorganizing away from Model 5 is less clear than in other cases, the similar structural path by former Model 5 donors suggests that path dependence may be an important factor in determining organizational forms.

\subsubsection{Who Uses Which Model and Why?}

Perhaps a second notable trend emerging from Figure 4 is that certain groups of donors, which share cultural and historical similarities, appear to gravitate towards similar organizational forms. For instance, since 1962, Model 4 is only used by AngloAmerican countries (Australia, Canada, UK, US), while Model 1 is primarily used by Nordic donors (Denmark, Norway and Finland) as well as the Netherlands. ${ }^{25}$ This convergence among countries with similar histories and cultures could provide preliminary evidence of path dependence as a factor in determining organizational models. Indeed, Verhoest et al. (2012) suggest that the use of government 'agencies' varies across, rather than within, regional groupings, adding credence to the potential for such groupings to adopt similar models for aid agency organization.

\footnotetext{
${ }^{24}$ Indeed, in the Austrian case, structural change driven by path dependence would likely have seen Austria adopt a Model 2, rather than Model 3 structure. Prior to reorganization, responsibility for Austria's bilateral program (outside of Eastern Europe) was located in the Department for Development Co-operation (DDC), a Directorate operating as part of the Ministry of Foreign Affairs. The DDC was responsible for the second largest share of Austria's ODA (20\%); the Ministry of Finance, which managed Austria's contributions to international financial institutions, debt relief and export-credits controlled $22 \%$ of aid resources (OECD, 1999a). Recalling that Model 2 structures locate development directorates within foreign ministries, it seems that the structural components of Austria's aid management system were closer to a Model 2, than Model 3 structure.

${ }^{25}$ This is not to say that all Anglo-American and Nordic donors adopt Model 4 and Model 1 structures New Zealand and Ireland are exceptions in the Anglo-American case, as are Sweden and Iceland in the Nordic example.
} 
The question then is why Anglo-American countries have tended to adopt autonomous aid agency models, and conversely, why Nordic countries have preferred Model 1 structures? In terms of Anglo-American countries, the tendency to adopt Model 4 structures could be linked to a preference towards agencification across these countries. According to Halligan and James (2012), Anglo-American countries have been some of the most aggressive adopters of agencies to organize and manage public sector activities. In particular, Halligan and James (2012) note that agencification in the public sector in some Anglo-American countries, notably Australia and the UK, intensified in the late 1970s and early 1980s when budgetary pressures due to global economic crises led to the creation of new government agencies in efforts to move "state activity to special purpose arm's-length bodies and reduce the overall size of government" (p. 79). Indeed, in a scale measuring patterns of agencification across countries, Van Theil (2011) finds that AngloAmerican countries are the most radical reformers in terms of agency creation in recent decades, and have tended to privatize and create agencies to manage government functions more fervently than other groups of countries.

In the Nordics, the tendency to adopt Model 1 structures could be linked to the "well-established system of central agencies" and relative importance of the state in supporting a universal welfare and an egalitarian culture (Balle Hansen et al., 2012 p. 259). The significant role of the state, versus the market, as the provider of public goods in Nordic countries could explain the preference for more integrated organizational structures in terms of aid management. This is not to say that Nordic countries centralize all government functions; Nordic countries have a long history of agencification (Greve et al., 2016). However, there appears to be a concerted effort on the part of Nordic 
countries to balance autonomy and control, with some countries, such as Norway and Denmark preferring somewhat less autonomous relationships in public organization (Balle Hansen et al., 2012). Importantly, Van Thiel (2011) also find that the Netherlands shares a similar "pattern of agencification" with Nordic countries, considering both to be “decentralized modernizers" (p. 22).

In this sense, the preference towards agencification in the case of AngloAmerican donors and more centralized action for Nordic countries provides a basic explanation for understanding the use of Model 1 and 4 by similar countries. While this finding cannot explain why other donors have not sought to adopt either model, it does suggest historical and structural facets of donors, many of which are shared across countries with similar historical and cultural roots, are likely to determine organizational choices pertaining to aid management.

\subsubsection{Convergence to Models 2 and 3}

Lastly, Figure 4 highlights a distinct shift towards Model 2 and 3 structures over time, with the majority of donors currently using the semi-autonomous (Model 2) or implementing agency (Model 3) structure to organize aid activities. ${ }^{26}$ The choice to use these structures over other models will undoubtedly require special attention in the quantitative analysis presented in the following Chapter. However, there are two important points that can be made in relation to this trend.

First, donors using Model 2 and 3 appear to differ on one key dimension - size. Donors that adopt Model 2 are on average, smaller than those that use Model 3. While a

\footnotetext{
${ }^{26}$ Over the sample period, Model 2 and 3 are utilized most frequently by donors. Model 2 occurs throughout the sample at a rate of $30.08 \%$. Model 3 is the second most used at $(28.61 \%)$, followed by Model 5 (17.87\%) and Model 4 (14.06\%). Model 1 is use the least frequently, occurring at a rate of $9.38 \%$ across the sample period.
} 
number of small donors have also selected the Model 3 structure, this model has also been used by large donors including the US, Germany, France and Japan. In comparison, no large donors currently adopt the Model 2 structure.

Data shows that Model 2 is typically used by the smallest donors. On average, donors using Model 2 manage $\$ 1.9$ billion (\$US, constant) in ODA per year. By comparison, Model 3 donors manage almost triple the amount at an average of $\$ 5.4$ billion. While Model 3 donors do not have the largest average budget size (Model 4 donors allocate $\$ 8.2$ billion on average), the difference in the size of the budgets managed by the two most common organizational forms could reflect differences in donor understandings of the capacity of specific organizational models to support efficient aid management according to the size of aid programs.

Second, as already mentioned, the shift towards Model 3 structures by donors that previously used Model 5 organizational forms appears to be driven, at least in part, by path dependence. However, over the last decade, a number of newer donors also appeared to use Model 2 and 3 structural forms at the time they joined the OECD-DAC. The use of similar structural forms, particularly by new donors, could suggest that legitimacy, or the search for institutional legitimacy, may be a key determinant of organizational choice in these cases.

There is some evidence that the search for legitimacy is part of donor rationale for developing aid programs. In a recent paper, Gulrajani and Swiss (2017) argue that the desire for reputational legitimacy is a key factor determining the proliferation of new donors, where establishing development programs is driven by efforts to enhance the reputation of new donor states as advanced and influential countries. While one could 
expect that if donors are engaging in development to advance international standing, they should, in theory, seek to emulate the examples of other donors (be it in terms of policies or structure), Gulrajani and Swiss (2017) find that new donors tend to seek legitimacy through adopting donor "form" (i.e. by becoming a donor) rather than "function" (i.e. emulating best practice). This suggests that while new donors may view engaging in donorship as a way to enhance legitimacy, they may not adopt such structures to mimic the institutional forms of those deemed to exemplify best practice as suggested by institutional theories (see DiMaggio and Powell, 1983).

In this context, convergence towards Models 2 and 3 could indicate that donors are emulating the structures used by similar countries, perhaps in terms of aid budget size or neighboring countries with shared historical/cultural features. Indeed, as described above, countries with similar historical and institutional roots tend to converge towards similar organizational forms. Alternatively, it is possible that the increase in usage of the Model 2 and 3 structures encourages more donors to adopt similar structures, where the sheer frequency of usage amongst the donor population legitimizes the structure and leads to further isomorphism across the group (see DiMaggio and Powell, 1983). The reasons why donors adopt the Model 2 and 3 structures, and the potential role of legitimacy in explaining structural choice, will be tested and explored in further detail throughout the following chapters.

\subsection{Conclusion}


This chapter mapped and analyzed the organizational structures used by OECDDAC donors from 1962 to the present day. This marks the first exploration of trends in aid agency management over time and provides a key contribution to current knowledge of aid agency structure and change by highlighting the full range of organizational models used since the 1960s.

In doing so, this chapter identified three main trends in the use of specific models over time. First, this chapter finds that the Model 5 structure became obsolete during the 2000s and is no longer used by donors. This trend appears to align with Cunningham's theory that reactive donors prefer the Model 5 structure, where the shift away from the Model 5 structure is aligned with an increase in the use of country programming and the adoption of active donor roles. Model 5 is also used more frequently in the early years of aid programs, and could be considered a potential "starter" model.

Second, mapping organizational models showed clear similarities in organizational preferences across countries with cultural and historical similarities. Most notably, Anglo-American donors are the only countries to adopt Model 4 structures, while Nordic donors (plus the Netherlands) have tended to prefer Model 1 forms. Taken together, this finding could provide early evidence of a relationship between structural choice and historical/cultural factors.

Finally, the organizational snapshots show a convergence towards Model 2 and 3 in recent years, with more donors tending towards these structures over time. Such convergence broadly highlights the potential role of legitimacy as a driver of organizational choice. Moreover, the adoption of Model 2 and 3 tends to differ by donor size, where smaller donors appear to prefer Model 2 structures while larger donors tend 
to converge towards Model 3. In addition, the finding that all Model 5 donors adopted a Model 3 structure upon reorganization could provide early evidence of path dependence as a determinant of structural choice.

In each case, more research is needed in order to fully understand the factors that contribute to these trends. The next chapter expands on these preliminary findings by testing the relationship between organizational structure and key determinants of structural choice. Doing so sheds further insight on the structural determinants underlying the trends in aid agency structure. 
CHAPTER 4

WHAT FACTORS DETERMINE ORGANIZATIONAL STRUCTURE? A QUANTITATIVE MODEL 
This chapter builds on the theoretical foundation developed in Chapter 2 and data presented in Chapter 3 to test a statistical model for understanding the determinants of aid agency structure. Using an original dataset, which traces the organizational development of aid agencies for all OECD-DAC donors since the 1960s, this chapter tests the full range of identified hypotheses and potential determinants of aid agency structure. While previous studies of aid agency organization have tended to examine individual cases, this chapter adds to the literature by testing the structural determinants of aid agencies across donors.

The regression analysis highlights several main findings. Firstly, it identifies key variables associated with organizational choice including political ideology, purpose, internal structural characteristics and donor size. The estimation also points to differences between the determinants of structural choice across organizational models. For instance, despite organizational similarities between Models 1 and 2, the factors shown to contribute to the decision to adopt these models differs in terms of efficiency, politics and purpose.

This chapter begins by outlining the main variables and estimation technique used in this study to test various determinants of aid agency structure derived from the aforementioned hypotheses. A second section highlights key results from the estimation, while the third section discusses the key findings drawn from the analysis. The final section offers conclusions based on main findings throughout. 


\subsection{Towards a Model of Aid Organization}

While Chapter 3 identified major trends in the use of organizational Models across donors, efforts towards understanding the determinants of aid agency structure require a deeper engagement with key variables deemed to contribute to the choice of organizational model. This chapter presents a statistical model designed to explore the determinants of aid agency structure over time and across the entire sample of OECDDAC donors. As the first study to test the determinants of aid agency structure across all OECD-DAC donors and across time, this chapter provides a first attempt at quantitatively modeling the choice of aid agency structure.

Before describing the model, it is necessary to engage with key criticism surrounding the use of quantitative techniques to examine questions of aid agency organization. Such criticism, which has been identified throughout the development of this study, raises questions concerning whether quantitative techniques can reasonably capture the variables identified as potential determinants of aid agency structure. While it is recognized the proxy variables used in this study to capture the main factors identified by theory are admittedly imperfect measures, the quantitative model is important due to its capacity to capture variation across the entire population of OECD-DAC donors. Indeed, in order to develop an understanding of the determinants of aid agency structure that is generalizable and applicable across OECD-DAC donors, it is necessary to test hypotheses across the largest possible sample of donors. Seeing as practical constraints prevent the ability to conduct qualitative comparative case studies across all donors, quantitative modeling allows for preliminary insight into the determinants of structure across the largest number of donors. In addition, the fact that no studies have attempted 
to model or understand aid agency structure across donors makes findings from a large-n comparative model particularly interesting. In this vein, the quantitative model is used to generate preliminary insight into the determinants of aid agency structure, with the view that findings from this section will be explored in greater detail through case studies presented in the following chapters.

\subsection{Variables}

This section describes the variables used to capture the determining factors of aid agency structure as presented in the theoretical discussion of the previous chapter. Key information about the variables including data sources and connection to theory are provided.

The dependent variable for this study is the organizational model (model) adopted by donor agencies. These models are coded from 1-5 based on the organization design of aid agencies in each year that each donor was a member of the OECD-DAC. The dependent variable is coded based on data describing organizational forms compiled from OECD Aid Reviews, where model forms were coded to match the OECD's typology of aid agency structures presented in the introductory chapter. ${ }^{27}$

For the purpose of this study, the dependent variable is treated as a nominal value where donor models are understood as discrete categorical choices. Such choices are not meaningfully ordered and do not represent progression along a scale. While it could be

\footnotetext{
${ }^{27}$ It should be noted that seeing as the dependent variable is coded according to typological definitions, the variable is ultimately a "construct" and is subjective. As such, all quantitative results are subject to this important caveat. A full description of the data used to map organizational structures over time is provided in the prior section. Typology of OECD-DAC donor models follows the following form: Model 1 structures are fully integrated in the Ministry of Foreign Affairs, Model 2 use a "Directorate" within a foreign ministry, Model 3 use an implementing agency for programming operations while policy is made in a ministry, Model 4 uses an autonomous aid agency and Model 5 uses multiple ministries for agency policy and implementation.
} 
suggested that the models represent varying degrees of organizational decentralization from Model 1 (most centralized) to 5 (most decentralized), there is no evidence or precedent throughout the literature for understanding organizational choices along such a continuum.

In addition, the dependent variable is run on a one-year lead in order to control for potential concerns surrounding endogeneity caused by simultaneous causality. ${ }^{28}$ For instance, while the model attempts to capture the factors that determine aid agency structure, it is possible that such factors, particularly concerning the purpose of aid programs, may also be outcomes of the organizational choices made by donors. By leading the dependent variable, the organizational models selected by donors are measured against the independent variable scores for the prior year, delineating the direction of causality more clearly. ${ }^{29}$

The model uses a one-year, rather than multi-year lead, to ensure that all independent variables are adequately captured. While most of the independent variables used in this study are structural, slow moving and incremental, the variable measuring

\footnotetext{
${ }^{28}$ The model was also tested using a two-year and three-year lead. Results showed some change. Using a two-year lead, significance on strategic purpose and fiscal balance was lost for Model 1. Using a three-year lead, significance is lost on humanitarian purpose for Model 3, Modelcount (Model 3 and 4) and Ideology (Model 1). This suggests that the decision to adopt specific organizational models is based on the recent past, with some variables losing significance over time.

${ }^{29}$ In addition, panel variable granger tests were conducted for the purpose variables, administrative cost variable, and donor size variable to test for potential reverse correlation. Using the "pvargranger" command, variables were tested against each organizational models with multiple lags. Evidence of reverse correlation was only found for the trade variable in relation to Models 1 and 4 . This suggests that the adoption of Model 4 can lead to more commercially oriented aid, and less commercially driven aid for Model 1 donors. No other variables returned significant results for reverse correlation. While these findings run counter to conventional wisdom, which suggests that institutional autonomy is more likely to lead to less commercially oriented allocation, both can be explained by examining the countries that historically used each model. Model 4 for instance was historically used by Canada, Australia, the UK and US; the UK and US in particular were well-known for linking aid to strategic and commercial orientation (see Schraeder et al., 1998; McKinlay and Little, 1977; McKinlay and Little, 1979). Alternatively, despite the merged structure, Model 1 tended to be adopted by Scandinavian countries which are typically associated with strong developmental purposes.
} 
political ideology is prone to more frequent and substantive changes. Due to the relatively short political time-horizons, a short lead is deemed best able to capture the potential relationship between changes in political ideology and preferences regarding aid agency structure.

This study uses several independent variables to test each of the hypotheses derived from the theory. To test hypotheses $\mathrm{H} 1$ and H1(A-D), which identifies the purpose of aid programs as a primary determinant of aid agency structure, four proxy variables are used to measure the relative influence of the main "purposes" identified by the literature (political/strategic, commercial, development and humanitarian).

The degree to which donors pursue a political/strategic purpose through aid programs is measured as the proportion of aid provided to the ten developing countries that most consistently vote in alignment with individual donors at the UN General Assembly in each year. The variable (strategic) is calculated by joining dyadic ODA data from the OECD Stat Extract (total ODA, net disbursements, constant \$US) to UN General Assembly Voting Data (Dyadic Dataset) produced by Voeten, Strezhnev and Bailey (2009). Using the "agree3un" variable included in the UN General Assembly Voting Data ${ }^{30}$ which measures voting similarity between dyadic pairs as an index score between $0-1$, data was sorted to extract the top ten developing country recipients with the highest index value (indicating voting similarly) for each donor in each year of the sample period. The sum of corresponding levels of aid to each of the top ten most similar

\footnotetext{
${ }^{30}$ The "agree3un" variable is computed using category vote data ("yes", "no", and "abstain"). An alternative measure "agree2un" was also considered for constructing this variable. The "agree2un" variable also constructs a voting similarity index, however it does not code for voting abstentions. In this case, the "agree3un" variable is preferred due to its inclusion of abstentions. This is consistent with much of the literature, which suggests that donors may bribe recipients not only to comply but avoid noncompliance through abstaining (see Dreher et al., 2008; Zimmerman, 1993).
} 
developing country voters was then taken as a proportion of total ODA for each donor in each year. In essence, this variable shows the proportion of aid received by countries that most commonly vote in alignment with donors, where higher proportions of aid to recipients with high voting similarity scores could indicate the presence of "political alliances between countries", where donors provide more aid to allied partners of countries with similar economic and strategic interests (Alesina and Dollar, 2000 p. 46). ${ }^{31}$ Dyadic UN voting patterns have routinely been used as a proxy for measuring strategic donor behaviour (see Alesina and Dollar, 2000; Dreher, Nunnenkamp and Thiele, 2008; Hoeffler and Outram, 2008; Gates and Hoeffler, 2004), rendering the variable consistent with the academic literature. ${ }^{32}$

Similarly, the commercial purpose of aid is measured using the proportion of aid allocated to top ten developing-country trading partners of each donor in each year. Based on the understanding that donors using aid for commercial purposes may provide larger proportions of aid to trading partners, particularly those that import goods from donor countries (donor exports), identifying the proportion of aid allocated to top importers of donor goods could provide insight into the degree to which donors prioritize commercial interests. In this sense, higher proportions of aid to top importers of donor goods are presumed to indicate the use of aid to support commercial purposes.

To construct this variable (commercial), dyadic ODA data was taken from the OECD Stat Extract (total ODA, net disbursements, current \$US) while dyadic trade data

\footnotetext{
${ }^{31}$ While some have interpreted this variable as the presence of "vote buying", Alesina and Dollar (2000) contend that in many cases, UN votes are not particularly important, making it unclear why donors would bother using aid to "buy" votes.

${ }^{32}$ An alternative variable typically used to measure strategic relationships include percentage of aid to former colonies. While this variable was considered, UN voting patterns were chosen instead due to the fact that all donors included in the sample were not former colonial powers. Indeed, it is for this reason that Alesina and Dollar (2000) note that UN voting patterns are a preferable and more "objective" measure of donor strategic interests.
} 
was sourced from the IMF's Direction of Trade database (Goods, Value of Exports, Free on Board (FOB), current \$US). Trade data was sorted to derive the top ten developing country trading partners for each donor over each year of the sample period. Corresponding values of ODA to top ten trading partners were added and taken as a proportion of total ODA in the matching year. The resulting variable shows the degree to which donors allocate aid to developing countries that support their commercial interests.

A third purpose of aid programs (developmental) is measured as the proportion of total net ODA disbursements allocated to Least Developed Countries (LDCs) and Low Income Countries (LICs) by each donor in each year. All data to construct this variable was taken from the OECD Stat Extracts and uses the OECD's classification of LDC and LIC recipients. In essence, this variable is designed to capture the degree to which donors allocate aid to the poorest recipients and is based on the understanding that more aid to needy countries could indicate a commitment to using aid programs to support developmental priorities. The point here is not to suggest that some donors do not prioritize development, but rather that there may be variation in the degree to which donors prioritize the developmental purpose of aid programs, and that this difference may influence structural design.

The final purpose of aid programs (humanitarian) is to support humanitarian crises and needs. While both the developmental and humanitarian purposes emphasize support for developing countries as the primary purpose of aid programming, the difference between the humanitarian and development purposes is linked to differences between responding to humanitarian crises and planning programs to support long-term 
development. The proxy to capture the humanitarian purpose measures humanitarian aid as a proportion of total ODA disbursements using data on humanitarian and total ODA disbursements taken from the OECD Stat Extracts. ${ }^{33}$

The ideology of government executive variable (ideology) is constructed to measure the political ideology of the ruling party for each donor in each year of the sample. This variable is included in order to test hypothesis H1(E), which links the political ideology of donors to organizational preferences. This variable is constructed using data from the Comparative Manifestos Project (CMP) database, which ranks all major political parties featured in each election across countries since the 1950s on a leftright continuum measured in increments of 10 on a scale from 10-90. Higher scores represent more conservative preferences while lower scores represent more socialist platforms.

It should be noted that the strict categorical nature of the ideology variables, as measured in the CMP data, makes it an imperfect measure of ideology. The categorical separation of parties is unable to provide a nuanced understanding of the variety of ideological stances that exist between parties categorized as either "liberal" or "conservative". Ideally, ideological scores should account for differences within the international conception of "conservative" or "liberal", understanding that the degree of "conservative" values may differ between right-of-center parties across countries and over time. In the CMP dataset, all conservative or liberal parties receive the same ideological score. However, in the absence of alternate measures, the CMP data presents the best available option.

\footnotetext{
33 Data for this variable is only available from 1971 onwards, making it the variable with the shortest time-
} period included in the sample. 
Two variables are used to capture various dimensions of the relative "efficiency" of aid agencies in alignment with $\mathrm{H} 2$. The first understands efficiency in terms of the administrative costs related to running aid programs. This variable (administration) measures the proportion of ODA spent on administrating aid programs. ${ }^{34}$ Both ODA amounts and aid administrative cost data are taken as net disbursements in constant \$US from the OECD Stat Extract database. ${ }^{35}$ Measuring administrative costs in this manner is consistent with other studies including Easterly and Williamson (2011) and Gulrajani (2012), which use proportional administrative costs to measure differences in the cost of aid management across donors. It should be noted that the point of this variable is not to suggest that the optimal overhead ratio for aid administration is zero, nor that minimizing the costs of aid administration is necessarily better. As Easterly and Williamson (2011) point out, a "well-managed aid effort requires funding of management activities such as fiduciary oversight, monitoring and evaluation and project design and implementation" (Easterly and Williamson, 2011 p. 19). However, Easterly and Williamson also note that "spending a large percent of the budget on overhead could be interpreted as a diversion of funds to sustain bureaucracy rather than deliver funds to the intended recipients" (p. 19), suggesting that higher levels of administrative spending could, in some instances, represent inefficiencies. While there is no benchmark for "optimal" levels of administrative spending, the purpose of this variable is to capture any meaningful differences between the relative costs of administering aid agencies across organizational

\footnotetext{
${ }^{34}$ Specifically, the indicator used to measure administrative costs is "administrative costs not included elsewhere" (code 1700) from the OECD Stat database (OECD-DAC, 2010).

${ }^{35}$ While administrative costs data is available from 1979 onwards on the OECD database, additional data was compiled by hand from a set of historic Development Co-operation Reports obtained through primary research at the OECD in Paris, conducted in June 2015. Statistical annexes included in the reports list "administrative expenses" as a proportion of ODA for OECD donors as early as 1970. To ensure comparability across measures, amounts listed in the OECD database were spot-checked with later issues of the Development Co-operation Reports.
} 
models. Given that recent mergers, including that in Canada and Australia, have been rhetorically linked to efforts to improve efficiency, this variable is intended to identify whether some structures are, on average, associated with higher or lower administrative costs. $^{36}$

The second variable understands efficiency as the ability for donors to meet spending commitments - i.e. to disburse aid predictably. Based on the understanding that disbursing aid funds and implementing aid programs is the main function of aid agencies, measuring the degree to which donors regularly meet spending commitments serves as a proxy for the capacity of donors to perform their main function. Administratively, a number of issues within donor systems could slow the disbursement of funds, including slow administrative approvals, complex procurement systems and inadequate human resources, particularly in contexts of increasing aid budgets (see OECD, 2009a). Given differences across organizational models, some of which involve more administrative units and presumably may require more coordination to manage aid planning and disbursement processes (this could be the case for Model 5 structures), this variable aims to capture potential differences in efficiency in terms of the ability for donors to meet spending commitments. This variable (commitments) uses gross ODA disbursements and commitment data (constant \$US) taken from the OECD Stat Extract database to measure the degree to which donors produce aid according to funding commitments.

To test hypothesis H3, ODA as a percentage of GNI is used as a proxy for legitimacy. The long-term institutionalization of the $0.7 \%$ ODA spending target as best

\footnotetext{
${ }^{36}$ It is recognized that there are important weaknesses with this variable, particularly over time. For instance, Gulrajani (2017) notes that key weaknesses of measuring efficiency as administrative costs include "divergent definitions of administrative costs and its self-reported nature" (p. 4). However, despite such concerns, Gulrajani (2017) concedes that "administrative costs remain the most robust efficiency measure collected across the DAC". (p. 4)
} 
practice for donors makes it one of the few standards capable of acting as a proxy for legitimacy over the entire period of the study. ${ }^{37}$ This variable (legitimacy) is logtransformed in order to normalize a highly skewed distribution. Data for this variable was sourced from the OECD Stat Extract database.

The potential influence of the New Public Management paradigm on organizational structure, as outlined in $\mathrm{H} 4$, is proxied as a binary variable to mark the years in which NPM was dominant as a paradigm. The year 1980 is selected as the start date of NPM based on the understanding that NPM first emerged in the 1980s (Manning, 2001). The binary variable ( $\mathrm{npm}$ ) is coded " 1 " for the years in which NPM was prevalent, while a score of 0 is given to years prior to the rise of NPM. It is assumed that once NPM gained prominence, its effect on organizational thinking remains prevalent regardless of its continued usage, where a score of " 1 " is awarded in each year following 1980.

The degree to which path dependence determines aid agency structure, as presented in hypothesis $\mathrm{H} 4 \mathrm{~A}$ and $\mathrm{H} 4 \mathrm{~B}$, is perhaps one of the most difficult variables to capture via proxy. While several studies have begun to explore ways of measuring path dependence using time-series data (see Bramson, 2008; Freeman, 2012), in a crosscomparative study, the challenge appears to be one of creating models capable of unpacking historical causality across donors. However, recalling that path dependence typically involves multiple stages (1. new models or structures are built on an initial sequence of events; 2 . The decisions leading to such models or structures are reproduced over time; 3. Path becomes "locked-in"), it seems prudent to suggest that while modeling

\footnotetext{
${ }^{37}$ Other measures of legitimacy would include performance on the Paris Principles for instance. However, limited data availability for such measure makes it inappropriate for use in this study.
} 
Phase I and II across a panel sample is problematic due to difficulties in identifying and capturing all historical contextual factors that influence organizational choices in each case, it may be possible to examine the degree to which paths are "locked-in" by examining the amount of time donors use each organizational model. In this sense, a count variable (count) measuring the number of years that donors adopt a particular organizational structure is used to account for inertia that occurs in the third phase of path dependence, where positive values indicate that donors adopt structural forms for extended periods. While this measure is admittedly imperfect, additional insight into the degree to which path dependence influences aid agency structure will be explored in the qualitative analysis.

Finally, a binomial variable (countryprogram) is used as a proxy for the role adopted by donors as outlined in H5. Based on Cunningham's theory that the choice of donor role influences organizational structure, where the use of country programming is viewed as a clear indicator for active donor roles, the country programming variable captures donor role by assigning a score of 1 to donors in each year that country programming is used, and a score of 0 in years where donors do not actively develop programs with partner countries. A full table outlining the use of country programs by donors is presented in Appendix 1.

In addition, several control variables are used to capture within country institutional features that may contribute to the adoption of particular organizational structures. Based on the understanding that regional and historical similarities may influence organizational structures, particularly regarding preferences towards the use of agencies (see Voerhost et al., 2012), two binomial variables are used to capture 
institutional similarities in terms of the type of government system adopted by donors. The first variable (federal) captures differences between the organizational preferences of federal (1) versus unitary (0) government structures. Similarly, the second variable (presidential) identifies differences between the preferences of donors that use presidential (1) versus parliamentary (0) political systems.

A logged ODA variable (size) is used to control for the effect of aid budget size on organizational decisions. Grounded in the logic of contingency theory, which suggests that organizations are designed to "fit" constraints such as size, gross ODA budget size (constant \$US) is used to capture any relationship between the absolute size of aid agencies and their organizational preferences. The ODA variable is logged in order to normalize the distribution. Data for this variable was sourced from the OECD Stats Extract database.

Similarly, variables measuring levels of unemployment in donor countries and levels of government debt are used to account for donor macroeconomic conditions that may influence preferences towards aid programs and structures. In part, the logic underlying the inclusion of such proxies stems from the private and public sector organizational literatures, both of which highlight the importance of broader environmental factors (political, economic, etc.) as key drivers of structural choice (Pennings, 1992) and organizational change (see Pollitt and Bouckaert, 2004). In this sense, two macroeconomic control variables are used to test the relationship between changes in donor macroeconomic conditions and the adoption of different organizational models. The first variable measures unemployment rates (unemployment) and is included on the understanding that donors with poor economic climates, where unemployment is 
high, may face domestic pressure to align aid resources with donor commercial or strategic interests. This could make merged structures more likely in cases where unemployment is high. Data for the unemployment variable was taken from the OECD's Annual Labour Force Statistics Database and measures the "rate of unemployment as a \% of the civilian labour force" (OECD, 2017a). Data is available from the 1960s onward.

Similarly, a proxy for fiscal surplus/deficits (fiscal) is used to account for a breadth of literature, which links fiscal costs and crises to lower aid effort (Dang, Knack and Rogers, 2009). Based on the connection between ODA budget size and organizational structure, where budget size is seen as a potential determinant of structure under contingency theory, negative changes to domestic fiscal conditions may cause government to alter ODA spending and subsequently, pursue structural changes or adopt organizational models that cut costs or foster a clear connection between aid and domestic interests. While data on government fiscal balances is not available over the long term, fiscal balance is proxied by taking the first difference of annual debt-toGDP. $^{38}$

At this point, it is perhaps prudent to recognize that many of the variables presented are proxies and are necessarily imperfect measures of complex phenomena. While care has been taken to ensure that the proxies used properly operationalize the phenomena and are based on the best data currently available, there is a question about

\footnotetext{
${ }^{38}$ By taking the first difference, the measure intends to capture positive or negative changes to debt stock, providing an indication of overall fiscal balances. Data for this variable was taken from the "Historical Public Sector Debt Database" compiled by Ali Abbas et al. (2010), which provides data from the 1960s and is available from the IMF's website. ${ }^{38}$ While the historical database is "linked to the World Economic Outlook (WEO) database to facilitate regular updates", the historical data currently does not extend beyond 2012. In efforts to extend data to cover the full sample period, gross government debt-to-GDP, the same variable used in the creation of the Historical Public Sector Debt Database, was sourced from the WEO and updated manually for each country in the sample. Given the database's stated link to the WEO dataset, there is reasonable assurance that the data used is meaningfully comparable.
} 
the viability of conducting precise regressions based on proxy variables. In this study, the use of regressions based on proxy variables can be justified on the basis that regression analysis provides the only viable method for examining the entire phenomena of interest - all OECD-DAC donors since the 1960s - to examine key trends in the factors that determine structural choices over time. While the results of this analysis are not definitive (given data limitations), it does not limit the value of conducting this type of analysis to identify statistical trends across the broader phenomena.

In light of limitations concerning the imperfection of proxies, case studies are conducted in Chapter 6 and 7 to follow-up and confirm regression findings. This is typical of mixed method sequential studies, where qualitative analysis is used to further interpret and explain results of quantitative analysis (see Cresswell and Plano Clark, 2006). In essence, while the imperfections of statistical approaches are recognized, the value of these approaches for identifying trends across a large sample warrants their use, particularly in conjunction with cases to further explore and verify quantitative findings.

\subsection{The Model}

The main equation estimated in this study is:

Model $_{t+1}=\beta_{0}+\beta_{1 \text { strategic }_{t}}+\beta_{2}$ commercial $_{t}+\beta_{3}$ developmental $_{t}+\beta_{4}$ humanitarian $_{t}+$ $\beta_{5 \text { ideology }_{t}}+\beta_{6}$ administration $_{t}+\beta_{7 \text { commitment }_{t}}+\beta_{8}$ legitimacy $_{t}+\beta_{\text {gnpm }_{t}}+\beta_{10 \text { count }_{t}}$ $\beta_{11 \text { countryprogram }_{t}}+\beta_{12 \text { federal }_{t}}+\beta_{13 \text { president }}+\beta_{14 \text { Size }_{t}}+\beta_{15 \text { unemployment }}+$ $\beta_{16}$ fiscal $_{t}+\mathrm{u}_{t}$.

The equation is estimated using panel data that covers all 28 bilateral OECDDAC donors between the years 1971-2014. ${ }^{39}$ Data for this study is constrained by what is available. Humanitarian spending is unavailable prior 1971 and prevents analysis

\footnotetext{
${ }^{39}$ Due to differences in the year when donors joined the OECD-DAC, the dataset is unbalanced.
} 
beyond this period. Similarly, codes for UN Voting similarity from the UN General Assembly Voting Dyadic Dataset has not been updated to include 2015 as of the time of writing (Feb, 2017). As a result, data for 2015 is incomplete and not included in the estimation.

The model is estimated using a multinomial logit technique to examine the probability of different possible outcomes across a categorically distributed dependent variable. Multinomial logit models are typically used in cases where the dependent variable represents a range of discrete and unrelated choices (Hausman and McFadden, 1984), such as the choice between the organizational model which donors could seek to adopt. ${ }^{40}$ When running a multinomial logit model, one of the possible categorical responses of the dependent variable is nominated as the base category against which the log-odds for all other categories are assessed. While each category of donor model can be used as the base category, Model 2 is selected as this model is used most frequently throughout the sample. ${ }^{41}$

The model is estimated using clustered standard errors to control for nonindependence within countries. ${ }^{42}$ Understanding that the coefficients generated by the

\footnotetext{
40 The ordered logit model was also considered as a possible option for estimating variation in organizational structure. This model is used when estimating ordered categorical dependent variables. However, it is unclear that the organizational structures of donor agencies follow any meaningful "order". While it could be argued that aid agency structures follow an order based on degrees of centralization, where Model 1 is the most centralized and Model 5 is the most decentralized, there is no evidence to suggest that the choice of donor model should be understood as a choice between different degrees of centralization, rather than as a choice between discrete organizational forms.

${ }^{41}$ Model 2 is utilized by donors most frequently, occurring throughout the entire sample at a rate of $32.72 \%$ compared to other models (Model 3 occurs at a frequency of $27.11 \%$, Model 5 is used at a rate of $17.72 \%$, Model 4 is used in $14.33 \%$ of instances, and Model 1 is used $8.13 \%$ of the time).

${ }^{42}$ Fixed effects models are useful for controlling for differences within donor countries as well as for potential omitted variable bias. However, the fixed effects multinomial logit model available in Stata (femlogit) drops 13 groups, 200 observations, and 2 variables from the inference due to a lack of variation. The high number of observations lost through this technique (almost one third of total observations) makes it sub-optimal. In the absence of fixed effects, clustered standard errors by country are used to account for
} 
multinomial logit model are unable to provide a clear estimate of the magnitude of the likelihood of selecting between the five organizational models for each independent variable, marginal effects are reported in below. ${ }^{43}$

Prior to the estimation, all independent variables were tested for multicollinearity using the "collin" command in STATA. ${ }^{44}$ This command uses variance inflation factors (VIF) to test for harmful collinearity between variables. As a rule of thumb, harmful collinearity is detected when VIF scores are greater than 10 (see Kennedy, 1992). The test returned VIF scores no higher than 1.64 and a mean VIF for the model of 1.33. As a result, it is safe to conclude that multicollinearity is not a factor in this estimation.

within country effects. However, it is recognized that this method cannot account for unknown or unmeasurable changes over time.

${ }^{43}$ For multinomial logit models, Wulff (2015) states that marginal effects are preferable over relative risk or odds ratios (typically reported with logit models). The coefficients from a multinomial logit regression show the "probability of observing a particular category relative to the base category" (Wulff, 2015 p. 305), meaning that any interpretation derived from these results must be restricted to comparison with the base. According to Wulff (2015) "this is quite different from making statements about the relationship between a predictor and the probability of a specific outcome" (305). Seeing that the intention here is to understand the degree to which each predictor variable influences organizational form, marginal effects are preferred due to their capacity to clearly identify the relationship between predictors and outcomes. Marginal effects "are defined as the slope of the prediction function at a given value of the explanatory variable and thus inform us about the change in predicted probabilities due to a change in a particular predictor" (Wulff, 2015 p. 305). This fact has led some to conclude that "if one wishes to draw valid conclusions about the direction and magnitude of the relation between an independent and dependent variable in an MLM [multinomial logit], one must calculate marginal effects" (Wulff, 2015 p. 305).

${ }^{44}$ A basic correlation table was also created using the command "correlate" in STATA. Results of this test can be found in Appendix 7. 
Table 3: Estimation 1: Multinomial Logit (Annual Model) ${ }^{45}$

\begin{tabular}{|c|c|c|c|c|c|}
\hline & Model 1 & Model 2 & Model 3 & Model 4 & Model 5 \\
\hline$\%$ ODA to top $10 \mathrm{UN}$ voting partners & $\begin{array}{c}-0.029 * \\
(0.012)\end{array}$ & $\begin{array}{l}0.026 * * * \\
(0.005)\end{array}$ & $\begin{array}{r}0.000 \\
(0.012)\end{array}$ & $\begin{array}{c}0.007 * \\
(0.003)\end{array}$ & $\begin{array}{l}-0.004 \\
(0.004)\end{array}$ \\
\hline$\%$ ODA to LDCs and LICs & $\begin{array}{l}-0.004 * * \\
(0.001)\end{array}$ & $\begin{array}{l}0.005 \\
(0.003)\end{array}$ & $\begin{array}{l}-0.002 \\
(0.004)\end{array}$ & $\begin{array}{l}0.001 \\
(0.002)\end{array}$ & $\begin{array}{l}0.000 \\
(0.001)\end{array}$ \\
\hline$\%$ ODA to top 10 trading partners & $\begin{array}{l}-0.009 * * * \\
(0.002)\end{array}$ & $\begin{array}{l}0.000 \\
(0.003)\end{array}$ & $\begin{array}{l}0.003 \\
(0.003)\end{array}$ & $\begin{array}{l}0.005 * * \\
(0.002)\end{array}$ & $\begin{array}{l}0.000 \\
(0.001)\end{array}$ \\
\hline Humanitarian as $\%$ of ODA & $\begin{array}{l}0.001 \\
(0.001)\end{array}$ & $\begin{array}{l}-0.005 \\
(0.007)\end{array}$ & $\begin{array}{l}0.014 * \\
(0.007)\end{array}$ & $\begin{array}{l}-0.002 \\
(0.004)\end{array}$ & $\begin{array}{l}-0.008 \\
(0.005)\end{array}$ \\
\hline ODA as $\%$ of GNI & $\begin{array}{l}0.188 * * * \\
(0.026)\end{array}$ & $\begin{array}{l}-0.088 \\
(0.064)\end{array}$ & $\begin{array}{l}0.036 \\
(0.079)\end{array}$ & $\begin{array}{l}-0.057 \\
(0.052)\end{array}$ & $\begin{array}{l}-0.079 \\
(0.042)\end{array}$ \\
\hline Ideology of Executive & $\begin{array}{l}-0.001^{* *} \\
(0.000)\end{array}$ & $\begin{array}{l}0.007 * * \\
(0.002)\end{array}$ & $\begin{array}{l}-0.004 \\
(0.002)\end{array}$ & $\begin{array}{l}-0.002 \\
(0.001)\end{array}$ & $\begin{array}{l}-0.000 \\
(0.001)\end{array}$ \\
\hline Admin as $\%$ of ODA & $\begin{array}{l}0.031 * * * \\
(0.005)\end{array}$ & $\begin{array}{l}-0.031 \\
(0.017)\end{array}$ & $\begin{array}{l}-0.008 \\
(0.019)\end{array}$ & $\begin{array}{l}0.017 \\
(0.011)\end{array}$ & $\begin{array}{l}-0.009 \\
(0.009)\end{array}$ \\
\hline Disbursements as $\%$ of commitments & $\begin{array}{l}-0.000 * * * \\
(0.000)\end{array}$ & $\begin{array}{l}-0.002 \\
(0.001)\end{array}$ & $\begin{array}{l}0.001 \\
(0.001)\end{array}$ & $\begin{array}{l}0.001 \\
(0.001)\end{array}$ & $\begin{array}{l}0.000 \\
(0.000)\end{array}$ \\
\hline ODA (budget size) & $\begin{array}{l}0.002 \\
(0.010)\end{array}$ & $\begin{array}{l}-0.106^{* * *} \\
(0.029)\end{array}$ & $\begin{array}{l}-0.035 \\
(0.043)\end{array}$ & $\begin{array}{l}0.128 * * * \\
(0.033)\end{array}$ & $\begin{array}{l}0.012 \\
(0.021)\end{array}$ \\
\hline Model Count & $\begin{array}{l}-0.006^{* * *} \\
(0.001)\end{array}$ & $\begin{array}{l}0.007 \\
(0.004)\end{array}$ & $\begin{array}{l}-0.008 * \\
(0.003)\end{array}$ & $\begin{array}{l}0.003 * * \\
(0.001)\end{array}$ & $\begin{array}{l}0.005 \\
(0.002)\end{array}$ \\
\hline Country Programming & $\begin{array}{l}0.223 * * \\
(0.076)\end{array}$ & $\begin{array}{l}-0.288^{* *} \\
(0.088)\end{array}$ & $\begin{array}{l}-0.001 \\
(0.127)\end{array}$ & $\begin{array}{l}0.291 * * * \\
(0.070)\end{array}$ & $\begin{array}{l}-0.225^{* * *} \\
(0.051)\end{array}$ \\
\hline Presidential/Parliamentary & $\begin{array}{l}0.101 * * * \\
(0.019)\end{array}$ & $\begin{array}{l}-0.117 \\
(0.085)\end{array}$ & $\begin{array}{l}0.317 * * \\
(0.097)\end{array}$ & $\begin{array}{l}-0.340 * * * \\
(0.077)\end{array}$ & $\begin{array}{l}0.039 \\
(0.057)\end{array}$ \\
\hline Unitary/Federal & $\begin{array}{l}-0.331 * * * \\
(0.051)\end{array}$ & $\begin{array}{l}-0.148 \\
(0.084)\end{array}$ & $\begin{array}{l}0.239 * * \\
(0.086)\end{array}$ & $\begin{array}{l}0.223 * * * \\
(0.060)\end{array}$ & $\begin{array}{l}0.018 \\
(0.061)\end{array}$ \\
\hline NPM & $\begin{array}{l}0.322 * * * \\
(0.032)\end{array}$ & $\begin{array}{l}-0.160 \\
(0.094)\end{array}$ & $\begin{array}{l}-0.070 \\
(0.107)\end{array}$ & $\begin{array}{l}-0.152 * * * \\
(0.041)\end{array}$ & $\begin{array}{l}0.059 \\
(0.046)\end{array}$ \\
\hline Unemployment & $\begin{array}{l}0.005 \\
(0.003)\end{array}$ & $\begin{array}{l}0.014 * \\
(0.007)\end{array}$ & $\begin{array}{l}-0.011 \\
(0.008)\end{array}$ & $\begin{array}{l}-0.005 \\
(0.003)\end{array}$ & $\begin{array}{l}-0.002 \\
(0.004)\end{array}$ \\
\hline Fiscal Balance (surplus, deficit) & $\begin{array}{l}-0.003 * \\
(0.002)\end{array}$ & $\begin{array}{l}0.000 \\
(0.003)\end{array}$ & $\begin{array}{l}0.009 * \\
(0.004)\end{array}$ & $\begin{array}{l}-0.006 * \\
(0.003)\end{array}$ & $\begin{array}{l}0.000 \\
(0.003)\end{array}$ \\
\hline Observations & 728 & 728 & 728 & 728 & 728 \\
\hline Psudeo-R2 (McFadden) & 0.586 & 0.586 & 0.586 & 0.586 & 0.586 \\
\hline
\end{tabular}

Marginal effects reported, standard errors in parentheses $* \mathrm{p}<0.05, * * \mathrm{p}<0.01, * * * \mathrm{p}<0.001$

${ }^{45}$ The constant term is included in each estimation in this study. However, the "margins" command in STATA does not report the constant term when marginal effects are calculated for multinomial logit models - constants are calculated, but not reported. This is due to the fact the "constant" term is, by definition, constant. Seeing as marginal effects measures the change in the predicted likelihood of selecting a specific organizational model given the change in explanatory variables, the constant nature of the constant term means that there is no change to observe, rendering the marginal effects meaningless. Prior to computing marginal effects, the base regression output shows statistical significance for the constant term for Model 4, suggesting that it is statistically different from Model 2 (the base outcome). 


\subsection{Results}

Table 3 presents the results of the multinomial logit estimation. ${ }^{46}$ The results show clear differences in the range of variables that influence the choice of structure across organizational models.

Results show that the purpose of aid agencies is a significant determinant of structural choice. Models 1, 2 and 4 are statistically significant on the variable measuring the strategic purpose of aid. Negative marginal effects (ME) suggest that donors which prioritize the strategic purpose of aid are less likely to select Model 1, while positive ME suggest that donors providing more aid to strategic partners are more likely to adopt Models 2 and 4. The finding that the strategic purpose of aid is negatively related to Model 1 runs counter to theory, which predicts that Model 1 may be preferred by donors seeking to enhance the strategic purpose of aid as the institutional closeness between foreign ministries and aid agencies afforded by this structure could make it easier to align development programs to strategic objectives. This finding could be explained by the fact that Model 1 donors (Nordic countries plus the Netherlands) have tended to prioritize the developmental purpose of aid over strategic interests (see Gates and Hoeffler, 2004). Positive and significant marginal effects for Model 4 also run counter to theory and suggest that the Model 4 structure is preferred by donors that more actively pursue the strategic purpose of aid. Similarly, this result can be explained by the understanding that Model 4 donors (particularly the US) have traditionally allocated aid to pursue strategic purposes (see Berthelemy and Tichit, 2004; Meernik et al., 1998; Alesina and Dollar,

\footnotetext{
${ }^{46}$ It should be noted that the estimated coefficients from this study represent conditional correlations rather than causal parameters.
} 
2000; Maizels and Nissanke, 1984; McKinlay and Little, 1977; Schraeder, Hook and Taylor, 1998).

The developmental purpose variable is only significant for Model 1. Negative marginal effects show that an increase in aid to poorer countries decreases the likelihood of selecting the Model 1 structure. This finding shows support for the theory that integrated models are less likely to be used by donors seeking to enhance the developmental purpose of aid programs.

Models 1 and 4 show significant results for the commercial purpose of aid. In both cases, the results run counter to theoretical expectations. In the case of Model 4, positive and significant ME show this structure is preferred by donors pursuing the commercial purpose of aid despite the understanding that the institutional separation of development and trade through autonomous models is more likely to be adopted by donors seeking to use of aid for developmental, rather than commercial, purposes. Alternatively, negative and significant ME for Model 1 suggest that it is more likely to be adopted by less commercially oriented donors. This is the opposite of the expected result, with theory suggesting that institutional closeness between various policy objectives in the Model 1 structure make this model more likely to be adopted by commercially driven donors. In both instances, the discrepancy between expected and actual results can be linked to the traditional purposes pursued by the donors that have adopted these models in the past. While Nordic donors (who typically use Model 1) have tended to prioritize recipient need over commerical objectives (Lundsgaarde, Breunig, and Prakash, 2010; Gates and Hoeffler, 2004), Model 4 donors, specifically Australia and 
the US, have been shown to use aid for commercial purposes (Schraeder, Hook and Taylor, 1998; Berthelemy and Tichit, 2004).

The legitimacy variable is statistically significant and positive for Model 1 , suggesting that the probability of selecting Model 1 is $19 \%$ higher than other models when average ODA/GNI increases by one unit. ${ }^{47}$ This is perhaps unsurprising given the use of Model 1 by Scandinavian donors, which traditionally have been the most generous. In essence, the estimation is likely picking up the continued generosity of these donors and long-standing commitment to reaching, and often surpassing, the $0.7 \%$ international development spending target.

The political ideology of donor governments is statistically significant for Models 1 and 2. This finding suggests that more conservative donors (with higher ideological scores) are more likely to adopt Model 2 structures and is aligned with the hypothesis that more conservative donors are more likely to favor models that prioritize institutional closeness between aid programs and foreign ministries. Model 1 is also statistically significant for ideology, where negative ME show that donors adopting Model 1 are more likely to have lower ideological scores indicating more "liberal" governments. While this finding runs counter to theory, which suggests that conservative governments are more likely to pursue merged structures such as Models 1 and 2, the Nordic donors typically

\footnotetext{
${ }^{47}$ There are a few things to note here. Firstly, this variable is measured as a percentage, where a one-unit change represents an increase in ODA/GNI of one percentage point. A one percent change in ODA/GNI would represent a substantial change in ODA spending (or in GNI), and has never actually occurred (the largest increase in the dataset is $0.41 \%$ when Portugal tripled its aid spending in 2004. Portugal increased spending from US\$447 million in 2003 ( $0.22 \%$ of GNI) to US $\$ 1283$ million in 2004 ( $0.63 \%$ of GNI). The following year, Portugal's spending went back to 2003 levels.) In this sense, the high probability of selecting Model 1 may partly be driven by the unit of measure and the improbability of a change of that magnitude taking place. Perhaps a better way to understand this finding is that more generous donors are more likely to adopt Model 1.
} 
associated with the Model 1 structure are known for pursing more socially-driven and liberal policies.

Of the two variables intended to capture the potential for efficiency to determine organizational choices, both show significant results for Model 1. For administrative costs, positive and significant results for Model 1 show that the likelihood of selecting Model 1 increases by $3.1 \%$ when average administrative costs are higher. This finding is counter-intuitive given the shared space for development and foreign affairs within the foreign ministry, and could suggest that the choice to adopt the Model 1 structure is driven by factors beyond efficiency. For the predictability of aid, Model 1 donors show negative and significant results, suggesting that donors that allocate aid in accordance to spending plans are less likely to adopt Model 1.

The variable controlling for aid budget size is positive and significant for Model 4 and negative and significant for Model 2. For Model 4, the positive results suggest that donors are $12.8 \%$ more likely to select Model 4 over other structures when aid budgets increase by one-unit. This finding is unsurprising as two of the largest donors, the US and UK, adopted Model 4 for a number of years. For Model 2, the negative and significant results show that the likelihood of selecting Model 2 decreases by $10.6 \%$ with a one-unit increase in budget size. This finding is ultimately in line with argumentation from Chapter 3 and suggests that smaller donors are likely to prefer Model 2 structures over alternative organizational forms.

Marginal effects for Models 1, 3 and 4 are significant for the count variable used as a proxy for path dependence. Negative and significant results for Models 1 and 3 suggest these models are, on average, used for shorter periods of time. This is 
unsurprising given the adoption of both Model 3 structures by a number of donors (Japan, Austria, Spain, Portugal, Italy, US) over the past decade, while all four donors currently using Model 1 structures (Denmark, Netherlands, Norway and Finland) adopted the structure in the 1990s and 2000s. Alternatively, positive and significant results for Model 4 suggest that Model 4 structures may be, on average, used for longer periods of time and could suggest that the use of autonomous structure is (at least in part) determined by path dependence.

The country-programming variable, used to test Cunningham's theory of the relationship between donor role and organizational structure, is negative and significant for Models 2 and 5 . This suggests that donors adopting country programming are $28.8 \%$ less likely to adopt Model 2 and 22.5\% less likely to adopt Model 5. For Model 5, this finding is consistent with Cunningham's theory that reactive donors tend to avoid engaging in long-term development programming due to small size and a lack of incentive to engage in active programming. While for Model 2, this finding is unexpected as such structures are more closely associated with active donor roles, it could be explained by the reactive nature of some Model 2 donors during the 1970s and 1980s (Switzerland and New Zealand, for instance). This variable also returns positive and significant ME for Model 4 and Model 1, suggesting that donors using country programming are $29.1 \%$ more likely to adopt Model 4 structures and $22.3 \%$ more likely to adopt Model 1. For Model 4, the finding is likely driven by the fact that Model 4 donors have appear to have been the most consistent in terms of their use of country programming for the longest period of time (see Appendix 1), while all donors using Model 1 were already active when they adopted this model. 
Both of the variables used to control for domestic political/institutional factors presidential and federal government structures - show relatively strong results. The presidential variable is found to be positive and significant for Models 1 and 3, suggesting that donors with presidential governments structures are $10 \%$ and $31.7 \%$ more likely to adopt such structures, respectively. Alternatively, the presidential variable returned negative significant results for Model 4, suggesting that donors with presidential governments are $34 \%$ less likely to use Model 4 . Similarly, the federal variable is significant across Models 1, 3 and 4. While Model 1 returns negative ME, suggesting that countries using federal state structures are 33\% less likely to adopt Model 1 forms, Models 3 and 4 returns positive ME suggesting that donors with federal state structures are $23.9 \%$ more likely to adopt Model 3 and $22.3 \%$ more likely to adopt Model 4 . The finding that donors with similar state structures (federal/unitary) and government types (presidential/parliamentary) tend to converge towards similar models is significant and provides evidence that the structure of aid agencies are, at least in part, likely to be determined by pre-existing institutional structures pertaining to the organization of government.

The new public management variable returns a negative and significant result for Model 4 and a positive and significant result for Model 1. These findings are somewhat curious. In terms of Model 4, negative results suggest that donors that are influenced by NPM are $15.2 \%$ less likely to adopt autonomous agencies. This result is unexpected given that the contracting out of aid policy and implementation associated with NPM appears aligned with this structure. Indeed, the contracting out function typically associated with NPMs propensity towards agencification is perhaps best embodied by the 
Model 4 structure, which allocates total responsibility for aid policy and implementation to a separate agency, and allows for the development of specialized expertise for performing development programming. That said, this result could be explained by looking at the data. In the case of Model 4, only one country adopts this structure following the emergence of NPM - the UK. All other Model 4 donors begin using the structure in the 1960s and 1970s prior to the emergence of NPM as a theory for public management. The NPM variable also shows positive results for Model 1. This result is likely driven by the fact that all donors currently using Model 1 adopted the structure following the rise of NPM in the 1980s.

The unemployment variable returned positive and significant ME for Model 2, suggesting a one percent increase in unemployment makes donors $1.4 \%$ more likely to adopt this structure. This finding is perhaps consistent with the expectation that during harder economic times, when unemployment may increase, political appetite for aid is likely to wane and may increase the likelihood for donors to adopt structural forms that allow for alignment of aid with strategic and commercial priorities, as is possible with the merged Model 1 structure.

The control variable for fiscal cycles returns results for Models 1, 3 and 4 . Negative results for Models 1 and 4 suggest that donors are more likely to adopt this model when the debt-to-GDP ratio decreases. This finding matches expectations for Model 4, which is predicted to be preferred by donors with strong economic situations. Positive and significant results for Model 3 show that donors are more likely to select this model when debt-to-GDP ratios increase, suggesting that this model may be preferred during harsher economic conditions. 


\subsection{Sensitivity Test}

To test the robustness of the results, the same equation is estimated using fiveyear rolling averages for each of the independent variables. Multi-year averages are commonly used with historical time-series data to "evaluate stability and predictive accuracy" of the data over time (Zivot and Wang, 2003 p. 313). Results of the five-year average model are presented in Estimation Two reported in Appendix 5. The results support those of the annual estimation, however the five-year averaged model shows greater significance overall.

There are three instances where results from the annual model lose significance completely in the five-year averages. Two instances appear on Model 1 for the ideology and developmental purpose variables. The remaining instance affects the NPM variable for Model 4. A further four cases show a marginal reduction in the degree of significance - the country program variable for Model 1 and 2, predictability for Model 1 and presidential control for Model 1 - yet in each case these variables remain significant at $90 \%$ confidence. Overall, relatively few instances of total loss of significance suggests that the model is fundamentally robust.

To further test the robustness of the annual model, all outlier values were removed from each independent variable and the model was re-estimated. The removal of outliers resulted in the reduction of significance in two instances - for the unemployment variable for Model 2 and the fiscal cycle variable for Model 3. However, in the case of the unemployment variable, the results remained significant at $90 \%$ confidence. In all other 
cases, significance was retained, if not improved, once outliers were removed from the estimation. Results of the clean estimation are reported in Appendix 6. Outliers are included in the main estimation (Estimation 1) based on the understanding that these values, while anomalies, do occur in the data and may represent key observations or changes for some donors.

A final test of robustness was conducted by comparing the predicted likelihood that donors will adopt each of the five organizational models from both the annual and five-year average estimations. Predictions show the organizational model most likely to be chosen by donors in each year according to each estimation. Between the annual and five-year model, donors are predicted to select the same organizational model $84.4 \%$ of the time.

Taken together, the robustness tests show few changes to results when tested, suggesting that the model is robust and adding confidence that the results reported accurately reflect the actual relationship in the data.

\subsection{Discussion}

The results from the structural estimation highlight a number of key findings. Firstly, the results show key variables found to be significant determinants of aid agency structure. Second, the results show key differences in the structural determinants across models. These differences could shed further insight to the trends identified in the previous chapter.

\section{$\underline{\text { 4.6.1 Key Results - Significant Variables }}$}


The results show that the purpose of aid programs acts as a determinant of aid agency structure in some instances. Significance on the purpose variables suggests that donors select organizational models that match their substantive priorities. This finding provides support for the main hypothesis (H1) and lends credence to the theory presented in Chapter 2, which argues that the substance of aid programs is a key determinant of structural choices.

Of the four purpose variables, the strategic purpose measure shows significance across multiple organizational models. This finding suggests that on average, donors may seek to align organizational structures to strategic priorities more so than other aid purposes. This is not to say that donors necessarily select structures to increase strategic linkages with aid; the negative coefficient for Model 1 suggests that this structure is used by donors that are less likely to prioritize strategic purposes. Rather, this finding suggests that the strategic considerations of aid programs are the substantive choices that are most commonly considered when making structural decisions.

In terms of purpose, it is also important to note that the autonomous Model 4 structure, which has been touted for its capacity to ensure a more singular focus on development, is found to be utilized by donors that are both strategically and commercially oriented in their aid practices. This finding is surprising in light of recent discourse surrounding the virtues of autonomy and suggests that despite the DFID example, Model 4 donors have not always been associated with best practice. Indeed, the association of Model 4 with strategic and commercial objectives is aligned with the broader allocation, which historically found Model 4 donors, notably the US, to prioritize the use of aid for geopolitical and economic purposes (see Maizels and Nissanke, 1984; 
Alesina and Dollar, 2000). In essence, this finding questions the logic surrounding the perceived benefits of autonomous structures by showing that over the long-term, autonomous models have not been selected by the most development-oriented donors.

A further finding is that the political ideology variable is only a significant determinant of organizational choice for Models 1 and 2. While significance for Model 1 and 2 suggest that political ideology has some effect, it is curious that ideology does not have a more pronounced role in determining other structural forms. The finding could suggest that anecdotal evidence surrounding the relationship between ideological preferences and structure may not be representative of wider trends in the degree to which politics has determined structural forms over time. Indeed, ideology is just one measure of political preferences and necessarily does not account for the preferences of key individuals or bureaucracies. Going forward, it will be important to explore the relationship between structure, political ideology and other political forces in greater detail.

Lastly, key structural variables, such as presidential and federal, are found to be significant across a number of organizational models. This finding suggests that preexisting institutional features of donors is a strong predictor of organizational choices. This finding is important for two reasons. First, it suggests that structural choices are somewhat path dependent and predicated on pre-existing structural forms. Second, if structural choices are dependent on donor institutional features, it follows that aid agency structures could be predicted by pre-existing institutional features and the choices made by similar donors.

\subsubsection{Key Results - Differences Across Models}


Perhaps as expected, the results of Estimation 1 highlight differences in the variables that determine the choice of adopting each of the five organizational forms. While the specific variables associated with each organizational model are outlined in the prior sections, taken together, the results show four main findings.

First, despite organizational similarities between Models 1 and 2, the factors shown to contribute to the choice between these models differ in terms of ideology and purpose. Speaking of ideology, results for Model 1 show that this model is less likely to be adopted by more conservative donors, standing in contrast to Model 2, which is preferred by conservative governments. Given similar degrees of institutional integration, which provides similar opportunities for governments seeking to either align aid with strategic purposes, the usage of Models 1 and 2 by governments with different ideological preferences raises questions. Similarly, the difference in the relationship between strategic purposes and organizational choices for Models 1 and 2 is also curious. While Model 1 is less likely to be adopted by donors that pursue a strategic and developmental purpose, Model 2 is more likely to be adopted by more strategic donors. Again, the contrast between these two similar models raises questions as to why only Model 2 is more likely to be used by donors pursuing a strategic aid purpose. De-coding the rationale for adopting Model 2 versus Model 1 for donors that pursue a strategic aid purpose will be further explored in the case studies.

The second finding is that of the five organizational models, Model 1 shows the greatest number of significant determinants. This could suggest that fully merged structures are adopted by donors that are the most similar, as a group. Alternatively, these donors may be the most different to other OECD-DAC members. Given that Model 
1 has only been used by Nordic countries (plus the Netherlands), there is perhaps some merit to the idea that shared historical or cultural ideals and institutions may lead such donors to prefer similar behaviours and structural preferences.

Finally, the absence of significance for the variable measuring institutional legitimacy suggests that the recent convergence to Model 2 and 3 is not driven by attempts to emulate donors that support best practice as initially proposed. The question here again becomes one of understanding convergence towards these models. If donors adopting Model 2 and 3 are not the most legitimate, then perhaps this trend is explained by the relative benefits of these structures in relation to other models or efforts to avoid perceived weaknesses in Models 1 and 4. With Models 1 and 4 typically selected by similar donors, the convergence could also indicate that the majority of donors do not view the choice of Model 1 and 4 structures as viable options for aid management, or that the sheer number of donors adopting Models 2 and 3 render them appealing options. Uncovering the reasons for the convergence towards Models 2 and 3 (or divergence away from Models 1 and 4) will be further explored in the case studies presented in Chapters 6 and 7.

\subsection{Conclusions}

This chapter presented a first attempt to model the choice of aid agency structure across all OECD-DAC donors and over time. Building on the theoretical framework outlined in Chapter 2, key variables derived from diverse theories of organizational structure were operationalized and tested using a multinomial logit model to examine the determinants of aid agency form. 
Results of the estimation show clear differences in the variables that determine structural choices. Of these, the purpose variables, particularly those measuring the strategic prioritization of aid programs, were found to be some of the most significant determinants of aid agency structure, suggesting that the substantive preferences of donors are likely to influence structural choices. Ideology of donor governments and structural factors were also shown to be significant determinants of aid agency structure. The significance of the structural variables echoes findings from Chapter 3 and suggests that countries with similar structural factors may be more likely to adopt similar organizational models.

Moreover, the estimation highlighted key differences in the determinants of specific organizational models. Notably, despite similarities between the theoretical reasons for adopting Models 1 and 2, results of the estimation show differences in the main determinants of merged models. In addition, the estimation showed that efforts to emulate best practices are not associated with the convergence towards Models 2 and 3, perhaps supporting preliminary findings outlined in Chapter 3. Understanding why Models 1 and 2 are determined by different variables and why donors are converging towards Models 2 and 3 remains outstanding questions to be explored in greater depth through the case studies presented in Chapter 6 . 
CHAPTER 5

WHY DO DONORS REORGANIZE? 
While the prior model sought to provide insight into the determinants of aid agency structure, in many cases, these structural forms are the product of organizational changes. In efforts to develop a holistic understanding not only of organizational choices, but of the determinants of organizational change, this section develops a model to answer the question: why do donors reorganize? To the best knowledge available, this question has not been explored in the academic literature, making this section a further contribution to the literature on aid management.

At the most basic level, this model is built on the theory and formula developed in the prior sections. In many cases, theories of organizational structure are intimately linked to questions of organizational change, where changes in the variables perceived to act as determinants of structure are seen to provide an incentive for change. For instance, Cunningham asserts that the role of donors influences the choice of aid agency structure. By the same logic, changes to the role of donors are likely to result in changes to a donor's structural preferences. Indeed, the literature review provided in Chapter 2 highlights many of the variables that theoretically could influence the likelihood of organizational change.

To ensure that no variables responsible for organizational change are overlooked, a brief supplementary literature review is provided in the next section. This review is intended to identify potential determinants of organizational change beyond those listed in the previous chapter. The review will be followed by a description of the key hypotheses, variables, and the model used to identify the factors that prompt donors to reorganize aid agencies. The model presented ultimately finds that organizational change is associated with changes to the size of donor budgets and changing structural environments. 


\subsection{Understanding Organizational Change}

Theories of organizational change are built on the premise that organizations change to continue surviving (Burke, 2010 p. 2). Such change can be understood in two ways: as the outcome of deliberate decision-making that results in a choice to reorganize structures or processes (see Child, 1997), or as the result of evolutionary selection where organizational inertia forces change for survival (Hannan and Freeman, 1984). In the case of aid agencies, financial guarantee by donor governments suggests that the evolutionary understanding of organizational choice is perhaps less relevant; the continuity of aid agencies is expected for as long as aid programs are deemed relevant investments for donor governments. While institutional inertia may render some aid programs less effective, it will not necessarily threaten aid agency survival. As a result, this study will understand organizational change as a deliberate choice to restructure aid agencies due to a range of potential determining factors (i.e. independent variables identified in Chapter 4). The question at this stage is whether there are additional variables beyond those previously identified that could prompt donors to choose to reorganize.

In the private sector, the literature on organizational change focuses on the content of change (i.e. the type of change dynamics such as the requirement of new behaviour by employees), the context of change (which examines the change response as a reaction to stressors), change process, and change outcomes (Pettigrew, Woodman and Cameron, 2001; Burke and Litwin, 1992; Greenwood and Hinings, 1996). Of these, examining the context of change is perhaps the most relevant for understanding the determinants of reorganization. To this end, several studies have identified key variables 
including organizational culture (Rashid, Sambasivan and Rahman, 2004), competition (McKinlay and Starkey, 1988), deregulation (Kelly and Amburgey, 1991), legislative changes (Haveman, 1992), and innovation and technology (Hage, 1999; Colombo and Delmastro, 2002) as drivers of change in the business environment. Each of these factors aligns with the contingency theory perspective, where changes to the internal or external environment alters the degree of "fit" with contingencies and prompts change to improve structural alignment with environmental factors to enhance efficiency.

Similar to the literature on structural choice reviewed in Chapter 2, institutional theories also provide a frame for understanding organizational change. Specifically, DiMaggio and Powell (1991) link organizational changes to efforts to enhance organizational legitimacy by adopting structures or practices most commonly aligned with accepted or best practice within a given field. While the adoption of similar structures or practices by similar organizations is likely to lead to homogenization and inertia within a given institutional field, changes to the overarching structure or practices deemed most "legitimate" could also spark field-wide change towards new best practice or structural forms.

In the public sector, there seems to be less clarity surrounding the factors that contribute to change, and how or whether these differ from those identified in the private sector literature. Van der Voet (2014) for instance, notes that there is "a lack of empirical evidence about the specificity of organizational change in the public sector" (p 2). This sentiment is echoed by Kickert (2014) who suggests that not only is most literature on organizational change based on studies about private sector commercial firms, but also that "hardly any stud[ies] exist about possible differences between organizational change 
in the private and public sector" (p. 694). The exception is Robertson and Seveniratne's (1995) study, which compared the process and outcomes of change in public and private organizations, finding "no overall significant differences" between the change induced by key factors in public and private organizations that undergo planned organizational reform (p. 554).

Where studies of public sector reorganization do exist, they tend to focus on changes related to new public management (see Pollitt and Bouckaert, 2004; Jespersen et al, 2002) or reorganizations in specific sub-sectors including health care (Weissert and Goggin, 2002) and education (De Boer et al., 2007). Importantly, theories of organizational change in the public sector tend to resemble theories of structural choice reviewed in Chapter 2. Factors including environmental changes (Tria and Valotti, 2012; Pollitt and Bouckaert, 2004), personal preferences of political leaders (Pollitt and Bouckaert, 2004; Sepper and Alas, 2008), institutional legitimacy (DiMaggio and Powell, 1991) and public management ideas/paradigms (Pollitt and Bouckaert, 2004) are all viewed as drivers of both structural choice as well as change in the public sector.

Moreover, the aid literature offers little further insight into the determinants of changes to aid organization. There is limited literature on aid agency change. Where it exists, studies tend to focus on cases studies, highlighting the role of political factors (see Barder, 2005) including strong leadership (Gulrajani, 2012; Barder, 2005) and desire for political control over development (Gulrajani, 2017). An important exception is perhaps Cunningham's (1974) work on aid management. While Cunningham does not touch on issues of organizational change, his theory of the linkage between active and reactive 
donors implies that change in donor roles and substantive preferences could be linked to organizational reform.

This brief review finds that much of the theoretical literature that underlies the framework for understanding organizational choice, as developed in Chapter 2 and operationalized in Chapter 4, is closely aligned with determinants of organizational change. This suggests that there is no real reason to expect variables beyond those identified to act as determinants of organizational change. As a result, the model developed in this chapter will take the variables used in Chapter 4 as the basis of analysis. The variables and their respective operationalization are identified in Table 4, below.

\subsection{Variables}

The dependent variable measures instances of organizational change in aid agency structure. For the purpose of this study, organizational change refers exclusively to changes between donor models, where the merging or creation of new structures by donors that do not result in new organizational classifications according to the OECD organizational typology are not counted as instances of change. ${ }^{48}$ This is done to ensure consistency with the prior quantitative model, which explores determinants of aid agency structure. To capture "instances of change", the dependent variable is measured as a binomial; a score of 1 is awarded for years in which donors alter the organizational structure of aid agencies and a score of 0 is allocated in each year where no change is

\footnotetext{
${ }^{48}$ For instance, in January 2011, Germany merged three of its development arms (German Technical Cooperation (GTZ), the German Development Service (DED), and Inwent) to form a new development cooperation agency (GIZ). While the merger was a "sweeping" reform in the German context, it did not fundamentally change the organizational model used by Germany according to the OECD definitions (Nabiyeva, 2011). Prior to the merger, Germany used a Model 3 organizational structure with the German Federal Ministry for Economic Cooperation and Development (BMZ) providing policy direction and GTZ acting as the main implementation arm. Post-merger, BMZ continued to direct German development policy, while the new GIZ became the main implementing apparatus.
} 
reported. This variable was derived using the organizational structure dataset defined in the previous section.

Many of the independent variables utilized in this model share the same underlying data and basic justification reported in the structural model. However, seeing as the current model intends to capture organizational change, all variables have been transformed to emphasize differences that could serve as inputs into change. In theory, organizational change is likely to be sparked by changes in the independent variables identified as significant determinants of aid agency structure. For instance, if donors reorganize to enhance efficiency, then it is expected that a change in relative efficiency of donor programs would change prior to reorganization. As a result, the variables are designed to capture change by measuring them as the first difference of the structural variables. The transformation applied to each variable, as well as the justification for the transformation, is explained in Table 4 below. ${ }^{49}$

\section{Table 4: Independent Variables}

\begin{tabular}{|c|c|}
\hline Variable & Justification \\
\hline $\begin{array}{l}\text { Change in } \% \text { of ODA } \\
\text { to top } 10 \text { most similar } \\
\text { voting partners (UN } \\
\text { General Assembly) }\end{array}$ & $\begin{array}{l}\text { Change in ODA to top } 10 \text { most similar voting partners is used to } \\
\text { capture the degree to which changes in the proportion of aid } \\
\text { allocated to strategic partners relates to changes in organizational } \\
\text { structure. The variable tests whether changes in the substantive } \\
\text { preferences of donors (strategic) drives reorganization. } \\
\text { This variable was constructed using data from the OECD's } \\
\text { Statistics Database and the UN General Assembly Voting Data } \\
\text { (Dyadic dataset). }\end{array}$ \\
\hline $\begin{array}{l}\text { Change in ODA to } \\
\text { LDCs and LICs }\end{array}$ & $\begin{array}{l}\text { Change in the proportion of ODA allocated to poor recipients is } \\
\text { used to measure whether changes to the developmental purpose of } \\
\text { donors contributes to reorganization. This variable tests whether } \\
\text { changes in the substantive preferences of donors (developmental) } \\
\text { drives reorganization. } \\
\text { The variable uses data taken from the OECD Statistics Extract }\end{array}$ \\
\hline
\end{tabular}

\footnotetext{
${ }^{49}$ A basic correlation table was created using the command "correlate" in STATA. Results of this test show no sign of collinearity and can be found in Appendix 8.
} 


\begin{tabular}{|c|c|}
\hline & Database. \\
\hline $\begin{array}{l}\text { Change in ODA to top } \\
10 \text { developing country } \\
\text { trading partners }\end{array}$ & $\begin{array}{l}\text { Change in the proportion of ODA allocated to top ten trading } \\
\text { partners is used to measure identify if changes to the commercial } \\
\text { purpose contribute to reorganization. This variable tests whether } \\
\text { changes in the substantive preferences of donors (commercial) } \\
\text { drives reorganization. } \\
\text { This variable was constructed using dyadic trade data from the } \\
\text { IMF's Direction of Trade Statistics database and ODA data from } \\
\text { the OECD's Statistics Extract Database. }\end{array}$ \\
\hline $\begin{array}{l}\text { Change in } \\
\text { Humanitarian aid as } \% \\
\text { of total ODA }\end{array}$ & $\begin{array}{l}\text { Change in the proportion of ODA allocated to humanitarian issues } \\
\text { is used to capture the relationship between the humanitarian } \\
\text { purpose and organizational change. This variable tests whether } \\
\text { changes in the substantive preferences of donors (humanitarian) } \\
\text { drives reorganization. } \\
\text { Data for this variable was taken from the OECD Statistics Extract } \\
\text { Database. }\end{array}$ \\
\hline $\begin{array}{l}\text { Change in ODA as \% } \\
\text { of GNI }\end{array}$ & $\begin{array}{l}\text { Change in ODA as a proportion of GNI is aligned with the } \\
\text { institutional theory literature and is used to test whether changes to } \\
\text { the relative legitimacy of donors sparks reorganization, i.e. } \\
\text { whether donors change organizational forms to improve } \\
\text { performance in alignment with international best practice } \\
\text { (legitimacy). } \\
\text { Data for this variable was taken from the OECD Statistics } \\
\text { Database. }\end{array}$ \\
\hline $\begin{array}{l}\text { Change in ODA } \\
\text { volume }\end{array}$ & $\begin{array}{l}\text { Change in ODA volume, measured as constant gross ODA \$US } \\
\text { millions, is used to capture changes in the size of aid programs. } \\
\text { Tests whether changes to donor size affect structure as predicted } \\
\text { by contingency theory (size) } \\
\text { Data for this variable was taken from the OECD Statistics } \\
\text { Database. }\end{array}$ \\
\hline $\begin{array}{l}\text { Change in ideology of } \\
\text { Government } \\
\text { Executive }^{50}\end{array}$ & $\begin{array}{l}\text { Change in government ideology is used to assess whether changes } \\
\text { in the political ideology of governments contribute to } \\
\text { reorganization. This variable is measured as a binomial. A score }\end{array}$ \\
\hline
\end{tabular}

${ }^{50}$ A binary variable was also tested to control for the potential effects of election years on aid agency structure. The variable ascribed a score of " 1 " to each year donors held an election and a score of "0" in years where no election took place. While aid agency reorganization is unlikely to be an election issue, or even an issue so high-profile that it would warrant immediate post-election response, March and Olson's (1983) assertion that government reorganization is often linked to the political system and short-term incentives makes it prudent to test the potential connection between reorganization and elections. Moreover, there is at least one instance, in the context of aid agencies, of reorganization closely following an election. Notably, in 2013, PM Tony Abbot announced the merger of AusAID with Australia's foreign ministry the day after taking power. The variable was tested in each estimation reported below but was 


\begin{tabular}{|c|c|}
\hline & $\begin{array}{l}\text { of " } 1 \text { " indicates change in ruling party, a score of "0" represents no } \\
\text { change from the prior year. This variable captures the influence of } \\
\text { changes to political ideology as a driver of organizational change } \\
\text { (ideology). } \\
\text { Data for this variable was compiled from the Comparative } \\
\text { Manifestos Project. }\end{array}$ \\
\hline $\begin{array}{l}\text { Change in } \\
\text { administrative spending } \\
\text { as a } \% \text { of ODA }\end{array}$ & $\begin{array}{l}\text { Change in administrative spending as a proportion of ODA is used } \\
\text { to capture changes in the efficiency of aid agencies } \\
\text { (administration) and controls for a potential relationship between } \\
\text { organizational change and organizational performance. } \\
\text { This variable was developed using data from the OECD Statistics } \\
\text { database, and was supplemented with data compiled by hand from } \\
\text { OECD-DAC Development Co-operation Reports from the early } \\
\text { 1970s. More information on the data is available in the prior } \\
\text { chapter. }\end{array}$ \\
\hline $\begin{array}{l}\text { Change in } \text { ODA } \\
\text { disbursements as a } \% \\
\text { of Commitments }\end{array}$ & $\begin{array}{l}\text { Changes in the proportion of disbursements allocated as a } \\
\text { percentage of commitments in each year is used as a second proxy } \\
\text { for measuring changes in organizational performance } \\
\text { (disbursements). } \\
\text { Data for this variable was taken from the OECD Statistics Extract } \\
\text { Database. }\end{array}$ \\
\hline NPM & $\begin{array}{l}\text { The NPM variable used in the structural estimation is also included } \\
\text { here. Recall that NPM calls for governments to create new } \\
\text { "agencies" for managing government activities and sparked } \\
\text { numerous reforms in the } 1980 \text { s and 1990s. Controlling for the } \\
\text { effect of NPM on government organization is aligned with public } \\
\text { sector theories that link organizational changes in government to } \\
\text { public management paradigms }(N P M) \text {. } \\
\text { This variable is measured as a binomial. A score of " } 1 \text { " is used for }\end{array}$ \\
\hline
\end{tabular}

never found to be statistically significant and was subsequently removed. No other variables were affected by the addition or removal of this variable.

A number of additional interactive terms were also tested to assess the potential relationship between political factors and organizational change. The first tested whether having a right-wing government during a period of fiscal deficit was more likely to contribute to change. A second interactive term combined the predicted probability of selecting the actual model chosen with change in head of government, and aimed to test whether new heads of government were more likely to reorganize aid agencies in instances of "mis-fit" between actual and predicted model. In essence, this variable tested whether lower degrees of "fit", as measured by predictions that donors would select actual model used, served as a condition for change. A third interactive variable combined the predicted probability of selecting the actual model used with the election binary, and sought to capture the potential for new governments to be more inclined to reorganize aid organizations when coming into power in instances of "mis-fit" between organization choices used and predicted. In each of the three cases, the interactive terms were tested in both the annual and five-year averaged model. The variables were never significant. Other variables were not affected by their addition or removal. 


\begin{tabular}{|c|c|}
\hline & each year after 1980 , a score of "0" is used in all years prior. \\
\hline Country programming & $\begin{array}{l}\text { The country program variable measures the relationship between } \\
\text { donor roles and organizational structure as presented in } \\
\text { Cunningham's theory (countryprogram). The variable is measured } \\
\text { as a binary as described in the structural model. }\end{array}$ \\
\hline $\begin{array}{l}\text { Change in the } \\
\text { unemployment rate }\end{array}$ & $\begin{array}{l}\text { Annual changes to the unemployment rate in donor countries is } \\
\text { used to control for the impact of changes to donor economic } \\
\text { contexts on organizational structure in alignment with theories } \\
\text { from both the public and private sector literature that link } \\
\text { environmental conditions to organizational change } \\
\text { (unemployment). } \\
\text { This variable was constructed using the "unemployment rate as a } \\
\% \text { of the civilian labour force" taken from the OECD's Annual } \\
\text { Labour Force Statistics database. }\end{array}$ \\
\hline Cash surplus/deficit & $\begin{array}{l}\text { The first difference of a debt-to-GDP measure is used as a proxy } \\
\text { for the fiscal cycle. Similar to the prior model, this variable } \\
\text { controls for changes to the domestic fiscal situation and is a proxy } \\
\text { for changes in donor environmental conditions ( } f \text { iscal). In the } \\
\text { absence of long-term fiscal surplus/deficit data, the first difference } \\
\text { of debt stock is used to mimic changes in the fiscal cycle. } \\
\text { This variable is constructed using the IMF's Historic Public Sector } \\
\text { Dataset with supplementary data taken from the World Economic } \\
\text { Outlook for } 2014 \text { and } 2015 \text {. }\end{array}$ \\
\hline Structural predictors & $\begin{array}{l}\text { A new variable (structural) is added to control for the changes to } \\
\text { the structural predictors of organizational choice estimated in the } \\
\text { prior model (presented in Chapter Four). Based on the } \\
\text { understanding that changes to the underlying factors that lead to } \\
\text { particular organizational choices over time could lead donors to be } \\
\text { "out of fit" with structural conditions, the new variable captures } \\
\text { the degree to which changes in such factors alter pressure for } \\
\text { reorganization. } \\
\text { The variable is measured as the predicted likelihood that donors } \\
\text { select the actual organizational model used in each year (generated } \\
\text { using the "predict" command in STATA following the } \\
\text { multinomial logit regression conducted in Chapter Four). If the } \\
\text { structural factors are significant determinants of organizational } \\
\text { change, then it is expected that the likelihood of donors selecting } \\
\text { the actual model chosen should decrease prior to an organizational } \\
\text { change. } 51\end{array}$ \\
\hline
\end{tabular}

${ }^{51}$ Two further proxies related to the structural model were also developed and tested. Both variables were binomials intended to capture the presence of close "alternative" organizational choices. Using the predicted likelihood that donors will select each of the five organizational models, a score of "1" was 
The inertia (or path dependence) variable is excluded due to its theoretical inability to predict change. While in the prior model, the count variable was used as a proxy for path dependence and inertia across various models, inertia has often been considered a consequence of organizational selection rather than a factor contributing to change (Hannan and Freeman, 1984). Understanding that inertia is about resistance to change and does not provide a meaningful determinant of reorganization, the count variable is removed from the current model.

\subsection{Model}

The main equation estimated in this study is:

$$
\begin{aligned}
& \text { Model }_{t}=\beta_{0}+\beta_{1} \text { strategic }_{t-1}+\beta_{2} \text { developmental }_{t-1}+\beta_{3} \text { commercial }_{t-1}+\beta_{4} \text { humanitarian } \\
& t_{t-1}+\beta_{\text {slegitimacy }} t-1+\beta_{6} \text { size }_{t-1}+\beta_{\text {7ideology }} t-1+\beta_{8} \text { admininstration }_{t-1}+ \\
& \beta_{9} \text { disbursements }_{t-1}+\beta_{10} N P M_{t-1}+\beta_{11} \text { countryprogram }_{t-1}+\beta_{12} \text { unemployment }_{t-1}+ \\
& \beta_{13} \text { fiscal }_{t-1}+\beta_{14 \text { structural }} \text { t-1 }_{1}+\mathrm{u}_{t-1} \text {. }
\end{aligned}
$$

The model uses an unbalanced panel dataset that covers all 28 bilateral OECD-DAC donors from 1962 to $2015 .{ }^{52}$ The model is estimated using the rare events logistic regression method developed by King and Zeng (2001). Rare event logit models are typically used in cases where the binary dependent variables possess "dozens to thousands of times fewer ones (events, such as wars, coups, presidential vetoes, decisions

awarded in cases where the second most-likely organizational choice was within 5\% of the most likely predicted model. A second variable awarded a score of " 1 " when the second most-likely model was within $10 \%$ of the most-likely choice. In both cases, a score of " 0 " was awarded when there was no close alternative. In essence, both variables were used to test whether the presence of a close alternative made donors more likely to change organizational model. Both variables were tested in both the annual and fiveyear average models reported below but were never found to be statistically significant. As a result, both variables were removed from the model. Results for other variables did not change in response to the addition or removal of either variable.

${ }^{52}$ While variables were collected for the full range of the sample period where possible, the actual estimation is limited by the availability of a few variables. Notably, data for humanitarian aid is not available prior to 1971 and UN Voting data is not available post-2014 at the time of writing. As a result, the actual period measured in this estimation covers the years 1971-2014. 
of citizens to run for political office, or infections by uncommon diseases) than zeros ('nonevents')" (King and Zeng, 2001 p. 138). In essence, the rare events model corrects for biases caused by event infrequency.

In the proposed model, the outcome variable (organizational change) reports an "event" 28 times in a total sample of 800 observations, justifying the use of a model capable of correcting for potential biases derived from a small number of events. Alternative estimation techniques, such as the Firth model, were also considered. However, the Firth model is particularly adept at correcting for separation within the data when using categorical predictor variables (Williams, 2016). Given that the proposed model mostly uses continuous variables, there is little reason to expect the problem of separation.

The change model is tested using two estimations. The first mirrors the annual estimation from the structural model with all independent variables run on a one-year lag. The lagged independent variables are used to control for potential endogeneity. In terms of organizational change, a one-year lag is used to test whether organizational change is "catalyzed" or "triggered" by any of the independent variables identified. ${ }^{53}$

The second model is measured using five-year rolling averages for all continuous independent variables. Based on the understanding that reorganizations occur infrequently, and may be driven by longer-term trends that reflect deeper shifts to independent variables, the five-year rolling averages are used to capture longer-term changes in key independent variables. Indeed, Cunningham's basic theory of aid agency

\footnotetext{
${ }^{53}$ Two and three year lags were also tested. Changes in structural predictors remain significant with twoyear lags, and changes in budget size are significant on the three-year lagged structure. There is no clear reason for expecting donors to base organizational decisions on a specific lag structure. Of the three tested, the one-year lag shows the greatest significance.
} 
structure (that structural choices are dictated by substantive preferences) implies that the time-horizon for organizational shifts align with the time necessary to shift or cause a change in substantive preferences. While such a timeline is difficult to determine and is likely to vary across donors, the point remains that assuming that organizational changes are only driven exclusively by annual shifts seems unrealistic. As a result, all continuous independent variables are measured not only as year-on-year changes, but as five-year rolling averages. A five-year time horizon was chosen due to its prevalence in the aid literature (see Alesina and Dollar, 2000).

While rolling averages are used for continuous variables, binomial variables capturing "event"-type data is treated somewhat differently. Based on the understanding that one-off events, such as elections or changes in ruling party happen at a specific point, transforming the variable into a rolling average makes little sense. Instead, these variables remain in their original binary form, but are tested using one, two, three and four-year lags to identify potential differences in the relationship between such variables and organizational change over time. ${ }^{54}$ Both models are estimated using clustered standard errors by donor to account for within country factors. Results are reported in Table 5 below.

\footnotetext{
${ }^{54}$ Given than political cycles are generally $4-5$ years, extending the lags for political event variables makes
} little sense. It is unlikely that governments will undertake organizational changes at the end of their term. 
Table 5 - Estimation 4: Results of Rare Events Logit ${ }^{55}$

\begin{tabular}{|c|c|c|}
\hline & Annual & 5 -year \\
\hline$\%$ ODA to top $10 \mathrm{UN}$ voting partners & $\begin{array}{l}1.040 \\
(1.415)\end{array}$ & $\begin{array}{l}1.190 \\
(0.753)\end{array}$ \\
\hline$\%$ ODA to LDCs and LICs & $\begin{array}{l}0.909^{*} \\
(-2.058)\end{array}$ & $\begin{array}{l}0.796 \\
(-1.245)\end{array}$ \\
\hline$\%$ ODA to top 10 trading partners & $\begin{array}{l}0.983 \\
(-0.778)\end{array}$ & $\begin{array}{l}1.011 \\
(0.140)\end{array}$ \\
\hline Humanitarian as $\%$ of ODA & $\begin{array}{l}0.944 \\
(-0.876)\end{array}$ & $\begin{array}{l}0.976 \\
(-0.091)\end{array}$ \\
\hline ODA as $\%$ of GNI & $\begin{array}{l}0.266 \\
(-0.402)\end{array}$ & $\begin{array}{l}0.000^{*} \\
(-2.433)\end{array}$ \\
\hline ODA (budget size) & $\begin{array}{l}1.000 * * * \\
(3.752)\end{array}$ & $\begin{array}{l}1.001 * * * \\
(3.879)\end{array}$ \\
\hline Admin as $\%$ of ODA & $\begin{array}{l}1.076 \\
(0.506)\end{array}$ & $\begin{array}{l}1.605 \\
(0.615)\end{array}$ \\
\hline Disbursements as $\%$ of commitments & $\begin{array}{l}0.986 \\
(-1.354)\end{array}$ & $\begin{array}{l}0.895 \\
(-1.742)\end{array}$ \\
\hline Ideology of Executive (1yr lag) & $\begin{array}{l}1.595 \\
(0.616)\end{array}$ & $\begin{array}{l}2.152 \\
(0.920)\end{array}$ \\
\hline Ideology of Executive (2yr lag) & & $\begin{array}{l}2.643 \\
(1.342)\end{array}$ \\
\hline Ideology of Executive (3yr lag) & & $\begin{array}{l}2.097 \\
(0.923)\end{array}$ \\
\hline Ideology of Executive (4yr lag) & & $\begin{array}{l}1.131 \\
(0.109)\end{array}$ \\
\hline NPM & $\begin{array}{l}0.607 \\
(-0.588)\end{array}$ & $\begin{array}{l}0.350 \\
(-0.712)\end{array}$ \\
\hline Country program & $\begin{array}{l}0.987 \\
(-0.020)\end{array}$ & $\begin{array}{l}0.613 \\
(-0.643)\end{array}$ \\
\hline Unemployment & $\begin{array}{l}0.852 \\
(-0.852)\end{array}$ & $\begin{array}{l}4.651 \\
(0.789)\end{array}$ \\
\hline Fiscal Balance (surplus, deficit) & $\begin{array}{l}1.023 \\
(0.582)\end{array}$ & $\begin{array}{l}0.974 \\
(-0.350)\end{array}$ \\
\hline Structural Model & $\begin{array}{l}0.127 * * * \\
(-3.469)\end{array}$ & $\begin{array}{l}0.144 * * * \\
(-2.604)\end{array}$ \\
\hline Constant & $\begin{array}{l}0.162^{*} \\
(-2.331)\end{array}$ & $\begin{array}{l}0.374 \\
(-0.849)\end{array}$ \\
\hline Observations & 676 & 568 \\
\hline
\end{tabular}

\footnotetext{
${ }^{55}$ Both estimations were tested without the structural predictors to test which factors are most significant in the absence of the structural control. In both cases, the results closely mirror those reported in Table 5. For the annual estimation, results are the same, but the "strategic purpose" variable becomes significant. For the five-year estimation, the "constant" variable becomes significant. There are no other changes in results. Pseudo-R2 is not reported for this estimation as the "relogit" command does not generate summary statistics. R2 value also cannot be generated through post-estimation techniques following the "relogit" command.
} 


\subsection{Results}

Table 5 presents the results of the rare-events logit estimations. The annual estimation suggests that the likelihood of organizational change is most closely linked to four variables: changes in developmental purpose, ODA budget size, and structural determinants and the constant. Positive coefficients on ODA budget size suggest that organizational changes are more likely to follow increases in overall ODA budget size. Alternatively, negative coefficients on the developmental purpose, structural predictor and constant term suggests that the likelihood of organizational change increases when donors provide lower proportions of aid to development partners and or when structural determinants reduced the likelihood of adopting the organizational model actually used.

The second estimation shows statistical significance on the variables measuring changes in ODA budget size, structural determinants, and the donor aid effort (ODA as a $\%$ od GNI). Positive and significant results for the ODA budget size show that organizational change becomes more likely when donors increase the size of their aid budgets (on average) over five years. Negative and significant results for the structural variable shows that the odds of organizational change is lower when the five-year averages predicted likelihood of donors selecting the actual models used increases. In both cases, these findings mirror those from the annual estimation. A third significant variable shows that the likelihood of organizational change increases when ODA/GNI ratios decline.

Taken together, the estimations show that ODA budget size and the structural model predicted values appear to be the most consistent determinants of aid agency reorganization. However, it seems that changes in the developmental purpose of aid 
agencies could act as a catalyst for organizational change over the shorter term, while long-term declines in the aid effort may also contribute to instances of organizational change.

\subsection{Discussion}

The results from the rare-events logit point to four main findings. Perhaps most notably, consistent significant and negative values for the structural variable suggests that lower probabilities of donors selecting the actual model used may signal that donors are out of fit with their structural context and increases pressure for change. This finding is perhaps unsurprising and speaks to the logic of contingency theory, where organizational change becomes a response to internal and external environmental or structural changes. Perhaps the most important implication is that changes to donor contexts and structural environments likely contribute to reorganization.

Secondly, the finding that changes in budget size contribute to reorganization suggests that donors view different budget sizes as requiring different institutional set-ups to manage and allocate funds effectively. Combined with results from the structural estimation, which show that budget size is positively related to the choice of adopting Model 4 and negatively related to the choice of adopting Model 2, the size of aid programs becomes an important variable for understanding reorganization and structural choice. Indeed, for donors with small or declining budgets in particular, budget size may not only influence the decision to change, but also the decision to adopt a Model 2 structure. Understanding the structural dimensions that render small donors more likely to adopt or reorganize towards Model 2 structures will be further explored in the following chapters. 
Third, the results show limited impact of changes to the purpose of aid programs on the likelihood of reorganization, with only the developmental purpose variable showing significance in the annual estimation. Combined with the structural estimations, which show some significance across each of the purpose measures, limited influence of changes to purpose of aid programs on reorganization could suggest that purpose is more likely to determine the choice of structure than on the decision to reorganize. However, of the four purposes, the finding that the developmental purpose is a significant determinant of both reorganizational and structural form suggests that donors are more likely to enact organizational and select structures based on their developmental purpose. This finding will be explored in greater detail in the following chapters.

Lastly, the finding that changes in the ideology of government is not a significant determinant of organizational change suggests that there is no clear link between changes in ruling party ideology and the propensity for organizational change. This finding is somewhat surprising given examples of organizational change occurring following a change in ruling party, which include the 1997 creation of DFID and 2013 merger of AusAID with DFAT. This finding suggests that recent experiences and observed linkages between organizational change and ideological preferences are not representative of change cases over time.

While this finding is perhaps unexpected, it should be noted that this variable is necessarily only able to capture the relationship between changes to political ideology of the executive and organizational change. It cannot account for individual and bureaucratic preferences, which likely contribute to organizational changes. These types 
of political preferences and influences will be explored in greater detail throughout the case studies presented in Chapters 6 and 7.

\subsection{Conclusion}

This chapter presented the first systematic attempt to understand the drivers of reorganization in aid agencies. Following a brief review of the literature on organizational change, this chapter developed and tested a rare-events logit model to examine the influence of key factors on aid agency reorganization. The model found that organizational change is most closely linked to changes in the predicted likelihood of adopting the actual structure used and changes to ODA budget size. In terms of budget size, this finding aligns with contingency theories presented in Chapter 2, which suggest that changes in organizational size will likely require changes to organizational structure in order to maintain efficiency. In conjunction with findings from Chapter 4, which finds budget size to be a key determinant of structural choice, the size of aid programs appears to be a key factor in understanding structural choice and change.

Moreover, the finding that lower predicted likelihood of adopting the actual model chosen is associated with organizational change suggests that changes underlying organizational choice contribute to structural change. An important question going forward is which is theses factors matters the most and in what contexts? The case studies presented in Chapter 7 will aim to provide further insight into the individual variables that comprise the structural predictor values and how they contribute to organizational change. 
While the benefit of the quantitative analysis is its ability to examine factors that contribute to aid agency change across the full sample of OECD-DAC donors, such techniques are unable to provide a complete explanation for the nuances of organizational choices and require the use of qualitative research to supplement and confirm these findings. In order to further explore unanswered questions concerning the organizational determinants of aid agencies, and the impetus for change, the next two chapters present six case studies designed to gain a deeper understanding of the factors that influence structural choice and change. 
CHAPTER 6

THE DETERMINANTS OF AID AGENCY STRUCTURE IN IRELAND,

ICELAND AND THE NETHERLANDS 
Building on the findings from Chapter 4, this chapter uses case studies of the Icelandic, Irish and Dutch aid programs to further explore the determinants of aid agency structure. Recall that Chapter 4 identified a number of key factors that contribute to the adoption of specific aid management structure including the purpose of aid programs, structural factors, and in two cases (Models 1 and 2), political ideology. While the model presented in Chapter 4 identified which factors contribute to structural choice, this chapter uses cases to both confirm findings from the quantitative model and explore how and why these variables affect the choice of aid management structure.

The use of qualitative analysis following quantitative modeling is typical for sequential explanatory mixed-method studies, where qualitative analysis is used to validate and provider deeper insight into the phenomena in question (Ivankova, Cresswell and Stick's, 2006). This method is often used in cases where one method (quantitative or qualitative) is insufficient to capture the trends and details of a particular situation (Ivankova et al., 2006). In such cases, the use of quantitative and qualitative research in sequence is particularly adept at helping to "explain, or elaborate on, the quantitative results obtained in the first phase" (Ivankova et al., 2006 p. 5). Ivankova et al (2006) contend that while "quantitative data and their subsequent analysis provide a general understanding of the research problem, the qualitative data and their analysis refine and explain those statistical results by exploring participants' views in more depth" (p. 5). In this sense, the use of qualitative analysis to build on, confirm, and further explore findings from Chapter 4 appears appropriate for this study, where in-depth case analysis will allow findings from the previous chapters to be verified. 
To do so, this chapter is divided into six sections as follows. The first section describes the methodology used to select case studies. The second section provides a brief discussion of the structured-focused comparison method used throughout this chapter and the next. Following this discussion, the next three sections conduct structured-focused case studies of the determinants of aid agency structure in Ireland, Iceland and Netherlands, respectively. A final section discusses findings across the cases and highlights key conclusions.

\subsection{Case Selection and Data}

Chapter 4 identified the main determinants of aid agency structure across all OECD-DAC donors and organizational models. Following the main estimation presented in Chapter 4 (Estimation 1), the "predict" post-estimation command in STATA was used to extract the predicted likelihood (or probabilities) that donors would adopt each of the five organizational choices. In essence, the probabilities do two things.

First, they show the likelihood that donors will select the model actually chosen and the relative strength of the prediction compared to other models. Together, the sum of the probabilities for the five organizational models in each country in each year is equal to 1 . As a result, a high probability on any model means that the remaining models will necessarily be poorly predicted. The predictions also show the presence of alternative choices when the predicted likelihood of selecting between two countries are comparable. For instance, in Finland in 1993, the model estimates a 45.2\% likelihood of adopting Model 2 (actual model used) and a 43.5\% likelihood of using Model 1, suggesting that Finland has a similar likelihood of adopting either Model 1 or 2. 
Second, the predictions show cases of "mismatch", where the Model actually used by donors differs from the organizational structure that donors are predicted most likely to select. Cases of mismatch are particularly interesting as they show instances where the organizational model chosen may not be the best "fit" for donors based on the predictor variables used in Estimation 1. Alternatively, cases where donors consistently use the model predicted implies that donor factors are well aligned with those that contribute to selecting a particular model. In both cases, the question becomes one of identifying and understanding the factors that contribute to a "match" between model and internal conditions (in the case of strongly predicted outcomes), or that lead to the selection of one model over another in mismatched cases.

In efforts to develop a deeper understanding of the factors that contribute to the choice of aid agency structure, the case studies will seek to maximize variation in the relative fit of the predicted and actual models chosen by donors. To do so, this study will use one case where predictions strongly fit the actual choices of donors, one case with high levels of mismatch, and one case displaying the average fit. Selecting cases in this manner first requires measuring the level of mismatch for each donor.

To do so, the probabilities of each donor in each year included in the estimation were searched for cases when the model donors actually selected was different from the model predicted most likely to be selected based on the estimation of structural determinants. The number of years in which a donor actually used a model that did not match the most strongly predicted was taken as a proportion of the total number of observations for each donor to measure the level of mismatch. This was done to account 
for differences in the number of observations for each donor due to differences in OECDDAC membership and data availability.

The levels of mismatch, per donor, are presented in Figure 5 below. Higher values indicated more instances of mismatch and lower values indicate fewer. It should be noted that these results are based on unbalanced data, where new OECD-DAC donors including Czech Republic, Korea, Iceland, Poland, Slovenia and Slovakia are only represented by 2-3 years of observations in each case. As a result, the finding that these donors tend to show either full match or mismatch is perhaps unsurprising. To account for this issue, case selection is not based solely on proportional match, but also on the strength of the predictions. This is discussed in greater detail below.

Figure 5: 'Mismatch' between actual and predicted organizational models as $\%$ of observations per donor

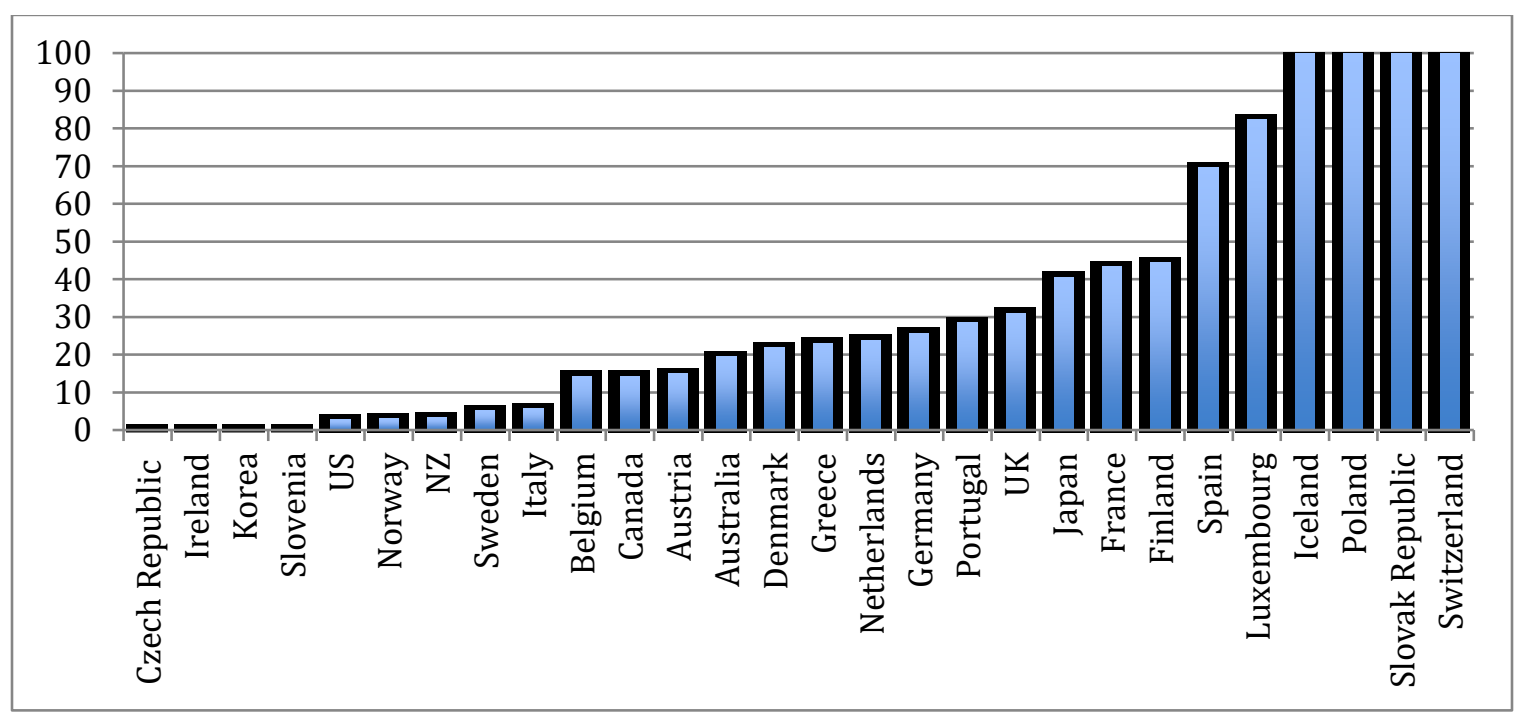

\subsubsection{Extreme "match" - Ireland}

The results show that the actual organizational models chosen consistently matches the predicted outcome in four cases - Czech Republic, Ireland, Korea and Slovenia. To distinguish between these cases, I begin by examining the average predicted 
likelihood of selecting the actual model chosen over the sample period for each of the four cases of perfect match. This shows the average strength of the prediction; in theory, countries with a higher average predicted likelihood show a higher probability of adopting the actual model used. Of these countries, Ireland by far has a higher average predicted likelihood of selecting the actual model chosen at $93.4 \%$ since joining the OECD-DAC in 1985. This means that while Ireland was predicted to adopt the model it used in each year, the prediction was, on average, over $90 \%$ likelihood in each year. This result far surpassed Korea, Slovenia and the Czech Republic, which scored 77.4\%, 86.4\% and $54.4 \%$ respectively. Of these four cases, Ireland not only shows the most extreme and persistence match, but also has the most observations, suggesting that the finding of exact match is less likely to be due to fewer observations, which may be the case for newer donors.

That said, Ireland has fewer observations than other donors that also show high degree of "match" to structural predictors. Indeed, a further 5 countries (US, Norway, New Zealand, Sweden and Italy) show very low proportions of mismatch of less than $6 \%$ in each case, with predictions showing that donors adopt the models predicted in all but one or two instances. To ensure that Ireland is the most extreme example of match throughout the sample, I compare Ireland's results to those of these five donors. Results are compared in two ways.

First, I compare the average strength of match results for each donor to the Irish case. Ireland's 93.4\% remains the strongest degree of "match". Results for the other donors are as follows: US (79.7\%), Norway (80.6\%), New Zealand (86\%), Sweden $(62.6 \%)$ and Italy $(76.5 \%)$. 
Second, given some discrepancies in the number of observations across this group of donors, with Ireland showing the fewest observations (29) and Sweden reporting the most (39), it is possible that averaging the predicted likelihood will dilute the strength of results for countries with more observations. To account for this, I also look at the frequency of extremely high likelihood of selecting the actual model chosen. Examining the frequency should control for differences in the number of observations as donors with more data have more potential opportunities for achieving extreme values. For each donor, I examine the number of instances where donors are predicted to adopt the actual model chosen with 90\% likelihood. Results are reported in the table below.

Table 6: Frequency of Extreme Match Results 56

\begin{tabular}{|l|c|c|}
\hline Donor & Number of observations $>\mathbf{9 0 \%}$ match & Number of observations $>\mathbf{8 5 \%}$ match \\
\hline Ireland & 24 & 25 \\
\hline Italy & 4 & 10 \\
\hline New Zealand & 16 & 16 \\
\hline Norway & 9 & 11 \\
\hline Sweden & 1 & 2 \\
\hline US & 12 & 19 \\
\hline
\end{tabular}

Table 6 clearly shows that no matter how the data is examined, the Irish case shows the most extreme example of match over time, even when compared to donors with longer time horizons. As a result, the Irish case is selected.

\footnotetext{
${ }^{56}$ These results hold even if the cutoff for extreme match is reduced to $80 \%$.
} 


\subsubsection{Extreme "mismatch" - Iceland}

Similarly, four countries (Iceland, Poland, Slovak Republic and Switzerland) show consistent differences between the predicted and actual models chosen. Again, most of these donors (except Switzerland) are relatively new OECD-DAC members, suggesting that results are likely driven by fewer observations. ${ }^{57}$

To select between these cases, the average predicted probability of donors selecting the actual model used is taken to highlight the most extreme cases of mismatch. Of the four, Iceland is the most "out of fit", with a predicted likelihood of selecting the model actually used of 7.3\%. The next lowest predicted likelihood was Slovak Republic at $25.9 \%$, Switzerland at $26.4 \%$ and Poland with $37.9 \%$. As a result, Iceland is shown as the least likely to adopt the model actually used.

Again, the issue here is that as a new member of the OECD-DAC, basing case selection on few observations may skew results in Iceland's favour. To account for this issue, I also examine the prevalence of extreme values in next five most mismatched donors (Luxembourg, Spain, Finland, France and Japan). While three of these donors have more "match" instances than "mismatch", they are included in this to ensure that long-term OECD-DAC donors are represented. All other donors with high levels of mismatch joined the OECD at later dates (see Appendix 2 for full dates of OECD-DAC membership).

\footnotetext{
${ }^{57}$ Results for the Swiss case should also be interpreted with caution. Data for the Swiss case is more limited than other donors. Despite being an OECD-DAC member since the 1960s, Switzerland's late membership to the UN, which it achieved in 2002, limits observations for the strategic purpose variable and reduces the number of observations included for this case. As a result, while the Swiss case shows clear mismatch, it is impossible to identify the degree to which such mismatch is present across the entire sample period.
} 
I begin by comparing the average level of mismatch to the Icelandic case. Iceland maintains the lowest average likelihood of selecting the actual model chosen; results for the other donors are as follows: Luxembourg (28.6\%), Spain (33.1\%), Finland (27.4\%), France $(19.6 \%)$ and Japan $(25.5 \%)$. As in the prior section, these averages are likely to dilute results and obscure individual instances of extreme mismatch. To account for this, I examine the frequency of extreme mismatch, where donors are predicted to use a model other than the actual model chosen by more than $90 \%$.

Table 7: Frequency of Extreme Mismatch Results

\begin{tabular}{|l|c|c|}
\hline Donor & Number of observations $\mathbf{> 9 0 \%}$ mismatch & Number of observations $\mathbf{> 8 5} \%$ mismatch \\
\hline Iceland & 0 & 2 \\
\hline Luxembourg & 0 & 0 \\
\hline Spain & 0 & 0 \\
\hline Finland & 0 & 0 \\
\hline France & 0 & 1 \\
\hline Japan & 0 & 2 \\
\hline
\end{tabular}

The results of Table 7 show that instances of extreme mismatch are rare even across donors with more observations. Given the absence of a clear choice, I select the Icelandic case for inclusion in this study. This is done for a few reasons. First, the results of the structural estimation presented in Chapter 4 point to clear differences between large and small donors in terms of structural choice, as evidenced by the finding that small donors are more likely to adopt Model 2 structures. Based on this finding, analyzing structural choice in the context of a small donor promises to highlight the different constraints and factors that make small donors more likely to adopt different models than larger donors. Indeed, understanding the issues faced by small donors 
regarding organizational structure could provide insight of value for new OECD-DAC donors or countries seeking to join the DAC in the future.

Secondly, while the Icelandic case presents few observations, four out of the six cases included in this study joined the OECD-DAC as founding members in 1962 (Netherlands, Japan, Germany) or shortly thereafter (Australia joined in 1966). ${ }^{58}$ As a result, it can be argued that the majority of cases included account for the full period of aid programs, further justifying the inclusion of a new OECD-DAC donor.

\section{$\underline{6.1 .3 \text { Average "match" - Netherlands }}$}

Having selected cases from both extremes of the mismatch range, the third case will be selected to illustrate the typical case. To select the typical case, I calculate the average degree of mismatch for the entire sample by taking the total frequency of mismatch cases as a proportion of total observations. Across all 728 observations included in this study, "mismatch" between predicted and actual cases selected occurs in 174 instances, or in $23.9 \%$ of cases. The closest donor to this value is the Netherlands, with $23.8 \%$. As a result, the Netherlands is selected as the third case.

\subsection{Data and Methodology}

The three cases selected will be examined using a structured, focused comparison research design to analyze the main determinants of aid agency structure over time. Structured, focused comparisons allow for the systematic analysis of multiple cases to explore data aligned with key hypotheses. The main advantage of this method is that its

\footnotetext{
${ }^{58}$ The method used to select the Australian, Japanese and German case studies selected to understand the determinants of aid agency change are detailed in Chapter 7. Taken together, the six cases presented in Chapters 6 and 7 comprise a representative sample of OECD-DAC donors, accounting for differences in size, years of OECD-DAC membership, and the organizational Model adopted; all five organizational models are represented across the sample of selected countries.
} 
"structured" nature ensures comparability in the data collected and analysis conducted across cases by utilizing a precise methodology for assessing the relative importance of key variables as determinants of organizational structure in each case (George and Bennett, 2005). Doing so allows findings from individual contexts to be meaningfully compared across cases.

As the second part of a mixed-method explanatory sequential design, the aim of these cases is to confirm and further probe results from the quantitative model. As a result, it is important to ensure that the cases presented throughout this chapter focus specifically on examining the influence of variables identified in prior chapters. To do so, each case will focus specifically on examining the six key variables that underlie the hypotheses presented in Chapter 2 and which were tested using quantitative analysis in Chapter 4. Specifically, each case study will be composed of four main parts:

1. History of aid management - Each case begins with a brief history of the organizational development of the aid program. This section aims to outline main factors in the decision to adopt specific structures, or in the absence of structural change, key points in time where other structures were considered. This section should not be considered a comprehensive history of an aid program, but rather a "focused" overview of key trends and major events in relation to organizational choices. ${ }^{59}$

2. Analysis of Key Variables - A second section explores the degree to which the six main variables used in this study contributed to the choice to adopt a specific structural model. These variables include: efficiency, legitimacy, politics, purpose, NPM and path dependence. Each variable corresponds to a key hypothesis proposed in Chapter 2,

\footnotetext{
${ }^{59}$ History sections were informed by a combination of multiple primary and secondary resources. While it is acknowledged that all sources have particular bias, these sections engaged with multiple sources to understand historical contexts and events, and limit bias in the historical analysis as much as possible.
} 
which were tested in the estimations presented in Chapters 4 and 5. Part of the value of qualitative analysis is the ability to explore facets of these variables that are not easily captured through quantitative indicators. As a result, the case studies will move beyond the indicators used in Chapters 4 and 5 to take a broader understand of the variables in alignment with theory presented in Chapter 2 .

3. Discussion - The third section offers a summary of main findings and explores the degree to which these findings match results from the statistical model (Estimation 1). Specifically, it will look for links between the factors that contribute to the choice of a specific model, how these factors influenced structural choice, and to what degree key findings match results of the quantitative model.

4. Conclusions - Each case closes with a short summary of main findings from the case.

\subsubsection{Data Collection and Interviews}

The case studies are largely based on desk research of primary and secondary materials. Most of the information comes from official documents released by donors and the OECD-DAC Peer Reviews from 1962 to the present. Other reports, books and articles were used to provide greater context into domestic conditions and factors that likely affected the choice of structure.

In addition, 2-3 interviews were conducted per case with key individuals with knowledge of their country's development program. Interviewees were typically current or former senior government employees with knowledge of development activities. Most occupied (or have occupied) at least a "Director" level post within respective aid programs. The highest ranked interview participants were Director-General level; in both cases, this made them the Head of their respective bilateral aid agencies. One interview 
was conducted with an individual currently posted in the field, while several others also had experience working on assignment in developing countries.

As much as possible, interviewees were targeted to ensure representation from all major organizations within a country's aid management system. For instance, in Iceland, interviewees represented both the Foreign Ministry and the former Icelandic International Development Agency (ICEIDA). Given the admittedly limited sample of interviewees per case, targeting participants from different organizations was done in efforts to limit potential bias by ensuring multiple positions and organizational viewpoints were accounted for throughout the analysis.

Interviewees were generally targeted due to their position within aid management structures. In two cases, academics with expertise in the subject of aid management in their respective country were also interviewed. All interviewees were approached by email using publicly available email addresses. Interviewees participated in one 30-60 minute semi-structured interview conducted by phone or by Skype; interviews took place between March and August, 2017.

\subsubsection{Limitations}

There are several important limitations to the scope and content included in the case studies presented in this chapter and the following. First, it is acknowledged that often times, official government statements and reasons for pursuing specific action differ from the actual reasons or motivations behind a particular choice. While the case studies that follow often relied on official documents and sources for insight into the rationale for adopting specific organizational models or undertaking organizational change, conversations with interviewees and secondary literature were also used to provide 
additional context and insight into official policies and statements. By seeking to understand the context in which official statements and decisions were presented, this study sought to uncover the actual as well as official reasons for organizational choices.

Second, it is acknowledged that there is important ideational change within the development landscape across the study period. Perhaps the most pronounced change occurs in 2008, when almost a decade of increasing development spending and international focus on aid effectiveness saw an abrupt shift following the global financial crisis. The post-2008 period saw declining aid volumes, particularly to the poorest countries (OECD, 2015a). In addition, the domestic impact of the crises in donor countries has been linked to rising conservatism and appetite to align aid spending more closely to other donor foreign policies including trade and political strategy (Troilo, 2015). Both Canada and Australia, for instance, saw "conservatives execute plans to bridge fiscal austerity, national security, diplomacy and trade with foreign aid through organizational amalgamation" (Troilo, 2015). Moreover in Ireland, the post-2008 period saw greater alignment between the development and trade portfolios (Interview 10, 2017) ${ }^{60}$ While attempts have been made to acknowledge and account for such ideational shifts by highlighting and acknowledging contextual factors connected to organizational choices and change, it is acknowledged that all such shifts in development thinking over time cannot be captured in this limited study.

Third, there are, admittedly, some discrepancies in the amount of detail covered for each case. In part, differences were due to factors within the cases themselves - for instance, the Australian case showed four instances of organizational change, while most other cases had one major organizational shift. Additionally, differences in the

\footnotetext{
${ }^{60}$ Notably through the creation of the Africa Strategy. More details are provided in the next section.
} 
availability of information in English contributed to discrepancies between cases. While attempts were made to ensure an equal treatment of cases, it is acknowledged that some differences persist.

Having reviewed the main methodological structure and data used throughout the case studies presented in this and the following chapter, the next three sections provide analysis of the Irish, Icelandic and Dutch cases.

\subsection{Ireland}

The Irish case presents an example of a donor that consistently adopts the organizational model that it is predicted to select. Since first creating an aid program in 1974, responsibility for Ireland's development program has been located in the Development Cooperation Division (DCD) within the Department of Foreign Affairs and Trade (DFA, formerly Department of Foreign Affairs). This means that Ireland has used a Model 2 structure throughout the history of its aid program. ${ }^{61}$ This case will seek to understand both how and why the Model 2 structure "fits" in the Irish case.

\subsubsection{History of Irish Aid}

In 1973, Garret FitzGerald, Ireland's then-Minister of Foreign Affairs, announced that Ireland would launch an official development program (Murphy, 2012). The announcement followed rising support for development activities throughout the 1960s and 1970s both within Ireland and internationally (Murphy, 2012). In Ireland, the first whispers of a government-run aid program emerged in response to the UN FAO's call to

\footnotetext{
${ }^{61}$ Irish Aid will be used here interchangeably with "DCD" to discuss the unit responsible for the management of Ireland's aid program. However, interviewees from Ireland stressed that Irish Aid is the "brand" of Ireland's development program, which is most recognizable by people outside of Ireland. Within Ireland, the unit responsible for development is known as DCD.
} 
establish a national "Freedom from Hunger" campaign in the 1960s. While the Irish Red Cross was initially charged with overseeing the campaign, responsibility was soon transferred to a new organization called "Gorta", which fell under the responsibility of the Department of Agriculture (Murphy, 2012; O'Sullivan, 2007). Over the next few years, pressure for the Government of Ireland to do more to support development continued to grow as "People recognized that it was not enough for missionaries and charitable individuals to help: a more sustained approach was needed and the Government should play its part” (Murphy, 2012 p. 17).

In 1974, the year after FitzGerald's announcement, a "new section within the Economic Division of the Department of Foreign Affairs was established to administer the new [development] program" (O'Neill, 1982, p. 5). The unit was initially considered an interim measure as Garret FitzGerald considered the question of how to organize Ireland's aid program. At the time, it was recognized that the coherent expansion of Ireland's aid program would require the Government "to design appropriate structures for its execution" (Sutton, 1985 p. 7). To this end, FitzGerald sought to explore his options.

Debate about the structure of Ireland's development cooperation continued until 1978 (Murphy, 2012 p. 42). On one hand, officials from within the DFA, who were granted early control over the aid program, believed that they should be charged with managing development over the long-term (Murphy, 2012). Murphy notes that "there was an element of territoriality" in arguments from DFA officials, who sought to retain control over aid. Moreover, officials stressed "concerns about accountability for the new funds which were coming on stream" and argued that public money would be safer if the aid program was under government control (Murphy, 2012 p. 42-43). There was also an 
issue of policy alignment, with officials arguing that development was a key part of Ireland's foreign policy and should be retained within the DFA on that basis (Murphy, 2012 p. 42).

On the other hand, leadership within the DFA, including FitzGerald, were said to prefer an independent agency structure (Murphy, 2012). Indeed, Garret FitzGerald "was not persuaded by the officials' argument that the programme should be run by Foreign Affairs and wished to have all options examined including that of an agency or semi-state body" (Murphy, 2012 p. 30). To this end, Minister FitzGerald reviewed the structures used by other donors including Norway, Denmark, Sweden, New Zealand, Australia, Canada, the US, UK and Japan and worked to produce a White Paper answering the structural question (Murphy, 2012). ${ }^{62}$ However, FitzGerald ultimately ran out of time to address the structural issue, failing to produce the White Paper prior to a change in government in 1977.

With the new government, Michael O'Kennedy took the post of Minister of Foreign Affairs. The new minister "did not favour the agency model" and tasked a Working Group with exploring the structural question (Murphy, 2012). The Working Group report was finished in August 1978 and argued in favour of keeping development within the DFA. The report stated that "there were strong and valid reasons for retaining the administration and coordination of aid within the Department of Foreign Affairs" (Murphy, 2012 p. 43, citing Working Group Report), suggesting that the DFA's "primary, central and coordinating role now seems to be generally accepted through the argument about a semi-state agency will inevitably surface from time to time" (Murphy,

\footnotetext{
${ }^{62}$ A recent list of Garret FitzGerald's personal papers during his time as Minister of Foreign Affairs transferred to the University College Dublin's Archives notes two documents reviewing the administrative structures of development programs of 14 countries (see UDC, 2017 p. 175).
} 
2012 p. 43, citing Working Group Report). For the moment, the debate was settled.

The structural question re-emerged in a 1991 report by Ireland's Advisory Council on Development Cooperation (ACDC). The ACDC had been set up decades earlier following recommendations from the Working Group examining agency structure. The ACDC was seen as a 'quid pro quo' for the merged structure and worked to inform the government (via the Minister of Foreign Affairs) on a range of issues pertaining to development (Murphy, 2012). The report "claimed, in effect, that as far as development was concerned, the Department of Foreign Affairs was not up to the job" (Murphy, 2012 p 74) ${ }^{63}$ According to the OECD (1990), a key issue raised by the ACDC pertained to the "unwieldy" project approval process, which required an Inter-departmental Committee on Development Cooperation to approve all development projects. For the ACDC, this process "did not provide an adequate basis for carrying out other stages of the project cycle", where "Lack of systematic presentation of data in [project] appraisals" meant that aspects of programs were overlooked (OECD, 1990 p. 12-14).

While no action was taken to reform Irish Aid at the time, debate over the structural question arose again in 1999 when an internal review of Irish Aid and the OECD-DAC's Peer Review of Ireland noted that while the current structure was appropriate in the short-term, "In the longer term, establishing an independent implementation agency is an appealing option from an operational point of view" (O’Neill, 2000 p. 281). In part, calls for structural change stemmed from rapid growth to Ireland's aid program which increased from $0.16 \%$ of GNI in 1992 to $0.4 \%$ by 2000 (OECD, 2003). In this context, the 1999 OECD Review of Ireland's development

\footnotetext{
${ }^{63}$ A major aspect of ACDC's criticism was the absence of a clear policy document for Irish Aid's activities.
} 
assistance presented four long-term structural options for reforming Ireland's aid program to meet the needs of a growing program:

1. Maintaining the "improved status quo" (Model 2) by formalizing coordination channels across actors engaged in Ireland's development efforts, and addressing challenges in DCD's staffing structure. At the time, only diplomatic staff were able to work in both Dublin and in the field, making Irish Aid vulnerable to a high turn-over of professional development staff. Due to this rule, development programme officers working in recipient countries were employed on two-year contracts to a maximum of five years in any country. Once their term ended, they could not be re-deployed to Dublin. The OECD recommended that such issues would need to be addressed if Ireland chose to retain the same structure going forward (OECD, 1999c).

2. Establishing an independent implementing agency (Model 3) was recommended by the OECD as a way to improve operations. The OECD suggested that this option would "allow greater flexibility in staffing matters while offering greater employment stability and improved career prospects" (OECD, 1999c p. 44).

\section{Creating an integrated, geographically-based Department of Foreign Affairs (Model}

1) was proposed; this option would involve de-compartmentalizing development in the DFA "by creating integrated regional/country desks to take responsibility for all aspects of Ireland's bilateral relations" (OECD, 1999b p. 44). However, the OECD notes that this "would not appear, however, to be a preferable option in view of the size of Ireland's Department of Foreign Affairs and the dilution of aid experience this option would entail" (OECD, 1999c p. 44).

4. Create an administratively-autonomous aid agency or department (Model 4) which 
could integrate key volunteer organizations such as the Agency for Personal Service Overseas (APSO) into a single ministry (OECD, 1999b p. 44). That said, the OECD suggested that it was "doubtful" whether Irish Aid possessed "the critical mass which would make this option a viable alternative" (OECD, 1999c p. 44).

The Irish Government essentially adopted option 1 after a 2002 report by the Ireland Aid Review Committee (IARC) concluded that "a dedicated directorate of the Department of Foreign Affairs offers the best potential for management of the expanding programme," despite challenges outlined by the OECD (DFA, 2002 p. 116 cited in O’Neill, 2005 p. 332). However, Ireland's aid management system remained an ongoing source of debate. Indeed, the 2003 OECD Peer Review urged Ireland to continue reviewing its administrative structure to ensure it possessed the operational flexibility needed to manage its aid program (O'Neill, 2005; OECD, 2003).

The structural question emerged again in 2008 when the DFA commissioned a third-party review of the Management of Irish Aid. The review was conducted on the recommendation of the 2006 White Paper, which suggested reviewing the management and capacity requirements of Irish Aid to "advise on the optimal development of Ireland's aid program to ensure total quality assurance, as it moves towards reaching the target of $0.7 \%$ " (Irish Aid, 2006 p. 110). The Review was framed in the context of a major organizational change undertaken at the time which relocated DCD staff from DFA Headquarters in Dublin, to the town of Limerick. The move was part of a governmentwide decentralization, which relocated 10,300 public posts and to draw attention and resources to areas outside of Dublin (OECD, 2009b; Interview 6, 2017). Most of DCD was relocated to Limerick while other branches of DFA remained in Dublin due to 
political connections particularly with the embassies of other countries (Interview 6, 2017).

In this context, the Review explored three organizational options for managing Irish Aid: integrating development fully across the department (Model 1), maintaining the status quo (Model 2), adopting an "agency" model (Model 4). ${ }^{64}$ Ultimately, the Review argued that DFA should consider integrating Irish Aid further into the activities of the department (Model 1), suggesting that the Department could be renamed to the Department of Foreign Affairs and International Development to solidify the central role of development as part of Ireland's foreign policy (FGS Consulting, 2008). In essence, the reviewers suggested that integrating development into DFA fit "with the overarching global integration, harmonization and coherence trends and considerations which offers the best prospect of adopting an integrated whole of Government approach to an effective aid programme" (FGS Consulting, 2008 p. 29). This option was also deemed best for easing staffing challenges, particularly in light of the move to Limerick, by creating the opportunity to establish two headquarters for DFA functions (FGS Consulting, 2008).

Alternatively, the option of maintaining the status quo (Model 2) was considered, but not recommended on the basis that "it exposed to the danger of fudging the coherence agenda in programme delivery" and alignment with other Divisions and partners (FGS Consulting, 2008). Importantly, the Review warned that this option "would be the most difficult in terms of successfully implementing the Government decision on decentralization" to Limerick and essentially regarded the aid program as a "discrete activity" with minimal relations to other departmental functions (FGS Consulting, 2008 p. 28). Alternatively, creating a separate aid agency (Model 4) was viewed as the

\footnotetext{
${ }^{64}$ Limerick is approximately a two-hour drive from Dublin (Interview 6, 2017).
} 
"cleanest" option in terms of matching structure to the decentralization of Ireland's aid program. However, this model was seen to be costliest and the "most at odds with the overarching global integration, harmonization and coherence trends" (FGS Consulting, 2008 p. 28).

While Ireland continued to adopt a Model 2 structure, it sought to deepen the integration of development with other department activities in alignment with recommendations for the Management Review. Notably, the DFA underwent an internal organizational change in 2011 when its mandate was enlarged to take responsibility for trade promotion and was re-named the Department of Foreign Affairs and Trade (DFAT). Integration of trade into the DFA also resulted in policy shifts to deepen coherence across the trade, political and development branches. This was the case in the 2011 Africa Strategy, which created a unified and overarching vision for Ireland's engagement with Africa. The Africa Strategy focused particularly on aligning development and trade, pointing to trade as a driver for long-term growth in Africa, but also seeking to "expand two-way trade and investment" (DFAT, 2011). In terms of organization, the joined-up approach proposed in the Africa Strategy is accompanied by a new "Africa Unit" within the DFA to bring together "the existing Africa Section from Political Division and Programme Desks from Development Cooperation Division, which will also manage aspects related to foreign trade and investment promotion activities" (DFAT, 2011 p. 23).

While the creation of the Africa Unit and efforts to integrate development, trade and political concerns through whole-of-government polices marks a change in the structure and policy of DFAT which brings it closer to a Model 1 structure, such integration has not resulted in a shift in Ireland's organizational structure according to the 
OECD typology. Indeed, DCD remains responsible for Ireland's development cooperation, with the Africa Unit as the only integrated structure within DFAT. As a result, Ireland continues to use a Model 2 structure

\subsubsection{Determinants of Ireland's aid agency structure}

In the Irish case, there are two main questions that need to be examined. First, what factors determined the choice to adopt a Model 2 structure in the first instance. Second, given numerous reviews of Ireland's aid management, which opened opportunities for reorganization, the absence of organizational change raises the question of why Ireland has continued to use the same structure? The analysis that follows shows that efficiency, politics, purpose and path dependence are the main determinants of organizational choice in the Irish case, where the continued use of the Model 2 structure is rooted in a combination of these factors.

\section{Efficiency}

In the Irish case, there is evidence that efforts to strengthen efficiency influenced the choice of organizational structure over time. Perhaps most notably, this can be seen in responses to repeated calls to improve the efficiency of Ireland's aid program. For instance, in response to the 1999 OECD-DAC Peer Review, which called on Ireland to adapt its aid management via one of four potential structural options, Ireland's Aid Review Committee, determined that Ireland should maintain a Model 2 structure with DCD as the main division responsible for development within the DFA, as this structure was believed to be most attuned to Ireland's needs at the time (OECD, 2003). Notably, the choice to adopt a Model 2 structure was somewhat at odds with OECD recommendations, which suggested that the staffing and coordination challenges facing 
Ireland would render the creation of an implementing agency (Model 3) the most “operationally" viable solution. While Ireland's Aid Review Committee acknowledged the need for some changes to "staffing levels and managerial flexibility" (OECD, $2003 \mathrm{p}$. 77), its decision was based on the understanding that the Model 2 structure remained the best option. Indeed, one interviewee with knowledge of discussions surrounding the proposed organizational change noted that the department saw "no gains from separating implementation" into a new agency, arguing that "what you gain from having a department doing implementation, you lose in managing relations" (Interview 6, 2017). In this sense, it appears that the decision to retain a Model 2 structure despite the recommendation and opportunity for reform was based on the active determination that the Model 2 structure remained more viable than other organizational options.

The same is true in the case of the 2008 Aid Management Review. In this case, the Review recommended reorganizing Ireland's aid management structure to counter potential inefficiencies linked to the decentralization of DCD to Limerick. Specifically, further integrating development into the DFA (Model 1) was recommended to overcome the coordination and staffing challenges of a decentralized department. While the government ultimately adopted the Review's main recommendation to deepen integration, it did not do so in a way that altered the fundamental organizational model used. Rather, efforts to improve efficiency were taken through integrating Ireland's aid program into the DCD to improve coordination within the Model 2 structure, where development was formally integrated with political and trade objectives in the new Africa Unit. ${ }^{65}$

\footnotetext{
${ }^{65}$ While the integration of development and traditional foreign policies within a geographic unit responsible for managing bilateral relations across policy areas is definitive of the Model 1 structure,
} 
Overall, it seems that efforts to improve efficiency through adaptations within the Model 2 structure were well placed in the Irish case. When asked about Ireland's choice of structure, none of the interviewees expressed concern about administrative efficiency nor believed that Ireland's aid program would be more efficient under a different model (Interview 10, 2017; Interview 5, 2017; Interview 6, 2017). Indeed, the shared sentiment across interviewee was that, at the current point in time, the Model 2 structure "works" for Ireland.

\section{Legitimacy}

There is little evidence that Ireland's initial or continued choice to adopt a Model 2 structure was linked to efforts to strengthen Ireland's "legitimacy". In terms of the inception of Ireland's development program, while FitzGerald examined the models used by other donors, his efforts led him to prefer an implementing agency structure that was never selected. As a result, it cannot be argued that his research into other donors contributed to the choice of structure adopted.

While legitimacy may drive Ireland's broader development efforts, particularly its continued momentum and stated goal of reaching $0.7 \%$, there is little to suggest that such factors are also linked to structural choices. Particularly, there is no evidence that Ireland has sought to mimic the organizational model of other donors. Rather, calls for organizational change have been followed by internal or commissioned reviews of Ireland's development program and have been adjusted on the basis of these findings.

\section{Politics}

Politics played a role in determining the early structure of Ireland's aid

policies were only integrated in this way for the Africa Unit, and did not mark a systemic change across all geographic divisions. 
management system. In particular, political factors exerted considerable influence over the initial choice to adopt a Model 2 structure. The initial choice to adopt Model 2 was heavily influenced by the preferences of the then-Minister of Foreign Affairs, Michael O'Kennedy, and the DFA bureaucracy. At the time, the Model 2 structure was strongly preferred by the DFA bureaucracy, which had managed the aid program since its launch in 1974. While the previous Minister for Foreign Affairs, Garret FitzGerald, sought to explore a range of organizational options, preferring an independent agency structure, DFA voices consistently maintained that the Ministry should remain responsible for development, and actually impeded FitzGerald's exploration of alternative structural options (see Murphy, 2012; FitzGerald, 1991). Indeed, in his biography FitzGerald (1991) recalled that the ministry's unwillingness to support his exploration of organizational choice was "the first and only time the department failed to do the job I asked it to do" (p. 191).

In addition, the choice to adopt a Model 2 structure was a clear preference of Minister O'Kennedy and was explicitly considered by the Working Group created to explore the structural question as part of its analysis and recommendations. Explicitly, Murphy (2012) states that "Noting that the Minister had rejected the semi-state model, it [the Working Group] took the view that 'there were very strong and valid reasons for retaining the administration and coordination of aid within the Department of Foreign Affairs"' (Murphy, 2012 p. 43). In this sense, it seems that the choice to adopt the Model 2 structure was clearly linked to the preferences of the Minister.

While politics influenced the initial choice of structure, it appears to have had limited influence on questions of structural choice over time. Perhaps a unique feature of 
Ireland's development sphere is the degree to which it enjoys cross-party political support for development. Such support is buttressed by strong public support for aid and a culture that values aiding others as part of a deep-seated missionary tradition, staunch anti-colonial sentiments and a Christian worldview (O'Sullivan, 2013). ${ }^{66}$ Indeed, the Irish example was the only case in this study without references to politicking around development, with neither interviewees nor the literature suggesting that the decision to maintain a Model 2 structure was linked to clear political preferences.

\section{Purpose}

There is evidence to suggest that Ireland's organizational form has been influenced by the purpose of its aid program, particularly with regards to the recent integration of Irish Aid's activities into DFAT. Perhaps the earliest mentions of a link between purpose and structure in the Irish case dates to the 1970s, when FitzGerald worked to ensure that planned ODA expansion was matched by a structure capable of managing an enlarged program (Sutton, 1985). To ensure the alignment between policy and structure, FitzGerald sought to develop a policy paper for Ireland's program; however, the paper was never written. While there appeared to be some understanding that the purpose of Ireland's aid program should influence its structure at the time of FitzGerald's command, it is not clear that Minister O'Kennedy, who ultimately made the decision to adopt the Model 2 model, viewed the relationship between structure and purpose in the same way.

\footnotetext{
${ }^{66}$ Anecdotally, Ronan Murphy points to this sentiment in his 2012 book, noting that Ireland's failure to meet the $0.7 \%$ ODA target by 2007 , as was promised in 2000 by Bertie Ahern, resulted in a public reaction that Murphy described as "a sense of betrayal, accusations that the government had reneged on a solemn promise" (2012, p. 200).
} 
More recently, the integration of development into the DFA, particularly through the creation of the Africa Unit and Strategy, can be linked to substantive changes occurring at the time. Specifically, the 2011 Africa Strategy, which emphasized a “joined-up" approach to Ireland's engagement in Africa, marked the beginning of a more integrated approach to Ireland's development policy that stresses maintaining trade, development and political linkages with Africa (DFAT, 2011; Interview 5, 2017). Organizationally, this policy shift was accompanied by the creation of an "Africa Unit" which combined staff working on Africa-related programs from the political and development divisions within DFAT, and provided the unit with responsibility for "aspects related to foreign trade and investment promotion" (DFAT, 2011 p. 23). The simultaneous change in policy and new structural unit is perhaps the clearest evidence of the relationship between substantive and organizational choices in the Irish case. Indeed, interviewees also noted the linkage between Ireland's shifting policy orientation in the post-2008 period and deepening structural integration (Interview 5, 2017; Interview 10, 2017).

\section{NPM}

There is no real evidence to suggest that the principles of NPM affected the organizational management of Ireland's development program. Firstly, the absence of organizational change throughout the history of Ireland's aid program suggests that any pressure to reform in line with NPM policies did not result in structural change. Perhaps more substantially, Hardiman and MacCarthaigh (2011) argue that the NPM agenda has had little influence over the management and structure of Ireland's public sector. Indeed, Ireland's main administrative reform over this period, called the Strategic Management 
Initiative (SMI), was designed to support efficiencies, but was not influenced by the "new right thinking" which prompted a market-based and privatized approach to government functions (Hardiman and MacCarthaigh, 2011). In terms of aid, the SMI identified six priorities for Ireland's development program: 1. Contribute to the needs of poor countries by working with partners and supporting partner priorities; 2. Support sustainable, equitable and poverty-focused growth in LDCs; 3. Advance sustainable development efforts; 4. Ensure fast and effective humanitarian responses; 5. Ensure coherence in Ireland's relations with partners; 6. Promote Ireland's participation in multilateral institutions (OECD, 1999c). None of these priorities, found within the major public reform agenda of the period, appear to promote or support the NPM agenda.

\section{Path Dependence}

There is clear evidence that path dependence played a role in determining the organizational structure of Ireland's aid program. Firstly, path dependence appeared to play a role in the initial adoption of the Model 2 structure in Ireland. Recall that responsibility for development had been granted to the DFA from the beginning of Ireland's aid program, and that those within the bureaucracy who handled aid programs were fiercely opposed to the alternate organizational arrangements explored by FitzGerald. To the degree that this opposition influenced the choice to continue using a Model 2 structure, the choice can be seen as path dependent, where the initial decision to manage aid within the DFA created ownership over the program within the DFA and bred bureaucratic opposition to future changes.

Second, provisions within Ireland's constitution reinforced the Model 2 structure by limiting the viability of alternate options, specifically the creation of an independent 
department for development. Ireland's constitution prevents the government from having fewer than seven or more than fifteen Ministers (Government of Ireland, 1937). According to Interviewee 10 (2017), this legislation makes it difficult to justify the creation of a separate department to manage Ireland's aid program (Model 4), and appears to reinforce the housing of development within the DFA (see also OECD, 2009b). In essence, the issue of limited ministerial "slots" creates a significant institutional barrier for the development of a separate department for aid management.

Third, using North's (1990a) definition of institutional path dependence, which views incremental and bounded changes typically taken by institutions as path dependent, the incremental nature of changes to Ireland's aid management structure can reasonably be linked to path dependence. Indeed, in the Irish case, numerous opportunities for more systemic or episodic change were met with small tweaks and incremental adjustments within the same Model 2 management structure. As a result, the absence of deeper changes to Ireland's aid management structure suggests that in part, Ireland's persistent use of the Model 2 structure has been path dependent.

\subsubsection{Discussion}

Analysis of the Irish case shows that efficiency, politics, purpose, and path dependence determined Ireland's use of the Model 2 structure over time. In the first instance, Ireland's choice to adopt the Model 2 structure was driven by politics and path dependence, while the continued use of this structure over time was linked to efficiency, purpose and path dependence.

Perhaps the most surprising finding from the Irish case is that while political drivers (i.e. Michael O'Kennedy's preferences) were key to the selection of the Model 2 
structure in the first instance, they had little influence on the continued use of Model 2. Indeed, the literature on Ireland's aid management made no real mention of key political figures or preferences in response to periodic calls for organizational change based on inefficiencies. Similarly, interviewees described the political environment surrounding aid as one of bipartisan support for development, stressing that development actions were primarily linked to Ireland's moral imperative rather than motivated by political strategy or self-interest (Interview 5, 2017; Interview 10, 2017). In the absence of clear political preferences concerning aid management, periodic calls for organizational reform to Ireland's aid agency structure were matched with incremental changes to improve efficiency and align structure to purposive objectives.

Moreover, the finding that efficiency played a role in the choice to adopt and maintain Model 2 is significant and runs counter to findings from Chapter 4. Indeed, in the Irish case, all organizational choices appeared to be based on the recommendations of committees or consultants that reviewed Ireland's aid management system, which tended to find the Model 2 structure as the most viable structural option. While Chapter 4 showed limited statistical significance on the efficiency variables, findings from this case suggest that efficiency may play a larger role in determining structural forms than captured by the quantitative models.

In addition, the finding that the purpose of Ireland's aid program contributed to the choice of model and organizational changes undertaken in recent years is also an important result from this case. This finding supports the general conclusion from Chapter 4 that purpose contributes to structural choice and sheds light on the relationships between purpose and structure proposed in Chapter 2. Perhaps most 
notably, deepening institutional integration in the Irish case is linked to the integration of trade linkages into Ireland's development program, suggesting an increase in the prioritization of aid for commercial purposes. This finding supports hypotheses presented in Chapter 2, which consider donors pursuing commercial and/or strategic purposes in addition to the developmental purpose of aid programs to be more likely to adopt a Model 1 or 2 structures.

Perhaps a final point on the Irish case concerns how and why the Model 2 structure "fits"; recall that Ireland is used here to illustrate a country that consistently adopts the structure it is predicted to select. The reasons for fit with the Model 2 structure in the Irish case are three-fold. First, the Model 2 structure appears to match the needs of Ireland given the size of its aid program. Indeed, two interviewees made the connection between size and structure in the Irish case (Interview 5, 2017; Interview 10, 2017), suggesting that the relatively small size of Ireland's aid program makes housing aid within DFAT appropriate. Other organizational models, particularly the autonomous aid agency structure, was seen as more appropriate for larger donors; conversely, one interviewee suggested that the Model 2 structure may not be appropriate for larger donors (Interview 5, 2017). Indeed, the finding that smaller donors are more likely to adopt the Model 2 structure fits with results from Chapter 4.

Second, in light of Ireland's smaller budget, the Model 2 structure supports the close functioning and interaction of those working on policy and program design. As one interviewee put it, "the structure fits for a small bureaucracy as the lines of communication are relatively short" allowing for coherence across DCD's activities (Interview 5, 2017). The sentiment is that integration leads to more "joined-up thinking 
for development" and allows DCD staff to work together, and with other branches of the DFA to support aid programs. In essence, the degree to which Model 2 fits Ireland's bureaucratic context and supports coherence across actions suggests that the Model 2 structure appears administratively efficient in the Irish case.

Third, interviewees suggested that bipartisan support for development cooperation, backed by public support, reduced the main threat associated with Model 2, i.e. that development will become subsumed to other interests. Moreover, one interviewee noted that the more integrated structure adopted in recent years actually helped to protect the development budget both at the senior bureaucratic and political level by enhancing the importance of development relative to other policy priorities (Interview 5, 2017). The argument suggests by integrating trade, political and development through single programs for countries in Africa, development has become a more integral part of Ireland's foreign policy and reduced the likelihood of budget cuts.

\subsubsection{Conclusion}

Overall, Ireland's choice to adopt a Model 2 structure is driven by efficiency, purpose, politics and path dependence. Of these, the political and purposive variables appear to match the results of Chapter 4 most closely.

In the Irish case, the initial choice to adopt Model 2 was driven by political factors and path dependence. In terms of political factors, evidence shows that the initial adoption of the Model 2 structure was aligned with the preference of Michael O'Kennedy during his tenure as Minister of Foreign Affairs. His predecessor, Garret FitzGerald preferred the Model 3 structure but was unable to settle the "structural question" prior to leaving office. In addition, path dependence appeared to contribute to the early adoption 
of the Model 2 structure, stemming from the DFA's pre-existing control over development resources.

However, the continued use of Model 2 in the Irish case can be linked to efficiency, purpose and path dependence. Over the last 15 years, the Model 2 structure has consistently been deemed as Ireland's best structural option by working groups and consultants, with the efficiency of the current model playing a key role in its continued use. Indeed, Ireland is shown to "fit" with the Model 2 structure due to its size, ability of the structure to foster cooperation, and public and political support for development. The absence of change in the Irish case also highlights path dependence as a key factor, while recent changes within the Model 2 structure appear to align with substantive changes linked to efforts to "join-up" development and trade through the Africa Strategy.

Going forward, it will be interesting to note whether Ireland continues down the path of further integration of policy, trade and development to the point where a Model 1 structure is adopted.

\subsection{Iceland}

Iceland joined the OECD-DAC on March 2, 2013. Despite being a relatively new DAC member, Iceland's engagement in international development dates back to the 1970s. From 1981-2015, responsibility for Iceland's development program has been split between the Ministry of Foreign Affairs (MFA), which was responsible for directing Iceland's development policy, and the Icelandic International Development Agency (ICEIDA), an autonomous agency responsible for implementing Iceland's bilateral development program. This gave Iceland a Model 3 structure. However, in 2016 ICEIDA's functions, responsibilities and staff were folded into the MFA. As a result, 
Iceland's aid program is now managed by the Directorate for International Development Cooperation within the MFA, giving it a Model 2 organizational form. As an example of mismatch between contextual factors and the choice of structure used, this case seeks to understand both how and why the Model 3 structure was out of "fit" in the Icelandic case. It is also worth noting that upon reorganizing, Iceland's aid agency structure matched the structure it was predicted to select in the years prior. For the years where data is available, the predicted likelihood of Iceland adopting a Model 2 structure was $89 \%$.

\subsubsection{History of Iceland's Aid Management System}

Iceland's aid program formally began in 1971 when the Icelandic Althingi (Parliament) passed legislation (Act on Iceland's Assistance to Developing Countries, No 20/1971) to establish its first development 'institution' - a five-person Board responsible for recommending, organizing and monitoring projects to benefit developing countries, either exclusively or in cooperation with others (Dagbjartsson, 2001) ${ }^{67}$ Iceland's interest in development began in the mid-1960s when the Icelandic public exerted pressure on the government to engage in international assistance. Notably, the 1965 "Herferð gegn hungry" campaign, an Icelandic version of the Food and Agriculture Organization's (FAO) "Freedom from Hunger" initiative (Loftsdóttir, 2014), popularized the concept of development in Iceland and mobilized support for development through activities targeted towards schools and cultural institutions (Loftsdóttir, 2014). The success of the campaign drew significant attention and fuelled efforts to establish Iceland's first development policy, which was framed by parliamentarians as a moral imperative linked to its (then) recent history of colonization. Iceland itself had "almost [been] eradicated by poverty and suppression” (Olgeirsson, 1964 quoted in Loftsdóttir and Björnsdóttir, 2010),

\footnotetext{
${ }^{67}$ The Board met once a week to discuss development issues - every Tuesday from $1 \mathrm{pm}-5 \mathrm{pm}$.
} 
leading Icelanders to "sympathize with less-developed nations" and generating support for their path towards "modernization" (Loftsdóttir and Björnsdóttir, 2010).

The Board continued to manage Iceland's aid program until 1981 when the Icelandic government passed legislation to create ICEIDA as the main institution for bilateral development cooperation (Act in International Development Agency, 1981). ICEIDA became an institute under the MFA and would work with the MFA to "promot[e] Icelandic co-operation with developing countries, with the objective of supporting attempts by the government of these countries to improve their economies and thereby participate in promoting their program and political independence on the basis of the United Nations charter" (Dagbjartsson, 2001 p. 4). In essence, ICEIDA became the main operational branch of development cooperation, designing and implementing projects in accordance to policy created by the MFA (Model 3).

Iceland retained the same organizational structure throughout the 1990s, a period marked by heightened multilateral engagement and an expansion of its field presence. However, by 2003, calls to reform the ICEIDA structure emerged when a 2003 Report on Iceland's Development Cooperation noted the Nordic trend towards integrating aid programs wholly or partially into foreign ministries and urged Iceland to consider leaning in the same direction (Interview 2, 2017). Not only were these calls not heeded at the time, but in 2005, Davíð Oddsson, former Prime Minister (1991-2004) who served as Minister of Foreign Affairs from 2004-2005, proposed the opposite - that all development functions should be moved into ICEIDA (Interview 2, 2017). The proposal faced significant opposition from the Permanent Secretary of Foreign Affairs and Oddsson ultimately "ran out of time" and left office before the change could be pushed 
any further (Interview 2, 2017).

In 2006, a proposed parliamentary resolution called for a review of Iceland's aid program and an update to the 1981 legislation (Manning, 2006). While re-organization was not the explicit aim of the review, ICEIDA's autonomy over its aid program was mentioned as a point for debate (Sveinbjarnardottir, 22 Feb, 2006). The following year, the annual report from the Minister of Foreign Affairs submitted report findings to Parliament. The Minister noted that the review found current administrative arrangements to foster inefficiency through overlap in activities conducted by ICEIDA and the MFA (Sverrisdóttir, 2007). As a result, the Minister's report called for a simplified organizational model and proposed three possible options for reorganizing Iceland's development cooperation system:

1) Merge ICEIDA with the Ministry of Foreign Affairs (Model 1 or 2).

2) Keep ICEIDA as a separate organization with more clearly defined roles and functions (Model 3).

3) Move all development functions, including multilateral spending, into ICEIDA essentially creating an autonomous aid agency (Model 4).

The report, dismissed option 3 outright, arguing that while it had also been considered, the autonomous agency structure was "not considered a feasible option" (Sverrisdóttir, 2007). ${ }^{68}$ Instead, the Report recommended that the government consider reforming ICEIDA in alignment with option 1, emphasizing that maintaining the status quo was not an option (Sverrisdóttir, 2007). Despite calls for reorganization, changes to Iceland's aid agency structure were not pursued at this time due to political opposition to the proposal

\footnotetext{
${ }^{68}$ Interestingly, the Report drew on a number of examples from neighbouring countries to explore the structural options used by similar countries as part of its discussion of organizational options.
} 
and a looming election, which prevented the proposal form passing and resulted in a change in government (Interview 1, 2017).

In 2008, the Government amended the 1981 law on development cooperation (Amending the Law on International Development Cooperation, 2008). The new legislation solidified responsibilities for policy formation in the MFA and moved ICEIDA's previously independent governing Board to place it "more directly under the auspices of the Ministry" (OECD, 2013b p. 31). In essence, this change closed the gap between ICEIDA and the MFA, while maintaining ICEIDA's operational autonomy. Similarly, the Directorate for International Development Cooperation was set-up within the MFA in the wake of the Act's passing to "increase collaboration and coordination between the Ministry and ICEIDA" (MFA, 2015 p, 1).

Calls for Iceland to reorganize were emphasized again in the 2013 Special Review of Icelandic Aid conducted by the OECD-DAC at Iceland's request prior to joining the DAC (see OECD, 2013b). While the Review noted that Iceland had made progress towards more clearly defining the roles, responsibilities and synergies between the MFA and ICEIDA, it encouraged Iceland to "assess the overall organisation and arrangement of development cooperation based on how to ensure the greatest results and efficiency in the context of Iceland's size" (MFA, 2015 p. 1). In addition, the OECD called on Iceland to "better coordinate both bilateral and multilateral engagements" to strengthen alignment with international best practice (MFA, 2015 p. 1). At the time, bilateral programming was managed by ICEIDA while MFA managed multilateral and humanitarian assistance.

The structural issue remained an ongoing concern and in 2014, the Icelandic Government commissioned a study to identify and make recommendations to the 
organization and arrangements for the implementation of development cooperation (Interview 2, 2017). The report conducted extensive interviews with "individuals in public administration in Iceland, the Ministry of Foreign Affairs, ICEIDA, academia, development cooperation directorates and/or agencies in the other Nordic countries, Ireland as well as other countries" (MFA, 2015 p. 2-3) and explored three options for organizing Iceland's aid program:

1) Merge ICEIDA within the MFA as part of a 'development office'.

2) Retain the same structure, using both ICEIDA and the MFA, however responsibility for monitoring program performance would be transferred to the MFA.

3) Move all development responsibilities (including managing UNU Iceland, cooperation with international organizations, disaster relief and peacekeeping) into ICEIDA, while the MFA would be responsible for monitoring performance.

The report concluded that Option 1 was the best way forward, noting that "the coordination of all parties working on development cooperation on behalf of the Icelandic Government should take place in one location. Only that way can the likelihood of achieving the greatest results in the most efficient manner be maximised" (Gudmundsson, 2014 p. 7).

Findings from this report were presented to Parliament in July 2014. In September, the then-Secretary of State created a working group tasked with drafting a bill in alignment with the findings from Mr. Gudmundsson's report. The bill was highly contentious and was presented and debated three times in Althingi. In late 2015, the bill 
was passed, on January 1, 2016, ICEIDA ceased to exist (Amending the Law on International Development Cooperation, etc. (organization), 2015). As a result, Iceland's aid program is now managed by the Directorate for International Development Cooperation within the MFA.

\section{$\underline{\text { 6.4.2 Determinants of Iceland's aid agency structure }}$}

In the Icelandic case, it is important to determine the factors that contributed to "mismatch" while using the Model 3 structure and led to the 2016 reorganization and adoption of the Model 2 form. This will be done through examining two questions. First, what factors led to the merger of ICEDA into the MFA? Second, why was the Model 2 structure selected over other organizational choices? The following analysis highlights the significance of efficiency, legitimacy, politics and path dependence as key determinants of structural choice in the Icelandic case. Of these, efforts to improve inefficiencies with the Model 3 structure in the Icelandic case acted the main determinant of organizational change.

\section{Efficiency}

There is strong evidence that efficiency was a significant determinant of the choice to reorganize and adopt a Model 2 structure in the Icelandic case. In the lead-up to the 2016 merger, inefficiencies including the duplication of efforts between MFA and ICEIDA staff as well as tense relations between ICEIDA and the MFA were highlighted to justify the need for organizational change (MFA, 2015). Indeed, parliamentary commentary on the (then) proposed reorganization highlighted the change as a way to improve the efficiency of Iceland's aid management, stating that:

By merging all development cooperation activities, increased momentum can be brought to the projects, as well as increased flexibility and 
coordination capacity and any overlap in policy development and implementation can be prevented. It also reduces inefficiencies and duplication of effort in operations and administration which leads to greater efficiency in the long run. A simpler and more focused organisation increases the likelihood of Iceland's objectives and emphasis in international development cooperation being successful and leading to more efficient development cooperation (MFA, 2015 p. 4-5).

In part, the efficiency argument stemmed from the size of the units that managed its aid program. According to parliamentary commentary presented in the lead up to the 2016 merger, the Directorate for International Development Cooperation within the MFA had 9 staff in the years prior to merging. While ICEIDA employed 38 staff at the time, only 9 staff worked in ICEIDA's head office in Reykjavik, with other staff members located in field offices (MFA, 2015). In essence, the MFA and ICEIDA both had 9 employees working in separate offices in Reykjavik to manage different components of its aid program (MFA, 2015). While cooperation between the MFA and ICEIDA had improved following the 2008 legislative change (OECD, 2013b), one interviewee noted that the "time-consuming" burden of cooperation for a small workforce responsible for a large workload was high and ultimately "resulted in [coordination] not being done" (Interview 3, 2017). Given the small size of the units tasked with managing development cooperation, merging the two units was seen as a way to enhance the capacity of both small teams. As one interviewee noted, it appeared to "make more sense" to have 18 staff working together on development, rather than to have 9 people working, towards the same goals, in separate units. In this context, the Model 2 structure was viewed as the best option to allow Iceland to work on "the whole set of piano keys" by providing a framework for bringing together the various pieces of Icelandic aid.

While efforts to improve coordination had been made in the years prior to the 2016 
merger, such changes did not address a key source of coordination challenges - the 'tense' working relationship between ICEIDA and the MFA. Indeed, the relationship between ICEIDA and the MFA was described as "tense" by each interviewee contacted from Iceland, with tensions rising following the 2008 legislative change which moved ICEIDA institutionally closer to MFA. ${ }^{69}$ At its core, the problems stemmed from a disconnect between development expertise and the locus of policy-decision making where ICEIDA, an organization staffed with development "experts", received policy direction from the MFA, which was ultimately in charge of Iceland's aid program. According to one interviewee, this created resentment between the two agencies; ICEIDA viewed the MFA as seeking control over its budget and the use of development resources in support of other foreign policy goals, while the MFA felt that ICEIDA wanted to "go it alone" (Interview 2, 2017). Moreover, differences in staffing requirements and pay scales between the two entities further exacerbated tensions (Interview 2, 2017). According to one interview participant, tensions between ICEIDA and the MFA were so high that former ICEIDA Director-General, Sighvatur Bjorgvinsson, was no longer on speaking terms with the MFA at the time of his resignation in 2011 (Interview 1, 2017). Such tensions acted as a key justification for not only the need for change, but the need to eliminate the institutional divisions that fostered such tensions. In this sense, the Model 2 structure was viewed as a viable option.

\section{Legitimacy}

In the Icelandic case, there is some evidence that legitimacy acted as determinant of choice to adopt a Model 2 structure. Notably, the 2014 consultancy report conducted at

\footnotetext{
${ }^{69}$ ICEIDA staff also moved into the MFA building in 2009, closing some of the physical distance between the two agencies.
} 
the request of the MFA examined the organizational models of other countries as key inputs into making recommendations for Iceland's aid program (Interview 2, 2017). The report examined the structures of a number of OECD-DAC donors including Australia, Canada, Iceland's Nordic neighbours (Norway, Finland, Sweden and Denmark), as well as the Irish aid program, for insight into organizational models. Speaking specifically about examples of recent mergers, one interview participant noted that the 2013 mergers in Canada and Australia had "influenced things" in the Icelandic case (Interview 1, 2017).

While it is unclear whether the recent mergers of aid programs into foreign ministries in other OECD-DAC donors prompted the decision to merge in the first instance, it seems prudent to suggest that awareness and reference to the structures used in other countries, particularly those with merged models, suggests that the experience of other donors likely influenced the choice of adopting a Model 2 structure. Indeed, all of the countries referenced in conversations with interviewees as examples of countries Iceland looked to when considering reorganization used a Model that located policy and operational functions for development within a foreign ministry, aligning with the Model 2 structure adopted.

\section{Politics}

Political factors also played a key role in determining Iceland's structural change. In terms of the decision to reorganize, interview participants agreed that the timing was politically driven. Discussions of potential reform to ICEIDA's structure had, after all, been present within policy circles in Iceland from the early 2000s. While efforts to prompt reform had been taken in 2005 and 2006/7, ICEIDA structure remained 
unchanged in both instances largely due to short political timelines and an inability to generate sufficient support for proposed actions. In 2013, a new government with an agenda of administrative reform provided an opportunity to re-visit the issue of reorganization and provided a longer timeline to push action through parliament. Indeed, one interviewee suggested that the choice to merge was always the government's preference, even prior to the 2014 study that recommended the change, arguing that the merger was explicitly political and linked to the preferences of the center-right party in power at the time (Interview 1, 2017). This party was the same as that in power in 2007 when the then Minister of Foreign Affairs unsuccessfully attempted to merge ICEIDA and the MFA.

\section{Purpose}

There is no evidence that changes to the substantive preferences of Iceland's aid program influenced the decision to reorganize and adopt a Model 2 structure. Notably, Iceland's strategic papers on development cooperation also show consistent policy priorities and no meaningful changes over time. In the 2011-2014 policy papers, Iceland notes three strategic priorities of "natural resources, human capital and peace-building", in the 2013-2016 policy document, Iceland's strategic priorities are similarly listed as "natural resources, social infrastructure and peace-building" (ICEIDA, 2011; 2013). Both strategy papers continue to note that, "Within those areas the focus will be on fisheries and renewable energy, education and health, good governance and reconstruction" and list identical geographic priorities (ICEIDA, 2011; 2013).

Moreover, none of the interviewees or literature consulted for this study mentioned aid purpose as a factor contributing to organizational change. Taken together, 
unchanging priorities and in the period prior to Iceland's 2016 merger suggests that the substantive purpose of Iceland's aid program did not serve as a determinant of change in this case.

\section{NPM}

New public management had no influence on the choice to merge. Understanding that NPM advocates for the creation of agencies and privatization of "operations" or service delivery units to promote efficiency, merging Iceland's aid agency within the MFA recentralizes development functions and poses the opposite organizational form than is typically associated with NPM. Indeed, one interviewee made this point, noting that by combining operational and policy units, the merger ran counter to traditional logics of efficient government (Interview 1, 2017). The interviewee compared the merger to other departments with operational and policy functions, such as the Ministry of Transport, suggesting that governments influenced by NPM would not consider merging units that develop road policy with those in charge of paving and maintaining road quality (operations) (Interview 1, 2017). In essence, there is little evidence to suggest that the 2016 merger was influenced by NPM.

\section{Path Dependence}

Path dependence appeared to influence the choice to adopt Model 2 structure rather than Model 1 following the choice to merge. Recall that Model 1 and 2 both take merged forms, with responsibility for policy and implementation located within a foreign ministry. However, the main difference pertains to the organization of development activities within the ministry itself - either as a semi-autonomous 'directorate' within the 
ministry (Model 2), or as an integrated part of the ministerial structure with development as a 'cross-cutting' theme across geographic programs.

When asked about the decision to adopt Model 2 versus the Model 1 structure once the choice to reorganize had been made, one interviewee noted that "Model 1 was not even an option" as Iceland's MFA was organized according to function, not geographic region (Interview 2, 2017). In essence, it was more administratively prudent to integrate development as a 'directorate' for two reasons. Firstly, a directorate for international cooperation already existed within the MFA to handle multilateral and humanitarian interventions, making the merger of ICEIDA staff into a pre-existing unit administratively efficient. Secondly, Iceland's MFA was organized by function rather than geographic unit, meaning that a Model 1 structure would first require a full reorganization of the ministry.

\section{$\underline{6.4 .3 \text { Discussion }}$}

In the Icelandic case, the choice to adopt a Model 2 structure by merging ICEIDA into the MFA was based on four factors: efficiency, legitimacy, politics and path dependence. In the Icelandic example, concerns surrounding the inefficiency of the Model 3 structure, which fostered tensions and duplication of work between two small units, served as a key factor contributing to change and structural choice. Concerns regarding coordination and relations between ICEIDA and the MFA when using the Model 3 structure undoubtedly prompted the adoption of Model 2 to overcome such challenges through institutional closeness. However, an important facet of coordination challenges in the Icelandic case links to the size of Iceland's aid management system, 
where the use of two very small units working independently appeared to create a high burden of coordination.

The implication is that smaller donors may not be suited to structures that require high levels of coordination (namely, Model 3). For small donors, the Model 3 structure necessitates that already limited resources be directed towards coordination by virtue of needing to align the actions of at least two units responsible for aspects of development cooperation. Indeed, the coordination burden of the Model 3 structure was part of logic against the use of this structure in the Irish case; as one interviewee noted, "what you gain form having a separate agency doing implementation, you lose in managing relations and spending more time doing coordination" (Interview 6, 2016). In this context, and a policy environment that prioritizes policy coherence for development more so than in prior decades, institutional closeness afforded by merged structures, such as Models 1 or 2, may reduce the coordination burden for small donors by centralizing responsibility for policy and implementation of development programs within a single ministry. It should be noted that the point here is not to suggest that large donors do not also face coordination challenges when using the Model 3 structure - indeed, the German and Japanese cases presented in Chapter 7 show that coordination issues are prevalent for large Model 3 donors also - the difference is that the proportional costs of coordination may be higher for smaller donors with fewer human and financial resources to allocate to coordination in the first place.

Perhaps an important question when asserting that Model 3 may exert a higher coordination burden on small donors is whether the Icelandic merger actually improved the coordination challenge. According to interviewees, the merger of ICEIDA with the 
MFA has improved the coordination and efficiency of Iceland's aid program (Interview 3 , 2017). While interviewees recognized that the joined structure was "still finding its way", they noted that the merger had resulted in increased efficiency and was easing tensions as former ICEIDA and MFA teams worked to "build a coherent department" (Interview 2, 2017; Interview 3, 2017). These findings are echoed by the OECD-DAC's 2017 Peer Review of Iceland, which states that "Iceland's new integrated structure for the administration of development co-operation activities is making such co-ordination an easier task - which in turn is making Iceland's development co-operation more flexible and pragmatic" (OECD, 2017 p. 18). Importantly, the finding that the merger eased efficiency concerns lends further support to the finding that smaller donors may be suited to merged structures and matches results from Chapters 3 and 4, which shows that small donors are, on average, more likely to select the Model 2 structural form.

Regarding other significant factors contributing to organizational choice in the Icelandic case, the finding that politics played a role in the adoption of the Model 2 structure is aligned with results from Chapter 4. Indeed, in the Icelandic case, the role of key individuals from the center-right party elected in 2013, which explored organizational reform in years prior, was directly linked to calls to merge ICEIDA and the MFA. Findings from Chapter 4 not only shows that political ideology is an important determinant of structural choice for Model 2 donors, but also that these structures are more likely to be adopted by more conservative governments. ${ }^{70}$

\footnotetext{
${ }^{70}$ Seeing as the theoretical reason for conservatives to prefer merged structures is linked to the ability to align developmental purposes with diplomatic or commercial objectives, as suggested in Chapter 2, future analysis on how and whether the purpose of Iceland's aid program changed following the merger could contribute to a deeper understanding of the link between political ideology and organizational choice. At the time of writing, there is no real evidence of substantive change in Iceland's aid policies following the reform.
} 
The finding that legitimacy contributed to the choice of adopting the Model 2 structure in the Icelandic case runs counter to findings from Chapter 4, which show limited significance of the legitimacy variable. The significance of the legitimacy variable in the Icelandic case could suggest that legitimacy is a more prominent determinant of structure than captured by the quantitative model. The disconnect may be related to issues of measurement, where evidence of the donors looking to others when making organizational choices may be captured more broadly through qualitative analysis. Importantly, the significance of the legitimacy variable in this case matches preliminary findings from Chapter 3, which suggests that apparent convergence towards the Model 2 and 3 structures could illustrate the role of legitimacy in driving structural choice.

Lastly, as a case of extreme "mismatch", it is important to ask how and why the Model 3 structure was out of fit with the Icelandic case. Notably, the Model 3 structure is out of fit with the size of Iceland's aid program, which contributed to inefficiencies in terms of relations between ICEIDA and the MFA, and coordination between the small units. The connection between size and structure was made by two interviewees who argued that the very small size of the units involved in Iceland's aid program made their separation unfeasible (Interview 2, 2017; Interview 3, 2017). In conjunction with the finding from Chapter 4 that small donors are more likely to adopt a Model 2 structure, the size of Iceland's aid program, which in 2016 was the smallest of all OECD-DAC donors in absolute terms, likely contributed to strong mismatch in this case.

It is perhaps noteworthy that many of Iceland's "most similar" donors in terms of region, culture and shared history, use a merged structure. Most notably, as a former 
Danish colony, Iceland likely shares a degree of institutional and cultural similarity to Denmark. More broadly, as a Nordic country, Iceland's aid management structure could be viewed in relation to such models. Importantly, the only Nordic donor currently using the Model 3 structure is Sweden - all others use a Model 1 merged structure, which locates development cooperation as a core and cross-cutting function of the foreign Ministry. Given the finding from Chapters 3 and 4, which show that countries from similar regions or with shared historical linkages tend towards similar models, the use of the Model 3 structure in the Icelandic case appears out of fit with the norm for similar donors.

\subsubsection{Conclusion}

Overall, the choice to adopt a Model 2 structure in the Icelandic case was primarily driven by efficiency concerns linked to tensions between ICEIDA and the MFA, and the high coordination burden associated with splitting responsibility for policy and implementation in Iceland's small aid program. Perhaps most notably, the Icelandic case highlighted the relationship between organizational size and structure, where the Model 3 form used by Iceland prior to organizational change was seen as inefficient given the size of Iceland's aid program. In essence, this case provided support for findings from Chapter 4, which showed clear differences in organizational choices according to organizational size, and found the small size of Iceland's aid program to be a key determinant of "mismatch" with the Model 3 structure.

The analysis also found that legitimacy, politics and path dependence also played a role in determining structural choice in Iceland, but to a lesser degree. Of these, the political and path dependence variables appear to match the results of Chapter 4 most 
closely. Political factors appeared important drivers of the choice to undertake organizational change in the Icelandic case, with numerous calls for reform linked to the centre-right party over the course of a decade. This finding matches the hypotheses presented in Chapter 2 and findings from Chapter 4, which show that conservative governments are more likely to prefer merged structures. Moreover, Iceland's exploration of the organizational models used by other donors suggests that structural choice in the Icelandic case was partly informed by the experiences of other OECD-DAC donors.

\subsection{The Netherlands}

Responsibility for the Dutch development program has always been located within the Ministry of Foreign Affairs (MFA). Specifically, the Directorate-General of Development Cooperation (DGIS) is responsible for the formulation of the Netherlands' policy direction. In 1996, the MFA underwent a significant restructuring that altered the organizational model of its aid management system from a Model 2 to a Model 1 structure (see Chang et al., 1999). The restructuring deepened integration between foreign policy, trade and development objectives by rendering geographic units responsible for developing integrated country strategies that accounted for trade, political and developmental objectives. $^{71}$

The Dutch case represents "average" match in terms of structure. In the Dutch case, mismatch occurs over 10 years, most of which is found in the lead up to the 1996 change; only two mismatch instances are recorded following the adoption of the Model 1

\footnotetext{
${ }^{71}$ As mentioned in Chapter 3, the Dutch case is perhaps a hybrid between the Model 1 and 2 structure, where the responsibility of DGIS for policy formation leans towards the Model 2 structure, while cross cutting units is closer to a Model 1 form.
} 
structure. As an example of average fit between contextual factors and the choice of structure used, the Dutch case will highlight the reasons why the Models 1 and 2 structures were chosen and fit with or mismatched the Dutch context at various periods.

\subsubsection{History of Dutch Aid Management}

The Dutch aid program formally began in 1949 in response to President Truman's Four Point Program (Spitz, Muskens and van Eqijk, 2013), which emphasized development as a key effort to combat the spread of communism. In the early days, the Dutch aid program was viewed as a way to "redefine the power status" of the Netherlands in the wake of three major events - decolonization of Indonesia, greater economic focus on Europe, and joining the Atlantic alliance system - each of which had altered the Dutch status and position in the international system (Arens, 2003 p. 457). At the time, the Netherlands was in the process of "construct[ing] another perception of self", with development efforts serving to advance the internationalist idealism that had long underscored Dutch foreign policy (Arens, 2003). More pragmatically, engagement in development cooperation was seen as a way to export Dutch expertise following decolonization and the loss of demand for Dutch brainpower in Indonesia (van der Veer, 2011; Arens, 2003; Hoebink, 1999).

Throughout the 1950s, the Dutch development program was managed primarily by the MFA, with the assistance of other ministries (Model 5) (Cunningham, 1974). However, this structure was not used for long and by the 1960s, the rising prevalence of development issues led to the adoption of a more streamlined aid management system. Specifically, in 1964, the Dutch Government created DGIS as a unit for aid management within the MFA, making it a Model 2 structure (Arens, 2003). The Directorate was 
founded on the merger of three divisions that had previously been involved in aid management - Department for International Organisations, Department for International Assistance, and the Department for Financial and Economic Development Aid. Despite being part of the MFA, Cunningham (1974) reports that the Directorate "enjoy[ed] a high degree of autonomy" (p. 145) due to the presence of a dedicated minister for development within the MFA structure. Indeed, 1965, the pre-existing post of State Secretary for development was upgraded to a Ministerial post without portfolio within the MFA; the Minister had equal status to the Minister of Foreign Affairs (Cunningham, 1974; Arens, 2003). ${ }^{72}$

A new period in the history of Dutch development cooperation began in 1973 when Jan Pronk, a member of the center-left Labour Party, was appointed Minister of Development Cooperation (Spitz et al., 2013; Hoebink, 1999). Under Pronk, Dutch development assistance became "more ideologically and morally motivated" marking a clear shift from the commercial-focus of the 1960s (Spitz et al., 2013 p. 11). Indeed, Pronk believed, and declared, that Dutch assistance should go "as directly and as much as possible to the poorest of the poor" (Hoebink, 2006 p. 12), solidifying this position in a White Paper on Bilateral Development presented as an Appendix to the 1977 Budget (Hoebink, 1999).

It was also under Pronk's leadership that the Netherlands first reached the UN spending target of $0.7 \%$ (Spitz et al., 2013). Indeed, the rapid growth of Dutch aid saw development spending more than double between 1970 and 1979 (see Figure 6). Administratively, steady and sustained growth throughout the 1970s brought

\footnotetext{
${ }^{72}$ While the Minister of Foreign Affairs was responsible for all aspects of MFA's work except development assistance, this post was seen as being more powerful and a politically senior figure (Cunningham, 1974).
} 
organizational challenges as rising aid levels were not matched with increases to aid personnel (Hoebink, 1999; van der Veer, 2011). While Hoebink (1999) reports that DGIS staff increased from 238 in 1970 to 303 in 1978 (p. 187), the 1978 OECD Aid Review noted that Dutch "manpower resources [were] expected to continue to be modest relative to the size of the programme and in comparison with some other DAC member countries" (OECD, 1978 p. 19), and ultimately resulted in a "ballooning reservoir of allocated but unspent funds" as staff were charged with managing much larger portfolios (van der Veer, 2011 p. 118).

\section{Figure 6: Dutch ODA, US\$ million, constant 2015 prices}

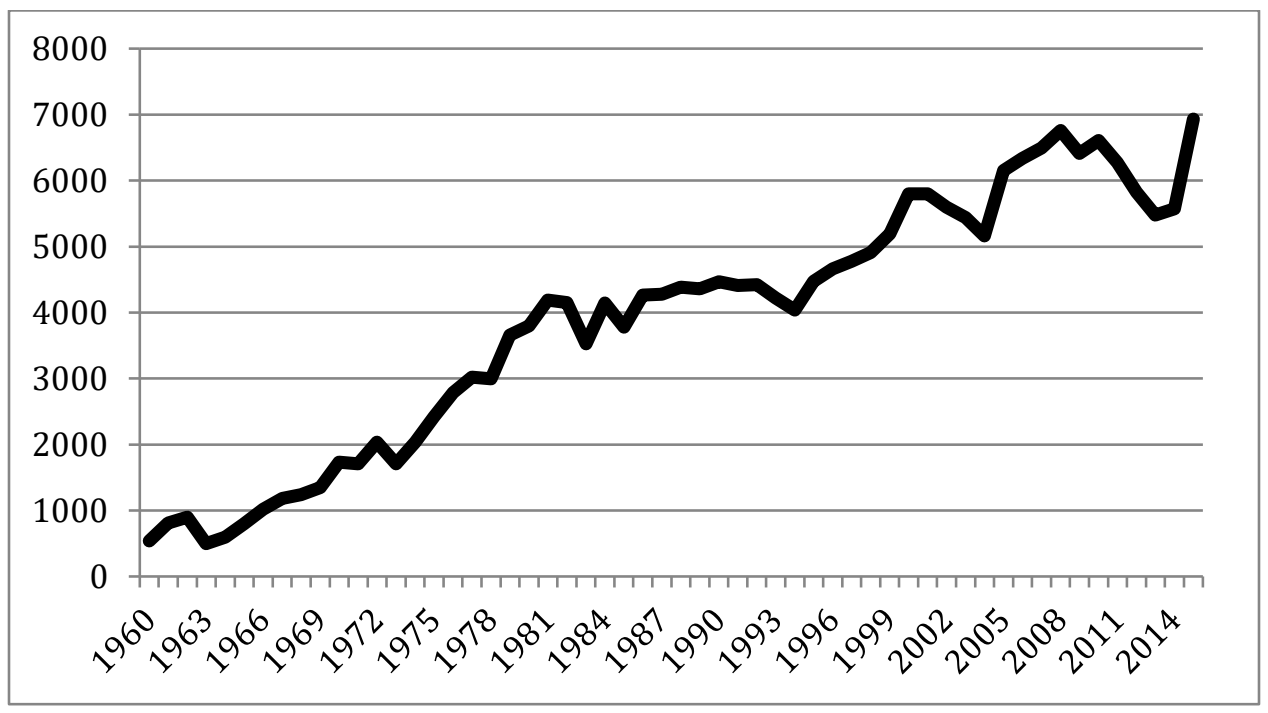

A number of internal changes within DGIS were undertaken in the late 1970s in efforts to improve the efficiency of the aid program (Hoebink, 1999; OECD, 1978). Notably, DGIS' structure was updated to integrate previously separate units for technical and financial aid; these were instead "replaced by regional directorates with country offices and a department for sectoral specialisations" (Hoebink, 1999 p. 189). Despite such changes, the reorganization did not affect the position of DGIS within the MFA, which retained the same Model 2 structure (OECD, 1978). 
The early 1980s saw a continuation of efforts to align Dutch development assistance with commercial objectives. According to van der Veen (2011), the new conservative government at the time went so far as to state that "the main goal of Dutch development policy will be supplemented by a sub-goal: increasing the importance of development cooperation to the economy and to employment in the Netherlands" (Netherlands, 1984 p. 42, cited in van der Veen, 2011 p. 118). The rhetorical alignment of Dutch development efforts with commercial and economic interests was met with heavy criticism from the media, legislature and interest groups who saw the new policy slant as a reversion to the 1960s, when Dutch aid was explicitly aligned with exports and commercial preferences (van der Veen, 2011; Hoebink, 1999).

In 1989, Pronk became Minister of Development Cooperation for the second time (Hoebink. 1999; Spitz et al., 2013, van der Veen, 2013). His return bought a new era in Dutch development assistance, one squarely focused on development effectiveness and the quality of Dutch ODA (Schulpen, 2005). Pronk's new policy direction was set out in a 384-page report, called $A$ World of Difference, which named "sustainable poverty alleviation" as the main goal of Dutch development assistance (Hoebink, 1999; Schulpen, 2005). This was, according to Schulpen (2005), the first time that the Dutch government had developed a "structured vision" for poverty reduction which addressed the economic, social and political drivers of poverty through investing in people, increasing access to basic needs, and participating in political affairs (Hoebink, 1999; Schulpen, 2005).

A few years later, the "optimism" underlying A World of Difference disappeared as a growing number of conflicts (Somalia, Liberia and Sierra Leone) began to define the development landscape. These changes to the international environment were reflected 
in a 1993 policy paper issued by Pronk called A World in Dispute, which highlighted tensions yet reiterated the need for poverty reduction as a precursor for sustainable development (Schulpen, 2005). The paper also recognized that emergency assistance and reconstruction efforts would be essential in the current development context, leading to calls for organizational change to deepen coordination between development and foreign policy to support programming in conflict affected regions (OECD, 1993b p. 7). In essence, the White Paper suggested that, "development policy [would] have to move beyond its hitherto limited 'compartment' in favour of a more coherent overall policy" (OECD, 1993b p. 7).

In this vein, the Dutch government launched a broad re-organization of its aid management structure in 1996, which "decompartmentalized" the MFA to improve policy coherence and coordination between various foreign policy matters (van der Veen, 2011; Schulpen, 2005; OECD, 1997). The change moved regional departments and country desks out of DGIS to the new Directorate-General Bilateral Relations (DGRB), which became responsible for developing medium-term policy documents that encompassed all bilateral relations (aid, trade, political) with partner countries (Schulpen, 2005; OECD 1997). In addition, the change shifted the "main responsibility for the bilateral aid programmes from The Hague to the various embassies, which, from January 1997 onwards, were the first entities responsible for the selection, assessment, monitoring and evaluation of development projects and programmes, receiving only general policy guidelines from the Hague" (Schulpen, 2005 p. 411). Such decentralization of responsibility was intended to improve the efficiency of programmes by keeping decision making close to recipients (Schulpen, 2005). Taken together, the focus on integration 
and efforts to align foreign policy and development activities through a new structural orientation resulted in the adoption of a Model 1 structure (see Chang et al., 1999).

The 1996 reorganization led to the emergence of new challenges, particularly regarding communication between The Hague and the Dutch Embassies (OECD, 2001a). By the early 2000's, the OECD reported the presence of a "psychological separation" between the field and headquarters that had led senior officials to feel that communication was "drying up" and that relations "drifting apart" (OECD, 2001a p. 36). The issue was blamed on the newness of the decentralized model and structural challenges related to the operational effectiveness of regional desks, which were "understaffed, too over-focused on non-development issues (foreign affairs priorities; Parliamentary enquiry), and too frequently lacking the depth and breadth of experience necessary, to be an effective interlocutor for the complex development and management issues coming from the field" (OECD, 2001a p. 36). By 2006, the OECD reported that communication challenges had improved through efforts to enhance the flow of information via a new planning and monitoring system (OECD, 2006c).

By the latter part of the 2000s, the orientation of Dutch aid began to shift, this time towards greater alignment between development and Dutch economic policy. The shift began as early as 2007 with the release of a new policy memorandum called Our Common Concern, which marked a "significant departure" from prior policies by focusing more acutely on economic sectors, the "self-reliance" of developing countries and global public goods in efforts to focus Dutch aid more squarely on supporting economic growth in recipient countries (OECD, 2011b; MINBUZA, 2007). In 2012, a change in government solidified the re-orientation with the creation of new ministerial 
post, which combined responsibility for foreign trade and development under a single Minister of Foreign Trade and Development Cooperation (OECD, 2017c).$^{73}$ Indeed, the increasing relationship between trade and development was embodied in the 2013 policy document called A World to Gain, which sets out a combined agenda for trade and development that focuses on "poverty eradication, sustainable development and increased trade for Dutch companies" (OECD, 2017 p. 16; Government of the Netherlands, 2016; MFA, 2013a).

While there is limited evidence of the Dutch Government considering other organizational relationships over time, Interviewees noted that a recent internal report explored the structural question, and examined current MFA policy making occurred and implementation processes (Interview 14, 2017; Interview 4, 2017). One of the major suggestions from the report was the option of creating a separate agency called "NLAID" to implement the Dutch aid program (Model 3) (Interview 14, 2017; Interview 4, 2017). While the option was considered, the absence of strong pressure for change both within the MFA, which feared losing power over development to a separate agency, and from Parliament meant that the option was not taken forward (Interview 14, 2017). Since then, there have been no further changes to the structure of the Dutch aid management system, which remains organized using a Model 1 structure.

\footnotetext{
${ }^{73}$ The cabinet-level ministerial post for development cooperation had been abolished a few years earlier. Specifically, in 2010, the Dutch Government abolished the post of Minister for Development Cooperation within the MFA (OECD, 2011b). The change was "part of a government-wide reduction in ministerial posts" which decreased the number of MFA ministers from three to two (OECD, 2011b p. 52). Instead, ministerial responsibility for development cooperation became located under the non-cabinet level Minister for International Co-operation and European Affairs (OECD, 2011b).
} 


\subsubsection{Determinants of Dutch Aid Agency Structure}

In the Dutch case, understanding the choice of organizational model involves answering three questions: what factors determined the use of the Model 2 structure? Why was reorganization undertaken in 1996? Why was the Model 1 structure adopted? Taken together, the analysis that follows shows that efficiency, politics, purpose and path dependency acted as the main determinants of organizational structure in the Dutch case. While path dependence determined the initial Model 2 structure, political factors, efficiency and purpose contributed to the 1996 reorganization and adoption of Model 1.

\section{Efficiency}

There is evidence that efficiency acted as a determinant of the choice to undertake reorganization in 1996 and adopt a Model 1 structure. Perhaps most notably, one interviewee stated that the 1996 merger was partly driven by administrative inefficiencies in the Model 2 structure used at the time (Interview 14, 2017). Specifically, these inefficiencies pertained to the duplication of efforts across directorates, where locating desks for the same bilateral partner in political and development directorates meant that multiple strategies were being created per country in separate parts of the department (Interview 14, 2017). In a sense, reorganizing to a Model 1 structure provided a way to overcome this inefficiency through merging regional units into the DGRB directorate, which became responsible for all bilateral relations, including development and political affairs, with individual countries (Interview 14, 2017). According to Interview 14 (2017), issues of duplication were overcome through the 1996 reorganization. 


\section{Legitimacy}

There is little evidence to suggest that legitimacy influenced the choice of aid agency structure in the Dutch case. Neither the interviews nor research conducted on this case showed any reason to suspect legitimacy as a determinant of structural change or choice. Perhaps most importantly, the structure adopted by the Netherlands is unique and does not perfectly match either the Model 1 or Model 2 form. Instead, the structure uses elements of both models to form a hybrid structure that was not found in any other donor at the time. ${ }^{74}$ Given that legitimacy theory suggests that donors adopt models to mimic others, the creation of a new model provides clear evidence that the Dutch case was not driven by legitimacy. Rather, the uniqueness of the Dutch model seems to suggest that the structure was designed to meet Dutch needs, in a specific context and at a particular point in time.

\section{Politics}

There is strong evidence that political factors played an important role in the choice of structure in the Dutch case. Notably, throughout the history of Dutch development cooperation, the Minister of Development Cooperation consistently acted as a key driver of development policy and management (Schulpen, 2005; Interview 14, 2017). In terms of the 1996 reorganization, evidence suggests that the administrative “decompartmentalization" matched the integration sought through Pronk's 1993 policy statement. Specifically, calls for integration of development with other policies, by Minister Pronk, was supported by a revised administrative structure capable of reducing the silos found within Model 2. In this sense, the Minister himself was largely seen as

\footnotetext{
74 The Finnish model, created in 1998, resembles the Dutch "hybrid" and can also be considered a mix of Model 1 and 2 structures. However, this model was adopted after the Dutch reorganization.
} 
responsible for driving the 1996 administrative reform. Indeed, Schulpen (2005) echoes the finding that Pronk played a key role in the Dutch development context, noting that, "the Minister is an important determining factor in Dutch development co-operation. In particular Pronk and Herfkens have had a major influence of policy" (p. 415). In this sense, Pronk's role in driving calls for deeper decompartmentalization at a policy and administrative level suggests that political factors contributed to both the need for change and the adoption of the Model 1 structure.

More recently, discussions concerning the option of creating a Dutch implementing agency further showed the importance of political actors in determining aid agency structure (Interview 14, 2017). Interviewees $(4,2017 ; 14,2017)$ noted that the Dutch government had recently considered creating an implementing agency (Model 3), partly in order to access EU development funds that are typically implemented through EU member government (Interview 14, 2017). The logic was that without an implementing branch, the Netherlands was unable to access such EU funding (Interview 14, 2017). While changing to the Model 3 structure was considered (Interview 4, 2017; Interview 14, 2017), the option was never adopted as neither the Minister nor Parliament had any interest in changing the form (Interview 14, 2017). Ultimately, the decision to sustain the Model 1 structure appeared to be linked to political preferences for the status quo, further showing the role of political actors as determinants of structural form.

\section{Purpose}

The shifting purpose of the Dutch aid program appears to be a strong determinant of the choice to undertake organizational change and adopt the Model 1 structure. Indeed, both Schulpen (2005) and van der Veen (2011) link the 
"decompartmentalization" of aid explicitly to efforts to deepen the coherence of foreign policy and development in a changing global context where inter and intra country conflicts were taking hold. For instance, on the link between purpose and structure, Schulpen (2005) stated that:

Given the changing international system following the fall of the Berlin Wall, it was felt that development co-operation was no longer the stepchild of international relations but instead should be viewed as an integral part...As such, development co-operation increasingly touched upon other policy fields. This called for 'decompartmentalisations' between Ministers such as Development Cooperation, Foreign Affairs and Economic Affairs, aimed at 'improving coherence, better coordination between the Ministries involved in foreign policy matters, and improving working links with Dutch society at large' (p. 410, citing OECD 1997 p. 13).

In this sense, the decision to engage in organizational change appears to be based on the understanding that a decompartmentalized structure would be best suited to implementing the Dutch vision for and understanding of development co-operation which emerged in the early 1990s.

Perhaps to a lesser extent, the relationship between development purpose and organizational choices can also be seen in the 2012 decision to merge the trade and development portfolios under the auspice of a single minister for Foreign Trade and Development. According to the Dutch Government's 2016 Memorandum submitted to the OECD ahead of its 2017 Peer Review, the change can be linked to a major revision of Dutch development policy, which was taking place under the first Rutte coalition from October 2010 to November 2012 (GoN, 2016). In essence, this policy shift included "a move towards economic sectors - away from social sectors like education - in order to focus Dutch support more directly on promoting economic growth and self-reliance in developing countries. Promoting market mechanisms and private institutions was 
recognised as indispensable in the fight against poverty" (GoN, 2016 p. 16). In this context, deepening integration between the trade and development portfolio through the use of a single Minister became a way to "enable a broad coherent approach that combines a focus on the poorest with efforts to make trade and investment contribute more to remunerative employment..." partly through encouraging deeper engagement from the private sector (GoN, 2016 p. 16). As a result, the creation of a single ministerial post to align trade and development in 2012 with policy changes taking place in the years prior suggests that deepening integration within the Model 1 structure is closely linked to policy priorities.

\section{NPM}

There is little evidence that NPM influenced the choice of aid agency structure in the Dutch case. Most notably, the Model 1 and 2 structures used to manage the Dutch aid program both locate primary responsibility for development policy and implementation within the MFA. Moreover, while the 1996 merger occurred at a time when NPM was dominant in international public sector management discourse, the reorganization served to solidify development's position within the MFA. This finding is further supported by the understanding that in the Netherlands, NPM reforms were mostly focused on "making the central government leaner by decentralizing more tasks to agencies and local authorities" (Jilke, Van de Walle and van Delft, 2013 p. 8). In the case of the Dutch development program, further integration within the Ministry shows the opposite approach. 


\section{Path Dependence}

There is some evidence to suggest that path dependence influenced the choice of aid agency structure in the Dutch case. In particular, path dependence appeared to act as a determinant of the initial choice to locate responsibility for development within the MFA using a Model 2 structure. Prior to formalizing the Dutch aid management system, the OECD reported that the formulation of Dutch development assistance policies was done by the MFA in consultation with the competent Ministries (OECD, 1962), suggesting that responsibility for development was largely located within the MFA in the years immediately prior to the formal adoption of the Model 2 structure. In this sense, the continued location and formalization of responsibility for development activities within the MFA could be linked to initial choices made in the early days of the Dutch aid program which granted responsibility for development to the MFA in the first instance.

\section{$\underline{\text { 6.5.3 Discussion }}$}

In the Dutch case, the choice to adopt the Model 1 and 2 structures can be linked to four factors: efficiency, politics, purpose and path dependence. Of these, the substantive policy preference towards policy coherence acted as the clearest determinant of both the need for change, as well as the choice to adopt a Model 1. Indeed, the mismatch between Pronk's new policy direction and the Model 2 structure appeared the drive the need for "decompartmentalization" to match the new integrated policy direction found in A World in Dispute (Hoebink, 1999). The direct alignment between substantive preferences and organizational choices in this case highlights the role of purpose as a driver of structural choice and aligns with findings from Chapter 4. 
Importantly, the finding that deepening policy integration is associated with the Model 1 structure could provide insight into the reasons why donors choose to select Model 1 over the more popular and structurally similar Model 2; namely, that the integrated Model 1 approach could enhance the capacity to pursue a more coherent policy for development. Indeed, there is evidence of a relationship between Model 1 structures and the desire to enhance policy coherence, with each of the four donors adopting the Model 1 structure citing policy coherence as a reason for the reform. In the Danish case, the 1991 reorganization which created the Model 1 structure was done with the view that "the new structure answers well to the need for one single focal point for Danish overall relations with individual developing countries and will by that token facilitate the achievement of improve policy coherence in these relations" (OECD, 1991 p. 26). Similarly, the 1998 reorganization in Finland was based on "a growing understanding that Finland's development cooperation should be an instrument of foreign policy and that relations with developing countries needed to be treated as a whole, not compartmentalised into trade and aid" (OECD, 1999b p. 31), while the 2004 merger in Norway was done "to make public administration more effective and improve policy coherence between institutions" (OECD, 2008b p. 43). While it is difficult to prove whether and to what degree the adoption of Model 1 actually contributed to deepening policy coherence in practice, the finding that Model 1 donors selected this structure to improve policy coherence provides support for the hypothesis that organizational choices follow from substantive preferences.

Moreover, the relationship between policy coherence and the Model 1 structure sheds some light on the rationale for selecting between Models 1 and 2. Importantly, the 
relationship between policy coherence and the Model 1 structure could assist in interpreting some results from Chapter 4, which showed that despite organizational similarities, Models 1 and 2 were associated with different purposes. Recall that Model 2 was more likely to be adopted by donors that pursued strategic purposes, while Model 1 was associated with donors that pursued commercial, developmental and strategic purposes to a lesser degree. While the Dutch case does not speak to the finding for Model 2, the emphasis on policy coherence could explain the negative coefficients for the purpose variables in relation to the Model 1 structure. At the most basic level, the pursuit of integration and policy coherence could mean that the main policy purposes of donors are each pursued to a lesser degree, where focusing on a coherent whole means that the individual policy preferences are secondary to broader integrated objectives. In this sense, negative results for purpose variables could simply be showing that relative to other donors, Model 1 donors appear to pursue individual policy purposes less forcefully in favour of a broader, "joined-up" policy goal.

Political factors were also found to be key determinants of structural choice in the Dutch case, aligning the case with findings from Chapter 4 as well as with the other cases presented in this chapter. Most notably, the Minister of Development Cooperation played a key role in determining structural forms in the Dutch case, highlighting the importance of the Ministerial post for driving policy and structure. A key question for the future of Dutch development cooperation will be how the now combined ministerial post for development and trade will affect the Dutch aid program.

As with the other cases presented in this chapter, efficiency was shown to be a significant determinant of organizational form. Importantly, this finding runs counter to 
results from Chapter 4, which shows that the Model 1 structure is associated with higher administrative costs. Given the clear linkage between structure and efficiency, it could be argued that while the new structure accounted for inefficiencies present within the Model 2 structure, reducing administrative costs may be seen as a lesser aim of reform than aligning policy with structure. Indeed, the Netherlands was experiencing a strong economic climate at the time, as the 1990s saw sustained economic growth and a sharp reduction in structural unemployment (Kanda, Scott and Weber, 2011), suggesting less pressure to reduce administrative expenditure.

Lastly, as an example of "average" match, it is perhaps important to note when and in what ways the Dutch structure was out of fit with predictions. Most instances of mismatch in the Dutch case occurred in the late 1980s and early1990s prior to the 1996 administrative reform. Most clearly, this analysis suggests that such mismatch could be linked to inefficiencies experienced over this period. Moreover, strong match with the use of the Model 1 structure could be liked to the clear relationship between structure and purpose.

\section{$\underline{6.5 .4 \text { Conclusion }}$}

Overall, the Dutch case shows that while the initial choice to adopt a Model 2 structure was primarily linked to path dependence, choice to adopt Model 1 was associated with political, efficiency and purposive concerns. Most notably, the Dutch case perhaps provides the clearest evidence so far of a relationship between structure and purpose, where the selection of Model 1 was closely linked to changing Dutch policy and efforts to enhance policy coherence. Specifically, substantive changes in Dutch development policy linked to a desire to decompartmentalize foreign policies and create a 
more joined-up approach to political, commercial and development relations with partner countries was seen as a key driver of the 1996 reform. Moreover, the policy of decompartmentalization in the Dutch case can be linked to the political leadership of Jan Pronk, who initiated and led the reform. At the time, inefficiencies concerning the duplication of efforts within the Model 2 structure also provided impetus for change to enhance the administrative efficiency of the development program.

Notably, the Dutch case provides some insight into findings from Chapter 4, which show that despite organizational similarities, Models 1 and 2 are selected by donors that pursue different purposes by highlighting the linkage between the use of the Model 1 structure and policy coherence. While both Models 1 and 2 present merged options that are theoretically capable of advancing policy coherence, the Dutch case shows the perceived value of the Model 1 structure in the presence of "joined-up" development policy.

\subsection{Contemplations and Main Findings}

The three cases presented in this chapter show remarkable similarity in terms of the factors found to influence the choice of aid agency structure. A summary of the variables shown to be significance in each case is provided below.

Table 8: Summary of Findings

\begin{tabular}{|l|c|c|c|}
\hline & Ireland & Iceland & Netherlands \\
\hline Efficiency & $\mathrm{X}$ & $\mathrm{X}$ & $\mathrm{X}$ \\
\hline Legitimacy & & $\mathrm{X}$ & $\mathrm{X}$ \\
\hline Politics & $\mathrm{X}$ & $\mathrm{X}$ & $\mathrm{X}$ \\
\hline Purpose & $\mathrm{X}$ & & $\mathrm{X}$ \\
\hline NPM & & $\mathrm{X}$ & \\
\hline Path Dependence & $\mathrm{X}$ & & \\
\hline
\end{tabular}


Taken together, these cases highlight the role of political factors, efficiency and path dependence as main determinants of aid agency structure. Of these, the finding that political factors are significant determinants of structural form broadly matches results from Chapter 4, which shows that Models 1 and 2 are predicted by donor ideology. In terms of efficiency, the cases presented highlight a much clearer picture of the role of efficiency as a driver of the need for structural reform than was apparent from limited significance in the quantitative model. The disconnect here may be one of measurement where some of the inefficiencies, such as tensions between MFA and ICEIDA staff in the Icelandic case, may not be directly captured by administrative costs. While the administrative variable remains the most robust measure of efficiency available across donors and time, it does have limitations and highlights the need for a deeper exploration of how we measure and understand efficiency in terms of aid management. Moreover, the significance of path dependence in influencing structural choice is unsurprising and could lend further support to the understanding that donors with shared histories and cultural similarities may tend towards similar structures.

However, beyond the individual variables connected to structural choice, the cases presented in this chapter have shed additional insight on three key findings from Chapter 4. First, the Icelandic case shows that small donors face different administrative constraints than their larger counterparts. Notably, smaller donors have fewer human resources to manage aid programs. As a result, structures that split responsibility for development policy and implementation (Model 3) are likely to create a large coordination burden relative to program size. Similarly, challenges of coordinating between foreign and development ministries in the Model 4 structure may also pose 
coordination challenges for small donors. Taken together, the connection between size and structure is important as it suggests that some donors may be better suited to particular models in the first instance; this indicates that there could be an "optimal" (or more optimal) model in terms of efficiency based on donor size. In the absence of any clear and systematic relationship between structure and effectiveness, which is yet to be proven, exploring the linkage between structure and size could provide an initial basis for advising donors on structural selection. The following chapter will further explore this connection by probing the relationship between changes in ODA budget size and reorganization in alignment with findings from Chapter 5.

The role of size as a factor in structural choice speaks to the finding from Chapter 4, which suggested that convergence towards the Models 2 and 3 could be driven either by perceived benefits of these structures, or perceived barriers to adopting Models 1 and 4. While donor size appears to act as a barrier to the Model 4 structure, the constitutional limitation in the Irish case also points to the idea that internal contexts and constraints within donor systems could make the adoption of a Model 4 structure more difficult. In this context, it becomes important to suggest that the limited usage of Model 4 over time could be due to structural barriers that prevent donors from adopting the model most commonly associated with the unimpeded ability to pursue best practice.

Lastly, this chapter found clear evidence of a relationship between substantive preferences and structural forms. In both the Irish and Dutch case, the linkage between purpose and structure is apparent in efforts to align organizational forms to match enhanced focus on policy coherence. In the Irish case, the recent creation of the Africa branch was done to support coherence across development, trade and foreign policy in 
bilateral relations with Africa through a new unit reminiscent of those found in Model 1 structures. Similarly, in the Dutch case the adoption of a Model 1 structure was explicitly linked to a "decompartmentalized" policy approach. In this sense, there appears to be a basic trend in the relationship between Model 1 and policy coherence, where this structure is chosen by donors seeking to align development, trade and foreign policy objectives in bilateral relations.

Perhaps a key question then is whether the Model 1 structure can actually be associated with greater policy coherence? A crude way to assess performance on policy coherence uses the Center for Global Development's Commitment to Development Index (CDI), which ranks donors on their dedication to policies that benefit development across seven thematic policy areas - aid, technology, environment, trade, finance, migration and security (see CDG, 2017; Gulrajani, 2017). In essence, the CDI is perhaps the most comprehensive measure of policy coherence for development currently available. While the CDI is not available prior to 2003 , making it impossible to tell whether the adoption of Model 1 structures is correlated to any change in policy coherence following the adoption of this model, the CDI can be used to assess whether there are any discernable trends in average performance of Model 1 donors on policy coherence relative to other DAC members.

Table 9 (below) shows the rank of Model 1 donors in each year from 2003. Strikingly, Model 1 donors tend to perform relatively well on the CDI over time, ranking within the top third of donors in almost every year. Perhaps most notably, Denmark, which has become the quintessential example of the Model 1 structure is consistently ranked within the top two donors in every year since the index has been measured. While 
it is not possible to meaningfully conclude any causal relationship between structure and policy coherence from this measure alone, the finding that Model 1 donors tend to perform well on coherence as measured by the CDI further suggests a connection between Model 1 and policy coherence.

Table 9: CDI Rank for Model 1 Donors ${ }^{75}$

\begin{tabular}{|c|c|c|c|c|}
\hline & Denmark & Finland & Netherlands & Norway \\
\hline $\mathbf{2 0 0 3}$ & 1 & 9 & 6 & 5 \\
\hline $\mathbf{2 0 0 4}$ & 2 & 7 & 5 & 3 \\
\hline $\mathbf{2 0 0 5}$ & 2 & 7 & 5 & 3 \\
\hline $\mathbf{2 0 0 6}$ & 2 & 7 & 4 & 3 \\
\hline $\mathbf{2 0 0 7}$ & 2 & 7 & 4 & 3 \\
\hline $\mathbf{2 0 0 8}$ & 2 & 9 & 4 & 2 \\
\hline $\mathbf{2 0 0 9}$ & 2 & 8 & 5 & 3 \\
\hline $\mathbf{2 0 1 0}$ & 2 & 8 & 4 & 3 \\
\hline $\mathbf{2 0 1 1}$ & 2 & 4 & 5 & 3 \\
\hline $\mathbf{2 0 1 2}$ & 1 & 5 & 6 & 3 \\
\hline $\mathbf{2 0 1 3}$ & 1 & 5 & 5 & 3 \\
\hline $\mathbf{2 0 1 4}$ & 1 & 3 & 7 & 5 \\
\hline $\mathbf{2 0 1 5}$ & 1 & 3 & 7 & 9 \\
\hline $\mathbf{2 0 1 6}$ & 2 & 1 & 7 & 6 \\
\hline $\mathbf{2 0 1 7}$ & 1 & 3 & 7 & 9 \\
\hline
\end{tabular}

\subsection{Conclusion}

Taken together, the cases presented in this chapter highlight several key determinants of organizational choices. The cases show that efficiency, politics and path dependence are particularly significant determinants of organizational structures. In particular, efficiency was found to be a consistently significant determinant of structure, where organizational changes undertaken in Iceland and the Netherlands were undertaken to address inefficiencies in the organizational models used. In Iceland, such inefficiencies underlay strong "mismatch" between the Model 3 structure and the small

${ }^{75}$ Commitment to Development Index (CDI) ranked 21 countries from 2003-2007, 22 countries from 20082011, and 27 countries from 2012-2017. 
Icelandic development program. Moreover, in the Irish case, the continued efficiency of the Model 2 structure, and ability to address inefficiencies with minor reorganizations within the Model 2 form, appears to contribute to the absence of organizational change and ultimately strong "match" between the Irish development program and Model 2 structure.

Political factors were also shown to be significant determinants of structural choice, with the Minister of Foreign Affairs (Ireland and Iceland) or Development Cooperation (Netherlands) leading organizational reforms, while the persistent significance of path dependence showed that organizational choices are influenced by pre-existing organizational arrangements. The purpose of aid agencies was also shown to be a significant determinant of structural choice. In particular, the Dutch case highlighted the link between substantive preferences for policy coherence and the use of the Model 1, rather than Model 2, structure. Building on this finding, the next chapter will further probe the link between policy coherence and structural change in the Australian context, where policy coherence was used to justify the 2013 merger of AusAID and DFAT. ${ }^{76}$

While the analysis presented in this chapter explored key determinants of structural choice, the degree to which such factors also influence the organizational change remains to be seen. The next chapter will present three case studies to build on the current findings and explore the determinants of organizational change.

\footnotetext{
${ }^{76}$ Policy coherence was also part of the official rhetoric surrounding the Canadian merger.
} 
CHAPTER 7

THE DETERMINANTS OF ORGANIZATIONAL CHANGE IN AUSTRALIA, JAPAN AND GERMANY 
This chapter builds on the logic and results of Chapter 5 to further explore the question of why donors reorganize their aid management systems. Recall that Chapter 5 provided initial analysis on this question, finding that increases in ODA budget size and underlying structural shifts are key determinants of organizational change. Using three case - Australia, Japan, Germany - this chapter takes a closer look at the determinants of organizational change and lend additional credence to statistical findings.

To do so, this chapter will proceed as follows. The first section describes the methodology used to select the three case studies presented in this chapter as examples of organizational change. The three sections that follow conduct structured-focused case studies of the determinants of organizational change in Japan, Australia and Germany, respectively. A final section discusses findings across the cases and highlights key conclusions.

\subsection{Case Selection}

Cases were selected based on findings from the estimation presented in Chapter 5. Specifically, qualitative comparative analysis (QCA) was used to identify the relationship between instances of organizational change and the variables found to be statistically significant determinants of change across both the annual and five-year estimations namely structural factors and ODA budget size. ${ }^{77}$ Using "Boolean logic", QCA tests "each possible combination of factors at specific levels" against event outcomes (Longest and Vaisey, 2008 p. 80). For instance, using two main predictors of organizational

\footnotetext{
${ }^{77}$ While the previous chapter selected cases on the predicted likelihood of adopting each organizational model, similar post-estimation techniques following a rare-event logit regression are unavailable. Instead, the QCA technique, which is routinely used for case selection in comparative social science studies, is adopted due to its ability to match change events with associated combinations of conditional correlations identified from the rare-event model in Chapter 5.
} 
change - structural predictors and changes in ODA budget size - QCA matches 'high' and 'low' values of each variable against event outcomes. ${ }^{78}$ Each observation is then matched with one of four possible outcome combinations - high structure and increases in budget size, high structure and decreases in budget size, low structure and increases in budget size, and low structure and decreases in budget size. According to Chapter 5, the outcome most likely to predict organizational change shows increases in ODA budget size (high), and low structural predictions (low). ${ }^{79}$ When tested against instances of organizational change, 8 of the 19 changes (or $42 \%$ ) included in this sample were associated with increases in ODA and low structural predictions. ${ }^{80}$ The capacity for QCA to identify the relationship between key predictor variables and instances of organizational change makes it a valuable technique for selecting cases.

Using the QCA output, cases are selected to account for three groups of possible outcomes - cases where organization change is predicted by the QCA analysis and occurs, cases where changes are not predicted yet occur, and cases where changes are predicted yet no change takes place. Selecting cases to account for these outcomes offers an opportunity to explore the conditions under which organizational change does, and does not, occur.

\footnotetext{
${ }^{78}$ For the purpose of this study, "high" and "low" outcomes are determined relative to the mean. It could be argued that setting the test limit at the mean would disproportionately prevent smaller donors from showing a positive outcome, particularly in terms of changes in ODA budget change. However, organizational changes are more likely to follow large changes in firm/agency size. In these cases, organizational changes become a necessary response to growth, which could require new organizational arrangements to maintain efficiency. Based on this logic, setting the test point at the mean ensures that the largest half of donor changes are captured - i.e., those with the greatest likelihood of requiring restructuring in response to budgetary growth.

${ }^{79}$ Recall that the results of both models in Chapter 5 showed positive and significant coefficients for change in ODA budget size, and negative and significant coefficients for structural predictions. In terms of QCA output, the positive coefficient for change in budget size suggests that increases in ODA are likely to contribute to reorganization. Similarly, in terms of structure, the negative coefficient suggests that lower predicted values are likely to be associated with organizational change.

${ }^{80}$ It should be noted that while there are 29 change events which occur across the entire sample, many of these events occur in the 1960s when data is unavailable.
} 
The first case was selected from 11 instances ${ }^{81}$ where organizational change occurred when it was not predicted. To distinguish between these cases, I simply looked for countries with multiple instances of un-predicted organizational change. Two countries each undergo multiple organizational changes that are not predicted by the model - Australia and the UK. Of these cases, Australia has the highest frequency of unpredicted change, which occurs three times, while in the UK unpredicted change events occur twice. As the country with the highest frequency of unpredicted change, the Australian case is selected for inclusion in this study.

The second case was selected to represent instances where change occurs when predicted. To select this case, QCA output was analyzed to identify the 8 cases $^{82}$ where organizational change occurred in the presence of increased budget size and decreased structural predictors. To select between cases, I began by searching for donors with multiple predicted changes; however, all of the 8 cases of predicted change occur in separate donors. In the absence of multiple predicted change events, I considered cases that would best complement the sample and ensure that all five organizational models were represented in the case studies. Up to this point, the four cases selected represent all organizational models except Model 5. From the 8 cases of change that occur when predicted, the Model 5 structure was used by three countries - Japan, Portugal and Spain. From these cases, I select Japan based on the understanding that it has been a consistent OECD-DAC donor since 1961, while Portugal and Spain joined the DAC in 1991.

\footnotetext{
${ }^{81}$ These include: Australia (1977, 1985, 2013), Austria (2004), Canada (2013), Denmark (1991), Finland (1998), France (1999), Norway (2004), UK (1974, 1997).

${ }^{82}$ These include: Belgium (1999), Italy (2014), Japan (2001), Netherlands (1996), Portugal (2003), Spain (2005), UK (1979), US (2004).
} 
The third case was selected from instances where change was predicted to occur but did not take place. These cases provide an important comparison as they serve to highlight the absence of conditions needed to 'prompt' change and can provide deeper insight into the reasons why change occurs at certain points and not others. To select the third case, QCA results were examined for the presence of extended "periods" of predicted change without change actually occurring. ${ }^{83}$

From 2000-2014, the UK, Germany and Sweden each show a high frequency of predicted change without change occurring. To select between the three, I simply look for the country with the largest number of predicted changes over the period. Germany shows the highest frequency of predicted change, with 12 instances of change predicted across the period, while both Sweden and the UK come a close second with 10 instances of predicted change each. As a result, Germany is selected as the third case.

\subsubsection{Case Diversity}

Taken together, the six cases selected in Chapters 6 and 7 - Iceland, Ireland, Netherlands, Australia, Japan and Germany - can be considered a diverse and representative sample of OECD-DAC donors. First, the cases collectively cover each of the five organizational models used by donors. While the majority of cases currently use Model 2 and 3 structures, Models 1, 4 and 5 were used by the Netherlands (Model 1), Australia (Model 4), and Japan (Model 5) for at least a decade in each case. A sample that covers each organizational form is well positioned to explore and understand the

\footnotetext{
${ }^{83}$ There were a number of options for selecting this third case. Cases could, for instance, be chosen based on the number of instances of predicted change as a proportion of total observations. While this technique was considered, the number of instances of predicted change alone may not be a good indicator of cases where predicted change did not result in actual change as individual or short periods of predicted change is found in the majority of cases.
} 
determinants of organizational structure and change across all possible structural alternatives.

Second, the sample includes a diverse mix of new and long-term OECD-DAC members. Of the countries included, the Netherlands, Japan, Germany and Australia joined the OECD-DAC in the 1960s and were among its original donors. Conversely, Iceland is a fairly recent member of the OECD-DAC, joining in 2013, while Ireland is a mid-length member, which joined in 1985. This diversity is important as it offers the potential to explain and understand differences in organizational change and structural choices at various stages of aid agency institutionalization and development.

Lastly, the sample includes representative cases from major "groups" of donors Anglo-Saxon donors, which are the only donors that historically used autonomous aid agency structures (Australia), and Nordic donors, which have historically been the most generous and the only donors to adopt the fully merged Model 1 structure (Iceland and the Netherlands). ${ }^{84}$ Including at least one case for each of these major donor groups further highlights the representativeness of the sample in the OECD-DAC context. Taken together, these three factors, as well as the methodology outlined for case selection, contribute to ensuring the internal validity of the case studies.

\subsubsection{Data and Methodology}

The data and methodology used for the three cases of organizational change follow the specifications outlined in Chapter 6. A main difference however, is that path dependence will not be examined as a determinant of organizational change. The logic of this is established in the discussion of variables included in Chapter 5; the basic

\footnotetext{
${ }^{84}$ While the Netherlands is not technically a "Nordic" country, several studies have shown that it behaves much like a Nordic donor in terms of aid policy and is often grouped with traditional Nordic donors (see Alesina and Dollar, 2000).
} 
understanding is that while path dependence has the potential to guide organizational choices, the presence of change itself suggests a break from an institutional "path". Other key variables - efficiency, politics, purpose, legitimacy and NPM - show the same theoretical capacity to influence both structural choice and change (see Chapters 2 and 5 for more). The exception to the inclusion of path dependence is the German case, which has been selected due to the absence of change when predicted. As a result, path dependence will be examined as a variable in this case to assess whether path dependence has prevented change from occurring when predicted.

Like the structural cases presented in Chapter 6, 2-3 interviews were conducted for each case; interview specifications are the same as those presented in Chapter 6 . While five cases included interviews with current donor government employees, this was not possible in the Australian case. While attempts were made to interview current employees from Australia's Department of Foreign Affairs and Trade (DFAT), none were able or willing to answer questions. Instead, interviewees for the Australian case were conducted with former AusAID employees.

\subsection{Australia}

Australia's aid program has undergone four organizational changes since it was first established in the 1950s as part of the Colombo plan. From 1950-1974, Australian aid was managed using a multiple ministry structure (Model 5). In 1974, management of Australia's aid program was transferred to the Australian Development Assistance Agency (AADA), a corporate body under the Department of Foreign Affairs (DFA) (Model 4). After two years in operation, the AADA was abolished and responsibility for 
ODA was moved to the Australian Development Assistance Bureau (ADAB) located within the DFA (Model 2). The ADAB remained responsible for Australia's ODA until 1985 when a re-vamped ADAB, called the Australian International Development Assistance Bureau (AIDAB, later AusAID) was established as an autonomous unit within the purview of the DFA (Model 4). Australia retained its Model 4 structure until 2013 when the Abbott government merged AusAID back into Australia's Department of Foreign Affairs and Trade (DFAT) (Model 2).

Importantly, none of these changes were predicted by changing ODA budgets or structural predictors. ${ }^{85}$ In cases where organizational change occurs when not predicted, the main question of interest is why change was undertaken? This question will underlie the following analysis of the Australian case.

\subsubsection{History of Australian Aid Management System}

Australia's aid program began in 1950 as part of the Colombo Plan (Sherlock, 1991). At the time, Australia viewed aid as necessary to both ensure the political stability and security of the region, particularly in the context of a communist China and fears that other Asian-Pacific countries may seek to adopt communist regimes (Wilkinson, 1976), and to develop Australia's reputation as a "purposeful and strong Pacific power" (Oakman, 2010 p. 44). From the very beginning, Australia's aid program was seen to serve multiple purposes, adopting a "triple mandate" that "unabashedly" viewed aid as a combination of "humanitarian, foreign policy and commercial objectives" (Rix, 2005 p. 105).

\footnotetext{
${ }^{85}$ Three of the cases were not predicted, the fourth (1974) was not included in the QCA analysis due to data limitations.
} 
From 1950, Australia's aid program was managed using a multiple ministry structure (Model 5), with responsibility for development dispersed across a number of government departments. Main actors included the Department of External Territories, which was responsible for aid to the Australian territory Papua New Guinea (PNG), the DFA, which was responsible for ODA to countries other than PNG and for managing multilateral contributions, and the Treasury, which had primary responsibility for engagement with international financial institutions (Sherlock, 1991; OECD, 1967; OECD 1966). Other ministries, including the Department of Education, managed activities related to their particular expertise (Sherlock, 1991; OECD, 1973; OECD 1971).

By the early 1970s, "practical and ideological imperatives" created momentum that would eventually result in the creation of Australia's first aid agency (Corbett, 2017 p. 21). In practical terms, "a growing realization of the complexities involved in delivering aid well" challenged standard practices of the day. Ideologically, issues of decolonization and questions about the independence of PNG "added imperative for Australian policymakers seeking to rethink the focus and management of their aid program" (Corbett, 2017 p. 22). It was within this context that a politically "fortuitous alignment of individuals" within a newly elected Labour Government, "proved to be a catalyst for considerable change in Australian aid policy and administration" (Corbett, 2017 p. 23) which resulted in the first of four major organizational changes to Australia's aid management.

In 1972, the Australian Labour Party (ALP) was elected after 23 years of coalition government (Corbett, 2017). Aid was not a high priority for the ALP and was not 
mentioned in the government's 1972 policy speech nor in other foreign policy statements (Wilenski, 1981). However, the creation of an aid agency would become an area of swift action for the new Labour government in alignment with a single line in the 1971 ALP platform which stated that: "in pursuit of a more meaningful aid programme the Labour Party proposes...to reorganize the various Australian aid programmes and to establish a mutual co-operation agency" (ALP, 1971 cited in Wilenski, 1981). The line had been added at the behest of W.L. Morrison, a former official in the DFA with experience in the Aid Division, who left the professional public service to run for political office in 1969 (Wilenski, 1981). According to Wilenski (1981), "Morrison had seen aid programmes administered abroad and...was aware of the extent to which the development aspects of aid were ignored in the Department and of the lack of professionalism in its aid branch" (p. 102), and pushed to include aid in the ALP platform during the party's annual conference in Launceston, Tasmania (Corbett, 2017).

While Morrison was a loud voice in the call for aid agency reform, so too was the newly elected Prime Minister Gough Whitlam. Whitlam was said to have championed the reform of Australia's aid management system, which was helped by his dual role of Prime Minister and Minister of External Affairs for the first nine months of his term in office (Wilenski, 1981; Corbett, 2017). Indeed, Whitlam's personal interest in the issue of aid management was noted by Wilenski (1981), who stated that Whitlam's private office maintained interest in the idea of an independent aid agency, ensuring Whitlam could take "an active role in decision making on the proposal, though it was never one of his dominant concerns" (p. 102). Wilenski, who served as Whitlam's principal private 
secretary, was also a strong supporter of reform to the aid system (Wilenski, 1981; Corbett, 2017).

While interest in creating an independent aid agency was present early in Whitlam's tenure as PM, PNG's upcoming independence on December 1, 1973, was seen as a catalyst for driving discussions of the need for organizational reform. In part, PNG's independence meant that the Department of External Territories, which had previously managed a bulk of Australian aid as overseer of relations with PNG, would essentially be abolished (Wilenski, 1981; Corbett, 2017). Morrison, who was the Minister of External Territories at the time, used the opportunity to open conversations with Whitlam about aid management and the need to relocate officers from his department (Corbett, 2017). According to Corbett (2017), Whitlam was disappointed by slow-progress from a parliamentary committee working on issues of aid management at the time and created a new task force "to provide options for a unified aid program" (p. 24). The task force would be chaired by the Department of Foreign Affairs and included members from each major department in Australia's aid administration.

Despite some bureaucratic infighting and efforts to "fight off encroachments on their existing [aid] empires", Wilenski (1981, p. 109) notes that the final report of the task force outlined five administrative options for organizational change:

1. Expanding the current Aid Branch within the DFA

2. Creating a new aid office within the DFA; the office would be directly responsible to the "Permanent Head"

3. Establishing a new bureau or agency within the DFA

4. Create a separate department responsible to the Foreign Minister 


\section{Create a separate department with its own Ministerial post}

After consultations with an external advisor and long-time aid advocate, Sir John Crawford (Corbett, 2017), Whitlam chose the Agency option (Option 4) and on September 17, 1973, "Cabinet agreed to the establishment of an Australian Development Assistance Agency (ADAA) as a statutory body to administer Australia's bilateral aid and our participation in all programmes of multi-lateral aid to developing countries" (PMO, 1973, cited in Wilenski, 1981 p. 111).

The ADAA was eventually established more than a year after the decision passed through Cabinet with ongoing interdepartmental disputes between the DFA and Treasury delaying its creation (Wilenski, 1981; Corbett, 2017). Disputes centered around two main issues. First, there were questions over how the ADAA would be staffed (by new appointments or by resources from aid program in relevant ministries). Second, there was concern over who would control the Agency, and how relations between the Ministry of Foreign Affairs and Director of the ADAA would be managed (Wilenski, 1981). Both issues were eventually resolved and the Australian Development Assistance Agency Act came into effect on 9 December, 1974.

In 1975, Whitlam was dismissed from office and replaced by Malcolm Fraser who headed the new Liberal and National Country Party coalition. Less than three months after coming to power, Fraser announced that ADAA would be merged into the DFA (Corbett, 2017). Poor economic conditions marked by high inflation and stagnant growth put the "rationalization of government administration" high on the Fraser Government's agenda from the outset (Corbett, 2017 p. 40; Fraser, 1975). Indeed, Fraser's Election Policy Speech (1975) called for the need for change from the "dark 
years" of the Whitlam Government, which Fraser claims was marked by “...more and more dependence on Government, more and more regulations, more forms, more controls, more bureaucracy" (Fraser, 1975). In essence, the government sought to reduce government spending, largely through administrative cuts.

Corbett (2017) notes that aid was on the chopping block from as early as the Coalition party's political platform, which stated that the "Government would undertake a thorough review of the administration of the Agency (ADAA) in light of Australia's current international assistance programs" (Coalition, 1975, cited in Corbett, 2017 p. 41). The review, which was launched in January 1976, was to be conducted by the Minister of Foreign Affairs "with a view to incorporating it [ADAA] into the Department of Foreign Affairs" (Corbett, 2017 p. 41). A few weeks later, the government announced plans to close the ADAA, with its functions relocated into a new "Bureau of Overseas Aid" within the DFA; the change was in alignment with the Fraser Administration's efforts to promote efficiency by reducing the number of agencies to limit government spending. Despite the quick decision, the ADAA remained in use until February 1977, when the Australian Development Assistance Bureau (ADAB), a semi-autonomous structure within the DFA, began operations. The change marked a shift to a Model 2 structure.

The 1980s saw a number of changes to Australia's aid program. For one, Australia's aid spending began to increase in the early years of the 1980s, 'recovering' from cuts made under the Fraser Government (OECD, 1981; 1983). Australia also began to diversify its allocation over the period by increasing aid to countries in Africa (OECD, 1983). Despite such changes, concern over the management of Australia's aid program 
remained an ongoing source of debate throughout the early 1980s (Joint Committee on Foreign Affairs and Defence, 1985).

In 1983, the Minister of Foreign Affairs, Bill Hayden, established an independent committee to Review Australia's aid program (Lim, 1985). The Review, named the Jackson Report after the Committee's chairman Sir Gordon Jackson, was conducted on the heels of a 1981 "efficiency audit" of Australia's aid program undertaken by the Auditor-General's Office (Eldridge, 1985). ${ }^{86}$ The Jackson Report devoted significant attention (almost one-fifth of the Report) to questions of aid management and concluded that widespread "shortcomings in ADAB's performance [were] a major drawback to improving the effectiveness of the aid program" (Joint Committee on Foreign Affairs and Defence, 1985 p. 26). The Report made a number of recommendations for strengthening Australia's aid program, including developing medium-term (5-year) country programs, strengthening the project cycle, and increasing staff training (OECD, 1985a). From an aid management perspective, the two most important recommendations included: 1 . Creating "a different internal structure which will allow the necessary work to be done in a professional style"; and 2. Locating aid to "a different place within the bureaucracy so that accountability is clear and necessary resources are available within the organization" (Joint Committee on Foreign Affairs and Defence, 1985 p. 27).

Reforms towards this end began in 1985. Internally, the ADAB undertook a significant reorganization that led to the redistribution of roles and responsibilities within the Agency across a number of divisions and units. These changes were intended to improve the effectiveness of the program by "strengthening the Bureau's policy

\footnotetext{
${ }^{86}$ The audit report was "highly critical", calling on ADAB to undertake significant reforms in a number of areas including staffing (notably staff training), program development, monitoring and overseas representation (Joint Committee of Public Accounts, 1982; Eldridge, 1985).
} 
capability and its capacity for appraisal, monitoring and evaluation" (OECD, 1987). In terms of the broader location of the aid program, changes to ADAB's status included strengthening its autonomy and increasing the Head of ADAB's leadership status from "Director" level to "Director-General" (Corbett and Howard, 2017). While ADAB would remain within the DFA, it became an "autonomous unit" within the portfolio of the Ministry (OECD, 1985a). In essence, this change, combined with newly granted authority over "all resources necessary to manage the aid program" transformed the ADAB into an "autonomous" (Model 4) aid structure called the Australian International Development Assistance Bureau (AIDAB) (OECD, 1985a p. 24).

By the early 1990s, the reforms made as a result of the Jackson Report were said to have "improved in a major way" the quality and professionalism of Australia's aid management (OECD, 1992 p. 3). However, a reduction in the aid budget throughout the 1980 s, which had fallen from $0.48 \%$ of GNI in 1985 to $0.36 \%$ in 1991 as a result of efforts to reduce government spending, as well as an upcoming election, raised concerns over the future of Australia's aid program (OECD, 1987; 1992). Politically, the election had the potential to be a turning point in Australian aid, with the opposition Liberal government running a platform that promised to reduce aid spending by $15 \%$ over two years, cut AIDAB staff by 50\% and re-merge remaining staff into the now Department of Foreign Affairs and Trade (DFAT) (OECD, 1992). The election was won by the incumbent Labour Government, which instead enhanced the profile of Australian aid through the appointment of Australia's first (and short-lived) Minister of Development Cooperation in 1993 (OECD, 1996) ${ }^{87}$ Visibility of Australia's aid program was further enhanced in 1995, when the AIDAB was renamed "AusAID" to strengthen name

\footnotetext{
${ }^{87}$ This Ministerial post would not be renewed in the next government.
} 
recognition of the program (OECD, 1996 p. 12). The change was made on the heels of a 1994 survey of public opinion on aid, which showed high support for Australian aid and low name recognition of the AIDAB brand.

In 1996, a change in government brought John Howard's Liberal Government to power. That same year, the Government launched an independent review of Australian aid called the Simon Review. The Review made a number of recommendations, including reaffirming the management of Australian aid by AusAID as an autonomous structure, and ensuring that Australian aid was more sharply focused poverty reduction relative to other competing interest (OECD, 2000). The Government agreed on both counts, issuing Australia's new policy document Better Aid for a Better Future in response.

Rapid expansion was a defining feature of Australia's aid program throughout the 2000 's with aid increasing from US\$2.4 billion in 2004 to US $\$ 4.8$ billion by 2012 (see Figure 7). The increase was spurred by a strong economy and a political understanding of the potential benefits of aid in the global fight against terrorism (Corbett and Horward, 2017). In 2007, a bipartisan commitment to reach an ODA/GNI level of $0.5 \%$ by 2016/17 showed further support for Australia's growing aid program (OECD, 2013a). To ensure that Australia's growing aid resources were used effectively, the Government commissioned an independent review of Australian aid in 2011 (see GoA, 2011). That same year, a new policy statement released by the government further highlighted Australia's emphasis on aid effectiveness and was followed by the 2012 Comprehensive Aid Policy Framework designed to clearly outline the expected results of Australian programming until 2015-16 (see AusAID, 2012b). 
Figure 7: Gross ODA, Constant US\$ Millions

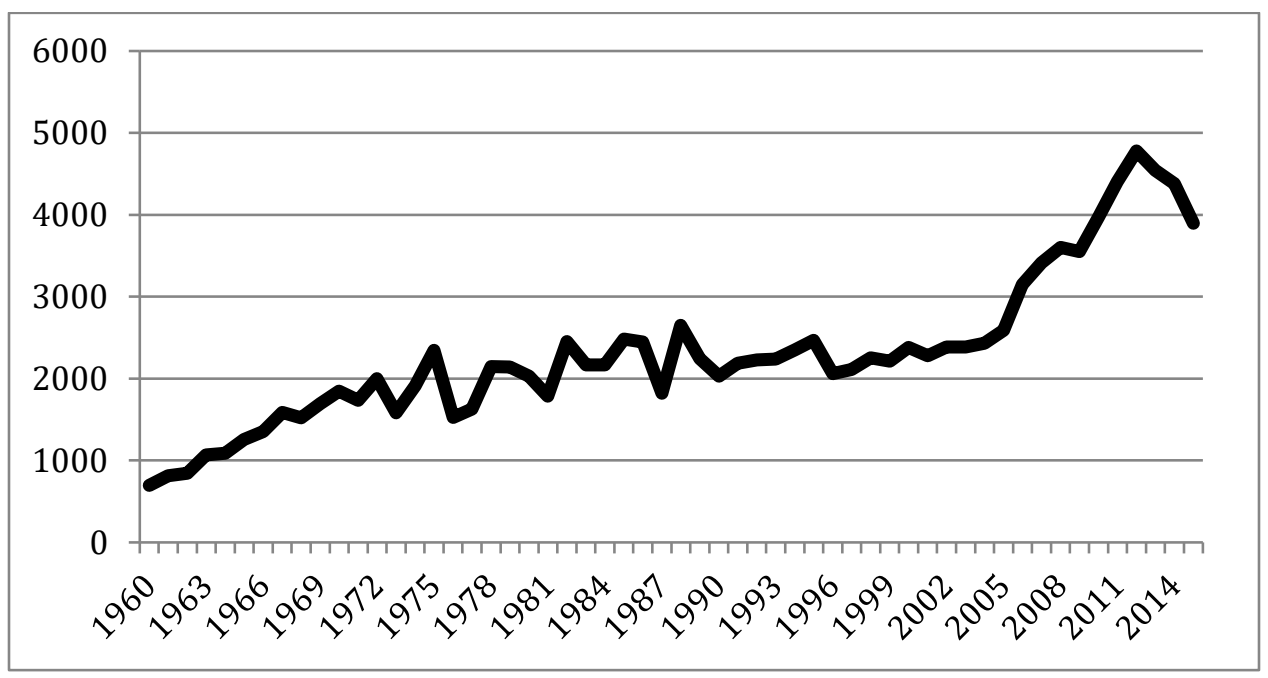

Administratively, Australia's aid program remained an autonomous structure (AusAID) within the portfolio of DFAT over this period of rapid growth. The most notably change came in 2010, when AusAID was formally granted the status of an Executive Agency under the purview of DFAT, with its Director-General reporting directly to the Minister of Foreign Affairs and Trade (OECD, 2013a).

On September 18, 2013, the same day as taking office, Australia's newly elected Prime Minister, Tony Abbott, announced his intentions to merge AusAID back into DFAT to foster alignment between aid and foreign policy (see Abbott, 2013). The merger came without warning; Mr. Abbott's Liberal platform had pledged to reduce aid spending however, there was no mention of organizational change at the time (Bruere and Hill, 2016). Indeed, one interviewee noted that as late as three days before Abbott took office, there were clear expectations of cuts to the aid program, but never a mention of organizational reform (Interview 9, 2017). The merger was swift ${ }^{88}$ and by November 1 , 2013, the Minister of Foreign Affairs, Julie Bishop, announced that DFAT was officially

\footnotetext{
${ }^{88}$ Interviewees noted that the Director-General, Peter Baxter, left after the announcement and did not return to the building again.
} 
"responsible for development policy and the delivery of Australia's aid program" (Bishop, 2013).

The merger was described as "rapid and ferocious" (Interview 8, 2017; Interview 9, 2017). Approximately $14 \%$ of AusAID's staff is believed to have resigned within the first months of the announcement (Towell, 2014). By 2015, AusAID had lost 549 jobs, all of which were said to be voluntary redundancies or natural attrition (SBS, 2015). The merger was also accompanied by deep cuts to Australia's aid spending, which fell from US\$4. 8 billion in 2012 to US\$3.9 in $2015 .{ }^{89}$

In essence, the merger shifted Australia's aid management structure from a Model 4 to a Model 2 system, with aid now managed as a branch within DFAT under the leadership of a Deputy Secretary. With the structure, DFAT is essentially responsible for Australia's aid policy and implementation. According to most recent estimates, no real changes to the aid program are expected anytime soon - aid spending is predicted to continue declining to AUD\$3.7 billion by 2020-21 (DevPolicy, 2017).

\subsubsection{Determinants of organizational change in Australia}

The Australian case provides several examples of organizational changes occurring in the absence of the predictors identified in Chapter 5. In terms of ODA changes, the only instance of change linked to an increase in ODA budget size was the most recent change in 2013, which followed a massive scale-up of Australian aid over a decade from 2002-2012 (see Figure 7 above)..$^{90}$

Importantly, there is evidence that the increases in Australia's ODA budget

\footnotetext{
${ }^{89}$ According to recent estimates, Australian aid declined by more than AUD\$1 bn from 2013-14 to 2016-17 down from AUD\$5.4 billion (inflation adjusted, 2016 prices) to AUD\$3.9 billion in 2016-17 (see DevPolicy, 2017).

${ }^{90}$ Figure 7 shows no discernable relationship with ODA budget size for the other three change events, showing organizational changes occurring following small dips in ODA spending.
} 
throughout the 2000s played a role in the 2013 merger. Explicitly, Corbett and Howard (2017) note that "The size of the agency was a key factor" in the 2013 decision to merge AusAID with DFAT (p. 210), while interviewees also pointed to size as a key determinant of change (Interview 8, 2017; Interview 9, 2017). Interviewees stated that rapid growth of the aid program, which was on its way to becoming the " $5^{\text {th }}$ or $6^{\text {th }}$ largest" ministry in Australia, had led many within AusAID to be weary that the department had become "too big for its boots" (Interview 8, 2017; Interview 9, 2017). The risk was particularly acute in the absence of any real voice of political or public support for aid. Politically, aid had previously been favoured by the last three Prime Minister's (John Howard, Kevin Rudd and Julia Gillard) (Interview 9, 2017) but appeared to have little place in Tony Abbott's "national interest" focused agenda. One interviewee also noted that Australia "does not have a loud pro-development voice" (Interview 8, 2017), providing limited public pressure to maintain high support for aid.

The relationship between reorganization and the increase in Australia's aid budget does not follow the expected logic of contingency theory, which suggests that changes in Australia's budget size would necessitate organizational change to ensure optimal functioning at the new budgetary level. In the Australian case, there is no real evidence of efficiency challenges in AusAID prior to the merger. In fact, Australia's last OECDDAC Peer Review, conducted in 2013 prior to the reform, quotes Erik Solheim, DAC Chair, stating that, "Australia's aid system is set up to deliver its growing aid programme effectively and efficiently" (OECD, 2013a). Rather, this case shows that growth was an important driver of change not from an efficiency perspective, but from a political one, where ODA growth led AusAID to "take up too much air" and become more "visible" 
then was perhaps politically palatable at the time (Interview 8, 2017). Indeed, Corbett and Howard (2017) note that rationales concerning the relationship between AusAID's size and the merger include the idea that AusAID "had become a symbol of Rudd-era largesse and thus its abolition was meant as a statement of intent", and that the "perceived arrogance" (or "hubris" as Interviewee 9 put it) within the department led AusAID to lose friends in other departments (Corbett and Howard, 2017 p. 210).

In addition to budget size, Chapter 5 suggests that organizational changes are also determined by broader structural shifts measured by the predicted likelihood that donors will select the organizational model they actually use. In the case of Australia, the 1985 change event is the only one linked to changes in the predicted likelihood of selecting the actual model chosen (see Figure 8 below). In this case, Figure 8 shows a decline in the predicted likelihood that Australia would select a Model 2 structure from around $80 \%$ in 1978 to $0.1 \%$ by 1984 (the last year of its use). Interestingly, in 1984, the likelihood of adopting the Model 4 structure, which would be chosen the following year, was $72 \%$. To a much lesser degree, the same is also true for the shift from a Model 4 structure to Model 2 in 1977, with the Model 4 structure predicted at a slightly lower rate than the Model 2 structure actually chosen (57\% for Model 2, 43\% for Model 4). ${ }^{91}$

${ }^{91}$ The earliest change in the Australian case, in 1974, is not predicted due to data limitations. 
Figure 8: Predicted Likelihood of Australia Adopting the Actual Model Chosen

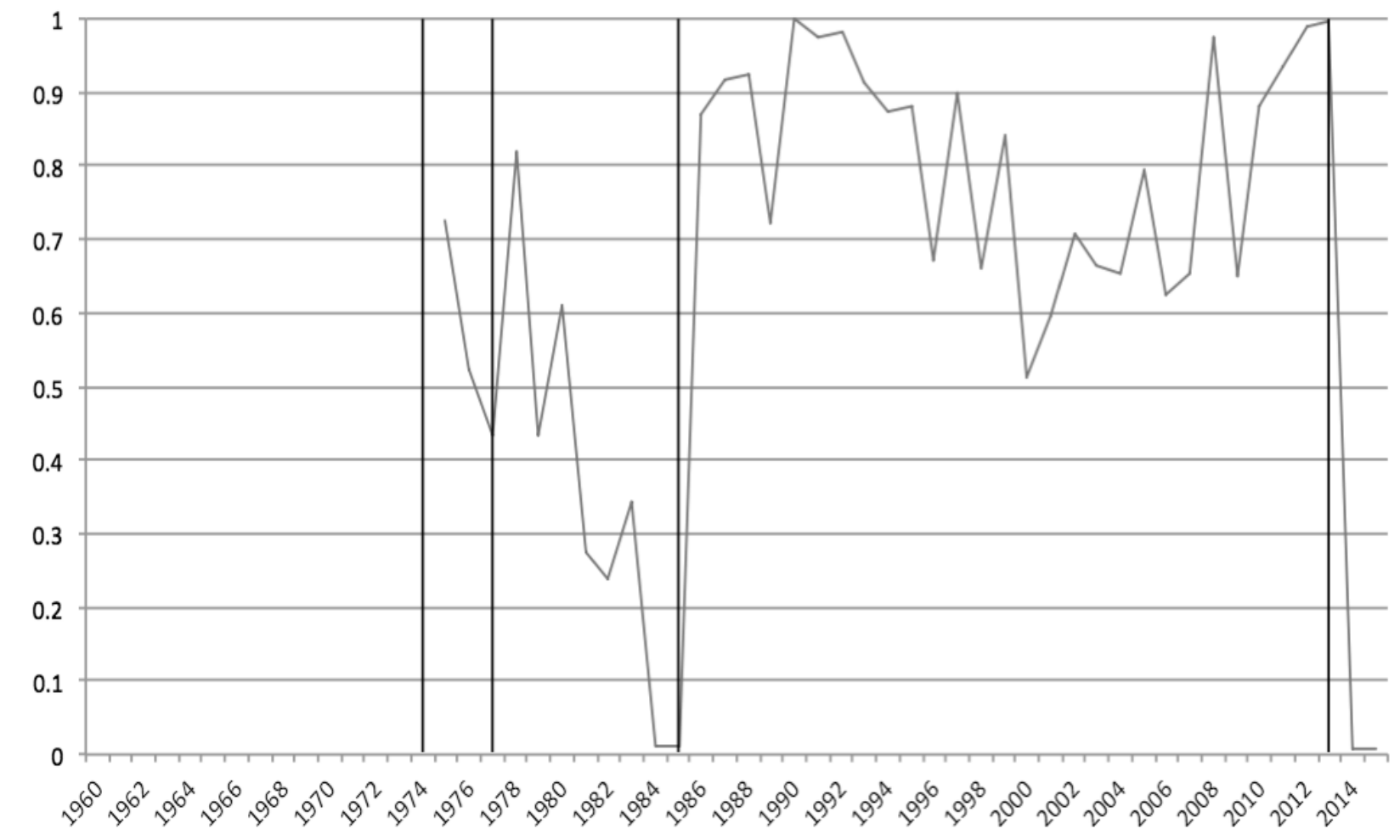

Figure 8 also shows that the autonomous AusAID (Model 4) structure was predicted as the most likely throughout the 1990s and 2000s, reaching a peak likelihood of $99 \%$ in 2013 , the last year of its existence. The higher likelihood of selecting the Model 4 structure suggests that the choice to merge AusAID into DFAT was not linked to broader structural changes that may have contributed pressure for change.

Taken together, these results show that none of the organizational changes undertaken by Australia align with both predictors of organizational change. In two cases in particular (1977 and 2013), the absence of structural predictors suggests that changes were likely driven by non-structural factors. A key question for exploration in this section is what factors contributed to organizational change in the absence of change predictors. Together, the analysis finds that organizational changes in Australia were driven by efficiency, legitimacy, politics and NPM. 


\section{Efficiency}

There is clear evidence that efficiency played a role in prompting the 1974 and 1985 changes to Australia's aid agency structure. The 1974 change, which shifted aid management from a Model 5 structure operated by multiple ministries to a Model 4 agency, was linked to efforts to: improve the efficiency of aid programming through reducing tensions between the agencies involved in development, improve the professionalism of the aid program, and create a more permanent and integrated approach to aid management. Essentially, the initial Model 5 structure was never intended to be permanent and was initially created to manage finite Colombo Plan commitments (Wilkinson, 1976). However, the longer-term use of the multiple ministry structure beyond the confines of the Colombo Plan had fostered competition between departmental stakeholders and limited development of a professional class of experts on development issues (see Corbett, 2017; Wilenski, 1981). Notably, the short-term nature of the Plan led to the employment of temporary staff, in compliance with the Australian Public Service Board's policy "of not creating permanent positions until it was established that they would be required for longer than seven years" (Wilkinson, 1976 p. 191). As it became clear that aid would become a longer-term objective of the government, calls for change began to follow.

Perhaps most explicitly, the Cabinet decision outlining the creation of the ADAA clearly framed the decision as one based on efficiency. The decision states:

The Government believes that improvements can and must be effected in almost all aspects of out aid endeavours - in the machinery for formulating policy, in assessing particular projects for assistance, in ensuring greater attention to the welfare and distributive effects of our aid, in evaluating the economic and social effectiveness of our various schemes, in apportioning and seeking approval for funds allocated for the programme, in bringing 
greater continuity and expertise into our staffing arrangements, and in more directly associating the community with the programme.

A fully unified aid administration will ensure that a comprehensive rational approach is adopted to foreign aid. The dispersal of aid functions among various Departments has reflected and sustained the sometimes conflicting viewpoints of individual Departments and has complicated the whole process of coordination... The new agency would be so constituted as to be able to formulate a comprehensive aid policy and to ensure that the various programmes are quickly and effectively put into action. (Wilenski, 1981 quoting PMO, 1973).

Indeed, the decision explicitly points to the need to improve aid administration and overall efficiency as a key driver of the choice.

Efficiency was also cited as a key driver of the Fraser Government's choice to close the ADAA. At the time, Fraser was focused on rationalizing the bureaucracy to promote efficiency during a poor economic period. For Fraser, the decision to close the ADAA was aligned with broader efforts to rein in government spending. Indeed, Australia's administrative costs as a percentage of ODA appeared to decline in the years following the re-integration of the ADAA into the DFA, falling from $2.1 \%$ in 1977 to $1.5 \%$ the following year.

Perhaps most notably, efficiency played a key role in the choice to create the AIDAB in 1985. In particular, the Jackson Review conducted in 1984 "essentially argued that the agency [ADAB] was administratively inept" (Corbett and Howard, 2017 p. 207); indeed, this sentiment was echoed by the Joint Committee on Foreign Affairs and Defence, which reviewed and responded to the Jackson Report in 1985. In terms of aid management, the committee highlighted long-term administrative challenges, stating "Aid administration in Australia has had a long and sad history of neglect which has had a cumulative and detrimental effect on the morale and capacity of ADAB. That ADAB's 
performance has been less than optimum has been recognised in recent years" (Joint Committee on Foreign Affairs and Defence, 1985 p. 26). Such inefficiencies squarely locate the decision to create the AIDAB as an autonomous structure (Model 4) in concerns about the administrative efficiency of the program and long-term challenges in Australia's aid management.

Lastly, there is some evidence to suggest that the 2013 merger was also an effort to improve efficiency by reducing administrative costs. While Abbott's press release announcing the merger did not point explicitly to costs, some commentators noted that, "we can also safely assume it [the Abbott Government] wants to see administrative efficiencies" (Davies, 2013). Indeed, there is perhaps some evidence of the expectation that the merger would enhance efficiencies in a press release issued by Minister Bishop, who stated that "The outcome of this major change will be the alignment of Australia's foreign, trade and development policies and programs in a coherent, effective and efficient way" (Bishop, 2013).

The rhetoric surrounding the merger and efficiency could have been driven by rising administrative costs in the years prior to reform. Despite being well functioning, AusAID's administrative spending had risen from $4.2 \%$ in 2010 to $6.6 \%$ in 2013, putting its administrative costs above the DAC-average (see Figure 9). The increase was driven by a spike in staffing, which was expected to grow by $66 \%$ from 2008-2016 (OECD, 2013a p. 69). ${ }^{92}$ While post-merger data shows a slight decrease in administrative spending following the reorganization, Davies (2017) recently noted that the merger did

\footnotetext{
${ }^{92}$ In the context of the staffing rise, the Shadow Parliamentary Secretary for International Development Assistance was quoted in 2012, expressing concern "that there is not the capacity even now to make sure this money is appropriately and effectively spent" (Corbett and Howard, quoting The Australian, 3 May, 2012). This suggests that even despite the rise, AusAID was far from a bloated bureaucracy.
} 
not result in any real administrative efficiency gains, stating that Australia's administrative expenditure accounted for a similar share of ODA in the 2017-18 budget as in 2012-13 prior to the merger - around 6\%. In this sense, the degree to which the merger affected efficiency may differ according to the data used.

\section{Figure 9: Administrative Costs as a \% of ODA}

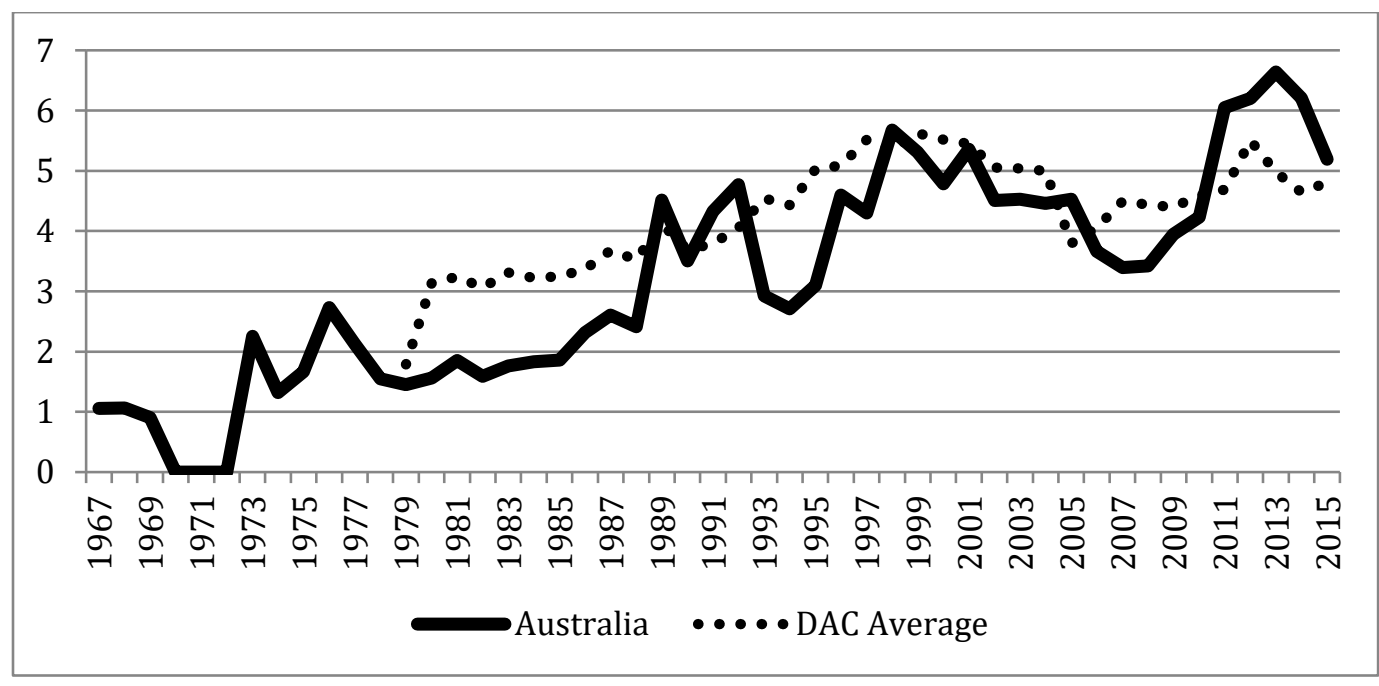

\section{Legitimacy}

There is some evidence that the experience of other donors influenced Australia's organizational choices. Notably, there is evidence of a link between Australia's structural choice and organizational legitimacy during the first reorganization when Australia developed the ADAA. At the time, many in Australia were aware that other like-minded donors, notably Canada and the US, were using autonomous agency structures. Indeed, Peter Wilenski actually visited Canada in the early 1970s, and is said to have modeled the ADAA on former CIDA (Corbett, 2017 p. 35).

Perhaps most obviously, some have suggested that the 2013 merger of AusAID may have been modeled on the CIDA-DFAIT merger announced just months before (ABC, 2013). In this sense, the Australian merger could have been influenced by the 
Canadian experience, pointing to the potential for policy diffusion, particularly across like-minded donors, to drive organizational change. While there are questions concerning the degree to which this merger done to enhance Australia's "legitimacy", as neither change was necessarily considered in the best interest of aid effectiveness or done

to advance best practice, the similarities between the mergers do suggest a form of "mimicry" across similar countries.

\section{Politics}

In the Australian case, there is strong evidence that political factors, particularly the preferences of political leaders, served as important determinants of organizational change. More so than in other cases explored so far, the political preferences of leaders, particular the Prime Minister, appeared to drive a number of Australia's aid agency changes. For instance, Australia's first aid agency change, in 1974, was notably driven by a group of key individuals who actively supported the development agenda including Morrison, Wilenski, and Prime Minister Whitlam. Indeed, both Corbett (2017) and Wilenski (1981) highlight the importance of key decision-makers in the creation of the ADAA. For Corbett, key individuals were so influential in securing the Cabinet's decision that momentum towards creating the agency "quickly dissipated" once these individuals turned attention elsewhere (2017 p. 26).

The reintegration of the ADAA into the DFA under the Fraser Government can also be seen as rooted in leadership preferences. Termed the "infanticide" of the agency (see Wilenski, 1981; Corbett and Howard, 2017), the abolition of the ADAA was linked to Malcolm Fraser's "cull of agencies" in efforts to rationalize the government bureaucracy during a time of financial crisis (Corbett and Howard, 2017 p. 206). While 
Fraser's efforts were also linked to a broader policy of rationalizing government spending, the decision displayed decidedly political overtones. For instance, from the outset, the Economic Committee of Cabinet charged with forming the government's rationalization strategy called for submissions with the "view to incorporating" the ADAA into the DFA, suggesting that other cost-saving options outside of a merger were not sought after. Indeed, the merger occurred despite objections from Andrew Peacock, the Minister of Foreign Affairs, who called on the government to retain the ADAA structure and instead recommended that the government "find savings within the bounds of existing programs" (Corbett, 2017 p. 41). To the degree that the choice to close the ADAA was pre-determined by the government and linked to a platform of spending cuts, the decision can be seen as political.

Perhaps the change event most explicitly linked to the preferences of political leadership was the 2013 merger, which is largely attributable to the whims of Tony Abbott. Firstly, the timing of Mr. Abbott's announcement, which was made the same day that he took office and came without prior warning or discussion, suggests a politically driven motivation. Indeed, when asked about the main drivers of the decision to reorganize Australia's aid program, Interviewees clearly stated that the decision appeared political, driven by Abbott himself (Interview 8, 2017; Interview 9, 2017). According to Interviewees, the strongest theory of the rationale behind the merger was that "someone from the Institute of Policy Affairs (IPA) was in the PM's Office, had his [Abbott's] ear, and planted the idea in his head" (Interview 9, 2017). The IPA is well-known for anti-aid sentiments and one Interviewee noted that "many people assume that it was Roskam (the Executive Director of the IPA) who advised Abbott to axe AusAID" (Interview 9, 2017). 
Additionally, it is perhaps significant to note that the Australian cases show a clear correlation between the adoption of Model 2 and Model 4 structures and political ideology. Specifically, both instances of reorganization from a Model 4 to Model 2 structure in the Australian case were made by conservative governments. Alternatively, both instances of change resulting in the adoption of a Model 4 structure (1974 and 1985) occurred under Labour governments with more liberal ideologies. These finding align with results from Chapter 4, which shows that Model 2 structures are associated with more conservative ideologies, and lends credence to the hypothesis concerning relations between ideology and structure presented in Chapter $2 .{ }^{93}$

\section{Purpose}

There is no evidence that the purpose of Australia's aid program had any real influence on the choice to reorganize. In general, the purpose of Australian aid has always been rooted in a combination of altruism and national interest, with Australian aid heavily focused on the Asia-Pacific region. The strategic orientation of Australian aid was obvious from its emergence in the Colombo Plan, when Australian aid was seen as both a humanitarian imperative and a "policy of serious self interest" (Wilkinson, 1976). This orientation was reiterated at various junctures. For instance, the Jackson Review acknowledged the "plurality of mandate" in the Australian case, which brought together humanitarian, strategic and commercial objectives as the joint goal of aid programming. While the Review called on the Government to strengthen Australia's developmental

\footnotetext{
${ }^{93}$ Two other notable reorganizations follow this trend. The creation of DFID in the UK in 1997, which involved a reorganization from the Model 2 structure to Model 4, was undertaken by a liberal government (Labour), matching the aforementioned linkage. Moreover, the 2013 merger of CIDA in Canada (from a Model 4 structure to a Model 2) occurred under Stephen Harper's Conservatives.
} 
objectives relative to other priorities, it is unclear whether this was a main driver of the change per se.

Australia did improve its development focus throughout the late 1990s and 2000s, when aid was increasingly concentrated in lower-income regions, notably South Asia and Africa. Indeed, Australia's development focus was stated in a 2012 policy document $A n$ Effective Aid Program for Australia: Making a Real Difference - Delivering Real Results, which acknowledged that Australia "cannot pretend to be tackling global poverty without increasing [its] investment in the world's two most impoverished regions" (AusAID, 2012a). ${ }^{94}$ However, prior to the 2013 merger, there were no policy statements or mentions of any policy-driven rationale for the change.

That said, it is worth noting that upon reorganization, the development narrative was re-framed to highlight the importance of aid as a means for self-interest. ${ }^{95}$ Notably, the 2013 merger was followed by a media release claiming that the change was the beginning of Australia's "new era in diplomacy", one which would foster policy coherence to "promote Australia's national interest, through contributing to international economic growth and poverty reduction, and support Australia's foreign and trade policy" (Bishop, 2013). While the official statement aligns the merger with efforts to enhance coherence and realign Australia's aid policy objectives, the timing of the policy announcement, which came more than a month after the merger was announced, suggests that there is no real evidence that the 2013 merger was undertaken in efforts to advance a

\footnotetext{
${ }^{94} \mathrm{An}$ increased focus on poorer regions was a key recommendation of an Independent Review of Australia's aid effectiveness conducted in 2011 (see GoA, 2011).

${ }^{95}$ This realignment is neither surprising nor necessarily unique to Australia. The 2008 financial crisis, and poor economic conditions and conservative wave that followed appears to have moved domestic development conversations towards highlighting national interest as a way to generate support for development spending.
} 
pre-conceived policy agenda or planned substantive changes. Rather, the merger, which "had not been foreshadowed prior to the election, nor had it been identified as an individual savings measure in the Coalition's pre-election costing" (Bruere and Hill, 2016), came without warning, suggesting that the Abbott government did not plan the change in any real sense, let alone as a way to match new substantive preferences. ${ }^{96}$

\section{NPM}

There is some evidence that organizational change in Australia's aid administration was linked to NPM. While Australia's earliest organizational changes, in 1974 and 1977, occurred in the period prior to the popularization of NPM as a driver of public sector reform, the 1985 establishment of AIDAB occurred in a period when NPM was in full force. At the time, the Hawke government was said to have adopted a moderate version of NPM and focused on enhancing public sector "efficiency" through sound management, and in some cases, by increasing the autonomy of certain agencies (Johnston, 2000; Mackay, 2011). In the case of the 1985 change, there is evidence that efficiency related concerns played a large part in justifying and prompting change, suggesting that the creation of the AIDAB matches the logic of NPM in this regard. Moreover, NPMs linkage to the "agencification" of government also matches the form of the 1985 reform, which saw the creation of an autonomous bureau for managing Australia's aid program.

\footnotetext{
${ }^{96}$ Consider the Dutch case presented in Chapter 6 in contrast to the Australian example. In the Dutch case, where substantive purposes were main drivers of organizational choice, the new decompartmentalized policy vision was outlined prior to reorganization and used as a clear justification for the need for reform. In the Australian case, the policy realignment was made explicit ex-post and cannot be meaningfully linked to policy considerations prior to reform.
} 


\section{Path Dependence}

Seeing as Australia underwent organizational change, the logic of institutional inertia inherent in path dependence is unlikely to apply.

\subsubsection{Discussion}

In the Australian case, instances of unpredicted organizational change have been driven by four variables: efficiency, legitimacy, politics and NPM. Of these, political factors stand out as particularly strong drivers of organization change over time, with two clear instances (1977 and 2013) of change driven by the preferences of political leaders in the absence of inefficiencies or structural change. ${ }^{97}$ Perhaps the most poignant example of politically driven change is the 2013 merger. In this case, the timing of the announced change as well as the absence of any indications that change was being considered prior to the election suggests that the choice was linked to the individual preferences of Tony Abbott upon taking office.

In the context of changes that are unpredicted by structural and budgetary factors, the 2013 reorganization indicates that the preferences of political leaders can act as drivers of change even in the absence of other predictors or need for change. The 2013 case is a particularly strong example of this as the reorganization took place in the context of strong fit between the actual model chosen (Model 4) and structural predictions at the time; Figure 8 (above) shows that the structure used at the time of the merger was predicted to be selected at 99\%. Moreover, while the 2013 merger did follow increases in aid expenditures, aligning with the finding that changes in ODA budgets

\footnotetext{
${ }^{97}$ The third instance of change influenced by political leadership mentioned above (1974) is not covered by the data used in the study so it is unclear whether this change is predicted or not. In addition, the 1974 change was driven by efforts to improve administrative efficiency as well as the preferences of political leaders.
} 
increase the likelihood of organizational change, it is perhaps significant that the merger of AusAID with DFAT is the opposite type of reform than expected in the presence of a growing aid program. Indeed, not only is it well established that larger public organizations are less likely to experience termination (see Downs, 1967; Kaufman, 1976), but the type of reform experienced runs counter to expectations presented in prior chapters. Indeed, recall that Chapter 4 points to a relationship between donor size and structural choice, where larger donors are shown to be more likely to adopt the Model 4 organizational structure. While Australia is more of a "mid-sized" than "large" donor, an increasing aid budget size should increase the relative likelihood of maintaining the Model 4 structure rather than adopting Model 2 form. In this sense, Australia's increasing budget size appears aligned with the use of a Model 4 structure, further suggesting that the change occurred in the absence of predictors and highlighting the ability for political factors to act as drivers of change.

Perhaps an important question stemming from the finding that instance of change occurred in the absence of predictors, is whether these changes can be linked to particular conditions in the Australian context at key points in time. Seeing as cases presented in Chapter 6 showed that organizational changes tend to be driven by factors beyond political drivers, it is important to fully unpack and examine whether broader contextual trends could have made politically driven change more palatable a key moments in time. Indeed, it is perhaps significant that both instances of unpredicted organizational change in the Australian case (1974 and 2013) followed a change in government that resulted in strong majorities by the former opposition parties and occurred in poor economic climate. 
In terms of the political climate, both reorganizations followed political victories that involved a change in the governing party from Labour to Liberal, where newly elected Liberal Government's won strong majorities. ${ }^{98}$ In 1975, Malcolm Fraser's Liberal-Country Party Coalition took power from the Whitlam government, winning 91 of 127 seats in Parliament (Barber and Johnson, 2014 p. 45). Within a month of the election, the Fraser Government launched its review of the ADAA, announcing its planned merger in the weeks that followed. ${ }^{99}$ Similarly, the 2013 election saw Tony Abbott and the Liberal/National Party Coalition win 90 of 150 seats, following two leadership changes in the Labour Party Government. In both cases, it is conceivable that strong majorities increased the capacity for Liberal leadership to reorganize aid programs unimpeded.

Indeed, the role of partisan political factors as determinants of organizational change echoes recent findings from the broader public sector literature, which suggest that changes to the partisan composition of the executive or legislature increase the likelihood of organizational termination (Lewis, 2002). In studying the relationship between political factors and the longevity of public agencies in the US context, Lewis finds that agencies are more likely to be terminated following a change in government, particularly in cases where the agency itself was established under the opposition party. Given that both the ADAA and AusAID were Labour government creations, and AusAID was strongly supported by the Rudd-Gillard government prior to the 2013 reform, their

\footnotetext{
${ }^{98}$ Both changes also occurred following tumultuous political periods. Fraser won his majority following a constitutional crisis involving former Prime Minister Gough Whitlam, while Abbott came to power after several leadership spills within the Labour Party that saw Kevin Rudd and Julia Gillard oust each other twice from 2010-2013 (from Kevin Rudd (2007-2010) to Julia Gillard (2010-2013), back to Kevin Rudd (2013)). That said, it is not clear how or whether such scandals influenced the likelihood of organizational change beyond paving the way for larger electoral victories for their opponents.

${ }^{99}$ By January 1976, the Fraser Government launched its review. However, the change did not formally take place until 1977.
} 
termination upon the election of Liberal governments could provide examples of partisan changes influencing structural longevity.

Second, both the 1977 and 2013 organizational changes in Australia occurred amidst poor economic conditions. From 1975 (when Malcolm Fraser's government came to power) to 1979, Australia faced "two episodes of cyclical weakness [in terms of GDP growth], in 1974-1975 and 1977" (Stevens, 2008 p. 20). Weak growth over the period was also linked to higher unemployment, which tripled from around 2\% in 1974 to almost $6 \%$ by 1977 (Stevens, 2008). ${ }^{100}$ While Australia weathered the 2008 global financial crisis relatively better than others, it still saw declining economic conditions in the post-2008 period slowed growth (McGrath, 2013b) and unemployment increasing by almost 2\% from 2008-2013 (McGrath, 2013a). Given the contingency theory understanding that environmental changes, including economic conditions, increase the likelihood of organizational change, such conditions in the presence of ideological changes in government and increased aid spending, ${ }^{101}$ may have further enhanced to the likelihood of reorganization.

Third, the ability for political leaders to enact change in the absence of clear need is perhaps enhanced by the lack of a clear constituency for development in Australia. Indeed, Interviewee 9 (2017) noted that "aid is a topic without much of a constituency" in Australia. In this context, the absence of political or institutional protections from reform could render aid agencies more vulnerable to institutional change. ${ }^{102}$ Similarly, while the

\footnotetext{
${ }^{100}$ While it is probably unfair to suggest that $6 \%$ unemployment illustrated "poor performance", in comparison to earlier in the decade, it marked a sharp change.

${ }^{101}$ Gross ODA (constant 2015 US\$) increased under the Whitlam government from US\$1.6 billion in 1972 to US\$2.3 billion by 1975 , while aid increased under the Rudd-Gillard Labour party from US\$3.4 billion in 2007 to almost US $\$ 4.8$ billion by 2012 .

${ }^{102}$ Interviewee 9 (2017), for instance, suggested that aid may be better protected by foreign ministries that could act as its "big brother or sister".
} 
1977 OECD-DAC Review of Australia's aid program notes that pubic awareness of development cooperation had increased, there is no evidence that development received broad or widespread support (OECD, 1977a). In the absence of a clear constituency for development, reorganizations could be more likely given the perception of reduced political consequences.

The point then is that while unpredicted changes in the Australian case highlights the role of political actors as drivers of change, contextual factors appeared to create conditions that fostered reform. This suggests that a combination of political and contextual elements, rather than politics alone, contributed to change. Whether organizational change to aid agency structure is possible in the absence of such conditions remains to be seen would require an analysis of all aid agency changes in order to clearly establish.

Beyond the role of political factors as drivers of change, the Australian case also sheds light on the perceived benefits of adopting a Model 4 structure. Notably, both instances of change resulting in the adoption of autonomous agencies (1974 and 1985) were done to improve the overall efficiency of Australia's aid system, pointing to the need for reorganization to strengthen the professionalization of staff and improve Australia's development capacity. Under the initial Model 5 structure and the ADAB, the professional capacity of Australia's development program was left wanting, suggesting that the autonomous structure was deemed as a more appropriate choice for nurturing and developing staff with specialized development knowledge.

The idea that Model 4 was selected at a time when Australia was seeking to strengthen the efficiency its aid program is notable in the context of recent rhetoric used 
to justify Australia's 2013 merger, which also cited improving efficiency as a driver of reform, and perhaps speaks to differences in how efficiency is understood in a development context. While recent mergers can be linked to efforts to reduce administrative costs in a period of economic stagnation, prior reforms in Australian show that the Model 4 structure has also been used to improve efficiency in terms of developing the professional development knowledge and capacity of staff. Indeed, the virtue of autonomous structures (both Models 3 and 4) for supporting the professionalization of development staff was a common thread throughout a number of interviews, with interviewees noting that autonomous structures were better for keeping and fostering a base of development expertise (Interview 1, 2017; Interview 3, 2017; Interview 5, 2017; Interview 8, 2017; Interview 9, 2017); when development is part of the foreign ministry, donors risk loosing development experts to rotation with other branches in foreign ministries. In this sense, it appears that part of the logic for reorganization to adopt autonomous structures could be linked to efforts to improve efficiency through creating a separate institutional space for professional staff development.

Lastly, the Australian case provides a clear example of the Model 5 structure being used as a "starter" model as suggested in Chapter 3. Indeed, in the Australian context, the Model 5 structure was a way to engage in aid without investing administratively in a structure for development; recall that in the 1950s, Australian officials presumed that their commitment to development would end with the finite period covered by the Colombo Plan. This provides further evidence to support the understanding that donors may adopt Model 5 structures in the initial years of aid 
programs, graduating to other structural forms over time. This finding could also lend support to Cunningham's thesis concerning the relationship between structure and substance, where multiple ministry structures are more readily employed in the years prior to investing in development policy and planning.

\section{$\underline{7.2 .4 \text { Conclusion }}$}

The Australian case explored four cases of organizational change over time, none of which were predicted to occur according to the results of the rare-events logit conducted in Chapter 5. As a result, this case sought to understand the reasons why organizational change occurred in the Australian case in the absence of change predictors.

Overall, instances of organizational change in the Australian case, which saw multiple shifts between the Model 2 and Model 4 structures, show that the changes in 1977 and 2013 in particular, were driven by the preferences of political leaders within a context that was conducive to change. Specifically, partisan political changes, the absence of a constituency for development, and economic conditions appeared to foster an environment that made reorganization more politically likely.

In addition, administrative efficiency within Australia's aid program was a main driver of change in both the 1974 reorganization as well as in 1985 . In both cases, clear institutional inefficiencies underscored domestic calls for reform. Moreover, Labour governments and key individuals eager to address inefficiencies provided impetus for change. In addition, instances of organizational change in the Australian case were also linked to legitimacy and policy diffusion, where the 2013 abolition of AusAID can be likened to the closure of CIDA just a few months prior. The logic of NPM agenda was 
also found to influence change in the Australian context, particularly the 1985 creation of the AIDAB.

\subsection{Japan}

The organizational roots of Japan's aid program are found in the system established to manage reparations following Japan's defeat in the Second World War II (Lancaster, 2007). Japan's aid program was managed using a complex system involving multiple ministries (Model 5) from the 1950s until the early-2000s. While many changes to the structure occurred at various junctures, substantive changes in the early 2000s solidified the role of the Ministry of Foreign Affairs (MOFA) and the Japanese International Cooperation Agency (JICA) as the main branches of Japan's aid management system, leading to the adoption of a Model 3 structure. Under the new structure, Japan's MOFA is responsible for overall policy direction while JICA works to implement Japan's technical assistance, grants and ODA loans (OECD, 2014c).

The Japanese case is used to represent an instance of organization change, which occurs when predicted by changes in budget size and structural factors. In cases where organizational change is predicted, a key question of interest is how and why budgetary and structural changes (and which structural changes) led to reorganization.

\subsubsection{History of Japan's Aid Management System}

The formal origins of Japan's aid program can be traced to the 1951 San Francisco Treaty, which mandated the Japan pay reparations for its role in World War II (Jain, 2015). Under the treaty, Japan began providing reparations to 13 Asia Pacific countries in 1954 (Lancaster, 2007; Jain, 2015). That same year, Japan joined the 
Colombo Plan and started providing small amounts of technical assistance to Asian countries, making the official beginning of Japanese aid (Lancaster, 2007).

According to Lancaster (2007), "The arrangements put in place by the Japanese government for managing those reparations shaped the way Japanese aid was administered later as well as the purposes that aid would serve" (p. 112). At the time, Japan used a complex system for reparation management involving a number of government agencies and private enterprises (Hasegawa, 1975; Lancaster, 2007). Several ministries were involved with various aspects of programming, including the Ministry of Foreign Affairs, Ministry of Trade and Industry (MITI), Ministry of Finance (MoF) and Economic Planning Agency (EPA) (Lancaster, 2007; Hasegawa, 1975). The MOFA was primarily responsible for coordinating requests from foreign governments; at the time, Japan used a "request based" aid model (or "reactive" donor role), where reparations funded projects at the request of recipients (Lancaster, 2007; Scheyvens, 1996). Additionally, MITI oversaw activities related to trade and production and possessed influence over industrial planning and finance, while the MOF managed internal budgeting and monetary policy and the Economic Planning Agency "was responsible for overall economic planning and for formulating Japan's five year plans" (Scheyvens, 1996 p. 35). A number of line ministries including Agriculture, Health and Wellness and Forestry and Fisheries were responsible for reviewing requests and bringing expertise to assessments of proposed projects (Lancaster, 2007). Together, the engagement of these ministries in aid management gave Japan a Model 5 structure.

In 1961, Japan's growing loan program, which had been launched a few years prior, led the Japanese government to create the Overseas Economic Cooperation Fund 
(OECF) to manage programming (Lancaster, 2007; Jain, 2015). In 1962, the Overseas Technical Cooperation Agency (OTCA), which would later become JICA, was created to deliver technical assistance programs abroad (Jain, 2105).

The creation of these agencies raised bureaucratic tensions over the questions of ownership and management (Lancaster, 2007; Jain, 2015). For the OECF, three agencies (MITI, MOF and MOFA) each sought to control the new loan program. Each of the departments had experience managing aid relations and the new aid program naturally fell within the purview of all three (Rix, 1980). The government eventually opted for a compromise by granting official responsibility to the EPA (Jain, 2015; Rix, 1980). ${ }^{103}$ There were similar questions over which agency should manage the OTCA. A number of ministries including MITI, the Ministry of Agriculture, Ministry of Transport and Forestry and Fisheries "claimed supervisory jurisdiction on OTCA through their emphasis on the technical cooperation aspect of the agency's brief' (Jain, 2015 p. 59). This was done on the basis that each ministry was responsible for technical cooperation on projects in their field. It was eventually decided that the OTCA would be supervised by the MOFA, which "emphasized the overseas aspects of the agency's main brief to undertake technical cooperation overseas" (Jain, 2015 p. 59). While this structure remained in use over the next decade, the highly disaggregated and bureaucratically driven nature of Japan's aid program sparked criticism and calls for "administrative unity" by actors within the government who pushed for the creation of a central aid agency (Model 4) (Rix, 1980; Hasegawa, 1975).

\footnotetext{
${ }^{103}$ Although, Jain (2015) notes that in practice, the OECF was essentially managed by a "four ministry system" which included the MoFA, MITI, MOF and EPA.
} 
By the 1970s, there was greater urgency in the need for reform as "international conditions began to favour a more coordinated approach to aid management" (Rix, 1980 p. 51). In part, the urgency was due to internal disputes and requests by ministries to establish their own aid structures. Both the MAF and MITI submitted proposals to the government to create an aid agency under their leadership (Rix, 1980). The proposals sparked controversy across ministries involved and resulted in the Tanka Government (1972-1974) submitting its own proposal for an aid agency in efforts to manage ministerial tensions.

In early 1974, a small team within the Foreign Minister's Secretariat was established to draft a proposal for a new agency. One of the key challenges faced in this process was reconciling the short-term objectives of MITI and the MAF, with the MFA's longer-term aspirations for Japan's development program (Rix, 1980). Importantly, Rix (1980) notes that disagreements between the agencies "were not about relations between Japan and the developing countries but were determined largely by domestic factors" including short timelines and fixed positions by ministerial stakeholders (p. 65). Specifically, issues around agency business, administrative control and relations across Japan's complex aid network led to conflict between actors, such tensions became particularly acute during discussions of aid management.

In 1974, JICA was established as a compromise. The agency merged the responsibilities and staff of three agencies - the OTCA, Japan Emigration Services (JEMIS) (managed by the MFA) and part of MITI's Japan Overseas Development Cooperation Body (JODC) and was formally managed by the MOFA (Rix, 1980). ${ }^{104}$

\footnotetext{
${ }^{104}$ Typically, Japanese agencies had four to five directors making the upper management of JICA particularly cumbersome (Rix, 1980).
} 
Despite setting the new structure, the "hurried" formation of JICA in response to rival requests meant that the scope of JICA's operations were largely unclear until 1979 "and arguments between ministries over jurisdictions prevented the smooth implementation of agency programmes” (Rix, 1980 p. 69).

Even with the creation of JICA, coordination across Japan's complex aid system remained an ongoing challenge. Specifically, policy coordination was a main concern as the absence of a "fixed bureaucratic 'home' and no steady political support, meant that fundamental changes in aid policy depended on the extent to which coordination could be effected (a) between aid and other national policies; (b) between the kinds of aid to a particular country; and (c) between different parts of the entire aid program" (Rix, 1980, p. 145). In the absence of an official policy statement on the objectives of Japan's aid program to guide ministerial action, such coordination was left wanting. These coordination challenges would persist throughout much of Japan's future.

The 1980s saw a profound change in the Japanese aid program, both in terms of budget and policy. Firstly, Japan's aid program expanded rapidly throughout the decade thanks to a series of "doubling plans" announced in 1977, 1981, 1985 and 1988 (see Figure 10) (Lancaster, 2007). By 1989, Japan had become the largest donor in the world. 
Figure 10: Japanese ODA SUS Millions, Constant

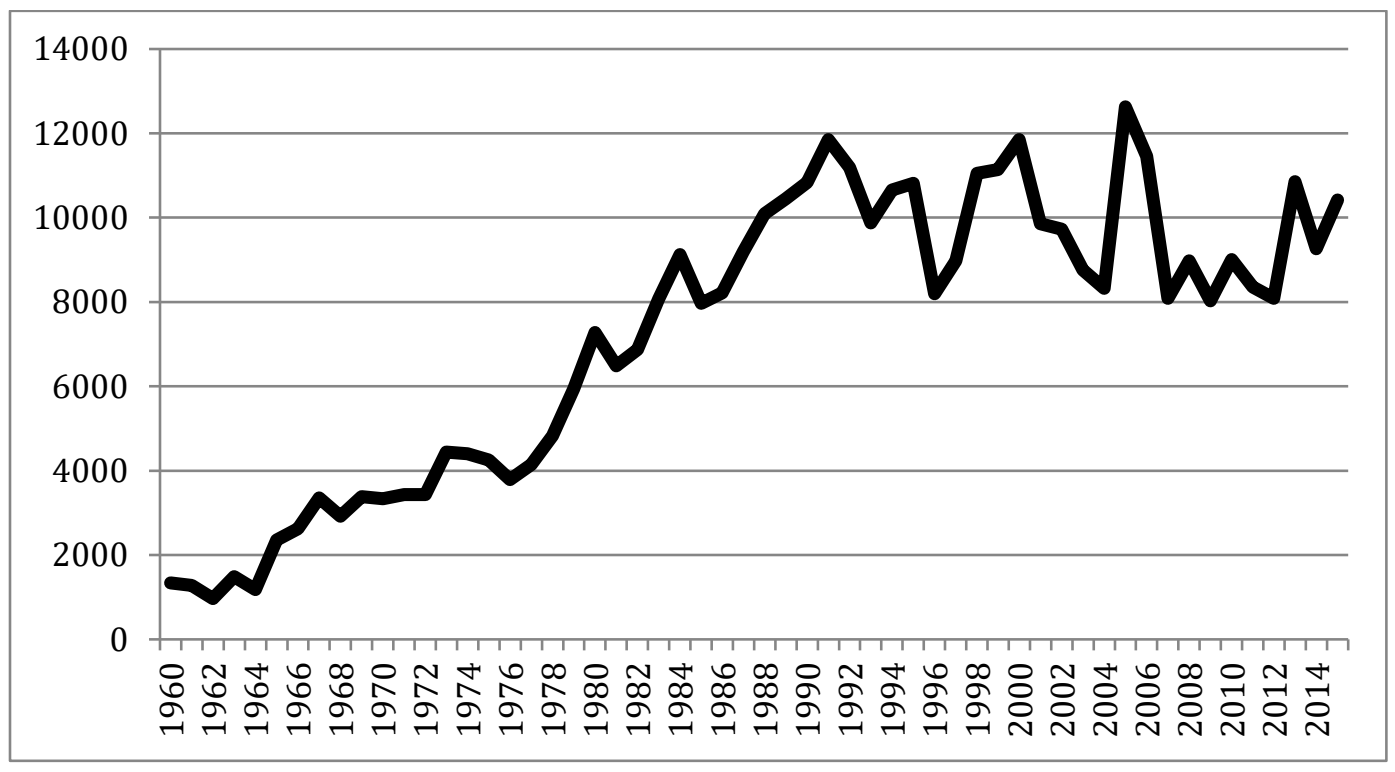

The increase in Japan's ODA budget attracted public attention and scrutiny to the aid program (Arase, 1995). While Japan's aid management structure remained the same throughout this period of rapid growth, calls to reform Japan's aid program began in the mid-1980s following a scandal related to OECF loans to the Philippines. Papers seized by the US Government when then President Marcos fled to the United States in 1986 revealed that $10-15 \%$ of OECF loans to the Philippines had been "kicked back to Marcos and his cronies by more than fifty Japanese contractors through a system of bid rigging, contract fraud, and illegal payments" (Arase, 1995 p. 114). The scandal resulted in an uproar and sparked calls for reform of Japan's aid management.

The scandal prompted the government to order its Management and Cooperation Agency (MCA) to conduct an "administrative inspection" of the Japanese aid system (Arase, 1995). Two reports released by the MCA in July 1988 called for five areas of reform: 1. Enhance project follow-up support; 2. Speed up processes for emergency aid distribution; 3. Relocate grant-aid paperwork from the MFA to JICA; 4. Ensure technical 
training met the needs of partner countries; 5. Develop "prepackaged" aid projects to enhance implementation speed (Arase, 1995). While these reforms amounted to little more than "tinkering" with Japan's administrative system, Arase (1995) suggested that, "it symbolized an effort by the government to tackle ODA reform" (p. 119). A further MCA report published later in 1988 examined Japan's larger loan program, calling for a clarification of the roles and responsibilities of key agencies including the MFA, MITI, MOF and EPA. More broadly however, the MCA reports had identified a key problem that there was "much evidence that Japan's ODA was not improving the welfare of recipient countries" (Arase, 1995 p. 120). While the MCA recognized that Japan's complex administrative system may have contributed to such results, MCA studies were "premised on maintaining the existing basic administrative structure" and "could not consider whether the division of ODA responsibilities among sixteen ministries and agencies had anything to do with the observed ineffectiveness or inefficiency of Japan's ODA" (Arase, 1995 p. 120).

In 1997, the Japanese Government launched an administrative reform of its ODA program (OECD, 1999d). The reforms occurred as part of a broader administrative reform, which reorganized a number of government ministries and agencies in efforts to strengthen government functions and enhance accountability of government to its citizens (Nakano, 1998; Kaneko, 1999). In terms of development, reforms aimed to improve the transparency and efficiency of Japan's aid program through “better coordination among different ministries, the private sector, and other donors; reduction of overlaps in project preparation; better utilization of NGOs; re-organization of JICA; and enhancement of field offices" (OECD, 1999d p. 26). 
To improve coordination, efforts were taken to reduce the number of actors in Japan's aid structure from 22 ministries to 12 by the year 2000 (Arase, 2005). Coordination was also strengthened through formalizing the role of the MOFA as the coordinating authority for ODA activities across Japan's aid management system (OECD, 1999d; Arase, 2005; MOFA, 2001). While the MOFA had assumed a coordinating role in the past, it had not previously possessed a clear mandate for coordinating development policy. In 2001, the MOFA's coordinating role was solidified in the Law for the Establishment of the Ministry of Foreign Affairs, which "assigned the Foreign Ministry jurisdiction over the coordination of planning and policy-making by each government agency in relation to a common ODA policy, technical cooperation, and yen loans" (MOFA, 2001 p. 51). According to the MOFA's 2001 White Paper, the formalization of the MOFA's role was done to enhance "coordination and collaboration among the government ministries and agencies and the various systems they employ" ( $p$. $51)$.

In late 2001, the Japanese government decided to grant JICA the status of an "Independent Administrative Institution" as part of its efforts to reorganize and rationalize public agencies (OECD, 2004c p. 45; MOFA, 2002). The law formalizing JICA's new status came into effect in 2003, providing JICA with greater autonomy and flexibility over organizational management and marked the first phase in JICA's reform (MOFA, 2002). Importantly, Japan's Parliament (called the Diet) also considered other organizational models for managing Japanese aid as part of the reform process. Namely, members of the Diet suggested that ODA operations be organized "around a single bureaucratic entity" or Model 4 structure (OECD, 2004c; Interview 12, 2017). However, 
the OECD reports that the model "was considered to contain operational disadvantages and to be politically unrealistic in the current context" (OECD, 2004c p. 45).

A second phase of reform occurred in 2008 when Japan established its "new JICA" by merging JICA with the development-focused branches of JBIC (OECD, 2004c; MoFA, 2003). ${ }^{105}$ The merger was a continuation of earlier efforts that "sought to establish cohesive institutional arrangements under which aid policy and related decisionmaking would be improved and more effective and efficient aid delivery achieved" (Jain, 2015 p. 60). Towards this goal, the merger located all three major branches of Japan's aid program - grants, loans and technical assistance - with the new JICA, making it the main implementing agency for all of Japan's ODA. In essence, the merger turned JICA into a "super-agency" which, as of 2010, managed "more money than any other DAC member agency" (OECD, 2010a p. 12).

A few years later, the OECD-DAC reported that the series of reforms undertaken by Japan had resulted in a clear division of labour and institutionalization of the roles and responsibilities of the main actors in Japan's aid program - the MoFA and JICA. The reforms served to strengthen the policies making and implementation capabilities of the agencies and had facilitated stronger cooperation. While the OECD reports that "there might be scope to further refine working arrangements and procedures to maximize the consistency, effectiveness and efficiency" of the contributions of the MoFA and JICA, the reforms had already produced improvements (OECD, 2014c).

\footnotetext{
${ }^{105}$ JBIC was formed in 1999 through a merger of the Overseas Economic Cooperation Fund (OECF) and the Export-Import Bank of Japan (JEXIM). In terms of ODA, JBIC's main function pertained to managing ODA loans. JBIC was not a pure development institution; two-thirds of JBIC staff worked on commercial operations (OECD, 2004c).
} 


\subsubsection{Determinants of Organizational Change}

The Japanese case provides an example of change occurring when predicted by budgetary changes and low structural predictors. In terms of budget size, Figure 10 (above) shows that aid increased in the years prior to the change in 2001. Moreover, the likelihood of Japan selecting the actual structure used declined in the years prior to the organizational reform, suggesting that changes in the Japanese context likely precipitated or contributed to change. A key question for exploration in this section is what factors contributed to a reduction in the likelihood of adopting the model chosen prior to reform. Together, the analysis finds that organizational changes in Japan were driven by efficiency, legitimacy, NPM and politics.

\section{Efficiency}

There is strong evidence to suggest that the reorganization of Japan's aid management system from a Model 5 to Model 3 structure was deeply rooted in efforts to improve administrative efficiency. Specifically, reforms of Japan's aid management system throughout the 1990 s and 2000s were driven by concerns over fragmentation in aid management due to the use of a multiple ministry structure. Indeed, calls for reform to enhance "administrative unity" within Japan's aid program had been articulated both domestically and internationally (by the OECD-DAC) since the 1970s, suggesting deepseated inefficiencies with the Model 5 structure. Following the 1986 Marcos scandal, concerns over the capacity of the Japanese system to conduct proper oversight and coordination across aid programs led to further calls for reform and resulted in a "push to improve transparency and efficiency" of the aid program (OECD, 1999d p. 16). In this sense, the adoption of a Model 3 structure can be seen as a direct effort to improve 
coordination and reduce the fragmentation of Japan's aid program by 1) formalizing the responsibility of the MOFA as the main entity responsible for development policy and coordination, and 2) locating primary responsibility for the implementation of Japan's loans, grants, and technical assistance within JICA.

\section{Legitimacy}

There is some evidence to suggest that legitimacy was a driver of organizational change in the Japanese case. Notably, Jain (2015) reports that throughout the 1990s and 2000s, the reorganization of Japan's aid system was partly driven by “external pressures on Japan to make aid institutions transparent and cohesive...driven largely by the DAC" (p. 60), a sentiment shared by Interviewee 11 (2017). In this sense, while there is no evidence to suggest that Japan modeled its Model 3 structure on other donors, it does suggest that normative pressure from the DAC influenced the decision to reduce fragmentation through organizational change.

\section{Politics}

Political factors also played a role in driving the public-sector wide reforms that resulted in altering Japan's aid management system. From a political perspective, organizational change can be linked to cross-government reforms oriented towards realigning the accountability of Japan's government towards its citizens and away from strong bureaucratic and private interests (Nakano, 1998). In the aftermath of several scandals and ensuing public scrutiny of Japan's development program, the Japanese government launched an initiative to "break the collusive relationship between politicians, bureaucrats and business" (sei-kan-gyo no yuckuka daha, cited in Nakano, 
1998 p. 291). ${ }^{106}$ For aid, the impact of the scandals were significant, with public support for development falling from $41 \%$ in 1991 to $19 \%$ by 2002 (Lancaster, 2007). In this context, the reform of Japan's aid system was a necessary effort to enhance the accountability of Japan's aid program through simplifying the structure and clearly delineating responsibility for development policy and implementation.

Interestingly, scrutiny of the Japanese development management system appeared to garner the Diet's (Japan's Parliament) interest in Japan's ODA. While the Diet typically plays a "limited role in policy debates and decision-making on aid" (Ohno, 2013 p. 17), the Diet's debate over structural reform acknowledged the need for Japan to improve the efficiency, transparency and effectiveness. It was during these discussions that the option of adopting an autonomous aid agency structure (Model 4) was considered and rejected by the Diet on the basis that the option was seen "to contain operational disadvantages and to be politically unrealistic" (OECD, 2004c p. 45). In this sense, government-led reform efforts and parliamentary engagement around questions of aid agency structure and change show the importance of political drivers as determinants of reorganization.

\section{Purpose}

The purpose of Japan's aid program does not appear to have contributed to organizational change. Notably, there has been limited change to Japan's aid policy over time. Historically, Japan's aid program focused on strategic and commercial objectives, with national interest remaining central to Japan's ODA today (MOFA, 2015). In the

\footnotetext{
${ }^{106}$ For instance, in the early 1990s, Muneo Suzuki, a Japanese politician was "accused of pressuring the MOFA to channel aid through enterprises in his constituency" (Lancaster, 2007 p. 129). There was also criticism surrounding historically large aid flows to Indonesia in the take of the Suharto government collapse on charges of corruption (Lancaster, 2007).
} 
early years of Japan's aid program, this objective underlay the efforts of individual ministries and continued to drive Japanese development assistance throughout its history, with the pursuit of Japan's national interest remaining central to the main priorities of Japanese ODA. For instance, Japan's 2003 ODA Charter states that "The objectives of Japan's ODA are to contribute to the peace and development of the international community, and thereby to help ensure Japan's own security and prosperity" (MOFA, 2003 p. 1). While the pursuit of peace and global development, such goals are clearly linked to securing “Japan's own security and prosperity” (MOFA, 2003). With little real change to the purpose of Japan's aid program over time, the substantive preferences of Japanese aid appeared to have had little influence over the choice to reorganize.

\section{NPM}

There is some evidence that Japan's reform process throughout the 1990s, which led to the reorganization of the Japanese development system, was influenced by the NPM agenda. The reform program was highly aligned with the principles of NPM, focusing on improving efficiency through the creation of independent administrative units which were used to "separate policy-making functions and policy-implementing functions to improve efficiency and quality of service" (Kaneko cited in Koike, 2000; Yamamoto, 2008). In terms of aid, granting "independent administrative institutions" status to JICA as part of the reform agenda could highlight the application of the NPM logic in the aid context. In essence, these reforms were driven by the logic of NPM and the search for administrative efficiency by separating out key implementation units, including JICA. 


\section{Path Dependence}

Seeing as Japan underwent organizational change, the logic of institutional inertia inherent in path dependence is unlikely to apply.

\subsubsection{Discussion}

In the Japanese case, organizational change appears to be driven by efficiency, legitimacy, politics and NPM. Most notably, efficiency can perhaps be considered the most prominent driver of reform, where clear inefficiencies in aid management, combined with scandals due to poor oversight, drove the need for changes in the aid management system. Indeed, in Japan, the need to reform the Model 5 structure to streamline responsibility for development policy and implementation was a long-running concern, highlighting clear pressure for change prior to change occurring. In the context of a large aid budget, poor oversight and challenges related to coordination and coherence within the Model 5 structure necessitated organizational change.

Notably, the need for reform in Japan's aid management system stands in sharp contrast to the Australian case, where certain instances of reform occurred in the absence of clear need and the presence of political drivers. Indeed, while politics played a role in driving Japan's reform agenda, the locus of decision-making power within the Japanese bureaucracy rather than the executive appeared to weaken the influence of any partisan differences or individual preferences concerning aid management. Rather, aid structure was determined by the push-and-pull between ministries seeking control over development. 
In the context of strong and competing bureaucratic interests, it is perhaps unsurprising that Japan adopted a Model 5 structure for managing its aid program in the first instance. It is however, interesting that Japan continued to use to Model 5 structure despite internal and international calls to streamline the aid program as early as the 1970s, notably due to difficulties satisfying bureaucratic tensions. In this regard, the Japanese case stands in contrast to other cases explored so far and is one of a few cases where the Model 5 structure was taken forward over the longer term; recall that in some instances, Model 5 acts as a "starter" model (see Chapters 3 and 6).

Importantly, the Japanese case may also shed insight on the relationship between the Model 5 and Model 3 structures noted in Chapter 3. Recall that all donors that used the Model 5 structure over a longer period adopted a Model 3 form upon reorganization. In the Japanese case, the basic tenets of the Model 5 system appeared to influence the eventual choice to adopt a Model 3 structure over other alternatives. Notably, the absence of centralized policy coordination within an individual ministry, as is the case for Models 1 and 2, meant that there was no "natural" driver of development policy and likely made merged options unfeasible. Similarly, tensions between bureaucratic entities likely made it difficult and "politically unfeasible" to create a separate aid agency, as where the agency would fall within the bureaucracy had no clear or easy answers. In this sense, Model 3 structure appeared the most aligned to the Model 5 form previously used, where the underlying features of the Model 5 structure including the role and responsibility of JICA as a separate implementing agency and increasingly the role of the MOFA as coordinator of development efforts across departments, were retained and strengthened in the Model 3 form. To the degree that the Japanese case can be used to illustrate other 
instances of donors moving from the Model 5 to Model 3 structure, it seems that part of the rationale for this type of reform is likely rooted in the alignment between the Model 5 and 3 structures.

Moreover, the Japanese case provides additional support for the role of legitimacy and NPM as drivers of organizational change. In terms of legitimacy, normative pressure by the DAC highlights its role in setting best practices concerning aid activities and in this case, aid management. Moreover, results from the Japanese case align with findings from the Australian example which link organizational changes to NPM driven reforms throughout the 1980s and 1990s.

\subsubsection{Conclusion}

The Japanese case provides an example of organizational change occurring when predicted according to the results of Chapter 5. In this case, organizational change was closely linked to deep-seated administrative inefficiencies in Japan's long-used Model 5 structure. Specifically, coordination challenges and fragmentation across a complex system drove calls for organizational reform.

The Japanese case stands in stark contrast to the Australian example in terms of the locus of political drivers for organizational reform. While the Australian case highlighted the importance of political ideology and the individual preferences of political leaders, the Japanese case highlighted bureaucratic actors and as key drivers of reform. Indeed, inter-ministerial efforts to control Japan's development program in part determined the Model 5 structure and appeared to institutionalize the model until the early 2000s. Moreover, the Japanese case provides initial insight into the relationship between the Model 5 and Model 3 structures, suggesting that the institutional 
fragmentation of the Model 5 structure is most clearly adapted to Model 3 forms over other models which concentrate responsibility for aid policy and implementation within a single agency.

\subsection{Germany}

Since the 1970s, Germany's aid program has been managed by the Ministry of Economic Cooperation (BMZ), which is responsible for policy development, and works with specialized agencies, such as Kreditanstalk fur Wiederaufbau (KfW) and recently, Deutsche Gesellschaft fur Internationale Zusammenarbeit (GIZ) to implement BMZ programs (Model 3). While Germany has retained a consistent organizational model over time, results from Chapter 5 show that Germany has been predicted to undertake organizational change in 12 of the last 15 years, without such change occurring. In instances where change is predicted but does not occur, the main question of interest is why Germany has not undertaken organizational change within conditions found to be conducive to change events.

\subsubsection{History of Germany’s Aid Management System}

Germany's aid program began in the 1950 s as part of its "rehabilitation" after World War II (Lancaster, 2007). At the time, Germany's development program was managed by up to sixteen separate ministries (Model 5), although the main actors were the Foreign Ministry (AA) and the Ministry of Economy (BMW) (Simon, 1982). In 1961, the creation of BMZ as a ministry devoted exclusively to the provision of Germany's development assistance made it the third major ministerial actor in Germany’s development system. 
The creation of BMZ was largely seen as a response to internal and external pressures at the time. Externally, the creation of BMZ was a "gesture towards the United States which had been pressuring West Germany to go into the aid business in order to share its aid and defence burden" (Cunningham, 1974 p. 134). At the time, the Kennedy administration was engaged in efforts to persuade rich nations to assume more of the global security burden, including through expanding aid efforts to developing regions (Lancaster, 2007; Holbik and Myers, 1968). From 1958 to 1961, the US Government put direct pressure on the German Chancellor, Konrad Adenauer, for Germany to contribute its share of the "burden of aid" (Simon, 1982 p. 125). According to Simon, the US tied the aid issues to German payments for US troops within West Germany with the expectation that "If the Germans had not agreed to provide substantial development assistance to LDCs, the American's would have demanded reimbursements of a larger share of its stationing costs" (Simon, 1982 p. 125).

Internally, the creation of BMZ was also the result of coalition politics. Germany's election in 1961 saw Chancellor Adenauer's Christian Democrats and sister party, the Christian Socialists, loose their majority government and form a coalition with Liberal Party leader Walter Scheel (Simon, 1982; Lancaster, 2007). At the time, Scheel was seeking a foreign policy portfolio and was said to have had special interest in development efforts (Lancaster, 2007). In this context, BMZ was created as a second ministerial post pertaining to foreign efforts, "making it possible for each major party in a governing coalition to have such a portfolio" (Lancaster, 2007 p. 173).

In its early days, BMZ primarily served a coordinating function, acting as chair for the inter-ministerial committees tasked with overseeing development efforts across 
multiple actors (Simon, 1982). Functionally, BMZ began to take over responsibility for development over the course of the 1960s. In 1962, BMZ was made financially responsible for its own budget ${ }^{107}$ and by 1968 had "attained full control over the principles, the program and the coordination of TC [technical cooperation] (from AA in December 1964), then over the implementation of TC (from BMW in 1968)" (Simon, 1982 p. 127).

By the later part of the 1960s, a change in government and increasing public interest in development brought with it a new purpose for Germany's foreign aid. At the time, the newly appointed Minister of BMZ, Social Democrat Erhand Eppler, sought to "depoliticize" aid, which he saw as subordinated to the prevailing Hallstein doctrine ${ }^{108}$, and instead aimed to enlarge BMZ's influence through garnering control of capital aid, and making BMZ Germany's main representative in international issues and efforts regarding development policy (Schmidt, 2003). According to Cunningham (1974), changes within BMZ throughout the 1960s set the stage for Eppler's policy shift, noting that by the time Eppler took over, "there were in the ministry enough staff of radical turn of mind to make it possible for Eppler to switch the emphasis of policy away from the commercial considerations...towards a more developmental approach" (p. 134). In part, conditions for Germany's shifting policy focus were also driven by the so-called "youth revolution" occurring throughout Europe, as "students and young people, who were energized by opposition to the war in Indochina and active in pressing (and sometimes attacking) their governments on issues of war and peace and development" (Lancaster, 2007 p. 175).

\footnotetext{
107 Although, Simon (1982) notes that it was not "functionally" responsible for it as yet (see p. 127).

${ }^{108}$ A policy of non-engagement with East Germany and supporting West Germany's economic interests (see Schmidt, 2003).
} 
The changing philosophy strengthened BMZ's voice within the government during a period that Lancaster (2007) calls the "consolidation" of development in Germany. It was at this time that BMZ become responsible for formulating Germany's development policy (Cunningham, 1974); in 1971, BMZ produced its first-ever development policy statement (Lancaster, 2007). By 1972, BMZ had also taken over responsibility for financial cooperation from BMW (Simon, 1982), solidifying its position as Germany's main development actor and marking the beginning of Germany's use of a Model 3 structure.

While BMZ had become the main actor responsible for development policy, by the 1970s, the implementation of Germany's aid program had been, and remained, the responsibility of a range of agencies with varying mandates. From 1975 onward, the implementation of Germany's technical cooperation was the responsibility of GTZ, a "private law company" wholly owned by the German Government (Simon, 1982 p. 132). Prior to 1975 , technical cooperation was the responsibility of two main agencies, the Bundesamt für gewerblicke Wirtschaft (BAW), which was established in 1958 and under the supervision of BWM until responsibility for technical cooperation was transferred to BMZ in 1968 (Simon, 1982). Under BMZ leadership, the BAW became the Federal Agency for Economic Cooperation (BfE) and was primarily responsible for "all nonministerial official tasks of technical assistance" (Simon, 1982 p. 131). According to Simon, BfE routinely worked with the German Cooperation for Technical Assistance to Developing Countries (GAWI), a private organization owned by the federal government, largely through contracting their services for development activities. On the 
recommendation of the Bunderechnungshof ${ }^{109}$, which conducted a review of the German aid system and was critical of inefficiencies, the BfE and GAWI were merged in 1975 to create GTZ (Simon, 1982). In this context, GTZ became responsible for the gamut of activities related to the planning and implementing of technical cooperation projects and programs on a behalf of BMZ. ${ }^{110}$

A further significant actor in Germany's development system is KfW. KfW was created in 1948 as a private corporation under public law designed to administer funds for German reconstruction (Simon, 1982). By the 1959, KfW had become the German government's development bank and provided funds for foreign aid. ${ }^{111}$ In essence, KfW acted as BMZ's second implementing agency, responsible for financial cooperation including grants and loans to low-income countries, and worked closely with BMZ which ultimately approved all funding proposals. Together with GTZ and BMZ, KfW was (and still is) the third branch in Germany's "triangular" development cooperation system (Interview 15, 2017).

Administratively, there were very few changes to the structure of Germany's aid management system throughout the 1980s. Perhaps most notably, the early 1980s marked the beginning of a new scheme for project management between Germany's two implementing agencies - KfW and GTZ. Throughout the 1970s, the use of two agencies for project implementation had caused some coordination challenges (OECD, 1982). While KfW and GTZ initially devised a program to share project lists and information on

\footnotetext{
${ }^{109}$ Simon (1982, p. 132) describes this as the German equivalent of the American Government Accountability Office.

${ }^{110} \mathrm{BMZ}$ and GTZ worked on a contractual basis. In essence, BMZ commission GTZ to on each specific task, where BMZ "makes decisions on specific projects according to an implementation plan prepared and submitted by GTZ" (Simon, 1982 p. 132). The relationship between the agencies was close, with the BMZ Minister acting as Chairman on GTZ's board of directors.

${ }^{111}$ It should be noted that only one third of KfW's staff were involved in development activities, with KfW also responsible for domestic investment and export credits (Simon, 1982).
} 
the dispatch of experts, and work together on implementation issues, the OECD reported that these "arrangements did not work very effectively and often led to long administrative delays - particularly in the case of integrated projects that required both capital and technical assistance inputs" (1982, p. 24). To address the ongoing challenge, KfW and GTZ came to a new agreement in 1980 whereby only one agency would implement any given project. In essence, KfW would implement projects that consisted mainly of capital assistance, while GTZ would implement technical assistance projects (OECD, 1982).

By the mid-1990s, a changing development context and declining aid budget raised questions about both the purposes of Germany's aid program and the long-term need for a separate ministry for development cooperation (ie. BMZ) (Lancaster, 2007 p. 178). Contextually, the 1990s saw increasing focus on "global problems", specifically issues related the governance quality, the environment and global health (Lancaster, 2007; Hill 2002). Such challenges raised issues of policy coherence, both internationally and within Germany (Ashoff, 1999). At the same time, the domestic costs of absorbing East Germany in the early 1990s placed pressure on government spending and led to a reduction in aid resources (Lancaster, 2007; Hill, 2002). Together, these issues sparked debate over how Germany could improve the efficiency and effectiveness of its aid program within a changing environment (Hill, 2002).

In this vein, a number of proposals were presented as ways to strengthen BMZ's authority and autonomy. According to Ashoff (1999), such proposals included: drafting 
legislation for development, creating a "Development Cabinet"112, strengthening BMZ's role vis-à-vis the federal government, expanding BMZ's role and responsibility, and "utilize[ing] fully BMZ's existing scope of action and to increase sensitivity in other ministries as regards the development impact of their policies" (Ashoff, 1999 p. 165173). At the same time that most were seeking to strengthen BMZ, a further proposal sought to merge BMZ with the Foreign Ministry (see Ashoff, 1999 p. 165-173). The proposal was raised in 1994 by Rudolf Scharping, a member of the Social Democrat Party who was running for the post of Chancellor in the upcoming federal election, who argued that BMZ should be merged with the Foreign Office (Ashoff, 1999). ${ }^{113}$ For Scharping, the merger was not only aligned with other reforms taking place in OECDDAC countries at the time, but was also justified as a way to "increase the political importance of development policy and to achieve greater policy coherence" (Ashoff, 1999 p. 170). Ashoff notes that Scharping saw the merger as a way to ensure that development was run by a strong ministry, which was needed to "give development policy the momentum required in view of the global character of development problems" (1999 p. 170). Strong public opposition from all political parties and a range of NGOs, churches and other development activists, who saw the proposal as a way to subordinate aid to other interests, prevented the merger from occurring (Ashoff, 1999). ${ }^{114}$

Additionally, the late 1990s saw a massive effort to decentralize Germany's aid program and strengthen its field presence. At the time, calls for greater coordination and

\footnotetext{
${ }^{112}$ This proposal would essentially render the Chancellor responsible for aid, suggesting that "the Development Cabinet should be chaired by the Chancellor and meet several times a year to define and monitor the goals of German foreign, development and security policies" (Ashoff, 1999, p. 167).

${ }^{113}$ Importantly, Ashoff (1999) also notes that the SDP were traditionally strong advocates for development assistance, with many members calling for proposals that would strengthen BMZ's role.

${ }^{114}$ Lancaster (2007) notes that the proposal to merge BMZ with the foreign office would be raised again during elections in 2002, but with "little effect".
} 
collaboration with host countries showed that Germany's field presence was "surprisingly weak" given the size of its program (OECD, 1995). ${ }^{115}$ By 1998, a significant decentralization effort was well underway by KfW and GTZ. While KfW created field offices housed with GTZ to enhance cooperation (OECD, 1998), GTZ expanded its field offices to 66 in 2006 up from 55 in 1995 (OECD, 2006b p. 54; OECD 1995).

Calls for greater decentralization of Germany's aid program continued throughout the 2000s, as new principles for aid effectiveness placed greater emphasis on partnership and recipient ownership of aid activities. With an already increased field presence by Germany's implementing agencies, the focus of decentralization from the mid-late 2000s was largely on the need to bring BMZ closer to recipients in order to align BMZ's "decision-making" capacity with GTZ and KfW's implementing competence (OECD, 2006b). Towards this end, the 2015 Peer Review noted that BMZ had increased its field presence by $78 \%$ from $2010-2015$, adding 46 staff to overseas embassies over a five-year period.

The 2000s also saw a number of efforts to reduce the fragmentation of Germany's complex development system. Indeed, in 2006, the OECD reported that in a new global aid context defined by the Paris Principles for Aid Effectiveness, "the German model of development co-operation may no longer be appropriate from a partner country perspective" (p. 12). Specifically, the OECD (2006b) noted that the number of agencies involved in the German aid system meant that German aid "runs the risk of being donordriven", increases the administrative burden for recipients, and reduces the time staff can spend on more strategic efforts due to the internal burden of coordination (p. 12). To this

\footnotetext{
${ }^{115}$ In part, this issue could have been linked to the private mandate of both GTZ and KfW, which prevented staff from representing Germany in any official capacity (OECD, 1995).
} 
end, a number of organizational changes to rationalize Germany's aid program took place throughout the 2000s, including the integration of the German Investment and Development Corporation (DEG) ${ }^{116}$ into KfW, the merger of two training organizations (Carl Duisberg Society (CDG) and the German Foundation for International Development (DSE)) into Capacity Building International (InWEnt), and an internal reorganization of BMZ into blended "teams" designed to integrate responsibilities across regions, sectors and types of aid to further improve efficiency and effectiveness (OECD, 2006b; Ashoff, 2005b).

Efforts to reduce the fragmentation of Germany's aid program continued as recently as 2011 when three technical cooperation agencies - GTZ, InWEnt, and the German Development Service (DED) - were merged to form the German Society for International Development (GIZ). Plans for the merger were announced by the German Development Minister in June 2010 as a way to address long-standing inefficiencies across multiple implementing agencies in the German system (Nabiyeva, 2011). As of 2015, the OECD had reported that merger was achieving its goals and had enhanced the efficiencies of Germany's aid program, and improved the strategic coherence of activities on the ground (p. 54). This sentiment was echoed by interviewees, who saw clear benefits from the merger (Interview 12, 2017; Interview 15, 2017; Interview 16, 2017).

While the creation of an enlarged GIZ through the 2011 merger marked a significant change in Germany's development program, it should be noted that it did not alter the ultimate structure used by Germany to manage aid programming. Today, Germany continues to use a Model 3 structural form, with BMZ responsible for policy

\footnotetext{
${ }^{116}$ Germany's development finance institute.
} 
direction and oversight of Germany's development cooperation, and GIZ and KfW responsible for implementing aid programming.

\subsubsection{Germany and the Absence of Change}

QCA analysis shows that 12 of the past 15 years presented the conditions for organizational change in the German case. In terms of ODA, Germany's aid budget increased over the past 15 years, growing from US\$8.6 billion in 2000 to more than US\$20 billion by 2015 (see Figure 11). Throughout this period, Germany's total ODA only declined twice, 2003 and 2009. While the 2009 dip is likely linked to the 2008 financial crisis, the change in 2003 was very minor falling by less than US\$100 million.

Figure 11: Germany's Total Gross ODA (US\$ millions, constant 2015)

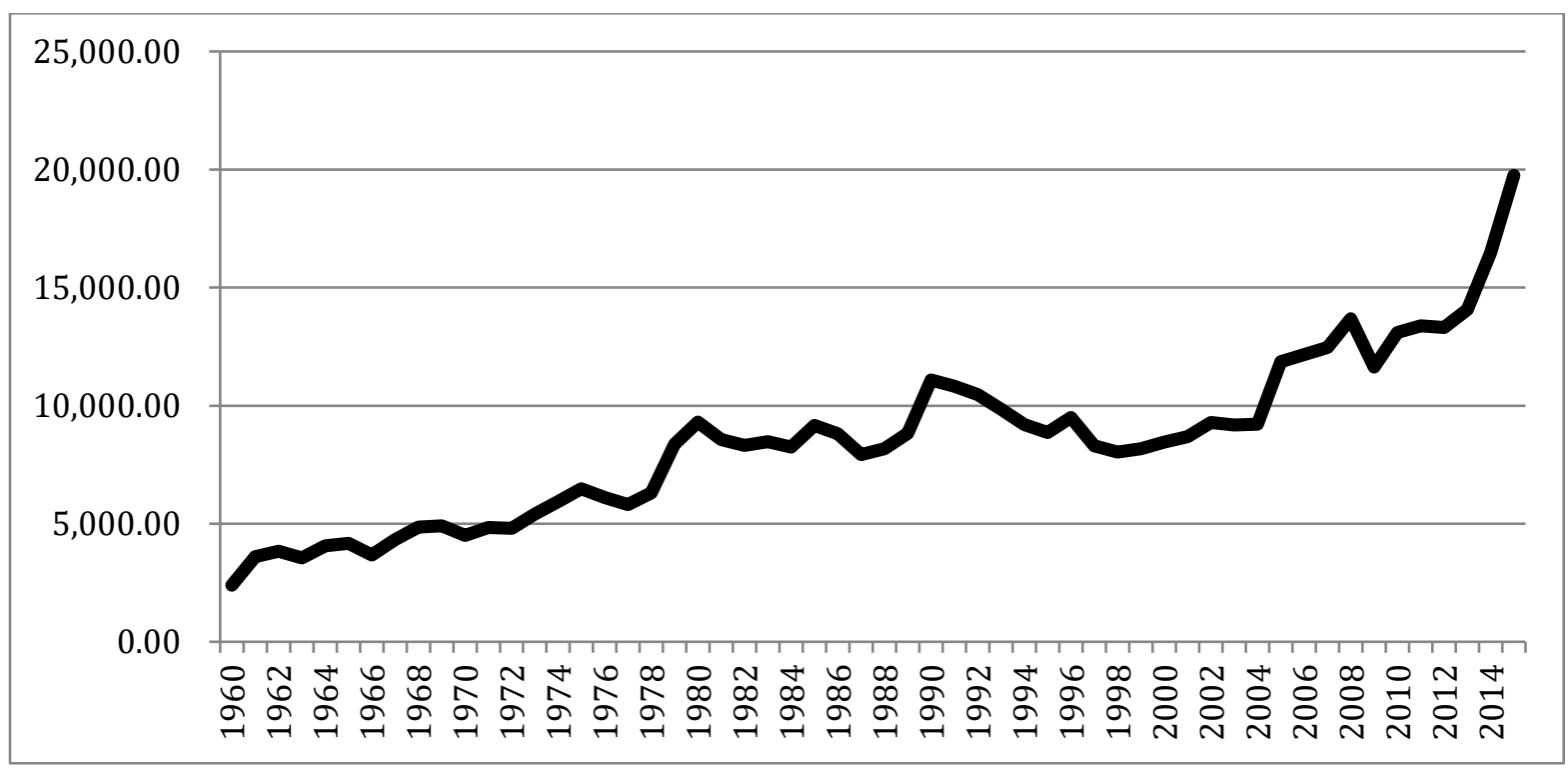

In addition, the last 15 years has shown a sustained decline in the overall likelihood that Germany will continue to select the Model 3 structure it actually uses. From 2003 onward, the likelihood of Germany selecting a Model 3 structure fell below $50 \%$ (see Figure 12). The post-estimation results show that from 2005-2013 Germany is 
predicted to adopt a Model 5 structure, while the most likely structural form in 2014 is Model 4.

Figure 12: Likelihood of Germany Selecting Model 3 Structure

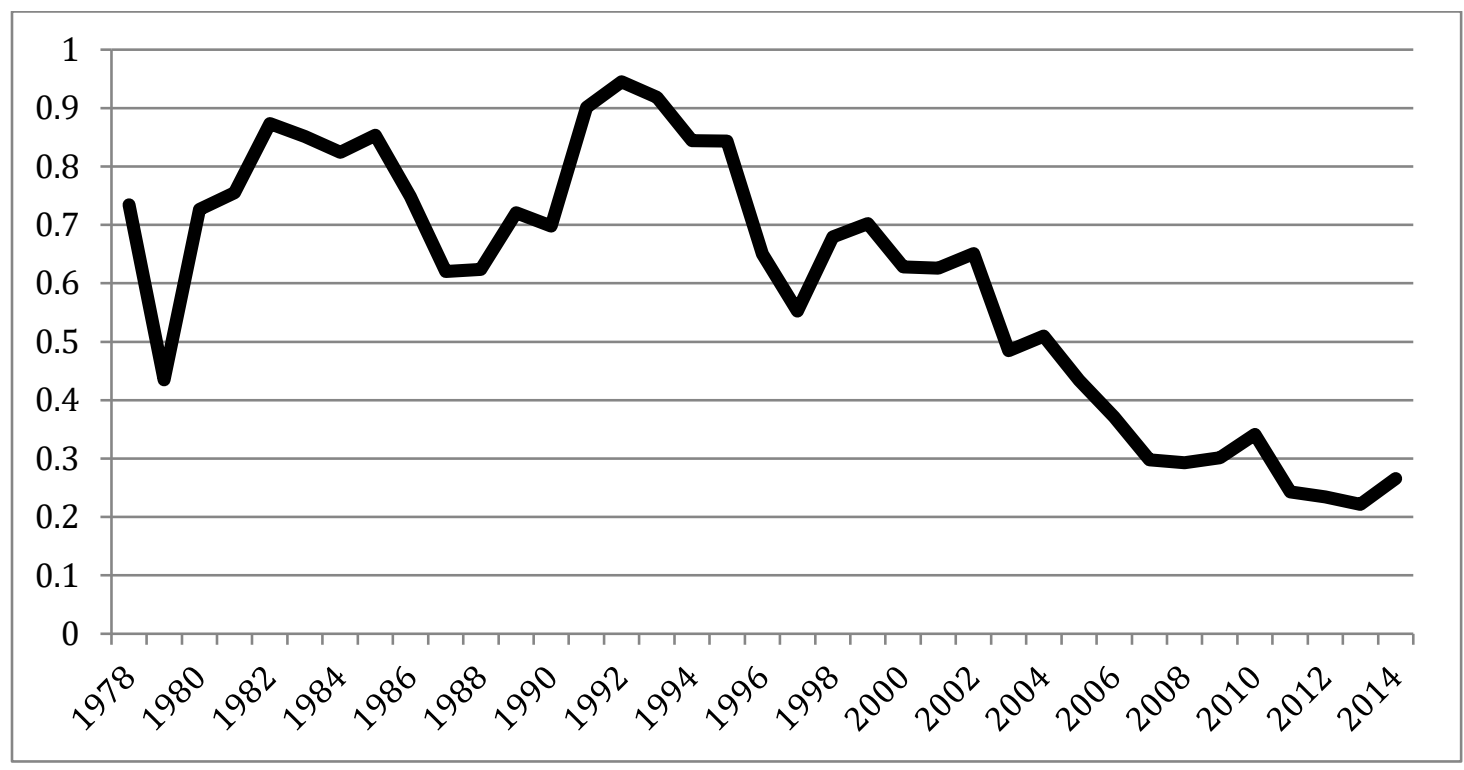

In the presence of increasing ODA and the reduced likelihood of selecting a Model 3 structure, change is predicted almost consistently throughout the last 15 years. While Germany has engaged in a number of internal changes and mergers to implementing structures, such changes did not result in a change in the organizational model used by Germany. The main question of interest is why change has not occurred in the presence of variables associated with change events. Given that change is most consistently predicted yet not acted upon from 2000-2015, analysis for this case will focus specifically on this period. The following analysis shows that the absence of change in the German case appears to be linked to low political impetus or need for cross-model reorganization. 


\section{Efficiency}

In the German case, there is clear evidence that concerns related to the efficiency of the aid program served as a key driver of internal reorganizations, mergers and changes that have taken place since 2000. Taken together, these initiatives were done in response to two main efficiency concerns: issues of coordination and concerns over the centralization of Germany’s aid management system.

Coordination across Germany's many aid actors has long been a concern within its aid management system. The 2002 OECD-DAC Peer Review, for instance, noted that coordination challenges persisted in three areas: i) across actors within Germany; ii) in the field, and iii) between KfW and GTZ (OECD, 2002). The merger of CDG and DSE to create InWEnt in 2002 was part of Germany's response to such criticism. So too was the 2011 merger of InWEnt, DED and GTZ to create GIZ. Both mergers were aimed at reducing the number of institutional actors in Germany's aid system to improve coordination both within the field by lessening the number of diverse agencies with which recipients need to engage. Similarly, efforts to improve coordination within Germany include strengthening BMZ's role in steering Germany's development policy at home, while recent decentralization of $\mathrm{BMZ}$ staff has solidified its position in leading policy dialogues with partners in the field (OECD, 2015b). Moreover, the location of GIZ and KfW staff in a common "German House" in partner countries has improved coordination across implementing branches (OECD, 2015b). In spite of such improvements, efficiency remains an ongoing challenge for the German management system. 
The second major administrative challenge facing Germany over the last 15 years concerns representation in partner countries (Interview 13, 2017; Interview 16, 2017). Indeed, Ashoff (2009) notes that despite recent efforts to increase Germany's field presence “Germany's ODA does not always meet the demand for dialogue, planning and decision-making, which increasingly arises at the country level" (p. 2). Perhaps most notably, part of the challenges relates to disparity in the field presence between BMZ, and GIZ and KfW. Specifically, BMZ's oversight function is not matched with commensurate representation, which often leaves implementing agency staff to engage in policy dialogues with partners due to limited BMZ capacity (Ashoff, 2009; Interview 13, 2017). While BMZ's field presence was recently increased and GTZ was granted the authority to respond and make programming-related decisions on the ground (see OECD, 2010b), the 2015 OECD Peer Review noted a need to delegate further autonomy to field offices.

Taken together, changes to Germany's aid program throughout the 2000s and 2010s were largely designed to address inefficiencies caused by the complex and multiactor aid system used in Germany, specifically seeking to improve coordination across actors. Interestingly, none of the efficiency related challenges in the German case necessarily required cross-model change to strengthen aid management. While a more systematic merging of implementing and policy structures could, in theory, also improve coordination, such changes did not seem to be recommended nor considered.

\section{Legitimacy}

There is little evidence (at least that is accessible and available in English) to suggest that Germany has looked to, or sought to emulate, the experience of other donors 
regarding its aid management. Notably, the absence of organizational change across models suggests that Germany has not sought to emulate the structures of other donors through recent changes. While reforms within the current model could be based on practices from other like-modeled countries, there is no real evidence to suggest this is the case. Indeed, the German system appears to be unique in its structure and management.

\section{Politics}

The absence of cross-model organizational change in the German case, particularly in light of calls to merge BMZ with the Foreign Minister in 2009, suggests that Germany may have lacked the political will to drive such changes. Indeed, the most explicitly political effort to engage with the structure of Germany's aid management system came in 2009 prior to that year's federal election. While there appeared to be consensus for the need to reform Germany's aid program, specifically through streamlining and simplifying the number of development actors to improve the coherence and coordination of German aid, the FDP party was calling instead for a more dramatic overhaul of the aid system through merging BMZ with the Foreign Office (Nabiyeva, 2011). In essence, the FDP saw development as part of Germany's foreign policy, arguing that as such, it should be located within the Foreign Ministry. While FDP became part of the 2010 coalition, and was given control over BMZ, providing a clear opportunity to act on the pre-election political posturing, the merger was never pursued. One commentator suggests that the absence of change was linked to the FDP's desire to control the large BMZ budget (Brombacher, 2009). Indeed, Ashoff (2005a) notes that BMZ's continued existence has always been based on "coalition arithmetic" more so than 
any "conventional wisdom" surrounding the virtues of a separate agency (p. 5). ${ }^{117}$ In this context, radical change to BMZ's structure would involve removing an agency of importance for German coalition politics - a move that appears political unlikely and perhaps unappealing for coalition governments.

Unlike other cases, where political factors have driven organization change, the German case suggests that the importance of BMZ as a desirable ministry for coalition partners reduces the likelihood of changes that would see it closed. Similarly, a second major change possible in the German context would involve shifting from a Model 3 to Model 4 structure by locating GIZ, KfW and BMZ in a single agency. However, the logic and rationale for such a change is largely unclear, especially given current improvements in coordination and coherence across German development actors following the creation of GIZ. Rather, recent calls for further coordination have sought to improve cooperation between GIZ and $\mathrm{KfW}$, which is unlikely to create any crossmodel shift.

Indeed, on the need to improve relations between GIZ and KfW, the 2013 Coalition Agreement showed cross-party support for further strengthening the efficiency of Germany's development program, stating that, "We want to improve the German development institutions further with regard to the efficiency concept. Cooperation between the German Society for International Cooperation (GIZ) and the KfW development should be intensified. We want to improve development-oriented, interdepartmental cooperation" (Government of Germany, 2015 p. 81). In essence, the Coalition platform suggests that at least until the end of the current government's term

\footnotetext{
${ }^{117} \mathrm{BMZ}$ serves as a second "foreign" ministry and is of considerable value in coalition making and negotiating.
} 
(elections are scheduled for September 2017), parties are aligned in thinking on the need to improve aid efficiency without making cross-model change.

\section{Purpose}

There is little evidence that the purpose of Germany's development program has undergone any major substantive changes since 2000. From 2000-2015, the orientation of Germany's aid program was highly poverty-focused in alignment with the MDGs and global efforts towards poverty reduction. In 2001, Germany's Cabinet approved the Programme of Action 2015 for Poverty Reduction (PA2015), which was seen as a milestone in German development assistance and framed poverty reduction as a task involving multiple actors with expertise beyond development (Ashoff, 2005b). By 2006, the OECD was reporting that the German government had continued its efforts to meet the PA2015 goals. Specifically, Germany had taken action to align bilateral programming with partner countries and various elements of Germany's development program. This was done in part through organizational changes including the internal restructuring of BMZ to reduce compartmentalization of functions, altering partnership arrangements with implementing agencies (which increase the ability for implementing agencies to respond to change and make-decisions as needed in the field) and increasing BMZs field presence to work more closely with partner countries (OECD, 2006b).

In 2010, a slight change in Germany's development vision is perhaps noticeable, as while the government continues to prioritize poverty reduction, such efforts are linked to "the government's foreign policy efforts to achieve a secure world" with a slight shift in the emphasis of Germany's programming towards the promotion of human rights, democracy and climate change (see OECD, 2010b p. 29). Importantly, this realignment 
was part of the newly elected center-right coalition government's development plan and coincided with calls for merging $\mathrm{BMZ}$ with the Foreign Office as noted in the prior section. In 2013, Germany's development vision was once again updated following the election that year. The Coalition Agreement called Shaping Germany's Future further affirmed poverty reduction as its central focus, while recognizing that achieving development objectives was in Germany’s “values and interests” (GoG, 2015). Such objectives were further solidified in the 2014 Charter for the Future, which was based on consultations with civil society actors concerning the priorities of Germany's aid program.

Taken together, there is little change in the policy orientation of Germany's aid program over the past 15 years, with poverty reduction as part of Germany's self interest acting as the main driver of development action. This finding echoes that of Faust and Ziaja (2012) who also show that German development policy undergoes only gradual changes in the post-reunification period. The relative consistency in Germany's development focus aligns with the absence of systemic organizational change, and suggests that substantive shifts did not contribute pressure for reorganization over the past decade.

\section{NPM}

In the German case, the absence of organizational change from the 1970s onward suggests that NPM had little, if any, impact on Germany’s aid program. Indeed, a recent study on the affects of NPM on European governments found "clear evidence that the arguably most pronounced NPM types of reform, such as privatization, contracting out or agencification are of only limited relevance in Germany" (Hammerschmid et al, 2013 p. 
25). Instead, Hammerschmid et al. (2013) suggest that recent reforms to Germany's public sector have focused on increasing coordination and "networked forms of governments" (p. 25), reflecting post-NPM ideals to address issues of fragmentation and a "hierarchical work culture" that appears pervasive throughout the German public sector (p. 29).

\section{Path Dependence}

Path dependence is a significant factor in the German case. From a path dependence perspective, BMZ for policy and GIZ (former GTZ) and KfW have been the most important and consistent actors in the German aid sphere for more than 50 years, suggesting a degree of institutionalization for each of their roles. More broadly, the longterm division of tasks between implementing agencies and BMZ could decrease the likelihood of undertaking broader organizational change, while international name recognition of GIZ, which is said to be very well branded, perhaps further reduces the incentive to alter these core institutions and risk losing a strong development brand (Interview 14, 2017).

In this context, the current Model 3 structure and the scale and institutional strength of the actors themselves may prevent the types of change events measured in this study from occurring, particularly in the absence of strong need or political impetus for reform. For the time being, the creation of GIZ appears to have lessened the need for deep reforms by improving the long-standing coordination challenge within the Model 3 structure. 


\subsubsection{Discussion}

The German case provides an example where predicted organizational change has not resulted in cross-model reform. Perhaps most notably, the absence of change seems to be linked to path dependence, a lack of political will for reform and the ability to mitigate efficiency concerns using within-model changes. In terms of path dependence, the institutionalization of Germany's development actors, name recognition of GIZ, and the long-term division of tasks between the two (and KfW) likely contributes to the absence of reform in the German case.

In addition, the absence of political drivers for organizational change is apparent in the German case, even when political parties called for systemic reform, and suggests that such change is unlikely without clear political incentives and backing. On this, there are perhaps two points worth noting. First, a main factor preventing politically-driven reorganization links to the role of BMZ as a crucial part of the "coalition arithmetic", where any change that threatens to subordinate or merge BMZ with other ministries has implications for the division of responsibility for new coalitions. Indeed, the central role of $\mathrm{BMZ}$ as part of the political landscape in Germany appears to safeguard its position more so than in other countries. In Australia, for instance, it is questionable whether Tony Abbott would have had the same latitude to abolish AusAID if the ministry served a purpose of supporting political relations. Perhaps a key implication then is that certain political structures, such as Germany's coalition-based governing model, could serve to support the institutional longevity of autonomous development ministries.

Second, bipartisan support for development in Germany could also contribute to less political demand for reorganization. Interview 16 (2017), for instance, noted that 
partisan politics appears to have little place in discussions surrounding development where even Germany's far right "Alternative fur Deutschland" (AfD) party has never suggested that Germany should "reduce or abolish development cooperation" (Interview 16, 2017). Even the case of the FDP's calls for organizational reform appeared to be linked to calls to increase the importance of development cooperation by putting it in the Foreign Office (Interview 16, 2017). The idea was that such a merger would reduce coordination challenges between BMZ and the Foreign Office and increase the influence of development cooperation by placing it within a strong ministry (Interview 16, 2017). This logic stands in sharp contrast to the Australian case where both mergers, which closed autonomous development structures, were undertaken by conservative governments. Moreover, in the case of the 2013 merger, the change led to declining aid resources, capacity and greater alignment between development and foreign policies. ${ }^{118}$ In this sense, the presence of a general consensus on the need for development could further explain limited organizational change in the German context. It is perhaps also noteworthy that the other country without organizational reform explored in this study (Ireland) also showed bipartisan support for development. While the Irish example highlighted the role of political leaders as key determinants of the original usage of the Model 2 structure, this case also showed few politically aligned calls for reform.

Importantly, the German case also showed calls for reorganization did not necessarily require cross-model reorganization. Rather, changes to strengthen the coordination and coherence of Germany's complex aid management system occurred within the framework of the Model 3 structure rather than systemically changing the

\footnotetext{
${ }^{118}$ Indeed, the "hostile takeover" of AusAID in the Australian case is perhaps best summed by the fact that "development" was never added to the name of the foreign ministry, which is still called the Department of Foreign Affairs and Trade.
} 
relationship or location of policy and implementation in this case. There is perhaps an important question of why more systemic reform was not undertaken, particularly in light of recent calls to merge BMZ and the Foreign Office. While incremental reforms taken in the German case could be aligned with the absence of clear need for cross-model reform to address inefficiencies, it is possible that the absence of political backing for more systemic changes also influenced how efforts to improve Germany's aid program were undertaken.

\subsubsection{Conclusion}

In conclusion, while Germany's aid program has been undergoing a significant reform over the last two decades, pressure for deep administrative changes to address underlying fragmentation and improve the coherence of the aid system have not resulted, nor necessarily required, cross-model change. In the German case, the underlying reason for the absence of change appears to be rooted in path dependence, low political will to initiate and lead change, and ultimately the ability to address inefficiencies without crossmodel reform.

Perhaps a key implication of findings from the German case is that certain political structures may be better able to safeguard development than others. For instance, the role that BMZ plays in "coalition arithmetic" seems to limit the likelihood of structural changes to abolish or systemically alter BMZ's location relative to other ministries. This stands in contrast to the Australian example, where organizational changes in 2013 and 1977 were driven by political factors. 


\subsection{Contemplations and Main Findings}

The case studies presented in this section explored the determinants of organizational change in relation to factors connected with reorganization as presented in Chapter 5. Importantly, the cases showed that efficiency and political factors have the biggest influence over instances of organizational change in both the presence and absence of structural predictors of change. While path dependence was also shown to be significant, it is seen as a factor contributing to the absence, rather than presence of change.

Perhaps most significantly, the cases highlighted the importance of political factors, including leadership preferences, political ideology and bureaucratic interests, as drivers of change. In the Australian case, political actors were key drivers of change in instances where high "match" between structural factors and the Model chosen made change unlikely. In the Japanese case, change occurred when predicted and was aligned with both calls for reform to overcome administrative inefficiencies and political drivers supporting and leading reform in the context of wider public sector rationalization. In the German case, organizational reforms occurred within the Model 3 structure, with little political impetus for more systemic change. Taken together, the cases highlight the role of political actors in driving (or preventing) change events.

The notion that political actors can prompt organizational change, as in the AusAID case, raises important questions about the nature of reorganization and expectations surrounding what politically motivated reforms can reasonably achieve. The question is one of intent; in the absence of clear need for reform, how and to what degree changes are designed to strengthen the aid management system (through improving 
efficiency, effectiveness or policy coherence) is unclear. Indeed, this discrepancy could explain recent findings that the 2013 merger in Australia led to no real improvements in either efficiency (see Davies, 2017) or policy coherence (see Gulrajani, 2017) despite both being stated objectives of the reform. While this study shines initial light on the main drivers of reform, a key question arising from this chapter is whether there is a difference in the effectiveness of aid programs pre/post organizational changes driven by leadership preferences or political factors versus those deemed as necessary for efficiency or substantive reasons.

Beyond exploring the main drivers of organizational change, this chapter deepened understanding of the rationale for selecting particular donor models. Specifically, the Australian case confirmed that the Model 5 structure has been used as a "starter" model as suggested in Chapter 3. Indeed, in the Australian case, the use of this model as a "temporary" measure before the institutionalization of Australia's aid program perhaps lends support to Cunningham's theory that donors use multiple ministry structures before "actively" engaging in efforts to program development assistance and when ODA budgets are relatively small - both of which are more likely to be associated with the early period of aid activity. Despite this finding, most new OECD-DAC donors have tended to adopt structures other than the Model 5 form. In part, this finding could be driven by the fact that new OECD-DAC donors have, despite recently joining the DAC, been "donors" for quite some time. For instance, Iceland has engaged in development since the 1970s, although only joined the DAC in 2013. Additionally, unlike long-term OECD-DAC donors, new donors have the example of their peers to learn from in terms of organizational management. Donors creating aid management 
systems in the 1950 s had no prior examples to look to for insight. Indeed, it is noteworthy that the clearest example of legitimacy informing aid management structure throughout this study was found in the case of Iceland, where there is clear evidence that the structures of other donors were consistently examined in the context of organizational discussions.

Further, this chapter contributes to understanding the relationship between the long-term use of the Model 5 structure and the adoption of Model 3. Recall Chapter 3 found that each of the donors using the Model 5 structure by the 1990s adopted the Model 3 form upon reorganization. The Japanese case sheds some light on the mechanism for this transition, showing that the institutional form adopted in the Model 5 structure, which separated policy from implementation, lent itself most naturally to the Model 3 form upon reorganization. This appears similar to the French case where the formalization of the French Development Agency (AFD) in 1998 became the basis of France's Model 3 form.

\subsection{Conclusions}

This chapter has examined the presence and absence of organizational change events in three countries - Australia, Japan, and Germany. Across the countries, political factors are found to be important drivers of reorganization in both the absence and presence of predictors typically associated with organizational change. In the Australian case, change in the absence of predictors was driven by political leaders in economic and political contexts that appeared to support change. Moreover, the Australian case confirms findings of a linkage between political ideology and organizational choice 
identified in Chapter 4, showing that both instances of change to the Model 2 structure was undertaken by conservative governments. In the case of Germany, the absence of political impetus for change appeared to contribute to the lack of change across models.

Similarly, all cases show a linkage between change and efforts to improve efficiency; however, in the German case, efforts to improve efficiency are taken within the context of the Model 3 structure. In the Australian case, two instances of change were driven by efforts to improve the efficiency of the aid program (1974 and 1985). Similarly, in the Japanese case, organizational reform was the eventual culmination of persistent calls for change at a moment of politically backed public sector reform.

While the cases examined here suggest that political and efficiency-related factors are the most important drivers of organizational change, there is significant scope for further analysis on the drivers of organizational reform. Specifically, more is needed on the conditions under which donors may be more or less likely to reform, particularly in the absence of efficiency related concerns or clear need for change. In addition, studies have not yet shown the value of organizational reform in terms of outcomes, nor whether a relationship exists between the types of reforms (politically driven versus efficiencybased, for instance) and any long-term results in terms of both administrative efficiency as well as donor effectiveness. These are key questions that require deeper analysis going forward. 


\section{CHAPTER 8}

\section{CONCLUSIONS}


“...[The development agency] seems to be in a constant state of change, it may be a department that is something of a mystery to you - - a modern version of the old Greek sea-god Proteus, who at one moment assumed the shape of an eel, the next moment had turned into an amphibian creature with four feet."

- Mr. Paul Gérin-Lajoie, Institute of Public Administration Conference, Regina, September 8, 1971. ${ }^{119}$

Since writing on this study commenced, two of the largest OECD-DAC donors have engaged in domestic discussions about issues of aid agency structure (Gulrajani, 2017). In the US, the Trump Administration called on all federal departments to submit plans, where appropriate, to reorganize agencies to improve "efficiency, effectiveness, and accountability" (White House, 2017). To this end, Secretary of State, Rex Tillerson, launched a "Listening Report" to account for the views of State Department and USAID employees (Ingram, 2017; Insigniam, 2017). The report found that most see value in maintaining a separate administrative structure for US development assistance and aligns with similar findings from the Congressional Task Force on Reforming and Reorganizing U.S. Foreign Assistance (Savoy and Yayboke, 2017). At present however, it remains unclear how or whether reforms will unfold. In the UK, the months preceding the 2017 election were met with speculation that a strong Conservative showing could see a major reorganization of DFID (Gulrajani, 2017). Indeed, the former Minister of International Development, Priti Patel, was quoted calling for the termination of DFID as early as 2013, when she suggested that DFID be replaced by a "trade-focused body to help businesses invest in the development world" (Mendick, Hennessy and Malnick, 2013).

With continued interest in aid agency structures and changes, this study presents a timely contribution to discussions of aid management. Notably, this study provides the

\footnotetext{
119 This quote is specifically in reference to CIDA. However, the constant changes and tweaks to aid agency structures identified throughout this study suggest that the sentiment has broader appeal.
} 
first systematic attempt to understand the determinants of aid agency structure and change. This was done in multiple phases. To begin, Chapter 2 developed a theoretical framework for understanding the determinants of aid agency structure by engaging in a systematic review of literature from organizational studies, public administration, and the international development, and building on key theories related to aid management. Specifically, Chapter 2 conducted a critical analysis of Cunningham's 1974 work on aid management, which pointed to the relationship between substantive choices and structural models in terms of the roles (active or reactive) adopted by donors. This analysis found that while donors have tended towards more active donor roles, suggesting limits to the degree to which Cunningham's distinction can explain current variation in aid agency structure, the fundamental linkage between substantive and structural choices is a viable theory for understanding aid management when substantive choices are understood as the purposes that donor seek to pursue through aid programs.

Building on the theory and hypotheses identified through the literature review, Chapter 3 conducts the first ever exploration of trends in aid agency structure for all OECD-DAC donors from 1962 to present day. This analysis identifies three key trends in aid agency structure: 1) that donors with shared histories (and institutional structures), such as the Nordics or Anglo-American countries, have tended towards similar models, 2) that Model 5, which Cunningham (1974) links to reactive donor roles, has faded from use (this finding aligns with analysis presented in Chapter 2), and 3) that the majority of donors have tended to adopt the Model 2 and 3 structures, with smaller donors tending towards Model 2 and larger donors generally adopting Model 3 forms. These trends and the data outlined in this chapter provided a basis for the quantitative analysis. 
To explore emerging trends more deeply, Chapter 4 built a dataset capable of accounting for organizational choices made by all OECD-DAC donors over time. This data is wholly original and allowed for the premier analysis of major trends in structural use, choice and change across donors and time. The results of Chapter 4 highlighted the importance of key variables including political factors, donor size, the purpose of aid programs and structural features as drivers of organizational choice. Several of these results shed further light on findings from Chapter 3, showing statistical support for the finding that countries with similar institutional features adopt similar organizational structures and confirming that donors tend towards different models according to size. Chapter 4 also highlighted key differences between donors that adopt similar organizational structures. Notably, despite similarities between Models 1 and 2 in terms of integration, which provides similar opportunities for donors looking to align aid to strategic and commercial priorities, such models are preferred by governments with different ideological leanings and that pursue different purposes.

Chapter 5 presents a quantitative model to test the determinants of organizational change. Using a rare-events estimation technique, develop and test a model to understand the drivers of organizational change across all OECD-DAC donors over time. The estimation found that reorganizations were more likely to occur in the presence of changes to ODA budget size and structural predictors. Combined with results from Chapters 3 and 4, the importance of ODA budget size as a determinant of organizational choice highlights the importance of the size contingency as a determinant of aid agency structure and change. In essence, this finding suggests that organizational change can be 
expected in countries experiencing growth in ODA budgets or other pressures, which may affect the compatibility with structural choices.

Chapters 6 and 7 conducted in-depth case studies of the organizational choices and changes made by six OECD-DAC donors. The cases built on findings from Chapters 4 and 5 and worked to further probe and explain key findings from the statistical analysis. Specifically, Chapter 6 presented three case studies of structural choice in Ireland, Iceland and the Netherlands. The cases were selected using post-estimations from Chapter 4 and represented cases that always, never, and sometimes adopted the structure they were predicted to select. The cases showed that political factors, efficiency, path dependence and the purpose of aid agencies act as the main drivers of structural choice. In addition, the cases further confirmed the importance of size as a driver of organizational change and argued that the choice to adopt the Model 1 structure is likely to be linked to the purpose of aid programs, specifically efforts to enhance policy coherence.

Similarly, Chapter 7 probed instances of organizational change in Australia, Japan and Germany. Cases were selected based on QCA analysis using data from Chapter 5 and included cases where change occurred when predicted, change occurred when unpredicted, and predicted changes did not result in organizational reform. The cases highlighted the importance of political factors and inefficiencies as key drivers of organizational change. The Australian case showed that under certain conditions, political actors were capable of enacting organizational change in the absence of any clear need for reform. In the Japanese example, organizational change followed calls to improve efficiency and politically-led action, while the German case showed that 
organizational changes to address inefficiencies occurred within the Model 3 structure while the role of BMZ as part of Germany's "coalition arithmetic" appears to have weakened the political impetus for cross-model change.

\subsection{Taking Stock of Key Findings: The Determinants of Organizational Choice}

To take stock of the contribution made by this thesis, it is prudent to return to the research question posed at the beginning of this thesis, namely, why do donor select the organizational models they adopt? The analysis presented throughout this study has highlighted key factors that contribute to the adoption of each of the five donor models. The key factors associated with each organization model are presented in Table 10 below.

Table 10: Key Findings

\begin{tabular}{|l|l|l|}
\hline Model & Variables & Description \\
\hline Model 1 & $\begin{array}{l}\text { Purpose, structural } \\
\text { factors }\end{array}$ & $\begin{array}{l}\text { Chapter 6 suggests that donors seeking to pursue } \\
\text { policy coherence are more likely to adopt Model } \\
1 \text { Moreover, Chapters 3, 4 and 6 showed that } \\
\text { Model 1 is associated with Nordic donors. }\end{array}$ \\
\hline Model 2 & $\begin{array}{l}\text { Political ideology, } \\
\text { efficiency } \\
\text { budget size) }\end{array}$ & $\begin{array}{l}\text { Chapters 3, 4 and 6 show that smaller donors have } \\
\text { tended to adopt the Model 2 structure. Moreover, } \\
\text { Chapter 4 and 7, show that conservative } \\
\text { governments have preferred this model. }\end{array}$ \\
\hline Model 3 & Path dependence & $\begin{array}{l}\text { Chapters 3 and 7 showed the relationship between } \\
\text { Model 5 and Model 3 structures, where all donors } \\
\text { that adopted the Model 5 structure adopted Model } \\
\text { 3upon reorganization. }\end{array}$ \\
\hline Model 4 & $\begin{array}{l}\text { ODA budget size, } \\
\text { structural factors }\end{array}$ & $\begin{array}{l}\text { Chapters 3 and 4 show that Model 4 tends to be } \\
\text { adopted by Anglo-American donors and countries } \\
\text { with larger ODA budgets (due to association with } \\
\text { the UK and US aid programs). }\end{array}$ \\
\hline Model 5 & Path dependence & $\begin{array}{l}\text { The initial adoption of the Model 5 structure is } \\
\text { commonly due to path dependence in the early } \\
\text { days of aid programming. Chapters 3 and 7 } \\
\text { suggested that this model is used as a "starter" } \\
\text { option. }\end{array}$ \\
\hline
\end{tabular}


Of the findings listed above, three in particular stand out as key insights derived from this study. The first finding is that the size of ODA budgets is likely to influence the choice of structure, where smaller donors are less likely to adopt either Model 3 or Model 4 structures. This finding was initially highlighted in Chapter 3, found to be statistically significant in Chapter 4, and confirmed through the Icelandic case presented in Chapter 6. Taken together, these findings show that size is an important determinant of structural choice, where smaller donors appear more likely to adopt merged organizational structures. The Icelandic case shows that this finding is rooted in issues of efficiency, where the Model 2 structure was considered a more administratively efficient option than the Model 3 structure Iceland used previously. Chapters 3 and 4 found evidence that larger donors tend to adopt either the Model 3 or Model 4 structures, respectively. More research is needed into why these structures are preferred by larger donors and Model 4 and what factors contribute to the choice between Model 3 and Model 4.

Second, despite results from Chapter 4, which showed the importance of substantive preferences as determinants of organizational choice, the purpose of aid programs was most clearly shown to be a determinant of structural choice in relation to the Model 1 structure as illustrated by the Dutch case. Specifically, the Dutch example suggested that donors seeking to enhance policy coherence are likely to adopt the Model 1 structure due to the institutional integration it affords. Indeed, using scores from the CDI, a basic linkage between policy coherence and the Model 1 structure was highlighted. However, a number of questions related to this linkage require further research. First, there remains a question of why stated efforts to advance policy 
coherence has led some donors to adopt the Model 2 structure instead of the Model 1 form, and whether Model 2 is also a viable choice for donors seeking to enhance policy coherence (Canada for instance, justified the 2013 merger as an efforts to advance policy coherence). ${ }^{120}$ Further research is also needed to explore why Model 1 donors have tended to perform better on policy coherence, and how much of this finding can reasonably be attributable to structural choice. Additionally, limited usage of the Model 1 structure over time raises questions of potential barriers to using this model.

Third, political factors were found to be significant determinants of structural choice across each of the cases presented in Chapters 6 and 7, while ideology was shown to be significant in the quantitative model presented in Chapter 4. In terms of ideology, results from Chapter 4 and the Australian case presented in Chapter 7 show that conservative governments tend to prefer the Model 2 structure and could lend support to the often-cited hypothesis that conservative governments prefer models that could allow for alignment of development with strategic objectives. In this vein, a key question remaining is perhaps one of effectiveness, and whether the institutional closeness afforded by the Model 2 structure impacts compliance with the Paris Principles for aid effectiveness.

\subsection{Taking Stock of Key Findings: The Determinants of Organizational Change}

In addition to understanding the determinants of structural choice, this thesis also engaged with the question of why donors undertake reorganization. The analysis presented in Chapters 5 and 7 highlighted the importance of changes to ODA budget size,

\footnotetext{
${ }^{120}$ Although, it could be that such call for policy coherence was a stated, rather than actual, objective of the merger.
} 
changes to the likelihood of adopting a particular organizational model, efficiency, and political factors as key drivers of organizational change. Specifically, the cases presented in Chapter 7 highlighted the role of political factors and efficiency as key drivers of organizational change. The importance of political variables in prompting reorganization aligns with findings from the structural choice analysis and shows that political considerations matter both for organizational choice and change. Perhaps importantly, reorganizations in Australia in 1977 and 2013, which occurred in the absence of inefficiencies or predictors of organizational change, highlighted the capacity for political leaders, in a context of ideological change and economic decline, to enact change in the absence of need. While this finding suggests that in certain contexts, political actors alone can drive reorganization, more research is needed to identify other instances of politically driven organizational changes (the Canadian case may be a good candidate for this exercise), as well as whether there are other contextual factors that contribute to the likelihood of politically driven reform. Similarly, the German case, which shows how the position of BMZ as part of the political coalition landscape appears to make it less susceptible to change, raises questions around the types of political structures that make organizational change in aid agencies more or less likely.

Efficiency, of course, is the other factor found to contribute to reorganization, as well as the choice of aid agency structure. Indeed, each of the cases presented in Chapter 7 showed the importance of efficiency related concerns as drivers of organizational change. In Australia, inefficiencies in the Model 5 structure led to the 1974 reorganization and the adoption of the Model 4 structure in 1985. Similarly, continued calls for reorganization in Japan and Germany led to reform across models in the case of 
Japan, and within the Model 3 structure in the German example. Moreover, instances of organizational change identified in Chapter 6, including in the Icelandic and Dutch case, also showed inefficiencies as key factors driving organizational reform. Perhaps an important and currently understudied question in terms of aid agency structure and change, is how we understand efficiency in terms of aid management, and what, if any, impact efficiency has to donor effectiveness. While such questions fall beyond the scope of this analysis, engaging more deeply with issues of efficiency in aid agencies will be important as governments grapple with ways to achieve more within constrained budgets.

\subsection{Importance and Implications}

This study marks an important contribution to the literature on aid agency structure in two main ways. First, through mapping the organizational choices of donors over time, this study presents new data that will enable future research on key issues of aid agency structure. This data is crucial to any time-series analysis of aid agencies across donors, and offers the potential to expand knowledge well beyond current studies.

The importance of this data and the analysis it affords can already be viewed from findings identified in the study. For instance, the ability to outline the organizational models used by donors in the early days of aid activities, such as the Model 5 structure, could be useful for new donors as they consider how to structure aid programs. Recent studies on aid agency structures tend to focus exclusively on the models currently in use (i.e. Models 1 to 4), making the identification of Model 5 as a potential "starter model" particularly significant. Similarly, the data and analysis presented in this study provided a starting point for thinking the potential relationship between organizational models and 
efficiency. Indeed, one of the key findings from this study - around the linkage between ODA budget size and organizational choice - highlights the potential to identify "optimal" organizational models for donors based on key characteristics. The ability to point to factors that align with organizational efficiency has clear implications for policy and could inform future discussions surrounding aid management.

Moreover, the findings presented in this study have key implications for new and emerging donors, some of which may look to their DAC-counterparts for options and things to consider when thinking about aid management. This study has a lot to offer such endeavours by providing a picture of organizational choices across all donors, and insight into why such choices were made. With key insights learned through interviews with people from development agencies, this study highlights a number of issues faced by donors in terms of aid management. In particular, this study shows the potential pitfalls of complex management structures involving many entities, as well as potential tensions that could arise across actors within the aid management landscape.

Lastly, the insight developed through this study has key implications for understanding the usage of autonomous versus merged structures, the distinction between which lies at the heart of conventional logic and discussions around aid agency structures. Findings from this study raises an important point for conventional wisdom that development effectiveness is best achieved through autonomous structures; namely, that such structures may be unfeasible options for some donors, notably those with smaller aid budgets. While this study did not explore the relationship between structure and effectiveness, and is not questioning the logic of conventional wisdom - in theory, autonomous structures provide the same benefits in terms of separating development and 
strategic objectives regardless of donor size - the point is that such logic may have limited potential to influence policy if it fails to account for the realities faced by donors. In this regard, this study has begun to highlight some of the realities that inform and potentially limit the actual organizational options available to donors and provides a basis for deeper exploration of how donors can work within constraints to consider management structures that fit for the future.

\subsection{Future Research}

In addition to making a significant contribution to the literature on aid management, this thesis points to several areas of future research. Perhaps the most obvious is the need to explore issues of aid agency structure beyond OECD-DAC donors. Identifying the range of organizational structures used by non-DAC donors over time remains largely understudied. As a result, any effort to compile data on the structures used by non-DAC donors over time would mark a large contribution to this space.

Second, the research presented in this study provides a basis for identifying optimal organizational models for individual donors based on administrative efficiency and key structural characteristics. On this, there is a lot more work to be done. Issues in need of further exploration include identifying the range of potential structural factors that could contribute to structural optimality as well as understanding the donor contexts in which such factors may be more of less viable. While this study provides a first step towards discussions of optimal donor models by highlighting the linkages between size and structural choice, efforts to extend the findings outlined in this dissertation could 
support the development of practical policy advice for new and current donors as they think about structural options.

Exploring questions around optimality is really about probing the relationship between structure and effectiveness; this is an area of research that remains highly underdeveloped. Current discussions of the relationship between structure and effectiveness have tended to look at single cases in isolation or multiple cases over static periods. Few, if any, have attempted to take a broader view of the relationship by examining the linkage over time. While there are limitations in conducting this type of analysis, not the least of which is important questions concerning how effectiveness is measured and understood, the dataset developed and utilized in this study provides the ability to identify the structures used over times and serves a starting point for the systematic pursuit of a link between effectiveness and structural model. Ultimately, the linkage between structure and effectiveness will likely be of greatest interest to donor governments going forward.

Third, in a changing global development landscape, there are and remain questions about whether the types of structures currently adopted by donors are designed to meet new demands and challenges; i.e. whether current structure are fit for the future. While some analysis has been conducted in this vein (see Gurajani, 2015b), questions of how donors can design aid structures that allow for the pursuit of best practice, while ensuring the accountability for public money, and possessing the flexibility to account for changing circumstances in the field, remains an ongoing challenge. Understanding how and why donors have adopted the structures used in the past may provide a valuable starting point for taking stock of what works, when and why. In this sense, there is 
scope for more detailed analysis of how or whether key determinants differ over particular periods/decades. Understanding differences in the periodic uses of structural forms and determinants of change could lend further insight into the conditions under which donors are more or less likely to select particular models and contribute to conversations about designing the aid agency of the future.

While the contribution made by this study to current knowledge on aid management is considerable, this exploratory study is only the beginning of what is needed to fully understand and ultimately inform aid management across donors. The field of aid management remains open to continued investigation to deepen current knowledge and identify key insights to help donors in their mission for global development. 


\section{References}

Abbott, T. (2013, September 18). The Coalition will restore strong, stable and accountable government [Press release]. Retrieved from http://pmtranscripts.pmc.gov.au/release/transcript-22997

Act on International Development Agency, No, 43 (Iceland). (1981). Retrieved from the Althingi of Iceland website: http://www.althingi.is/lagas/135a/1981043.html

Adam, C., Chambas, G., Huillaumont, P., Guillaumont-Jeanneney, S., \& Gunning, J.W. (2003). Performance-Based Conditionality: A European Perspective. (Centre D'Etudies et de Recherches sue le Developpement International 2003.06). Retrieved from: http://economics.ouls.ox.ac.uk/12896/1/2003.06.pdf

Alesina, A., \& Dollar, D. (2000) Who Gives Foreign Aid to Whom and Why? Journal of Economic Growth, 5, 33-63. doi:10.1023/A:1009874203400

Ali Abbas, S., Belhocine, N, ElGanainy, A., \& Horton, M. (2010). A Historical Public Debt Dataset. (IMF Working Paper WP/10/245). Retrieved from International Monetary Fund website: http://www.imf.org/en/Publications/WP/Issues/2016/12/31/A-Historical-PublicDebt-Database-24332

Amending the Law on International Development Cooperation, etc. (organization), 121/2008. (2008). Retrieved from the Althingi of Iceland website: http://www.althingi.is/altext/141/s/0810.html

Amending the Law on International Development Cooperation, etc. (organization), $145^{\text {th }}$ legislative session (2015). Retrieved from the Althingi of Iceland website: http://www.althingi.is/altext/145/s/0091.html\#Footref6

Annen, K., \& Strickland, S. (2016). Global Samaritans? Donor Election Cycles and the Allocation of Humanitarian Aid. (University of Guelph Department of Economics and Finance Working Paper 2016-07). Retrieved from University of Guelph website: http://www.uoguelph.ca/economics/repec/workingpapers/2016/201607.pdf

Arase, D. (1995). Buying Power: The Political Economy of Japan's Foreign Aid. London: Lynne Rienner Publishers.

Arase, D. (2005). Conclusion. In D. Arase (Ed.), Japans Foreign Aid: Old Continuities and New Directions, (pp. 267-275). Oxon: Routledge.

Arens, E. H. (2003). Multilateral Institution-Building and National Interest: Dutch Development Policy in the 1960s. Contemporary European History, 12(4), 457472. Retrieved from http://www.jstor.org/stable/20081178

Arel-Bundock, V., Atkinson, J., \& Potter, R.A. (2015). The Limits of Foreign Aid Diplomacy: How Bureaucratic Design Shapes Aid Distribution. International Studies Quarterly, 59(3), 544-556. doi: 10.1111/isqu.12191

Argyris, C. (1973). Some Limits of Rational Man Organizational Theory. Public Administration Review, 33(3), 253-267. doi:10.2307/974803

Ashoff, G. (1999). The Coherence of Policies Towards Developing Countries: The Case of Germany. In J. Forester \& O. Stokke (Eds.), Policy Coherence in Development Co-operation (pp. 128-179). UK: Frank Cass and Co. Ltd.

Ashoff, G. (2005a). Germany's Development Cooperation An Updated Overview. (Report for the Centro Studi di Politica Internazionale, Rome). 
Ashoff, G. (2005b). Germany's Development Co-operation Policy since the Early 1990s: Increased Conceptual Ambitions in Times of Severe Financial Constraint. In P. Hoebink \& O. Stokke (Eds.), Perspectives on European Development Cooperation (pp. 267-302). Oxon: Routledge.

Ashoff, G. (2009). Institutional Reform Needs of Germany's Bilateral Development Cooperation. (German Development Institute Briefing Paper 8/2009). Retrieved from German Development Institute website: https://www.die-gdi.de/briefingpaper/article/institutional-reform-needs-of-germanys-bilateral-developmentcooperation/

Askim, J., Christensen, T., Fimreite, A.L. \& Lægreid, P. (2008). Implementation of Merger: Lessons from the Norwegian Welfare Bureaucracy. (Stein Rokkan Centre for Social Studies Working Paper 11-2008). Retrieved from Stein Rokkan Centre for Social Studies website: http://bora.uib.no/handle/1956/4291

Australian Broadcasting Corporation (ABC). (2013, September 19). Australian Government Criticised over AusAID Merger. ABC News. Retrieved from http://www.abc.net.au/news/2013-09-19/an-ausaid-merger-reaction/4966976

AusAID. (2012a). An Effective Aid Program for Australia: Making a Real DifferenceDelivering Real Results. Canberra: Commonwealth of Australia.

AusAID. (2012b). Helping the World's Poor through Effective Aid: Australia's Comprehensive Aid Policy Framework to 2015- 16. Canberra: Commonwealth of Australia.

Balle Hansen, M., Laefreid, P., Pierre, J., \& Saliminen, A. (2012). Comparing Agencification in Nordic Countries. In Verhoest, S. Van Theil, G. Bouckaert and P. Laegreid (Eds.), Government Agencies: Practices and Lessons from 30 Countries (pp. 259-264). UK: Palgrave Macmillan.

Bandstein, S. (2007). What Determines the Choice of Aid Modalities? (SADEV Report 2007:4). Retrieved from OECD website: https://www.oecd.org/derec/sweden/modalities.pdf

Bandyopadhyay, S., \& Vermann, K.E. (2013). Donor Motives for Foreign Aid. The Federal Reserve Bank of St. Louis Review, 25(4), 327-336.

Bandyopadhyay, S., Lahiri, S., \& Younas, J. (2013). Financing Growth: Foreign Aid vs. Foreign Loans. (The Federal Reserve Bank of St. Louis Working Paper No. 2013-031A). Retrieved from Federal Reserve of St. Louis website: https://research.stlouisfed.org/wp/more/2013-031

Barber, S., \& Johnson, S. (2014). Federal Election Results 1901-2014. (Parliament of Australia, Parliamentary Library Research Paper Series, 2014-15). Retrieved from Parliament of Australia, Parliamentary Library website: http://australianpolitics.com/2014/07/17/federal-election-results-1901-2014.html

Barder, O. (2005). Reforming Development Assistance: Lessons from the UK Experience. (Centre for Global Development Working Paper 70, Oct 2005). Retrieved from Centre for Global Development website: http://www.cgdev.org/files/4371_file_WP_70.pdf

Berry, F.S. (1994). Innovation in Public Management: The adoption of strategic planning. Public Administration Review 54(4), 322-330. doi:10.2307/977379

Berthelemy, J. C. (2005). Bilateral Donor's Interest vs. Recipients' Development Motives in Aid Allocation: Do All Donors Behave the Same? Paper presented at 
the HWWA conference on the Political Economy of Aid, Hamburg, 9-11

December, 2004. Retrieved from http://hal.archives-

ouvertes.fr/docs/00/19/32/73/PDF/Bla05001.pdf

Berthelemy, J.C., \& Tichit, A. (2004). Bilateral Donors' Aid Allocation Decisions - A

Three-Dimensional Panel Analysis. International Review of Economics and

Finance, 13(3), 253-274. https://doi.org/10.1016/j.iref.2003.11.004

Bishop, J. (2013, November 1). A New Era in Diplomacy. Retrieved from

http://foreignminister.gov.au/releases/Pages/2013/jb_mr_131101a.aspx?w=tb1Ca

GpkPX\%2F1S0K\%2Bg9ZKEg\%3D\%3D

Bozeman, B. \& Bretschneider, S. (1994). The 'Publicness Puzzle' in Organization

Theory: A Test of Alternative Explanations of Differences between Public and

Private Organizations. Journal of Public Administration Research and Theory,

4(2), 197-224. Retrieved from http://www.jstor.org/stable/1181777

Blau, P. M. (1970). The Formal Theory of Differentiation In Organizations. American

Sociological Review, 35(2), 201-218. Retrieved from

http://www.jstor.org/stable/2093199

Bramson, A.L. (2008). Measures of Tipping Points, Robustness, and Path Dependence.

Retrieved from Cornell University Library website:

https://arxiv.org/abs/0811.0633

Bridges, W.P., and Villemez, W.J. (1991). Employment Relations and the Labour Market: Integrating Institutional and Market Perspectives. American Sociological

Review, 56(6), 748-764. Retrieved from http://www.jstor.org/stable/2096253

Brombacher. (2009, November 27). It's the Structure, Stupid. Where is German Development Cooperation Headed? The Broker. Retrieved from

http://www.thebrokeronline.eu/Blogs/Germany-Turn-or-Equal/It-s-the-structurestupid.-Where-is-German-Development-Cooperation-headed

Brown, S. (2013, March 25). Killing CIDA: The Wrong Solution to Real Problems. CIPS

Blog http://www.cips-cepi.ca/2013/03/25/killing-cida-the-wrong-solution-to-realproblems/

Brown, S. \& Swiss, L. (2013). The Hollow Ring of Donor Commitment: Country

Concentration and the Decoupling of Aid Effectiveness Norms from Donor

Practice. Development Policy Review, 31(6), 737-755. doi: 10.1111/dpr.12033

Bruere, W. \& Hill, C. (2016). Changes to Australia's Overseas Aid Program Under the Abbott

and Turnbull Governments 2013-2016: Key Policies and Responses.

(Parliamentary Library Research Paper Series 2016-17). Retrieved from

Parliament of Australia website:

http://parlinfo.aph.gov.au/parlInfo/download/library/prspub/4832715/upload_bina

ry/4832715.pdf;fileType=application/pdf

Bueno de Mesquita, B., \& Smith, A. (2007). Foreign Aid and Policy Concessions.

Journal of Conflict Resoultion, 51(2), 251-283. Retrieved from

http://www.jstor.org/stable/27638548

Bueno de Mesquita, B., \& Smith, A. (2009). A Political Economy of Aid. International

Organizations, 63(2), 309-340. https://doi.org/10.1017/S0020818309090109

Burke, W.W. (2010). Organization Change: Theory and Practice. Thousands Oaks: Sage

Publications. 
Burke, W.W., \& Litwin, G.H. (1992). A Causal Model of Organizational Performance and Change. Journal of Management, 18(3), 523-545.

doi:10.1177/014920639201800306

Burnside, C., \& Dollar, D. (2000). Aid, Policies and Growth. American Economic Review, 90(4): 847-868. Retrieved from http://www.jstor.org/stable/117311

Camara, M. The Impact of Programme versus Project Aid on Fiscal Behaviour in the Gambia: Implication for Aid Flows supporting the PRSP. Retrieved from: http://lnweb90.worldbank.org/exteu/SharePapers.nsf/(ID)/49A2BF44A1DF33BD 8525722900405196? OpenDocument

Camara, M. (2004). The Impact of Programme versus Project Aid on Fiscal Behaviour in The Gambia. Retrieved from:

http://lnweb90.worldbank.org/exteu/SharePapers.nsf/(\$all)/49A2BF44A1DF33B D8525722900405196/\$File/MORRO+CAMARA.PDF

Canadian Broadcasting Corporation (CBC). (2013, Match 22). Federal Budget Folds CIDA into Foreign Affairs. CBC News. Retrieved from http://www.cbc.ca/news/politics/federal-budget-folds-cida-into-foreign-affairs1.1412948

Canadian International Development Platform (CIDP). (2017). Responding to the Changing Global Development Context: How Can Canada Deliver? Retrieved from: http://cidpnsi.bbdp6cmt4ou6bl.netdna-cdn.com/wpcontent/uploads/2017/06/Responding-to-the-Changing-Global-DevelopmentContext-June-2017.pdf

Carment, D., Calleja, R., \& Samy, Y. (2013). Comparing Canada's Aid Effectiveness: Coherence and Focus at Risk. (Canadian Defence \& Foreign Affairs Institute Policy Paper). Retrieved from https://carleton.ca/npsia/wp-content/uploads/AidEffectiveness.pdf

Center for Global Development (CGD). (2017), Commitment to Development Index 2017. Retrieved from: https://www.cgdev.org/commitment-development-index2017

Chandler, A. (1962). Strategy and Structure: Chapters in the History of the Industrial Enterprise. Cambridge: M.I.Y. Press.

Chang, H., Fell, A. M., Laird, M., \& Seif, J. (1999). A Comparison of Management Systems for Development Cooperation in OECD/DAC Members. Paris:

Organization for Economic Cooperation and Development. Retrieved from: http://www.oecd.org/dac/peer-reviews/2094873.pdf

Chhotray, V., \& Hulme, D. (2009). Contrasting Visions for Aid and Governance in the $21^{\text {st }}$ Century: The White House Millennium Challenge Account and DFID's Drivers of Change. World Development, 37(1), 36-49. https://doi.org/10.1016/j.worlddev.2007.11.004

Child, J. (1972). Organizational Structure, Environment and Performance: The Role of Strategic Choice. Sociology, 6(1), 1-22. doi: 10.1177/003803857200600101

Child, J. (1997). Strategic Choice in the Analysis of Action, Structure, Organizations and Environment: Retrospect and Prospect. Organizational Studies, 18(1), 43-76. doi: 10.1177/017084069701800104

Christiansen, K., and Rogerson, A. (2005). Is the Current Aid Architecture 'Fit for Purpose'? London: Overseas Development Institute. Retrieved from 
https://www.odi.org/sites/odi.org.uk/files/odi-assets/publications-opinionfiles/2145.pdf

Christensen, L. T., Læfreid, P., Roness, P. G., \& Rovik, K.A. (2007). Organizationl Theory and the Public Sector: Instrument, Culture and Myth. Oxford: Routledge.

Christensen, T. \& Lægreid, P. (2008). Transcending New Public Management: The Increasingly Complexity of Balancing Control and Autonomy. Paper presented at The Third International Conference on Public Management in 21st century: Opportunities and Challenges, Macao, China Oct 14.-15., 2008. Retrieved from http://www.umac.mo/fss/pa/3rd_conference/doc/all\%20paper/English\%20paper/1 panelA/Tom\%20Christensen.pdf

Christensen, T., \& Læfreid, P. (2011). Complexity and Hybrid Public Administration Theoretical and Empirical Challenges. Public Organization Review, 11(4), 407423.

Christensen, T., \&Læfreid, P. (2016). The Ashgate Research Companion to New Public Management. New York: Routledge.

Clegg, S., Kronberger, M., \& Pitsis, T. (2011). Managing and Organization: An Introduction to Theory and Practice. California: Sage Publications.

Clements, B., Gupta, S., Pivovarsky, A., \& Tiongson, E.R. (2004). Foreign Aid: Grants versus Loans. Finance and Development, 46-49. Retrieved from https://www.imf.org/external/pubs/ft/fandd/2004/09/pdf/clements.pdf

Coase, R. (1937). The Nature of the Firm. Economica 4, 386-405.

Collier, P., \& Dollar, D. (2002). Aid Allocation and Poverty Reduction. European Economic Review, 46(8), 1475-1500. https://doi.org/10.1016/S00142921(01)00187-8

Colombo, M.G., \& Delmastro, M. (2002). The Determinants of Organizational Change and Structural Inertia: Technological and Organizational Factors. Journal of Economics and Management Strategy, 11(4), 595-635. doi: 10.1111/j.14309134.2002.00595.x

Corbett, J. (2017). Australia's Foreign Aid Dilemma: Humanitarian Aspirations Confront Democratic Legitimacy. London: Routledge.

Corbett, J., \& Howard, C. (2017). Why Perceived Size Matters For Agency Termination. Public Administration, 95(1), 196-213. doi: 10.1111/padm.12299

Cresswell, J.W., \& Plano Clark, V.L. (2006). Designing and Conducting Mixed Methods Research. London: SAGE Publications.

Cunningham, G. (1974). The Management of Aid Agencies. London: Overseas Development Institute.

Daft, R. (2013). Organization Theory and Design. Mason, Ohio: Cengage Learning.

Dagbjartsson, B. (2001). Icelandic International Development Agency: Reflections on a 20-year History. ICEIDA Newsletter No. 12. Retrieved from http://www.iceida.is/media/utgefid-efni/Newsletter_2001.pdf

Dang, H-A., Knack, S., \& Rogers, H. (2009). International Aid and Financial Crisis in Donor Countries. (World Bank Policy Research Working Paper 5162). Retrieved from IADB website: http://www20.iadb.org/intal/catalogo/PE/2010/04555.pdf

Davies, R. (2013, October 1). Bending AusAID or Breaking It? The Canberra Times. Retrieved from http://www.canberratimes.com.au/national/publicservice/bending-ausaid-or-breaking-it-20130929-2um04.html 
Davies, R. (2017). Five Lean Years: How Australia's Aid Program has Tightened its Belt. DevPolicy Blog. Retrieved from http://devpolicy.org/five-lean-yearsaustralias-aid-program-tightened-belt/

De Boer, H. F., J. Endersand \& L. Leisyte. (2007). Public Sector Reform in Dutch Higher Education: the Organizational Transformation of the University. Public Administration, 85(1), 27-46. doi: 10.1111/j.1467-9299.2007.00632.x

Denhardt, R.B. (2008). Theories of Public Organization ( $5^{\text {th }}$ ed). Belmont, CA: Thomson/Wadsworth.

Department of Foreign Affairs and Trade (DFAT). (2011). Ireland and Africa: Our Partnership With a Changing Continent. Dublin: DFAT. Retrieved from https://www.dfa.ie/media/irishaid/allwebsitemedia/20newsandpublications/public ationpdfsenglish/africa-strategy.pdf

Department of Foreign Affairs and Trade (DFAT). (2014). Australian Aid: Promoting Prosperity, Reducing Poverty, Enhancing Stability. Canberra: DFAT. Retrieved from http://dfat.gov.au/about-us/publications/Documents/australian-aiddevelopment-policy.pdf

DeSantis, V.S., \& Durst, S. (1996). Comparing Job Satisfaction Among Public- and Private-sector Employees. American Review of Public Administration, 26(3), 327343. doi: 10.1177/027507409602600305

DevPolicy. (2017). Trends. Retrieved from http://devpolicy.org/aidtracker/trends/

Diefenback, T. (2009). New Public Management in Public Sector Organizations: The Dark Sides of Managerialistic 'Enlightenment'. Public Administration, 87(4), 892-909. doi: 10.1111/j.1467-9299.2009.01766.x

Dietrich, S. (2012). Bypass or Engage? Explaining Donor Delivery Tactics in Foreign Aid Allocation. International Studies Quarterly, 57(4), 698-712. doi: 10.1111/isqu.12041

Dijkstra. G. A. (2002). The Effectiveness of Policy Conditionality: Eight Country Experiences. Development and Change, 33(2), 307-334. doi: 10.1111/14677660.00256

DiMaggio, P. J., \& Powell, W. W. (1983). The Iron Cage Revisited: Institutional Isomorphism and Collective Rationality in Organization Fields. American Sociological Review, 48(2), 147-160. Retrieved from http://www.jstor.org/stable/2095101

DiMaggio, P. J., \& Powell, W. W. (1991). The New Institutionalism in Organizational Analysis. Chicago: University of Chicago Press.

Djankov, S., Montalvo, J.G., \& Reynal-Querol, M. (2004). Helping the Poor with Foreign Aid: The Grants vs. Loans Debate. World Bank: Washington D.C.

Dollery, B., Kortt, M., \& Grant, B. (2012). A Normative Model for Local Government De-Amalgamation in Australia. Australian Journal of Political Science, 46(4), 601-615. Retrieved from http://dx.doi.org/10.1080/10361146.2011.623670

Donaldson, L. (1990). The Ethereal Hand: Organizational Economics and Management Theory. The Academy of Management Review, 15(3), 369-381. Retrieved from http://www.jstor.org/stable/258013

Donaldson, L. (2001). The Contingency Theory of Organizations. California: Sage Publications Inc. 
Donaldson, L. (2006). The Contingency Theory of Organizational Design: Challenges and Opportunities. In Burton, R. M., Eriksen, B., Hakonsoo, D. D., and Snow, C. C. (Eds.), Organization Design: The Evolving State-of-the-Art (pp. 19-40). USA: Springer Science and Business Media.

Downs, A. (1967). Inside Bureaucracy. Boston, MA: Little, Brown and Company

Dreher, A., Nunnenkamp, P., \& Thiele, R. (2008). Does US Aid Buy UN General Assembly Votes?: A Disaggregated Analysis. Public Choice, 136(1), 139-164. Retrieved from http://www.jstor.org/stable/27698295

Drury, A.C., Olson, R.S., \& Van Belle, D.A. (2005). The Politics of Humanitarian Aid: U.S. Foreign Disaster Assistance, 1964-1995. The Journal of Politics, 67(2), 454473. doi: 10.1111/j.1468-2508.2005.00324.x

Dunleavy, P. (1991). Democracy, Bureaucracy and Public Choice. Economic Explanations in Political Science. New York: Harvester Wheatsheaf.

Dunleavy, P., Margetts, H., Bastow, S., \& Tinkler, J. (2006). New Public Management is Dead - Long Live Digital-Era Governance. Journal of Public Administration Research and Theory, 16(3), 467-494. Retrieved from https://doi.org/10.1093/jopart/mui057

Easterly, W., \& Pfutze, T. (2008). Where Does the Money Go? Best and Worst Practices in Foreign Aid. Journal of Economic Perspectives, 22(2), 29-52. Retrieved from http://www.jstor.org/stable/27648240

Easterly, W., \& Williamson, C. (2011). Rhetoric versus Reality: The Best and Worst of Aid Agency Practices. World Development, 39(11), 1930-1949. Retrieved from https://doi.org/10.1016/j.worlddev.2011.07.027

Eldridge, P. (1985). The Jackson Report on Australia's Overseas Aid Program: Political Options and Prospects. Australian Outlook, 35(1), 23-32. Retrieved from http://dx.doi.org/10.1080/10357718508444868

Faure, R., Long, C., \& Prizzon, A. (2015). Do Organisational and Political Models for Development Cooperation Matter for Development Effectiveness? (Overseas Development Institute Working Paper). Retrieved from the Overseas Development Institute wesbite: https://www.odi.org/sites/odi.org.uk/files/odiassets/publications-opinion-files/9611.pdf

Faust, J. (2011). Donor Transparency and Aid Allocation. (German Development Institute Discussion Paper 12/2011). Retrieved from http://edoc.vifapol.de/opus/volltexte/2012/3552/pdf/DP_12.2011.pdf

Faust, J., \& Ziaja, S. (2012). German Aid Allocation and Partner Country Selection: Development-orientation, Self-interests and Path Dependency. (German Development Institute Discussion Paper 7/2012). Retrieved from the German Development Institute website: https://www.diegdi.de/uploads/media/DP_7.2012.pdf

Faust, J., \& Koch, S. (2014). Foreign Aid and the Domestic Politics of European Budget Support. (German Development Institute Discussion Paper 21/2014). Retrieved from the German Development Institute website: https://www.diegdi.de/uploads/media/DP_21.2014.pdf

FGS Consulting. (2008). Management Review - Final Report. Dublin: FGS Consulting. 
Fink, G., \& Redaelli, S. (2011). Determinants of International Emergency AidHumanitarian Need Only? World Development, 39(5), 741-757. Retrieved from https://doi.org/10.1016/j.worlddev.2010.09.004

FitzGerald, G. (1991). All in a Life. Dublin: Gill and Macmillan Ltd.

Fleck, R. K., \& Kilby, C. (2006). Why Do Political Changes Influence U.S. Bilateral Aid Allocations? Evidence from Panel Data. Review of Development Economics, 10(2), 210-223. doi: 10.1111/j.1467-9361.2006.00313.x

Food and Agriculture Network (FAO). (2012). A Guide to the Formulation of the Country Programming Framework. Retrieved from:

$\mathrm{ftp}$ //ftp.fao.org/TC/CPF/Guidelines/CPFGuidelines.pdf

Fraser, M. (1975). Transcript of Caretaker Prime Minister Malcolm Fraser's 1975 Election Policy Speech. Retrieved from http://whitlamdismissal.com/1975/11/27/fraser-election-policy-speech.html

Freeman, J. (2012). Can Time Series Methods Be Used to Detect Path Dependence? Paper prepared for Conference on Path Dependence, University of Minnesota, June 4-5, 2010. Retrieved from http://users.polisci.umn.edu/ freeman/pathdependenceFreeman7/13.pdf

Frumkin, P. (2003). Making Public Sector Mergers Work: Lessons Learned. IBM Center for The Business of Government. Retrieved from http://www.stateinnovation.org/Events/Event-Listing/Louisiana-WorkforceStrategy-Academy/Handouts/Making-Public-Sector-Mergers-Work---LessonsLearne.aspx

Führer, H. (1996). The Story of Official Development Assistance. Paris: OECD. Retrieved from http://www.oecd.org/dac/1896816.pdf

Galbraith, J. (1973). Designing Complex Organizations. Reading, MA: Addison-Wesley. Gates, S., \& Hoeffler, A. (2004). Global Aid Allocation: Are Nordic Donors Different? (Center for the Study of African Economics Series Working Paper Series 200434). Retrieved from University of Oxford Department of Economics website: http://www.csae.ox.ac.uk/workingpapers/pdfs/2004-34text.pdf

Gavas, M., Gulrajani, N., \& Hart, T. (2015). Designing the Development Agency of the Future. ODI Framing Paper. London: Overseas Development Institute. Retrieved from https://www.odi.org/sites/odi.org.uk/files/odi-assets/publications-opinionfiles/9610.pdf

George, A.L., \& Bennett, A. (2005). Case Studies and Theory Development in the Social Sciences. Cambridge: MIT Press.

Goldstein, M., \& Todd, M. (2005). Compassionate Conservatives or Conservative Compassionates? US Political Parties and Bilateral Foreign Assistance to Africa. Journal of Development Studies, 41(7), 94-103. Retrieved from http://dx.doi.org/10.1080/00220380500170949

GoA (Government of Australia). (2011). Independent Review of Aid Effectiveness. Canberra: Commonwealth of Australia. Retrieved from http://www.aidreview.gov.au/publications/aidreview.pdf

GoG (Government of Germany). (2015). Memorandum for the DAC Peer Review of Germany, 2015. Berlin: Government of Germany. Retrieved from https://www.oecd.org/dac/peer- 
reviews/Memorandum\%20for\%20DAC\%20Peer\%20Review\%20of\%20Germany $\% 202015 \% 20$ ENG.pdf

Government of Ireland. (1937). Constitution of Ireland. Dublin: Government of Ireland.

Retrieved from

https://www.taoiseach.gov.ie/eng/Historical_Information/The_Constitution/Febru ary_2015___Constitution_of_Ireland_.pdf

Government of the Netherlands (GoN). (2016). OECD DAC Peer Review of the

Netherlands 2017: Memorandum by the Netherlands. Hague: Government of

Netherlands.

Greenwood, R., \& Hinings, C.R. (1996). Understanding Radical Organizational Change:

Brining Together the Old and the New Institutionalism. The Academy of

Management Review, 21(4), 1022-1054. Retrieved from

http://www.jstor.org/stable/259163

Greve, C., Laegreid, P., \& Rykkka, L.H. (2016). Introduction: The Nordic Model in Transition. In C. Greve, P. Laegreid, \& L. H. Rykkja (Eds.), Nordic Administrative Reforms: Lessons for Public Management (pp. 1-21). London: Palgrave Macmillian.

Gudmundsson, T. (2014). Iceland's Development Cooperation-Organization, Efficiency and Performance. Retrieved from https://www.stjornarradid.is/media/utanrikisraduneytimedia/media/throunarsamvinna/Throunarsamvinna-Islands---lokaskyrsla.pdf

Gulrajani, N. (2012). Improving Canada's Performance as a Bilateral Donor: Assessing the Past and Building for the Future. In S. Brown (Ed.), Struggling for Effectiveness: CIDA and Canadian Foreign Aid. Brown (pp. 53-78). Canada: McGill-Queen's University Press.

Gulrajani, N. (2013, March 28). Global evidence suggests merging CIDA and DFAIT will be a mistake. Toronto Star. Retrieved from http://www.thestar.com/opinion/commentary/2013 /03/28/global_evidence_suggests_merging_cida_and_dfait_will_be_a_mistake.ht $\mathrm{ml}$

Gulrajani, N. (2014). Organising for Donor Effectiveness: An Analytical Framework for Improving Aid Effectiveness. Development Policy Review 32, 89-112.

Gulrajani, N. (2015a). Dilemmas in Donor Design: Organisational Reform and the Future of Foreign Aid Agencies. Public Administration and Development, 35(1), 152164. doi: 10.1111/dpr.12045

Gulrajani, N. (2015b). Bilateral Donors in the 'Beyond Aid' Agenda: The Importance of Institutional Autonomy for Donor Effectiveness. (Global Economic Governance Working Paper 2015/106). Retrieved from the Overseas Development Institute website:

http://www.geg.ox.ac.uk/sites/geg/files/WP_106\%20Bilateral\%20Donors\%20in\% 20the $\% 20 \%$ E2\%80\%98Beyond\%20Aid $\%$ E2\%80\%99\%20Agenda $\% 20$ -

$\% 20$ The $\% 20$ Importance $\% 20$ of\%20Institutional\%20Autonomy\%20for\%20Donor

$\%$ 20Effectiveness\%20Nilima\%20Gulrajani.pdf 
Gulrajani, N. (2017). How to Merge Development Agencies Sucessfully: Safeguarding the Aims and Ambitions of Effective Development Assistance. (Overseas Development Institute Briefing Note). Retrieved from ODI website at:

Gulrajani, N., \& Swiss, L. (2017). Why do countries become donors? (ODI Research Report). Retrieved from the Overseas Development Institute website https://www.odi.org/sites/odi.org.uk/files/resource-documents/11364.pdf

Hage, J., \& Aiken, M. (1967). Program Change and Organizational Properties: A Comparative Analysis. American Journal of Sociology, 72(5), 503-519. Retrieved from http://www.jstor.org/stable/2775676

Hage, J.T. (1999). Organizational Innovation and Organizational Change. Annual review of Sociology, 25, 597-622. Retrieved from https://doi.org/10.1146/annurev.soc.25.1.597

Hall, R. H. (1962). Intraorganziational Structural Variation: Application of the Bureaucratic Model. Administrative Science Quarterly, 7(3), 295-308. Retrieved from http://www.jstor.org/stable/2390944

Halligan, J., \& James, O. (2012). Comparing Agencification in Anglo-American Countries. In by K. Verhoest, S. Van Theil, G. Bouckaert, \& P. Laegreid,(Eds.), Government Agencies: Practices and Lessons from 30 Countries (79-82). UK: Palgrave Macmillan.

Hammerschmid, G., Gornitz, A., Oprisor, A., Stimac, V. (2013). Public Sector Reform in Germany: Views and Experiences from Senior Executives. (Country Report as part of the COCOPS Research Project). Retrieved from http://www.cocops.eu/wpcontent/uploads/2013/06/Germany_WP3-Country-Report.pdf

Hannan, M. T., \& Freeman, J. (1984). Structural Inertia and Organizational Change. American Sociological Review, 49(2), 149-164. Retrieved from http://www.jstor.org/stable/2095567

Hardiman, N., \& MacCarthaigh, M., (2011). The Un-Politics of New Public Management in Ireland. In J.-M. Eymeri-Douzans \& J. Pierre (Eds.), Administrative Reforms and Democratic Governance (pp. 55-67). London: Routledge.

Harman, G. (2000). Institutional Mergers in Australian Higher Education since 1960. Higher Education Quarterly, 54(4), 343-366. doi: 10.1111/1468-2273.00165

Harman, G. and Harman, K. (2003). Institutional Mergers in Higher Education: Lessons from International Experience. Tertiary Education and Management, 9(1), 29-44.

Hasegawa, S. (1975). Japanese Foreign Aid: Policy and Practice. New York: Praeger Publishers.

Haveman, H.A. (1992). Between a Rock and a Hard Place: Organizational Change and Performance Under Conditions of Fundamental Environmental Transformation. Administrative Science Quarterly, 37(1), 48-75. doi: 10.2307/2393533

Haunschild, P.R., \& Miner, A. S. (1997). Models of Interorganizational Imitation: The Effects of Outcome Salience and Uncertainty. Administrative Science Quarterly, 42(3), 472-500.

Hausman, J., \& McFadden, D. (1984). Specification Tests for the Multinomial Logit Model. Econometrica, 52(5), 1219-1240. doi: 10.2307/1910997

Heugens, P., \& Lander, M. W. (2009). Structure! Agency! (And Other Quarrels): A Meta-Analysis of Institutional Theories of Organization. Academy of 
Management Journal, 52(1), 61-85. Retrieved from http://www.jstor.org/stable/40390276

Hill, P. S. (2002). Organizational Responses to a Changing Aid Environment: the German Agency for Technical Cooperation (GTZ). International Journal of Health Planning Management, 17(3), 213-227. doi: 10.1002/hpm.672

Hoebink, P. (1999). The Humanitarianisation of the Foreign Aid Programme in the Netherlands. The European Journal of Development Research, 11(1), 176-202.

Hoebink, P. (2006). Some Long Burning Issues in the International Cooperation of the Netherlands: An Introduction to Yearbook 2007. In P. Hoebink (Ed.), The Netherlands Yearbook on International Cooperation (pp. 10-22). Assen: Van Gorcum.

Hoeffler, A., \& Outram, V. (2008). Need, Merit or Self-Interest - What Determines the Allocation of Aid? (CSAE Working Paper Series 2008-19). Retrieved from Oxford Centre for the Study of African Economics website http://www.csae.ox.ac.uk/workingpapers/pdfs/2008-19text.pdf

Honig, B., \& Karlsson, T. (2004). Institutional Forces and the Written Business Plan. Journal of Management, 30(1), 29-48. Retrieved from http://journals.sagepub.com/doi/abs/10.1016/j.jm.2002.11.002

Hood, C. (1991). A Public Management for All Seasons? Public Administration, 69(1), 3-19. doi: 10.1111/j.1467-9299.1991.tb00779.x

Hood, C. (1996). Exploring Variation in Public Management Reform of the 1980s. In Bekke, H., Perry, J., \& Toonen, T. (Eds.), Civil Service Systems in Comparative Perspective (pp.268-317) . Bloomington: Indiana University Press.

Hood, C. (2000). Paradoxes of Public-Sector Managerialism, Old Public Management and Public Service Bargains. International Public Management Journal, 3(1), 122. https://doi.org/10.1016/S1096-7494(00)00032-5

Huber, G. P., Sutcliffe, K.M., Miller, C.C., \& Glick, W.H. (1993). Understanding and Predicting Organizational Change. In G.P. Huber \& W.H. Glick (Eds.), Organizational Change and Redesign: Ideas and Insights for Improving Performance (pp. 215-267). New York: Oxford University Press.

ICEIDA. (2011). Strategy for Iceland's Development Cooperation. Retrieved from https://www.utanrikisraduneyti.is/media/MFA_pdf/MFA---Strategy-for-IcelandsDevelopment-Cooperation-2011-2014.pdf

ICEIDA. (2013). Strategy for Iceland's Development Cooperation. Retrieved from http://www.iceida.is/media/pdf/MFA-

StrategyforIcelandsDevelopmentCooperation-2013-2016-Fact-Sheet.pdf

Iglesia-Caruncho, M. (2011). The Politics and Policy of Aid in Spain. (Institute of Development Studies Research Report 65). Retrieved from Institute of Development Studies website: http://www.ids.ac.uk/files/dmfile/RR65.pdf

Ingram, G. (2017). Tillerson's Listening Report Reinforces that State and USAID Should be Separate. Retrieved from https://www.brookings.edu/blog/futuredevelopment/2017/07/24/tillersons-listening-report-reinforces-that-state-andusaid-should-be-separate/

Insigniam. (2017). U.S. Department of State Listening Report for the U.S. Department of State \& U.S. Agency for International Development. Retrieved from 
https://www.brookings.edu/wpcontent/uploads/2017/09/gs_20170927_dos_usaid_listening_report_2017.pdf

International Development Association (IDA). (2007). Aid Architecture: An Overview of the Main Trends in Official Development Assistance Flows. Retrieved from World Bank website:

http://documents.worldbank.org/curated/en/745221468313781790/pdf/387500ida secm200710103core.pdf

Irish Aid. (2006). White Paper on Irish Aid. Dublin: Government of Ireland. Retrieved from https://www.irishaid.ie/media/irishaid/allwebsitemedia/20newsandpublications/pu blicationpdfsenglish/white-paper-english-2006.pdf

Ivankova, N.V., Cresswell, J.W., \& Stick, S.L. (2006). Using Mixed-Methods Sequential Explanatory Design: From Theory to Practice. Field Methods, 18(3): 3-20.

Jelovac, I., \& Vandeninden, F. (2008). How Should Donors Give Foreign Aid? Project Aid Versus Budget Support. (CREPP Working Papers, University of Liege). Retrieved from http://www2.ulg.ac.be/crepp/papers/crepp-wp200804.pdf

Jain, P. (2015). Japan's Foreign Aid: Institutional Change and Shifting Policy Directions. In H. Kato, J. Page and Y. Shimomura (Eds), Japan's Development Assistance (pp. 56-71). New York: Palgrave Macmillian.

Jespersen, P.K., Nielsen, L. L. M., \& Sognstrup, H. (2002). Professions, Institutional Dynamics, and New Public Management in the Danish Hospital Field. International Journal of Public Administration, 25(12), 1555-74. Retrieved from http://dx.doi.org/10.1081/PAD-120014261

Jilke, S.,Van de Walle, S., \& van Delft, R. (2013). Public Sector Reform in the Netherlands: Views and Experience from Senior Executives. (Coordination for Cohesion in the Public Sector of the Future (COCOPS) Research Project). Retrieved from COCOPs EU website: http://www.cocops.eu/wpcontent/uploads/2013/06/Netherlands_WP3-Country-Report.pdf

Johnston, J. (2000). The New Public Management in Australia. Administrative Theory and Praxis, 22(2), 345-368. Retrieved from http://www.jstor.org/stable/25611437

Joint Committee on Foreign Affairs and Defence. (1985). The Jackson Report on Australia's Overseas Aid Program. Canberra: Parliament of the Commonwealth of Australia.

Joint Committee of Public Accounts. (1982). Efficiency Audit - Administration of Bilateral Overseas Aid. Canberra: Parliament of the Commonwealth of Australia.

Jones, H., Jones, N., Shaxson, L., \& Walker, D. (2012). Providing Practical Guidance for In-country Programming: The value of analyzing knowledge, policy and power. (Overseas Development Institute Background Note). Retrieved from https://www.odi.org/sites/odi.org.uk/files/odi-assets/publications-opinionfiles/8199.pdf

Kanda, D., Scott, A., \& Weber, S. (2011). Kingdom of the Netherlands - Netherlands: Selected Issues and Analytical Notes. (International Monetary Fund Country Report No. 11/143). Retrieved from International Monetary Fund website: https://www.imf.org/external/pubs/ft/scr/2011/cr11143.pdf

Kaneko, Y. (1999). Government Reform in Japan. Retrieved from http://www.iam.or.jp/asia-pacific_panel/pdfdownloads/london99-paper2.pdf 
Kaufman, H. (1976). Are Government Organizations Immortal? Washington, DC: Brookings Institute.

Kelly, D., \& Amburgey, T.L. (1991). Organizational Inertia and Momentum: A Dynamic Model of Strategic Choice. Academy of Management Journal, 34(3), 591-612. doi: $10.2307 / 256407$

Kennedy, P. (1992). A Guide to Econometrics. Oxford: Blackwell.

Khojasteh, M. (1993). Motivating the Private vs. Public Sector Managers. Public Personnel Management, 93(22), 391-402. doi: 10.1177/009102609302200304

Kickert, W.J.M. (2014). Specificity of Change Management in Public Organizations: Conditions for Successful Organizational Change in Dutch Ministerial Departments. American Review of Public Administration, 44(6), 693-717. doi: $10.1177 / 0275074013483871$

King, G., \& Zeng, L. (2001). Explaining Rare Events in International Relations. International Organization, 55(3), 693-715.

Kirkpatrick, I., Ackroyd, S., \& Walker, R. (2005). The New Managerialism and Public Service Professions. New York: Palgrave Macmillan.

Klingebiel, S., Mahn, T., \& Negre, M. (2016). The Fragmentation of Aid: Concepts, Measurements and Implications for Development Cooperation. Basingstoke: Palgrave Macmillan, UK.

Knack, S., Rogers, F.H., \& Eubank, N. (2010). Aid Quality and Donor Rankings. (World Bank Policy Research Working Paper 5290). Retrieved from the World Bank website: https://elibrary.worldbank.org/doi/abs/10.1596/1813-9450-5290

Koike, O. (2000). New Public Management in Japan and Southeast Asian Countries: A Magic Sword for Governance Reform? Paper presented at the IIAS/Japan Joint Panel on Public Administration, Bologna, Italy, June 21, 2000. Retrieved from http://unpan1.un.org/intradoc/groups/public/documents/APCITY/UNPAN027670. pdf

Læfreid, P., \& Verhoest, K. (2010). Introduction: Reforming Public Sector Organizations. In P. Læfreid \& K. Verhoest (Eds.), Governance of Public Sector Organizations: Proliferation, Autonomy and Performance (pp. 1-20). London: Palgrave Macmillan.

Lane, J. (2005). Public Administration and Public Management: The Principal-Agent Perspective. Great Britain: Routledge.

Lancaster, C. (2007). Foreign Aid: Diplomacy, Development, Domestic Politics. Chicago: University of Chicago Press.

Lancaster, C. (2008). Foreign Aid in the Twenty-first Century: What Purposes? In L.A. Picard, R. Groelsema, \& T.E. Buss (Eds.), Foreign Aid and Foreign Policy: Lessons for the Next Half-century (pp. 39-60). New York: M.E. Sharpe.

Leandro, J. E., Schafer, H., \& Frontini, G. (1999). Towards a More Effective Conditionality: An Operational Framework. World Development. 27(2), 285-299. Retrieved from https://doi.org/10.1016/S0305-750X(98)00127-2

Lee, K., \& Pennings, J. M. (2002). Mimicry and the Market: Adoption of a New Organizational Form. Academy of Management Journa, 45(1), 144-162. Retrieved from http://www.jstor.org/stable/3069289 
Leiderer, S. (2012). Fungibility and the Choice of Aid Modality. (UNU-WIDER Working Paper 68/2012). Retrieved from UNU-WIDER website:

https://www.wider.unu.edu/publication/fungibility-and-choice-aid-modalities

Lewis, D.E. (2002). The Politics of Agency Termination: Confronting the Myth of Agency Immortality. Journal of Politics, 64(1): 89-107. Retrieved from http://www.jstor.org/stable/2691666

Lim, D. (1985). The Jackson Report on Australian Aid: The Underlying Framework. Australian Outlook, 39(1), 19-22. Retrieved from http://dx.doi.org/10.1080/10357718508444867

Loftsdottir, K. (2014). Within a 'White' Affective Space: Racialization in Iceland and Development Discourses. Social identities, 20(6), 452-470. Retrieved from http://dx.doi.org/10.1080/13504630.2015.1004996

Loftsdóttir, K., \& Björnsdóttir, H. (2010). The 'Jeep-Gangsters' from Iceland: Local Development Assistance in a Global Perspective. Critique of Anthropology, 30(1), 23-39. Retrieved from 10.1177/0308275X09345423

Longest, K.C., \& Vaisey, S. (2008). Fuzzy: A Program for Performing Qualitative Comparative Analyses (QCA) in Stata. The STATA Journal, 8(1): 79-104. Retrieved from http://www.stata-journal.com/article.html?article=st0140

Lundsgaarde, E. (2013). Bureaucratic Pluralism and the Transformation of Development Cooperation. Paper presented at the Fragmentation or Pluralism? The Organization of Development Cooperation Revisited Conference in Bonn, Germany on Oct 10, 2013.

Lundsgaarde, E., Breunig, C., \& Prakash, A. (2010). Instrumental Philanthropy: Trade and the Allocation of Foreign Aid. Canadian Journal of Political Science 43(3), 733-761. Retrieved from doi:10.10170S0008423910000661

Mackay, K. (2011). The Performance Framework of the Australian Government, 1987 to 2011. OECD Journal of Budgeting, 11(3), 1-48. Retrieved from https://www.oecd.org/gov/budgeting/49042370.pdf

Maizels, A., \& Nissanke, M. (1984). Motivations for Aid to Developing Countries. World Development, 12(9), 879-900. Retrieved from https://doi.org/10.1016/0305750X(84)90046-9

Manning, N. (2001). The Legacy of the New Public Management in Developing Countries. International Review of Administrative Sciences, 67(2), 297-312. Retrieved from 10.1177/0020852301672009

Manning, R. (2006). Development Cooperation Report 2006. Paris: OECD.

March, J.G., \& Olson, J.P. (1983). Organizing Political Life: What Administrative Reorganization Tells Us About Government. The American Political Science Review 77(2), 281-296. Retrieved from http://www.jstor.org/stable/1958916

Martens, B., Mummert, U., Murrell, P., \& Seabright, P. (2002) The Institutional Economics of Foreign Aid. Cambridge: Cambridge University Press.

Martens, B. (2005). Why Do Aid Agencies Exist? Development Policy Review, 23(6), 643-663. Retrieved from doi: 10.1111/j.1467-7679.2005.00306.x

McGrath, P. (2013a, September 12). Australia's Unemployment Rate Climbs to 5.8 per cent to its Highest Level in Four Years. $A B C$ News. Retrieved from http://www.abc.net.au/news/2013-09-12/jobless-rate-up/4953338 
McGrath, P. (2013b, December 3). Australian Economy Grows 0.6 per cent in December Quarter, Annual GDP Growth Rate at 2.3 per cent. $A B C$ News. Retrieved from http://www.abc.net.au/news/2013-12-04/gdp-figures-september-quarter/5133640

McKinlay, A., \& Starkey, K. (1988). Competitive Strategies and Organizational Change. Organization Studies, 9(4), 555-571. Retrieved from 10.1177/017084068800900406

McKinlay, R. D., \& Little, R. (1977). A Foreign Policy Model of US Bilateral Aid Allocations. World Politics, 30(1), 56-86. Retrieved from http://www.jstor.org/stable/2010075

McKinlay, R. D., \& Little, R. (1979). The US Aid Relationship: A Test of the Recipient Need and the Donor Interest Models. Political Studies, 27(2): 236-250.

Meernik, J., Krueger, E.L., Poe, S. C. (1998). Testing Models of U.S. Foreign Policy: Foreign Aid During and After the Cold War. Journal of Politics 60: 63-85. doi: 10.1111/j.1467-9248.1979.tb01201.x

Mendick, R., Hennessy, P., \& Malnick, E. (2013, June 16). Some Countries do not need our Money any more, says Andrew Mitchell. The Telegraph. Retrieved from http://www.telegraph.co.uk/news/politics/10122842/Some-countries-do-not-needour-money-any-more-says-Andrew-Mitchell.html

Mendoza, R.U., Jones, R., \& Vergara, G. (2009). Will the Global Financial Crisis Lead to Lower Financial Aid? A First Look at United States ODA. (Fordham University, Department of Economic, Discussion Paper Series 2009-01). Retrieved from Fordham University website: https://legacy.fordham.edu/images/academics/graduate_schools/gsas/economics/d p2009_01_mendoza_jones_vergara.pdf

Miljan, L., \& Spicer, Z. (2015). De-Amalgamation in Canada: Breaking up is hard to do. Toronto: Fraser Institute. Retrieved from https://www.fraserinstitute.org/sites/default/files/de-amalgamation-in-canada.pdf

Miller, G. J. (2005). The Political Evolution of Principal-Agent Models. Annual Review of Political Science, 8, 203-225. Retrieved from https://doi.org/10.1146/annurev.polisci.8.082103.104840

Milner, H.V., \& Tingley, D. (2013). The Choice for Multilateralism: Foreign Aid and American Foreign Policy. Review of International Organizations, 8(3), 313-341. Retrieved from doi:10.1007/s11558-012-9153-x

Ministry of Foreign Affairs (MINBUZA). (2007). Our Common Concern: Investing in Development in a Changing World. Hague: MINBUZA. Retrieved from http://www.minbuza.nl/binaries/content/assets/minbuza/de/import/de/das_ministe rium/entwicklungszusammenarbeit/our-common-concern.pdf

Ministry of Foreign Affairs (MFA). (2013a). A World to Gain: A New Agenda for Aid, Trade and Investment. Hague: Ministry of Foreign Affairs. Retrieved from https://www.government.nl/documents/letters/2013/04/05/global-dividends-anew-agenda-for-aid-trade-and-investment

Ministry of Foreign Affairs (MFA). (2015). Commentary Pertaining to the Bill. Reykjavik: MFA.

Ministry of Foreign Affairs (MOFA). (2001). Japan's Official Development Assistance: White Paper 2001. Tokyo: Economic Cooperation Bureau, MOFA. Retrieved from http://www.mofa.go.jp/policy/oda/white/2001/contents.pdf 
Ministry of Foreign Affairs (MOFA). (2002). Japan's Official Development Assistance: White Paper 2002. Tokyo: Economic Cooperation Bureau, MOFA. Retrieved from http://www.mofa.go.jp/policy/oda/white/2002/part1 3 2.html

Ministry of Foreign Affairs (MOFA). (2003). Japan's Official Dēvelopment Assistance Charter. Tokyo: MOFA. Retrieved from http://www.mofa.go.jp/policy/oda/reform/revision0308.pdf

Ministry of Foreign Affairs (MOFA). (2015). Development Cooperation Charter: For Peace, Prosperity and a Better Future for Everyone. Tokyo: MOFA. Retireved from http://www.mofa.go.jp/files/000067701.pdf

Moe, T,M. (1984). The New Economics of Organization. American Journal of Political Science, 28(4), 739-777. Retrieved from http://www.jstor.org/stable/2110997

Moe, T.M. (1989). The Politics of Bureaucratic Structure. In J.E. Chubb \& P.E. Peterson (Eds.), Can the Government Govern? (pp. 267-329) Washington D.C.: Brookings Institute.

Morrison, D.R. (1998). Aid and Ebb Tide: A History of CIDA and Canadian Development Assistance. Waterloo: Wilfred Laurier University Press.

Moss, T. (2007). U.S. Aid to Africa After the Midterm Elections? A 'Surprise Party' Update. (Center for Global Development Notes). Retrieved from the Center for Global Development website: https://www.cgdev.org/publication/us-aid-africaafter-midterm-elections-surprise-party-update

Murphy, R. (2012). Inside Irish Aid: The Impulse to Help. Dublin: The Liffey Press.

Nabiyeva, K. (2011). In Sweeping Aid Reform, Merged German Agency Becomes Operational. Devex. Retrieved from https://www.devex.com/en/news/insweeping-aid-reform-merged-german-agency/71908.

Nakano, K. (1998). The Politics of Administrative Reform in Japan, 1993-1998. Asian Survey, 38(3), 291-309. Retrieved from http://www.jstor.org/stable/2645429

Neumayer, E. (2005). Is the Allocation of Food Aid Free From Donor Interest Bias? Journal of Development Studies, 41(3), 394-411. doi:

10.1080/0022038042000313309

North, D. (1990a). Institutions, Institutional Change and Economic Performance. Cambridge: Cambridge University Press.

North, D. (1990b). A Transaction Cost Theory of Politics. Journal of Theoretical Politics, 2(4), 355-367. Retrieved from doi: 10.1177/0951692890002004001

O’Neill, H. (1982). Irish Aid-Performance and Policies. (UCD Centre for Economic Research Policy Paper Series No. 3). Dublin: University College Dublin School of Economics. Retrieved from https://core.ac.uk/download/pdf/16338693.pdf

O’Neill, H. (2005). The Foreign Aid Policy of Ireland. In P. Hoebink \& O. Stokke (Eds.), Perspectives on European Development Co-operation: Policy and Performance of Individual Donor Countries and the EU (pp. 303-335). Oxon: Routledge.

O'Sullivan, K. (2007). Biafra to Lome: the Evolution of Irish Government Policy on Official Development Assistance, 1969-75. Irish Studies in International Affairs, 18, 91-107. Retrieved from http://www.jstor.org/stable/25469818

O'Sullivan, K. (2013). Ah, Ireland, the Caring Nation': Foreign Aid and Irish State Identity in the Long 1970s. Irish Historical Studies, 38(151): 476-491. Retrieved from https://doi.org/10.1017/S0021121400001607 
Oakman, D. (2010). Facing Asia: A History of the Colombo Plan. Canberra: ANU E Press.

Odedokun, M. (2003). Analysis of Deviations and Delays in Aid Disbursements. Journal of Economic Development, 28(1), 137-169.

Odedokun, M. (2004). Multilateral and Bilateral Loans Versus Grants: Issues and Evidence. World Economy, 27(2), 239-263. doi: 10.1111/j.14679701.2004.00598.x

OECD. (1966). Aid Review: Australia. Paris: OECD.

OECD. (1967). Aid Review: Australia. Paris: OECD.

OECD. (1971). Aid Review: Australia. Paris: OECD.

OECD. (1973). Aid Review: Australia. Paris: OECD.

OECD. (1977a). Aid Review: Australia. Paris: OECD.

OECD. (1977b). Development Co-operation Review. Paris, Organization for Economic Cooperation and Development.

OECD. (1978). Aid Review Netherlands. Paris: OECD.

OECD. (1981). Aid Review: Australia. Paris: OECD.

OECD. (1982). Aid Review: Germany. Paris: OECD.

OECD. (1983). Aid Review: Australia. Paris: OECD.

OECD. (1985a). Aid Review: Australia. Paris: OECD.

OECD. (1985b). Aid Review: New Zeland. Paris: OECD.

OECD. (1985c). Twenty-five Year of Development Co-operation: A Review. Paris, Organization for Economic Cooperation and Development.

OECD. (1987). Aid Review: Australia. Paris: OECD.

OECD. (1991). Aid Review: Denmark. Paris: OECD.

OECD. (1992). Aid Review: Australia. Paris: OECD.

OECD. (1993a). Aid Review: France. Paris: OECD.

OECD. (1993b). Aid Review: Netherlands. Paris: OECD.

OECD. (1995). Aid Review: Germany. Paris: OECD.

OECD. (1996). Aid Review: Australia. Paris: OECD.

OECD. (1997). Development Cooperation Review: Netherlands. Paris: OECD

OECD. (1998). Aid Review: Germany. Paris: OECD.

OECD. (1999a). Development Cooperation Review: Austria. Paris: OECD.

OECD. (1999b). Development Cooperation Review: Finland. Paris: OECD.

OECD. (1999c). Development Cooperation Review: Ireland. Paris: OECD.

OECD. (1999d). Development Cooperation Review: Japan. Paris: OECD.

OECD. (2000). Peer Review: Australia. Paris: OECD.

OECD. (2001a). Development Cooperation Review: Netherlands. Paris: OECD.

OECD. (2001b). Development Cooperation Review: Portugal. Paris: OECD.

OECD. (2002). DAC Peer Review: Germany. Paris: OECD

OECD. (2003). DAC Peer Review: Ireland. Paris: OECD.

OECD. (2004a). DAC Peer Review Australia. Paris: OECD.

OECD. (2004b). DAC Peer Review: Austria. Paris: OECD.

OECD. (2004c). DAC Peer Review: Japan. Paris: OECD.

OECD. (2005). The Paris Declaration on Aid Effectiveness. Paris: OECD.

OECD. (2006a). DAC in Dates: The History of OECD's Development Assistance Committee. Paris: OECD. 
OECD. (2006b). Peer Review Germany. Paris: OECD.

OECD. (2006c). Peer Review: Netherlands. Paris: OECD.

OECD. (2008a). Effective Aid Management: Twelve Lessons From DAC Peer Reviews. Paris: Organization for Economic Cooperation and Development.

OECD. (2008b). Peer Review: Norway. Paris: OECD.

OECD. (2009a). Better Aid: Managing Aid Practices of DAC Member Countries. Paris:

Organization for Economic Cooperation and Development.

OECD. (2009b). DAC Peer Review: Ireland. Paris: Organization for Economic

Cooperation and Development.

OECD. (2010a). Peer Review: Japan. Paris: OECD.

OECD. (2010b). Peer Review: Germany. Paris: OECD.

OECD. (2011a). 2011 DAC Report on Mulitlateral Aid. Paris: Organization for Economic Cooperation and Development. Available from: https://www.oecd.org/dac/aidarchitecture/49014277.pdf

OECD. (2011b). Development Cooperation Review: Netherlands. Paris: OECD.

OECD. (2013a). Peer Review Australia. Paris: OECD.

OECD. (2013b). Special Review of Iceland. Paris: OECD. Retrieved from

https://www.oecd.org/dac/dac-global-

relations/Iceland\%20Special\%20Review.pdf

OECD. (2014a). OECD Peer Review Reference Guide 2015-2016. Paris: OECD.

OECD. (2014b). Peer Review: Ireland. Paris: OECD.

OECD. (2014c). Peer Review: Japan. Paris: OECD.

OECD. (2015a, April 8). Development Aid Stable in 2014 by Flows to Poorest Countries Still Falling. OECD-DAC News. Retrieved from

http://www.oecd.org/development/development-aid-stable-in-2014-but-flows-topoorest-countries-still-falling.htm

OECD. (2015b). Peer Review: Germany. Paris: OECD.

OECD. (2016). History of the $0.7 \%$ ODA Target. Retrieved from:

http://www.oecd.org/dac/stats/ODA-history-of-the-0-7-target.pdf

OECD. (2017a). Annual Labour Force Statistics. Retrieved from

https://stats.oecd.org/Index.aspx?DataSetCode=ALFS SUMTAB

OECD. (2017). "Official Development Assistance 2016". Retrieved from

http://www.oecd.org/dac/development-aid-rises-again-in-2016-but-flows-to-

poorest-countries-dip.htm

OECD. (2017). Peer Review Netherlands. Paris: OECD.

Ohno, I. (2013). An Overview: Diversity and Complementarity in Development Efforts.

In K. Ohno, \& I. Ohno, Eastern and Western Ideas for African Growth: Diversity and Complementarity in Development Aid. London: Routledge.

Oireachtas. (1987, March 31). "Financial Resolutions, 1987: Budget 1987”. Debate Vol 371 No. 5. Retrieved from

http://oireachtasdebates.oireachtas.ie/debates\%20authoring/debateswebpack.nsf/ta kes/dail1987033100017

Olsen, J. (1996). Norway, Slow Learner-Or Another Triumph of the Tortoise. In J. Olsen, \& B.G. Peters, (Eds.), Lessons From Experience. Experimental Learning in Administrative Reforms in Eight Democracies. Oslo: Scandinavian University Press. 
Ostrom, E., Gibson, C., Shivakumar, S., \& Andersson, K. (2001) Aid, Incentives and Sustainability: An Institutional Analysis of Development Cooperation. Stockholm: Swedish International Development Agency.

Paul, E., \& Vandeninden, F. (2012). Foreign Aid Transaction Costs: What Are They and When Are They Minimised? Development Policy Review 30(3), 283-304. doi: 10.1111/j.1467-7679.2012.00577.x

Pennings, J. M. (1992). Structural Contingency Theory: A Reprisal. In B. M. Staw, \& L. L. Cummings (Eds.), Research in Organizational Behavior (pp. 267-309). Greenwich, CT: JAI Press.

Perry, J. L., \& Rainey, H. G. (1988). The Public-Private Distinction in Organization Theory: A Critique and Research Strategy. Academy of Management Review, 13(2), 182-201. doi: 10.5465/AMR.1988.4306858

Peters, B.G., Pierre, J., \& King, D.S. (2005). The Politics of Path Dependency: Political Conflict in Historical Institutionalism. The Journal of Politics, 67(4), 1275-1300. doi: 10.1111/j.1468-2508.2005.00360.x

Pettigrew, A.M., Woodman, R.W., \& Cameron, K.S. (2001). Studying Organizational Change and Development: Challenges for Future Research. The Academy of Management Journal, 44(4), 697-713. doi: 10.2307/3069411

Pierson, P. (2000). Increasing Returns, Path Dependence, and the Study of Politics. American Political Science Review, 94(2), 251-267. DOI: 10.2307/2586011

Pollitt, C., Bathgate, K, Caulfield, J., Smullen, A., \& Talbot, C. (2001). Agency Fever? Analysis of an International Policy Fashion. Journal of Comparative Policy Analysis: Research and Practice, 3(3), 271-290.

Pollitt, C., \& Bouckaert, G. (2004). Public Management Reform: A Comparative Analysis. Oxford: Oxford University Press.

Powell, A., \& M. Bobba. 2006. Multilateral Intermediation of Foreign Aid: What is the Trade-Off for Donor Countries? (Research Department Working Paper 594). Retrieved from the Inter-American Development Bank website: http://www.iadb.org/res/publications/pubfiles/pubWP-594.pdf

Prizzon, A. (2012). Development Ministers: Implications for Aid Quality and Quantity. (Research Report, Action Aid and BOND). Retrieved from the Action Aid website: https://www.actionaid.it/app/uploads/static/development_ministers_2012_0.pdf

Provan, K. G. (1987). Environmental and Organizational Predictors of Adaptation of Cost Containment Policies in Hospitals. Academy of Management Journal, 30(2), 219-239. Retrieved from http://www.jstor.org/stable/256271 .

Pugh, D. S., Hickson, D. J., Hinings, C. R., Macdonalds, K. M., Turner, C., \& Lupton, T. (1963). A Conceptual Scheme for Organizational Analysis. Administrative Science Quarterly, 8(3), 289-315. DOI: 10.2307/2390971

Pugh, D. S., Hickson, D. J., Hinings, C. R., \& Turner, C. (1969). The Context of Organizational Structures. Administrative Science Quarterly, 14(1), 91-114. DOI: $10.2307 / 2391366$

Quarles van Ufford, P., Kruyt, D., \& Downing, T. (1988). The Hidden Crisis In Development: Development Bureaucracies. Amsterdam: Free University Press and Tokyo: United Nations University. 
Rainey, H.G. (1983). Public Agencies and Private Firms: Incentive Structures, Goals and Individual Roles. Administration and Society, 15(2), 207-42.

10.1177/009539978301500203

Rainey, H. G., \& Bozeman, B. (2000). Comparing Public and Private Organizations:

Empirical Research and the Power of the A Priori. Journal of Public

Administration Research and Theory, 10(2), 447-469.

http://www.jstor.org/stable/3525651

Rashid, M.Z.A., Sambasvan, M., \& Abduk Rahman, A. (2004). The Influence of Organizational Culture on Attitudes Toward Organizational Change. Leadership and Organization Development Journal, 25(2), 161-179. doi:

10.1108/01437730410521831

Rix, A. (1980). Japan's Economic Aid. London: Croom Helm Ltd.

Rix, A. (2005). Japanese and Australian ODA. In D. Arase (Ed.). Japan's Foreign Aid $2^{\text {nd }}$ ed, (pp. 104-116). Oxon: Routledge.

Robertson, J., \& Seneviratne, S. J. (1995). Outcomes of Planned Organizational change in the Public Sector: A Meta-Analytic Comparison to the Private Sector. Public Administration Review, 55(6), 547-558. doi: 10.2307/3110346

Round, J. I., \& Odedokun, M. (2003). Aid Efforts and its Determinants. (UNU-WIDER Discussion Paper No. 2003/03). Retrieved from http://www.rrojasdatabank.info/aidpapers/dp2003-03.pdf

Sadler, P. J., \& Barry, B. A. (1970). Organizational Development. London: Longmans.

Savoy, C.M., \& Yayboke, E.K. (2017). Reforming and Reorganizing U.S. Foreign Assistance: Increased Efficiency and Effectiveness. (A Bipartisan Task Force Report of the CSIS Project on U.S. Leadership in Development). Retrieved from https://csis-prod.s3.amazonaws.com/s3fs-

public/event/170718_Runde_ReformReorgUSDevelopment_Web\%20\%281\%29. pdf?At.Z6jQV0wUJheqEusirs1 xyyGsQF6Yb

Sawada, Y., Kohama, H., \& Kono, H. (2004). Aid, Policies, and Growth: A Further Comment. Tokyo: University of Tokyo, Faculty of Economics.

SBS. (2015, June 3). 549 jobs lost through DFAT AusAID merger. SBS. Retrieved from http://www.sbs.com.au/news/article/2015/06/03/549-jobs-lost-through-dfatausaid-merger

Schillemans, T. (2013). Moving Beyond the Clash of Interests: On Stewardship Theory and the Relationship Between Central Government Departments and Public Agencies. Public Management Review, 15(4), 541-562. Retrieved from http://dx.doi.org/10.1080/14719037.2012.691008

Schmidt, H-I. (2003). Pushed to the Front: The Foreign Assistance Policy of the Federal Republic of Germany, 1958-1971. Contemporary European History, 12(4), 472507. Retrieved from http://www.jstor.org/stable/20081179

Scheyvens, H. (1996). The External Politics of ODA: A Case of Japan. (DP-96/2, Institute of Development Studies, Massey University Palmerston North). Retrieved from Massry University website: https://muir.massey.ac.nz/bitstream/handle/10179/8464/01_front.pdf?sequence=1 \&isAllowed $=\mathrm{y}$ 
Schraeder, P. J., Hook, S. W., \& Taylor, B. T. (1998). Clarifying the Foreign Aid Puzzle: A Comparison of American, Japanese, French, and Swedish Aid Flows. World Politics, 50(2), 294-323. Retrieved from http://www.jstor.org/stable/25054039

Schulpen, L. (2005). All in the Name of Quality: Dutch Development Co-operation in the 1990s. In P. Hoebink and O. Stokke (Eds.). Perspectives on European Development Co-operation: Policy and Performance of Individual Donor Countries and the EU (pp. 406-447). London: Routledge.

Scott, W. R. (1987). The Adolescence of Institutional Theory. Administrative Science Quarterly, 32(4), 493-511. Retrieved from http://www.jstor.org/stable/2392880

Scott, W. R. (2001). Institutions and Organizations (2 ${ }^{\text {nd }}$ Ed.). Thousand Oaks, CA: Sage Publications.

Sepper, R., \& Alas, R. (2007). Role of Politics in Public Sector Organizational Change. Journal of Business Economics and Management, 9(1), 13-23.

Sewell, W.H. Jr. (1996). Three Temporalities: Toward an Eventful Sociology. In McDonald, T.J. (Ed.), The Historic Turn in the Human Sciences (pp. 245-280). Ann Arbor: University of Michigan Press.

Sherlock, S. (1991). A Guide to the Australian Overseas Aid Program and Issues in Development Assistance. (Parliamentary Research Service: Background Paper). Canberra: Parliament of Australia. Retrieved from http://parlinfo.aph.gov.au/parlInfo/search/display/display.w3p;query=Id\%3A\%221 ibrary\%2Fprspub\%2FXFL00\%22

Simon, J. (1982). Administration of Development Assistance Projects in the U.S. Agency for International Development (AID) and the German Federal Ministry for Economic Cooperation (BMZ): A Comparative Study of Organizational Effectiveness. Indiana University Doctoral Thesis. Available from University Microfilm International.

Spitz, G., Muskens, R., \& van Ewijk, E. (2013). The Dutch and Development Cooperation: Ahead of the Crowd or Trailing Behind? Retrieved from https://www.ncdo.nl/sites/default/files/Report\%20Analysis\%20The\%20Dutch\%2 0and\%20Development\%20Cooperation\%20FINAL\%202013\%2003\%2004.pdf

Stein, J.G. (2013, March 22). Ending CIDA's Independence can only make out Foreign Policy More Coherent. Globe and Mail. Retrieved from: http://www.theglobeandmail.com/opinion/ending-cidas-independence-can-onlymake-our-foreign-policy-more-coherent/article10160796/

Stevens, G. (2008, May 15). The Australian Economy: Then and Now. Address by Mr. Glenn Stevens, Governor, to the Inaugural Faculty of Economics and Business Alumni Dinner, The University of Sydney, Sydney. Retrieved from https://www.rba.gov.au/publications/bulletin/2008/jun/pdf/bu-0608-3.pdf

Sutton, M. (1985). Irish ODA and the UN Target: A Faltering Commitment. Trocaire. Retrieved from https://www.trocaire.org/sites/default/files/resources/policy/1985irish-aid-un-targets.pdf.pdf

Sveinbjarnardottir, J. (2006, February 22). Development Cooperation with Other Countries. $132^{\text {nd }}$ Parliament, Session 73. Retrieved from http://www.althingi.is/altext/132/02/r22141856.sgml 
Sverrisdottir, V. (2006). Address on Foreign Affairs by Valgerdur Sverrisdottir, Minister of Foreign Affairs. Retrieved from https://www.mfa.is/news-andpublications $/ \mathrm{nr} / 3290$

Sverrisdottir, V. (2007). Report Secretary of State for Development Cooperation Arrangements. Retrieved from: http://www.althingi.is/altext/133/s/1062.html

Sydow, J., Schreyogg, G., \& Kock, J. (2009). Organizational Path Dependence: Opening the Black Box. Academy of Management Review, 34(4), 689-709.

Talbot, C., \& Talbot, C. (2011). The Structure Solution? Public sector mergers in the United Kingdom. In J. O'Flynn, D. Blackman, \& J. Halligan (Eds.), Crossing Boundaries in Public Management and Policy: The International Experience (pp. 92-110). London: Routledge

Taylor, F. W. (1947). Principles of Scientific Management. New York, New York: Harper.

Teo, H. H., Wei, K, K., \& Benbasat, I. (2003). Predicting Intention to Adopt Interorganizational Linkages: An Institutional Perspective. MIS Quarterly, 27(1), 19-49. Retrieved from http://www.jstor.org/stable/30036518

Tingley, D. (2010). Donors and Domestic Politics: Political Influence on Foreign Aid Effort. The Quarterly Review of Economics and Finance, 50(1), 40-49. Retrieved from https://doi.org/10.1016/j.qref.2009.10.003

Towell, N. (2014, September 15). DFAT puts the Brakes on Staff Cuts. The Canberra Times. Retrieved from http://www.canberratimes.com.au/national/publicservice/dfat-puts-the-brakes-on-staff-cuts-20140915-10h6e9.html

Tria, G., \& Valotti, G. (2012). Introduction: Challenges of Public Sector Reform. In G. Tria \& G. Valotti (Eds.), Reforming the Public Sector: How to Achieve Better Transparency, Service and Leadership. Washington D.C.: Brookings Institute.

United Nations. (1945). Charter of the United Nations and Statute of the International Court of Justice. San Francisco: United Nations.

United States Agency for International Development (USAID). (2016). Country Strategies. Retrieved from: https://www.usaid.gov/results-anddata/planning/country-strategies-cdcs

University College Dublin (UCD). (2017). Garret FitzGerald Papers: Minister for Foreign Affairs, 1973-77. Retrieved from http:/www.ucd.ie/t4cms/p0215-fitzgeraldgarret-descriptive-catalogue.PDF

Van de Sijpe, N. (2010). Is Foreign Aid Fungible? Evidence from the Education and Health Sectors. (University of Ghent Working Paper 2010/688). Retrieved from University of Ghent website: http://wps-feb.ugent.be/Papers/wp_10_688.pdf

Van der Veen, A.M. (2011). Ideas, Interests and Foreign Aid. USA: Cambridge University Press.

Van der Voet, J. (2014). The Effectiveness and Specificity of Change Management in a Public Organization: Transformational Leadership and a Bureaucratic Organizational Structure. European Management Journal, 32(3), 373-382. Retrieved from https://doi.org/10.1016/j.emj.2013.10.001

Van Theil, S. (2011). Comparing Agencification in Central Eastern European and Western European Countries: Fundamentally Alike In Unimportant Respects? Transylvanian Review of Administrative Sciences, Special Issue, 15-32.

Van Thiel, S. (2012). Comparing Agencies Across Countries. In K. Verhoest, S. Van 
Theil, G. Bouckaert and P. Laegreid (Eds.), Government Agencies: Practices and Lessons from 30 Countries (pp. 18-26). UK: Palgrave Macmillan.

Van Thiel, S., \& Yesilkagit, K. (2011). Good Neighbours or Distant Friends? Public

Management Review, 13(6), 783-802. Retrieved from

http://dx.doi.org/10.1080/14719037.2010.539111

Van Thiel, S., Verhoest, K., Bouckaert, G., \& Laegreid, P. (2012). Lessons and

Recommendations for the Practice of Agencification. In K. Verhoest, S. Van

Theil, G. Bouckaert and P. Laegreid (Eds.) Government Agencies: Practices and Lessons from 30 Countries (pp. 413-439). UK: Palgrave Macmillan.

Verhoest, K., Van Thiel, S., Bouckaert, G., and Laegreid, P. (2012). Introduction. In K.

Verhoest, S. Van Theil, G. Bouckaert and P. Laegreid (Eds.) Government

Agencies: Practices and Lessons from 30 Countries (pp. 3-17). UK: Palgrave

Macmillan.

Voeten, E., Strezhnev, A., \& Michael, B. (2009). United Nations General Assembly

Voting Data. Harvard Dataverse, V17. Retrieved from

https://dataverse.harvard.edu/dataset.xhtml?persistentId=hdl:1902.1/12379

Walz, J., \& Ramachandran, V. (2011). Brave New World: A Literature Review of

Emerging Donors and the Changing Nature of Foreign Assistance. (Center for

Global Development Working Paper 273). Retrieved from Center for Global

Development website: https://www.cgdev.org/publication/brave-new-world-

literature-review-emerging-donors-and-changing-nature-foreign-assistance

Weber, M. (1947). The Theory of Social and Economic Organization. Translated by

Talcott Parsons. New York, New York: Free Press.

Weissert, C. S., \& M. L. Goggin. (2002). Nonincremental Policy Change: Lessons from Michigan's Medicaid Managed Care Initiative. Public Administration Review, 62(2), 206-16. Retrieved from http://www.jstor.org/stable/3109904

White House. (2017, March 13). Presidential Executive Order on a Comprehensive Plan for Reorganizing the Executive Branch. Office of the Press Secretary.

Retrieved from www.whitehouse.gov/the-press-office/2017/03/13/presidentialexecutive-order-comprehensive-plan-reorganizing-executive.

Wildavsky, A. (1966). The Political Economy of Efficiency: Cost-Benefit Analysis, Systems Analysis, and Program Budgeting. Public Administration Review, 26(4): 292-310. doi: 10.2307/973301

Wilenski, P. (1981). Infanticide in the Bureaucracy: the Australian Development Assistance Agency. In S. Encel, \& P. Wilenski in collaboration with B.B. Schaffer (Eds.), Decisions: Case Studies in Australian Public Policy (pp. 101118). Melbourne: Longman Cheshire.

Wilkinson, A.E. (1976). The Politics of Australian Foreign Aid Policy 1950-1972. Unpublished $\mathrm{PhD}$ Thesis. The Australian National University.

Williams, R. (2016). Analyzing Rare Events with Logistic Regression. Retrieved from https://www3.nd.edu/ rwilliam/stats3/RareEvents.pdf

Williamson, O.E. (1979). Transaction-Cost Economics: The Governance of Contractual Relations. Journal of Law and Economics, 22(2), 233-261. Retrieved from http://www.jstor.org/stable/725118 
Williamson, O.E. (1981). The Economics of Organization: The Transaction-Cost Approach. The American Journal of Sociology, 87(3), 548-577. Retrieved from http://www.jstor.org/stable/2778934

Williamson, O.E. (1999). Public and Private Bureaucracies: A Transaction Cost Economics Perspective. The Journal of Law, Economics and Organization, 15(1), $306-342$.

Woodward, J. (1965). Industrial Organization: Theory and Practice. London: Oxford University Press.

Wooten, M. E., \& Hoffman, A. (2008). Organizational Fields: Past, Present and Future of a Core Construct. In R. Greenwood, C. Oliver, K. Sahlin, \& R. Suddaby (Eds.), The SAGE Handbook of Organizational Institutionalism (pp. 130-148).

California: Sage Publications.

Wulff, J.N. (2015). Interpreting Results From the Multinomial Logit Model Demonstrated by Foreign Market Entry. Organizational Research Methods. 18(2), 300-325. Retrieved from 10.1177/1094428114560024

Yamamoto, K. (2008). Has Agencification Succeeded in Public Sector Reform? Realities and Rhetoric in the Case of Japan. Asian Journal of Political Science, 16(2), 2440.

Younas, J. (2008). Motivation for Bilateral Aid Allocation: Altruism or Trade Benefits. European Journal of Political Economy, 24(3), 661-674. Retrieved from https://doi.org/10.1016/j.ejpoleco.2008.05.003

Zimmerman, R.F. (1993). Dollars, Diplomacy and Dependency: Dilemmas of U.S. Economic Aid. Boulder, Colorado: Lynne Rienner Publishing.

Zimmerman, F., \& Smith, K. (2011). More Actors, More Money, More Ideas for International Development Co-Operation. Journal of International Development, 23(5), 722-738. doi: 10.1002/jid.1796

Zivot, E., \& Wang, J. (2003). Modeling Financial Time Series With S-Plus. New York: Springer. 


\section{APPENDIX 1 - OECD-DAC Donor Organization by Year}

\begin{tabular}{|c|c|c|c|c|}
\hline Country & Early Programming & $\begin{array}{l}\text { Donor } \\
\text { Role }\end{array}$ & Planning Documents & $\begin{array}{l}\text { Donor } \\
\text { Role }\end{array}$ \\
\hline Australia & $\begin{array}{l}\text { In 1983, the OECD reported that while } \\
\text { Australian project selection resembled a } \\
\text { "shopping list" approach, "ADAB is currently } \\
\text { engaged in developing "country-profile" } \\
\text { reports of major recipients which aim at } \\
\text { providing relevant social and economic } \\
\text { indicators together with main development } \\
\text { objectives" (p. 26). }\end{array}$ & $\begin{array}{l}\text { Reactive } \\
\text { until } \\
1983\end{array}$ & $\begin{array}{l}\text { Each of Australia's country and regional programs } \\
\text { have "Aid Investment Plans" that outline how } \\
\text { Australia's aid will contribute to development, as well } \\
\text { as clear indicators for measuring program } \\
\text { performance. }\end{array}$ & Active \\
\hline Austria & $\begin{array}{l}\text { The first OECD-DAC review of Austria's aid } \\
\text { program in } 1965 \text { noted one of the main criteria of } \\
\text { Austrian aid is "as far as possible, assistance is } \\
\text { only to be considered if the country concerned } \\
\text { applies for it, and should be given within the } \\
\text { framework of bilateral agreements" (OECD, 1965, } \\
\text { p.7) } \\
\text { The } 1999 \text { OECD Peer Review states that Austria's } \\
\text { Department of Development Cooperation (DDC) } \\
\text { began drafting country strategies for its partners in } \\
\text { 1993. }\end{array}$ & $\begin{array}{l}\text { Reactive } \\
\text { until } \\
1993\end{array}$ & $\begin{array}{l}\text { The Austrian Development Agency produces } \\
\text { "Country Strategy" documents for its country } \\
\text { programs. These documents outline sectoral } \\
\text { priorities and basic features of cooperation. } \\
\text { http://www.entwicklung.at/en/media- } \\
\text { centre/publications/programmes/ }\end{array}$ & Active \\
\hline Belgium & $\begin{array}{l}\text { The OECD’s } 1981 \text { Review of Belgium's aid } \\
\text { program states that “Over the past two years, } \\
\text { Belgium has set up a new system for some } \\
\text { recipient countries...providing for indicative } \\
\text { five-year aid planning. Under this system, } \\
\text { countries are informed of the overall amounts } \\
\text { available for them and the sectors to which } \\
\text { Belgium intends to give priority" (p. 6). }\end{array}$ & $\begin{array}{l}\text { Reactive } \\
\text { until } \\
1980\end{array}$ & $\begin{array}{l}\text { In partnership with recipient countries, Belgium } \\
\text { generates "Indicative Cooperation Programs" (ICP) to } \\
\text { outline program priorities and spending. }\end{array}$ & Active \\
\hline
\end{tabular}




\begin{tabular}{|c|c|c|c|c|}
\hline Canada & $\begin{array}{l}\text { Cunningham reports that Canada produced } \\
\text { 'country books' for recipient countries which } \\
\text { "describe the recipient country's economy and } \\
\text { assesses its future potential, examines its } \\
\text { absorptive capacity for aid and its } \\
\text { administrative efficiency. The Canadian aid } \\
\text { effort in the country is analysed in detail and } \\
\text { proposals are made for the areas and sectors } \\
\text { where future Canadian aid should be } \\
\text { concentrated" (p. 18). }\end{array}$ & Active & $\begin{array}{l}\text { Canada does not appear to publish regular country } \\
\text { programs for priority partners. "Country Strategy" } \\
\text { documents developed in } 2009 \text { are available the GAC } \\
\text { website. While the Canadian government does not } \\
\text { appear to publish regular country reports, it } \\
\text { publishes three-year forward spending plans for } \\
\text { country-programmable aid on an annual basis. }\end{array}$ & Active \\
\hline $\begin{array}{l}\text { Czech } \\
\text { Republic }\end{array}$ & N/A & $\mathrm{N} / \mathrm{A}$ & $\begin{array}{l}\text { A preliminary OECD Review of the Czech aid program } \\
\text { noted that "In June 2005, the Czech Government } \\
\text { approved five-year development co-operation } \\
\text { programmes with eight priority countries" (p. 20), } \\
\text { The report continues to note that "The Country } \\
\text { Strategy Papers (CSP) tend to reflect the line } \\
\text { ministries' priority list of projects rather than local } \\
\text { needs" despite the use of recipient consultations. }\end{array}$ & Active \\
\hline Denmark & $\begin{array}{l}\text { In 1976, the OECD reported that Denmark had } \\
\text { established "country programming procedures" } \\
\text { which included "the provision of indications on } \\
\text { the future amount of assistance, the } \\
\text { strengthening of Denmark's representation in } \\
\text { recipient countries, new forms of co-operation } \\
\text { for the surveillance and control of Danish- } \\
\text { supported projects etc." (OECD, } 1976 \text { p. 13). }\end{array}$ & $\begin{array}{l}\text { Reactive } \\
\text { until } \\
1976\end{array}$ & $\begin{array}{l}\text { Denmark develops "Priority Country Policy Papers" } \\
\text { for each priority partner. These papers present } \\
\text { Denmark's policy and strategy towards recipients in } \\
\text { the realm of foreign policy, development cooperation } \\
\text { and commercial relations. Denmark also produces } \\
\text { "Partnership Strategy" papers for development } \\
\text { cooperation with some partners. } \\
\text { http://amg.um.dk/en/technical-guidelines/country- } \\
\text { policy-papers/ }\end{array}$ & Active \\
\hline Finland & $\begin{array}{l}\text { Finland appeared to adopt country } \\
\text { programming in 1975, the same year it joined } \\
\text { the OECD-DAC. The OECD (1976) reports that } \\
\text { "The first country programmes were set up for } \\
\text { Tanzania and Zambia in } 1975 \text { and preparations } \\
\text { are now being made for establishing a country } \\
\text { programme for Vietnam" (p. 14). These } \\
\text { programmes included indications to recipients }\end{array}$ & Active & $\begin{array}{l}\text { Finland develops "Country Strategy for Development } \\
\text { Cooperation" papers with some partners. These } \\
\text { documents outline the objectives of bilateral } \\
\text { programming with partners. }\end{array}$ & Active \\
\hline
\end{tabular}




\begin{tabular}{|c|c|c|c|c|}
\hline & $\begin{array}{l}\text { on the future amount of assistance and the } \\
\text { establishment of local aid representation. }\end{array}$ & & & \\
\hline France & $\begin{array}{l}\text { On France's use of country programming, } \\
\text { Cunningham (1974) writes, "Rigid adherence } \\
\text { to project aid is a clear characteristic of the } \\
\text { French method...Independent projects can be } \\
\text { regarded as one project, but there is no } \\
\text { question of allocating money to recipients on a } \\
\text { programme basis..." or committing future } \\
\text { funding on conditional terms (p. 177-178). }\end{array}$ & Reactive & $\begin{array}{l}\text { France develops partnership framework (document } \\
\text { cadre de partenariat, DCP) documents, which outline } \\
\text { key priorities for bilateral aid for } 17 \text { priority poor } \\
\text { countries (Benin, Burkina Faso, Burundi, Central } \\
\text { African Republic, Chad, Comoros, DRC, Djibouti, } \\
\text { Ghana, Guinea-Conakry, Madagascar, Mali, } \\
\text { Mauritania, Niger, Rwanda, Senegal, Togo). In } \\
\text { addition, French field offices, working with central } \\
\text { supervision, draw up country action frameworks } \\
\text { (cadre d'intervention pays, CIP) which align with DCP } \\
\text { priorities and the AFD's strategic frameworks. } \\
\text { OECD. (2013). Peer Review: France. Paris: OECD. }\end{array}$ & Active \\
\hline Germany & $\begin{array}{l}\text { Cunningham reports that while prior to } 1971 \\
\text { West Germany had not used country } \\
\text { programmes, a } 1971 \text { policy statement } \\
\text { announced that "the point of departure for the } \\
\text { effective application of the instruments of } \\
\text { German development assistance in the future } \\
\text { will be the long-term, integrated, country- } \\
\text { oriented and internationally co-ordinated aid } \\
\text { programme for individual developing } \\
\text { countries...It permits not only the examination } \\
\text { of the projects in individual cases as to their } \\
\text { economic and social effectiveness, but also the } \\
\text { selection of priorities, vocations and } \\
\text { combination of projects within the framework } \\
\text { of sectoral, inter-sectoral or regional } \\
\text { interrelationships" (cited in Cunningham, } 1974 \\
\text { p. 143) }\end{array}$ & $\begin{array}{l}\text { Reactive } \\
\text { until } \\
1971\end{array}$ & $\begin{array}{l}\text { Neither BMZ nor GIZ appear to produce regular } \\
\text { strategy documents for programs with bilateral } \\
\text { partners. One exception is the case of Afghanistan; } \\
\text { BMZ published a "Strategy Paper" for Afghanistan in } \\
\text { 2014. BMZ Strategy Papers typically outlines BMZ's } \\
\text { policy objectives for a particular sector. } \\
\text { BMZ does however, prepare spending plans on three- } \\
\text { year time horizons. The OECD notes that "While } \\
\text { Germany shares information on planned } \\
\text { disbursements for the next programming cycle } \\
\text { during bilateral negotiations with partner country } \\
\text { governments, it only provides additional information } \\
\text { for future years when partners request such } \\
\text { information" (2015, p. 63) } \\
\text { OECD. (2015). Peer Review: Germany. Paris: OECD. }\end{array}$ & Active \\
\hline Greece & $\mathrm{N} / \mathrm{A}$ & $\mathrm{N} / \mathrm{A}$ & $\begin{array}{l}\text { The } 2011 \text { Peer Review of Hellenic Aid called for } \\
\text { Greece to move towards country-based approaches. } \\
\text { At the time, a draft law proposed the use of two sets } \\
\text { of documents to outline programs with partners: }\end{array}$ & $\begin{array}{l}\text { Unclea } \\
\mathrm{r}\end{array}$ \\
\hline
\end{tabular}




\begin{tabular}{|c|c|c|c|c|}
\hline & & & $\begin{array}{l}\text { State agreements for development and country } \\
\text { strategy papers. It is unclear whether this law was } \\
\text { passed. } \\
\text { Little information is available on the Hellenic Aid } \\
\text { website. }\end{array}$ & \\
\hline Iceland & $\mathrm{N} / \mathrm{A}$ & $\mathrm{N} / \mathrm{A}$ & $\begin{array}{l}\text { Iceland has developed Country Strategy Papers for } \\
\text { two of its three partner countries (Malawi and } \\
\text { Uganda). In Mozambique, Iceland has a four year } \\
\text { project plan for support to the fisheries sector. }\end{array}$ & Active \\
\hline Ireland & $\begin{array}{l}\text { While the } 1990 \text { OECD Aid Review noted that } \\
\text { "There is little sense in Ireland trying to } \\
\text { exercise leverage aimed at bringing about more } \\
\text { sensible economic policies in developing } \\
\text { countries" (OECD, 1990 p. 14), suggesting the } \\
\text { use of reactive policies. By 1994, Ireland had } \\
\text { begun developing long-term 'partnerships' or } \\
\text { programs with key priority countries. }\end{array}$ & $\begin{array}{l}\text { Reactive } \\
\text { until } \\
1994\end{array}$ & $\begin{array}{l}\text { Irish Aid develops Country Strategy Papers for work } \\
\text { with its partner countries. These documents provide } \\
\text { a framework for programming that is aligned to } \\
\text { partner needs. } \\
\text { OECD. (2014b). Peer Review: Ireland. Paris: OECD. }\end{array}$ & Active \\
\hline Italy & $\begin{array}{l}\text { In the early 1980s, Italy began creating an } \\
\text { institutional framework that would enable } \\
\text { greater dialogue with recipient countries. The } \\
\text { dialogue resulted in the establishment of multi- } \\
\text { year programming with key partners (OECD, } \\
\text { 1982). } \\
\text { OECD. (1982). Peer Review: Italy. Paris: OECD. }\end{array}$ & $\begin{array}{l}\text { Reactive } \\
\text { until } \\
1980\end{array}$ & $\begin{array}{l}\text { Italy develops country-specific programs in line with } \\
\text { international aid effectiveness principles. The } \\
\text { program documents aim to explain and map } \\
\text { programming choices, goals and expected results. } \\
\text { Cooperazione Italiana allo Sviluppo (CIS). (2014). } \\
\text { Italy's Development Cooperation in the 2014-2016 } \\
\text { Three-year Period: Programme Guidelines and } \\
\text { Orientations. Italy: CIS. } \\
\text { http://www.cooperazioneallosviluppo.esteri.it/porta } \\
\text { ledgcs/portaledgcs/Documentazione/DocumentiNew } \\
\text { /MAE_Guidelines\%202014-2016_ENG.pdf }\end{array}$ & Active \\
\hline Japan & $\begin{array}{l}\text { In } 1977, \text { the OECD reported that "Country } \\
\text { programming is not a feature of the Japanese } \\
\text { programme" (p. 26), noting that inter- } \\
\text { governmental agreements could provide the } \\
\text { basis for country programming in the future. }\end{array}$ & $\begin{array}{l}\text { Reactive } \\
\text { until } \\
1999\end{array}$ & $\begin{array}{l}\text { Japan drafts Country Assistance Policies for most } \\
\text { partner countries. These documents outline Japan's } \\
\text { country-specific aid policy. Five year rolling plans } \\
\text { accompany Japan's country programs. Rolling plans } \\
\text { are revised annually and shared with partners. }\end{array}$ & Active \\
\hline
\end{tabular}




\begin{tabular}{|c|c|c|c|c|}
\hline & $\begin{array}{l}\text { By the } 1999 \text { OECD Peer Review, it was noted } \\
\text { that "The Japanese Government has therefore } \\
\text { decided to prepare a five-year policy guideline } \\
\text { and a country-by-country strategy, initially for } \\
11 \text { major recipient countries" (OECD, } 1999 \text { p. } \\
24-25 \text { ). }\end{array}$ & & $\begin{array}{l}\text { http://www.mofa.go.jp/policy/oda/assistance/outlin } \\
\text { e_cap.html }\end{array}$ & \\
\hline Korea & $\mathrm{N} / \mathrm{A}$ & $\mathrm{N} / \mathrm{A}$ & $\begin{array}{l}\text { Korea publishes Country Partnership Strategies } \\
\text { which outline key sectors, implementation strategies } \\
\text { and evaluation timelines for bilateral programming. }\end{array}$ & Active \\
\hline Luxembourg & $\mathrm{N} / \mathrm{A}$ & $\mathrm{N} / \mathrm{A}$ & $\begin{array}{l}\text { In 1994, Luxembourg began using 'target country } \\
\text { policies' Luxembourg uses Development Cooperation } \\
\text { reports to map current projects and outline potential } \\
\text { future initiatives in partner countries }\end{array}$ & Active \\
\hline Netherlands & $\begin{array}{l}\text { According to Hoebink (1997), the Netherlands } \\
\text { introduced country programmes at the end of } \\
\text { the } 1970 \text { s. These programs became more } \\
\text { detailed and longer term over time. By 1986, } \\
\text { "four-year country programmes were } \\
\text { introduced and presented to Parliament and } \\
\text { thus made available to the interested public" } \\
\text { (Hoebink, 1997, p 203) }\end{array}$ & $\begin{array}{l}\text { Reactive } \\
\text { until late } \\
\text { 1970s }\end{array}$ & $\begin{array}{l}\text { The Netherlands drafts multi-year Strategic Plans for } \\
\text { each partner country. The Plans outline details of the } \\
\text { Netherlands development cooperation policy with } \\
\text { the partner. Annual reports on progress achieved are } \\
\text { published on an annual basis. }\end{array}$ & Active \\
\hline New Zealand & $\begin{array}{l}\text { In 1984, New Zealand began using 'country } \\
\text { papers' for bilateral programming. The papers } \\
\text { were developed with the goal of going "beyond } \\
\text { the individual project approach and to } \\
\text { developing a broader view of the development } \\
\text { problems and potential of the island countries" } \\
\text { (OECD, 1985b p. 13). The country papers "will } \\
\text { analyse the countries economic structures and } \\
\text { potentials, assess their stated development } \\
\text { goals, take account of the total range of donor } \\
\text { assistance, consider the best role for the New } \\
\text { Zealand programme in this context and } \\
\text { recommend the strategic direction of the } \\
\text { programme accordingly" (OECD, 1985b p. 13). }\end{array}$ & $\begin{array}{l}\text { Reactive } \\
\text { until } \\
1984\end{array}$ & $\begin{array}{l}\text { New Zealand currently uses multiple planning } \\
\text { documents for partner countries. "Joint } \\
\text { Commitments for Development" are agreements } \\
\text { between recipient and donor political leadership } \\
\text { which outline key development priorities and } \\
\text { expected results. New Zealand currently uses these } \\
\text { agreements with } 14 \text { countries. } \\
\text { NZAID also uses Forward Aid Plans for projects in the } \\
\text { design phase. These plans include indicative funding } \\
\text { flows over three years. } \\
\text { NZAID is also developing "Country Strategy" tools to } \\
\text { capture long-term objective for individual partners. }\end{array}$ & Active \\
\hline
\end{tabular}




\begin{tabular}{|c|c|c|c|c|}
\hline & & & $\begin{array}{l}\text { OECD. (2015). Peer Review: New Zealand. Paris: } \\
\text { OECD. }\end{array}$ & \\
\hline Norway & $\begin{array}{l}\text { Writing in the early 1970s, Cunningham (1974) } \\
\text { reports that half of Norwegian ODA was } \\
\text { allocated through country programmes. }\end{array}$ & Active & $\begin{array}{l}\text { Norway does not appear to publish program strategy } \\
\text { documents with partner countries. While the OECD } \\
\text { notes that Norway shares indicative funding } \\
\text { commitments for multiple-years with partners to } \\
\text { foster predictable partnerships, annual budget cycles } \\
\text { mean that such numbers are frequently revised. } \\
\text { OECD. (2013). Peer Review: Norway. Paris: OECD. }\end{array}$ & Active \\
\hline Poland & $\mathrm{N} / \mathrm{A}$ & N/A & $\begin{array}{l}\text { Poland does not appear to publish cooperation } \\
\text { strategies with partner countries. Available reports } \\
\text { on Polish aid programming appear to take stock of } \\
\text { past programs. } \\
\text { The } 2017 \text { Peer Review of Poland's aid program } \\
\text { indicates that Poland is beginning to explore three- } \\
\text { five year "modular projects". However, it is unclear } \\
\text { whether such projects are actively programmed by } \\
\text { Poland or designed and implemented by partners, yet } \\
\text { funded by Poland. }\end{array}$ & $\begin{array}{l}\text { Reactiv } \\
\text { e }\end{array}$ \\
\hline Portugal & $\mathrm{N} / \mathrm{A}$ & $\mathrm{N} / \mathrm{A}$ & $\begin{array}{l}\text { For the last few years, Portugal used Indicative } \\
\text { Cooperation Programmes with partners to plan } \\
\text { multi-year programs. ICPs are now being replaced by } \\
\text { Strategic Cooperation Programs (SCPs). SCPs include } \\
\text { indicative financial envelopes and seek to align } \\
\text { programming with partner countries' development } \\
\text { priorities. } \\
\text { Camões Instituto da Cooperação e da Lingua Portugal. } \\
\text { (2015). "Memorandum of Portugal". Available from: } \\
\text { https://www.oecd.org/dac/peer- } \\
\text { reviews/memorandum-portugal-DAC-peer-review- } \\
\text { 2016.pdf }\end{array}$ & Active \\
\hline $\begin{array}{l}\text { Slovak } \\
\text { Republic }\end{array}$ & $\mathrm{N} / \mathrm{A}$ & $\mathrm{N} / \mathrm{A}$ & $\begin{array}{l}\text { Slovak Aid current has "Strategy for Development } \\
\text { Cooperation" agreements with Kenya and }\end{array}$ & Active \\
\hline
\end{tabular}




\begin{tabular}{|c|c|c|c|c|}
\hline & & & $\begin{array}{l}\text { Afghanistan. The program document provides an } \\
\text { overview of past initiatives and defines priorities and } \\
\text { development goals for cooperation. } \\
\text { Slovak Aid. (2016). "Ten Years of SlovakAid". } \\
\text { https://www.mzv.sk/web/en/foreign_policy/slovak_ } \\
\text { aid }\end{array}$ & \\
\hline Slovenia & $\mathrm{N} / \mathrm{A}$ & $\mathrm{N} / \mathrm{A}$ & $\begin{array}{l}\text { Slovenia does not appear to engage in active } \\
\text { programming with partner countries. }\end{array}$ & $\begin{array}{l}\text { Reactiv } \\
\mathrm{e}\end{array}$ \\
\hline Spain & $\mathrm{N} / \mathrm{A}$ & $\mathrm{N} / \mathrm{A}$ & $\begin{array}{l}\text { Spain uses Country Partnership Frameworks (CPFs) } \\
\text { to plan development activities with partner countries. } \\
\text { CPFs are developed in consultation with development } \\
\text { partners and include four-year indicative program } \\
\text { budgets. } \\
\text { OECD. (2016). Peer Review: Spain. Paris: OECD. }\end{array}$ & Active \\
\hline Sweden & $\begin{array}{l}\text { Sweden has prepared country programs with } \\
\text { priority partners since } 1971 \text {. These documents } \\
\text { provide analysis of aid requirements or } \\
\text { sectoral problems in recipient countries } \\
\text { (Cunningham, } 1074 \text { p. 164). }\end{array}$ & $\begin{array}{l}\text { Reactive } \\
\text { until } \\
1971\end{array}$ & $\begin{array}{l}\text { The MFA in Sweden develops multi-year "Country } \\
\text { Strategy" documents to outline planned programming } \\
\text { with partner countries. The Strategy documents } \\
\text { explore key contextual issues, primary sectors of } \\
\text { engagement and main activities. }\end{array}$ & Active \\
\hline Switzerland & $\begin{array}{l}\text { In 1981, the OECD reported that Switzerland } \\
\text { had established multi-year programming with a } \\
\text { number of its 'concentration countries' (OECD, } \\
1981 \text { p. 11). }\end{array}$ & $\begin{array}{l}\text { Reactive } \\
\text { until } \\
1981\end{array}$ & $\begin{array}{l}\text { The Swiss Agency for Development Cooperation } \\
\text { develops "Cooperation Strategy" documents to plan } \\
\text { engagement with partner countries. These } \\
\text { documents outline recipient contexts and priorities, } \\
\text { results of past cooperation, objectives for current } \\
\text { programming, monitoring timelines and budgetary } \\
\text { plans. }\end{array}$ & Active \\
\hline UK & $\begin{array}{l}\text { In the early } 1970 \text { s, the UK produced 'country } \\
\text { policy papers' on each major recipient country. } \\
\text { The papers describe the general economic and } \\
\text { aid situation in recipients, and makes proposals } \\
\text { for the amount of aid and priority sectors over } \\
\text { the next five-years (Cunningham, } 1974 \text { p. 18). }\end{array}$ & Active & $\begin{array}{l}\text { DFID's "Operational Plans" are produced for priority } \\
\text { countries and sectors. The Plans contain information } \\
\text { outlining the recipient context, the cooperation } \\
\text { 'vision', and expected results throughout the program } \\
\text { period. }\end{array}$ & Active \\
\hline US & $\begin{array}{l}\text { Cunningham reports that country } \\
\text { programming has been used most intensely by }\end{array}$ & Active & $\begin{array}{l}\text { USAID develops "Country Development Cooperation } \\
\text { Strategies" with each of its partner countries. These }\end{array}$ & Active \\
\hline
\end{tabular}




\begin{tabular}{|c|c|c|}
\hline & $\begin{array}{l}\text { the US, facilitated by a large field presence in } \\
\text { recipient countries. Every year, "AID missions } \\
\text { in the field prepare a country sub-mission. } \\
\text { Each country sub-mission covers the economic } \\
\text { condition of the recipient country and assesses } \\
\text { obstacles to development. Goals for the future } \\
\text { are stated and from these are derived the } \\
\text { desired figures for US aid and the way in which } \\
\text { it should be applied" (Cunningham, 1974 p. } \\
\text { '16). }\end{array}$ & $\begin{array}{l}\text { strategies describe the strategic approach to country } \\
\text { programs including mission goals and how results } \\
\text { will be achieved. These documents are amendable } \\
\text { during the program period to account for contextual } \\
\text { changes or lessons learned. } \\
\text { USAID. (2016). "ADS Chapter 201: Program Cycle } \\
\text { Operational Policy". } \\
\text { https://www.usaid.gov/sites/default/files/document } \\
\text { s/1870/201.pdf }\end{array}$ \\
\hline
\end{tabular}


APPENDIX 2 - OECD-DAC Donor Organization by Year

\begin{tabular}{|c|c|c|c|c|c|c|c|c|c|c|c|c|c|c|c|c|c|c|}
\hline Country & 1962 & 1963 & 1964 & 1965 & 1966 & 1967 & 1968 & 1969 & 1970 & 1971 & 1972 & 1973 & 1974 & 1975 & 1976 & 1977 & 1978 & 1979 \\
\hline Australia & & & & & 5 & 5 & 5 & 5 & 5 & 5 & 5 & 5 & 4 & 4 & 4 & 2 & 2 & 2 \\
\hline Austria & & & 5 & 5 & 5 & 5 & 5 & 5 & 5 & 5 & 5 & 5 & 5 & 5 & 5 & 5 & 5 & 5 \\
\hline Belgium & 2 & 2 & 2 & 2 & 2 & 2 & 2 & 2 & 2 & 2 & 2 & 2 & 2 & 2 & 2 & 2 & 2 & 2 \\
\hline Canada & 2 & 2 & 2 & 2 & 2 & 2 & 4 & 4 & 4 & 4 & 4 & 4 & 4 & 4 & 4 & 4 & 4 & 4 \\
\hline \multicolumn{19}{|l|}{ Czech Republic } \\
\hline Denmark & 1 & 1 & 1 & 1 & 1 & 1 & 1 & 1 & 1 & 2 & 2 & 2 & 2 & 2 & 2 & 2 & 2 & 2 \\
\hline Finland & & & & & & & & & & & & & & 2 & 2 & 2 & 2 & 2 \\
\hline France & 5 & 5 & 5 & 5 & 5 & 5 & 5 & 5 & 5 & 5 & 5 & 5 & 5 & 5 & 5 & 5 & 5 & 5 \\
\hline Germany & 5 & 5 & 5 & 5 & 5 & 5 & 3 & 3 & 3 & 3 & 3 & 3 & 3 & 3 & 3 & 3 & 3 & 3 \\
\hline \multicolumn{19}{|l|}{ Greece } \\
\hline \multicolumn{19}{|l|}{ Iceland } \\
\hline \multicolumn{19}{|l|}{ Ireland } \\
\hline Italy & 5 & 5 & 5 & 5 & 5 & 5 & 5 & 5 & 5 & 5 & 5 & 5 & 5 & 5 & 5 & 5 & 5 & 2 \\
\hline Japan & 5 & 5 & 5 & 5 & 5 & 5 & 5 & 5 & 5 & 5 & 5 & 5 & 5 & 5 & 5 & 5 & 5 & 5 \\
\hline \multicolumn{19}{|l|}{ Korea } \\
\hline \multicolumn{19}{|l|}{ Luxembourg } \\
\hline Netherlands & 5 & 5 & 2 & 2 & 2 & 2 & 2 & 2 & 2 & 2 & 2 & 2 & 2 & 2 & 2 & 2 & 2 & 2 \\
\hline New Zealand & & & & & & & & & & & & & & 2 & 2 & 2 & 2 & 2 \\
\hline Norway & 2 & 2 & 2 & 2 & 2 & 2 & 3 & 3 & 3 & 3 & 3 & 3 & 3 & 3 & 3 & 3 & 3 & 3 \\
\hline \multicolumn{19}{|l|}{ Poland } \\
\hline Portugal & & 5 & 5 & 5 & 5 & 5 & 5 & & & & & & & & & & & \\
\hline \multicolumn{19}{|l|}{ Slovak Republic } \\
\hline \multicolumn{19}{|l|}{ Slovenia } \\
\hline \multicolumn{19}{|l|}{ Spain } \\
\hline Sweden & & & & 3 & 3 & 3 & 3 & 3 & 3 & 3 & 3 & 3 & 3 & 3 & 3 & 3 & 3 & 3 \\
\hline Switzerland & & & & & & & 5 & 5 & 5 & 5 & 5 & 5 & 5 & 5 & 2 & 2 & 2 & 2 \\
\hline United Kingdom & 5 & 5 & 4 & 4 & 4 & 4 & 4 & 4 & 2 & 2 & 2 & 2 & 4 & 4 & 4 & 4 & 4 & 2 \\
\hline United States & 4 & 4 & 4 & 4 & 4 & 4 & 4 & 4 & 4 & 4 & 4 & 4 & 4 & 4 & 4 & 4 & 4 & 4 \\
\hline
\end{tabular}




\begin{tabular}{|c|c|c|c|c|c|c|c|c|c|c|c|c|c|c|c|c|c|c|c|c|}
\hline Country & 1980 & 1981 & 1982 & 1983 & 1984 & 1985 & 1986 & 1987 & 1988 & 1989 & 1990 & 1991 & 1992 & 1993 & 1994 & 1995 & 1996 & 1997 & 1998 & 1999 \\
\hline Australia & 2 & 2 & 2 & 2 & 2 & 4 & 4 & 4 & 4 & 4 & 4 & 4 & 4 & 4 & 4 & 4 & 4 & 4 & 4 & 4 \\
\hline Austria & 5 & 5 & 5 & 5 & 5 & 5 & 5 & 5 & 5 & 5 & 5 & 5 & 5 & 5 & 5 & 5 & 5 & 5 & 5 & 5 \\
\hline Belgium & 2 & 2 & 2 & 2 & 2 & 2 & 2 & 2 & 2 & 2 & 2 & 2 & 2 & 2 & 2 & 2 & 2 & 2 & 2 & 3 \\
\hline Canada & 4 & 4 & 4 & 4 & 4 & 4 & 4 & 4 & 4 & 4 & 4 & 4 & 4 & 4 & 4 & 4 & 4 & 4 & 4 & 4 \\
\hline \multicolumn{21}{|l|}{$\begin{array}{l}\text { Czech } \\
\text { Republic }\end{array}$} \\
\hline Denmark & 2 & 2 & 2 & 2 & 2 & 2 & 2 & 2 & 2 & 2 & 2 & 1 & 1 & 1 & 1 & 1 & 1 & 1 & 1 & 1 \\
\hline Finland & 2 & 2 & 2 & 2 & 2 & 2 & 2 & 2 & 2 & 2 & 2 & 2 & 2 & 2 & 2 & 2 & 2 & 2 & 1 & 1 \\
\hline France & 5 & 5 & 5 & 5 & 5 & 5 & 5 & 5 & 5 & 5 & 5 & 5 & 5 & 5 & 5 & 5 & 5 & 5 & 5 & 3 \\
\hline Germany & 3 & 3 & 3 & 3 & 3 & 3 & 3 & 3 & 3 & 3 & 3 & 3 & 3 & 3 & 3 & 3 & 3 & 3 & 3 & 3 \\
\hline \multicolumn{21}{|l|}{ Greece } \\
\hline \multicolumn{21}{|l|}{ Iceland } \\
\hline Ireland & & & & & & & 2 & 2 & 2 & 2 & 2 & 2 & 2 & 2 & 2 & 2 & 2 & 2 & 2 & 2 \\
\hline Italy & 2 & 2 & 2 & 2 & 2 & 2 & 2 & 2 & 2 & 2 & 2 & 2 & 2 & 2 & 2 & 2 & 2 & 2 & 2 & 2 \\
\hline Japan & 5 & 5 & 5 & 5 & 5 & 5 & 5 & 5 & 5 & 5 & 5 & 5 & 5 & 5 & 5 & 5 & 5 & 5 & 5 & 5 \\
\hline \multicolumn{21}{|l|}{ Korea } \\
\hline Luxembourg & & & & & & & & & & & & & 2 & 2 & 2 & 3 & 3 & 3 & 3 & 3 \\
\hline Netherlands & 2 & 2 & 2 & 2 & 2 & 2 & 2 & 2 & 2 & 2 & 2 & 2 & 2 & 2 & 2 & 2 & 1 & 1 & 1 & 1 \\
\hline New Zealand & 2 & 2 & 2 & 2 & 2 & 2 & 2 & 2 & 2 & 2 & 2 & 2 & 2 & 2 & 2 & 2 & 2 & 2 & 2 & 2 \\
\hline Norway & 3 & 3 & 3 & 3 & 3 & 3 & 3 & 3 & 3 & 3 & 3 & 3 & 3 & 3 & 3 & 3 & 3 & 3 & 3 & 3 \\
\hline \multicolumn{21}{|l|}{ Poland } \\
\hline Portugal & & & & & & & & & & & & 5 & 5 & 5 & 5 & 5 & 5 & 5 & 5 & 5 \\
\hline \multicolumn{21}{|l|}{$\begin{array}{l}\text { Slovak } \\
\text { Republic }\end{array}$} \\
\hline \multicolumn{21}{|l|}{ Slovenia } \\
\hline Spain & & & & & & & & & & & & 5 & 5 & 5 & 5 & 5 & 5 & 5 & 5 & 5 \\
\hline Sweden & 3 & 3 & 3 & 3 & 3 & 3 & 3 & 3 & 3 & 3 & 3 & 3 & 3 & 3 & 3 & 3 & 3 & 3 & 3 & 3 \\
\hline Switzerland & 2 & 2 & 2 & 2 & 2 & 2 & 2 & 2 & 2 & 2 & 2 & 2 & 2 & 2 & 2 & 2 & 2 & 2 & 2 & 2 \\
\hline $\begin{array}{l}\text { United } \\
\text { Kingdom }\end{array}$ & 2 & 2 & 2 & 2 & 2 & 2 & 2 & 2 & 2 & 2 & 2 & 2 & 2 & 2 & 2 & 2 & 2 & 4 & 4 & 4 \\
\hline United States & 4 & 4 & 4 & 4 & 4 & 4 & 4 & 4 & 4 & 4 & 4 & 4 & 4 & 4 & 4 & 4 & 4 & 4 & 4 & 4 \\
\hline
\end{tabular}




\begin{tabular}{|c|c|c|c|c|c|c|c|c|c|c|c|c|c|c|c|c|}
\hline Country & 2000 & 2001 & 2002 & 2003 & 2004 & 2005 & 2006 & 2007 & 2008 & 2009 & 2010 & 2011 & 2012 & 2013 & 2014 & 2015 \\
\hline Australia & 4 & 4 & 4 & 4 & 4 & 4 & 4 & 4 & 4 & 4 & 4 & 4 & 4 & 2 & 2 & 2 \\
\hline Austria & 5 & 5 & 5 & 5 & 3 & 3 & 3 & 3 & 3 & 3 & 3 & 3 & 3 & 3 & 3 & 3 \\
\hline Belgium & 3 & 3 & 3 & 3 & 3 & 3 & 3 & 3 & 3 & 3 & 3 & 3 & 3 & 3 & 3 & 3 \\
\hline Canada & 4 & 4 & 4 & 4 & 4 & 4 & 4 & 4 & 4 & 4 & 4 & 4 & 4 & 2 & 2 & 2 \\
\hline $\begin{array}{l}\text { Czech } \\
\text { Republic }\end{array}$ & & & & & & & & & & & & & & 3 & 3 & 3 \\
\hline Denmark & 1 & 1 & 1 & 1 & 1 & 1 & 1 & 1 & 1 & 1 & 1 & 1 & 1 & 1 & 1 & 1 \\
\hline Finland & 1 & 1 & 1 & 1 & 1 & 1 & 1 & 1 & 1 & 1 & 1 & 1 & 1 & 1 & 1 & 1 \\
\hline France & 3 & 3 & 3 & 3 & 3 & 3 & 3 & 3 & 3 & 3 & 3 & 3 & 3 & 3 & 3 & 3 \\
\hline Germany & 3 & 3 & 3 & 3 & 3 & 3 & 3 & 3 & 3 & 3 & 3 & 3 & 3 & 3 & 3 & 3 \\
\hline Greece & & & 2 & 2 & 2 & 2 & 2 & 2 & 2 & 2 & 2 & 2 & 2 & 2 & 2 & 2 \\
\hline Iceland & & & & & & & & & & & & & & 3 & 3 & 3 \\
\hline Ireland & 2 & 2 & 2 & 2 & 2 & 2 & 2 & 2 & 2 & 2 & 2 & 2 & 2 & 2 & 2 & 2 \\
\hline Italy & 2 & 2 & 2 & 2 & 2 & 2 & 2 & 2 & 2 & 2 & 2 & 2 & 2 & 2 & 3 & 3 \\
\hline Japan & 5 & 3 & 3 & 3 & 3 & 3 & 3 & 3 & 3 & 3 & 3 & 3 & 3 & 3 & 3 & 3 \\
\hline Korea & & & & & & & & & & & & & 3 & 3 & 3 & 3 \\
\hline Luxembourg & 3 & 3 & 3 & 3 & 3 & 3 & 3 & 3 & 3 & 3 & 3 & 3 & 3 & 3 & 3 & 3 \\
\hline Netherlands & 1 & 1 & 1 & 1 & 1 & 1 & 1 & 1 & 1 & 1 & 1 & 1 & 1 & 1 & 1 & 1 \\
\hline $\begin{array}{l}\text { New } \\
\text { Zealand }\end{array}$ & 2 & 2 & 2 & 2 & 2 & 2 & 2 & 2 & 2 & 2 & 2 & 2 & 2 & 2 & 2 & 2 \\
\hline Norway & 3 & 3 & 3 & 3 & 1 & 1 & 1 & 1 & 1 & 1 & 1 & 1 & 1 & 1 & 1 & 1 \\
\hline Poland & & & & & & & & & & & & & & 2 & 2 & 2 \\
\hline Portugal & 5 & 5 & 5 & 3 & 3 & 3 & 3 & 3 & 3 & 3 & 3 & 3 & 3 & 3 & 3 & 3 \\
\hline $\begin{array}{l}\text { Slovak } \\
\text { Republic }\end{array}$ & & & & & & & & & & & & & & 3 & 3 & 3 \\
\hline Slovenia & & & & & & & & & & & & & & 2 & 2 & 2 \\
\hline Spain & 5 & 5 & 5 & 5 & 5 & 3 & 3 & 3 & 3 & 3 & 3 & 3 & 3 & 3 & 3 & 3 \\
\hline Sweden & 3 & 3 & 3 & 3 & 3 & 3 & 3 & 3 & 3 & 3 & 3 & 3 & 3 & 3 & 3 & 3 \\
\hline Switzerland & 2 & 2 & 2 & 2 & 2 & 2 & 2 & 2 & 2 & 2 & 2 & 2 & 2 & 2 & 2 & 2 \\
\hline $\begin{array}{l}\text { United } \\
\text { Kingdom }\end{array}$ & 4 & 4 & 4 & 4 & 4 & 4 & 4 & 4 & 4 & 4 & 4 & 4 & 4 & 4 & 4 & 4 \\
\hline $\begin{array}{l}\text { United } \\
\text { States }\end{array}$ & 4 & 4 & 4 & 4 & 3 & 3 & 3 & 3 & 3 & 3 & 3 & 3 & 3 & 3 & 3 & 3 \\
\hline
\end{tabular}




\section{APPENDIX 3 - OECD-DAC Aid and Peer Review Schedule}

\begin{tabular}{|c|c|c|c|c|c|c|c|c|c|c|c|c|c|c|c|c|c|c|c|}
\hline & 1962 & 1963 & 1964 & 1965 & 1966 & 1967 & 1968 & 1969 & 1970 & 1971 & 1972 & 1973 & 1974 & 1975 & 1976 & 1977 & 1978 & 1979 & 1980 \\
\hline Australia & & & & & $\mathrm{X}$ & $\mathrm{X}$ & $\mathrm{X}$ & $\mathrm{X}$ & $\mathrm{X}$ & $\mathrm{X}$ & $\mathrm{X}$ & $\mathrm{X}$ & $\mathrm{X}$ & $\mathrm{X}$ & $\mathrm{X}$ & $\mathrm{X}$ & & $\mathrm{X}$ & \\
\hline Austria & & & & $\mathrm{X}$ & $\mathrm{X}$ & $\mathrm{X}$ & $\mathrm{X}$ & $\mathrm{X}$ & $\mathrm{X}$ & $\mathrm{X}$ & $\mathrm{X}$ & $\mathrm{X}$ & $\mathrm{X}$ & $\mathrm{X}$ & & & $\mathrm{X}$ & & $\mathrm{X}$ \\
\hline Belgium & $\mathrm{X}$ & $\mathrm{X}$ & $\mathrm{X}$ & $\mathrm{X}$ & $\mathrm{X}$ & $\mathrm{X}$ & $\mathrm{X}$ & $\mathrm{X}$ & $\mathrm{X}$ & $\mathrm{X}$ & $\mathrm{X}$ & $\mathrm{X}$ & $\mathrm{X}$ & $\mathrm{X}$ & & $\mathrm{X}$ & & $\mathrm{X}$ & \\
\hline Canada & $X$ & $\mathrm{X}$ & $\mathrm{X}$ & $\mathrm{X}$ & $\mathrm{X}$ & $\mathrm{X}$ & $\mathrm{X}$ & $X$ & $\mathrm{X}$ & $\mathrm{X}$ & $X$ & $\mathrm{X}$ & $X$ & $\mathrm{X}$ & & $\mathrm{X}$ & & $\mathrm{X}$ & $\mathrm{X}$ \\
\hline \multicolumn{20}{|l|}{$\begin{array}{l}\text { Czech } \\
\text { Republic }\end{array}$} \\
\hline Denmark & & $\mathrm{X}$ & $\mathrm{X}$ & $\mathrm{X}$ & $\mathrm{X}$ & $\mathrm{X}$ & $\mathrm{X}$ & $\mathrm{X}$ & $\mathrm{X}$ & $\mathrm{X}$ & $\mathrm{X}$ & $\mathrm{X}$ & $\mathrm{X}$ & $\mathrm{X}$ & $\mathrm{X}$ & & $\mathrm{X}$ & & $\mathrm{X}$ \\
\hline Finland & & & & & & & & & & & & & & $X$ & $X$ & & & $\mathrm{X}$ & $X$ \\
\hline France & $\mathrm{X}$ & $\mathrm{X}$ & $\mathrm{X}$ & $\mathrm{X}$ & $\mathrm{X}$ & $\mathrm{X}$ & $\mathrm{X}$ & $\mathrm{X}$ & $\mathrm{X}$ & $\mathrm{X}$ & $\mathrm{X}$ & $\mathrm{X}$ & $\mathrm{X}$ & $\mathrm{X}$ & $\mathrm{X}$ & & $\mathrm{X}$ & & $\mathrm{X}$ \\
\hline Germany & $\mathrm{X}$ & $\mathrm{X}$ & $\mathrm{X}$ & $\mathrm{X}$ & $\mathrm{X}$ & $\mathrm{X}$ & $\mathrm{X}$ & $\mathrm{X}$ & $\mathrm{X}$ & $\mathrm{X}$ & $\mathrm{X}$ & $\mathrm{X}$ & $\mathrm{X}$ & $\mathrm{X}$ & $\mathrm{X}$ & $\mathrm{X}$ & $\mathrm{X}$ & $\mathrm{X}$ & \\
\hline \multicolumn{20}{|l|}{ Greece } \\
\hline \multicolumn{20}{|l|}{ Iceland } \\
\hline \multicolumn{20}{|l|}{ Ireland } \\
\hline Italy & $\mathrm{X}$ & $\mathrm{X}$ & $\mathrm{X}$ & $\mathrm{X}$ & $\mathrm{X}$ & $\mathrm{X}$ & $\mathrm{X}$ & $\mathrm{X}$ & $\mathrm{X}$ & $\mathrm{X}$ & $\mathrm{X}$ & $\mathrm{X}$ & $\mathrm{X}$ & $\mathrm{X}$ & $\mathrm{X}$ & & & $\mathrm{X}$ & \\
\hline Japan & $\mathrm{X}$ & $\mathrm{X}$ & $\mathrm{X}$ & $\mathrm{X}$ & $\mathrm{X}$ & $\mathrm{X}$ & $\mathrm{X}$ & $X$ & $\mathrm{X}$ & $X$ & $X$ & $\mathrm{X}$ & $\mathrm{X}$ & $\mathrm{X}$ & $\mathrm{X}$ & $\mathrm{X}$ & $\mathrm{X}$ & $\mathrm{X}$ & $X$ \\
\hline \multicolumn{20}{|l|}{ Korea } \\
\hline \multicolumn{20}{|l|}{$\begin{array}{l}\text { Luxembou } \\
\text { rg }\end{array}$} \\
\hline $\begin{array}{l}\text { Netherland } \\
\mathrm{s}\end{array}$ & $\mathrm{X}$ & $\mathrm{X}$ & $\mathrm{X}$ & $\mathrm{X}$ & $\mathrm{X}$ & $X$ & $\mathrm{X}$ & $\mathrm{X}$ & $\mathrm{X}$ & $\mathrm{X}$ & $\mathrm{X}$ & $\mathrm{X}$ & $\mathrm{X}$ & $\mathrm{X}$ & $\mathrm{X}$ & & $\mathrm{X}$ & $\mathrm{X}$ & $\mathrm{X}$ \\
\hline $\begin{array}{l}\text { New } \\
\text { Zealand }\end{array}$ & & & & & & & & & & & & & $\mathrm{X}$ & $\mathrm{X}$ & & $\mathrm{X}$ & & $\mathrm{X}$ & \\
\hline Norway & & $\mathrm{X}$ & $\mathrm{X}$ & $\mathrm{X}$ & $\mathrm{X}$ & $\mathrm{X}$ & $\mathrm{X}$ & $\mathrm{X}$ & $\mathrm{X}$ & $\mathrm{X}$ & $\mathrm{X}$ & $\mathrm{X}$ & $\mathrm{X}$ & $\mathrm{X}$ & & $\mathrm{X}$ & & $\mathrm{X}$ & \\
\hline \multicolumn{20}{|l|}{ Poland } \\
\hline Portugal & $\mathrm{X}$ & $\mathrm{X}$ & $\mathrm{X}$ & $\mathrm{X}$ & $\mathrm{X}$ & & & & $\mathrm{X}$ & $\mathrm{X}$ & $\mathrm{X}$ & $\mathrm{X}$ & & & & & & & \\
\hline \multicolumn{20}{|l|}{$\begin{array}{l}\text { Slovak } \\
\text { Republic }\end{array}$} \\
\hline \multicolumn{20}{|l|}{ Slovenia } \\
\hline \multicolumn{20}{|l|}{ Spain } \\
\hline Sweden & & & & & $\mathrm{X}$ & $\mathrm{X}$ & $\mathrm{X}$ & $\mathrm{X}$ & $\mathrm{X}$ & $X$ & $X$ & $\mathrm{X}$ & $\mathrm{X}$ & $\mathrm{X}$ & & $\mathrm{X}$ & & $\mathrm{X}$ & \\
\hline $\begin{array}{l}\text { Switzerlan } \\
\text { d }\end{array}$ & & & & & & & $\mathrm{X}$ & $\mathrm{X}$ & $\mathrm{X}$ & $\mathrm{X}$ & $\mathrm{X}$ & $\mathrm{X}$ & $\mathrm{X}$ & $\mathrm{X}$ & & $\mathrm{X}$ & & & $\mathrm{X}$ \\
\hline $\begin{array}{l}\text { United } \\
\text { Kingdom }\end{array}$ & $\mathrm{X}$ & $\mathrm{X}$ & $\mathrm{X}$ & $\mathrm{X}$ & $\mathrm{X}$ & $\mathrm{X}$ & $\mathrm{X}$ & $\mathrm{X}$ & $\mathrm{X}$ & $\mathrm{X}$ & $\mathrm{X}$ & $\mathrm{X}$ & $\mathrm{X}$ & $\mathrm{X}$ & & $\mathrm{X}$ & & $\mathrm{X}$ & \\
\hline $\begin{array}{l}\text { United } \\
\text { States }\end{array}$ & $\mathrm{X}$ & $\mathrm{X}$ & $\mathrm{X}$ & $\mathrm{X}$ & $\bar{X}$ & $\mathrm{X}$ & $\mathrm{X}$ & $\mathrm{X}$ & $\mathrm{X}$ & $\mathrm{X}$ & $\mathrm{X}$ & $\mathrm{X}$ & $\mathrm{X}$ & $\mathrm{X}$ & $\mathrm{X}$ & $\mathrm{X}$ & $\mathrm{X}$ & $\mathrm{X}$ & \\
\hline
\end{tabular}




\begin{tabular}{|c|c|c|c|c|c|c|c|c|c|c|c|c|c|c|c|c|c|c|c|}
\hline & 1981 & 1982 & 1983 & 1984 & 1985 & 1986 & 1987 & 1988 & 1989 & 1990 & 1991 & 1992 & 1993 & 1994 & 1995 & 1996 & 1997 & 1998 & 1999 \\
\hline Australia & $\mathrm{X}$ & & $\mathrm{X}$ & & $\mathrm{X}$ & & $\mathrm{X}$ & & $\mathrm{X}$ & & & $\mathrm{X}$ & & & & $\mathrm{X}$ & & & $\mathrm{X}$ \\
\hline Austria & & $X$ & & $\mathrm{X}$ & & $\mathrm{X}$ & & $X$ & & $\mathrm{X}$ & & & $\mathrm{X}$ & & & $\mathrm{X}$ & & & $\mathrm{X}$ \\
\hline Belgium & $\mathrm{X}$ & & $\mathrm{X}$ & & & & $\mathrm{X}$ & & & $\mathrm{X}$ & & & & $\mathrm{X}$ & & & $\mathrm{X}$ & & \\
\hline Canada & & $\mathrm{X}$ & & $\mathrm{X}$ & & $\mathrm{X}$ & & $\mathrm{X}$ & & $X$ & & & & $\mathrm{X}$ & & & & $X$ & \\
\hline \multicolumn{20}{|l|}{$\begin{array}{l}\text { Czech } \\
\text { Republic }\end{array}$} \\
\hline Denmark & & & $\mathrm{X}$ & & $\mathrm{X}$ & & $\mathrm{X}$ & & $\mathrm{X}$ & & & $\mathrm{X}$ & & & $\mathrm{X}$ & & & & $\mathrm{X}$ \\
\hline Finland & & $\mathrm{X}$ & & $X$ & & $\mathrm{X}$ & & & $\mathrm{X}$ & & & $\mathrm{X}$ & & & $\mathrm{X}$ & & & $\mathrm{X}$ & \\
\hline France & & $\mathrm{X}$ & & $\mathrm{X}$ & & $\mathrm{X}$ & & & $\mathrm{X}$ & & $\mathrm{X}$ & & & $\mathrm{X}$ & & & $\mathrm{X}$ & & \\
\hline Germany & $\mathrm{X}$ & & $\mathrm{X}$ & & $\mathrm{X}$ & & $\mathrm{X}$ & & $\mathrm{X}$ & & & $\mathrm{X}$ & & & $\mathrm{X}$ & & & $\mathrm{X}$ & \\
\hline \multicolumn{20}{|l|}{ Greece } \\
\hline \multicolumn{20}{|l|}{ Iceland } \\
\hline Ireland & & & & & & $\mathrm{X}$ & & $\mathrm{X}$ & & & $\mathrm{X}$ & & & $\mathrm{X}$ & & & & & $\mathrm{X}$ \\
\hline Italy & $\mathrm{X}$ & & $\mathrm{X}$ & & $\mathrm{X}$ & & $X$ & & & $\mathrm{X}$ & & & $\mathrm{X}$ & & & $\mathrm{X}$ & & & \\
\hline Japan & & $\mathrm{X}$ & & $\mathrm{X}$ & & & $\mathrm{X}$ & & $\mathrm{X}$ & & $\mathrm{X}$ & & $\mathrm{X}$ & & $\mathrm{X}$ & & & & $\mathrm{X}$ \\
\hline \multicolumn{20}{|l|}{ Korea } \\
\hline Luxembourg & & & & & & & & & & & & & $X$ & & & & & $X$ & \\
\hline Netherlands & & $\mathrm{X}$ & & & $\mathrm{X}$ & & $\mathrm{X}$ & & $\mathrm{X}$ & & & $\mathrm{X}$ & & $\mathrm{X}$ & & & $\mathrm{X}$ & & \\
\hline New Zealand & $\mathrm{X}$ & & $\mathrm{X}$ & & $X$ & & $\mathrm{X}$ & & $X$ & & & $\mathrm{X}$ & & & & $X$ & & & \\
\hline Norway & $\mathrm{X}$ & & $\mathrm{X}$ & & $\mathrm{X}$ & & & $\mathrm{X}$ & & $\mathrm{X}$ & & & $\mathrm{X}$ & & $\mathrm{X}$ & & & & $\mathrm{X}$ \\
\hline \multicolumn{20}{|l|}{ Poland } \\
\hline Portugal & & & & & & & & & & & & & $\mathrm{X}$ & & & & $\mathrm{X}$ & & \\
\hline \multicolumn{20}{|l|}{$\begin{array}{l}\text { Slovak } \\
\text { Republic }\end{array}$} \\
\hline \multicolumn{20}{|l|}{ Slovenia } \\
\hline Spain & & & & & & & & & & & & & & $X$ & & & & $X$ & \\
\hline Sweden & $\mathrm{X}$ & & $\mathrm{X}$ & & $\mathrm{X}$ & & $\mathrm{X}$ & & & $\mathrm{X}$ & & $\mathrm{X}$ & & & & $\mathrm{X}$ & & & \\
\hline Switzerland & & $X$ & & $\mathrm{X}$ & & $\mathrm{X}$ & & $\mathrm{X}$ & & $X$ & & & $\mathrm{X}$ & & & $\mathrm{X}$ & & & \\
\hline $\begin{array}{l}\text { United } \\
\text { Kingdom }\end{array}$ & $\mathrm{X}$ & $X$ & & $\mathrm{X}$ & & $\mathrm{X}$ & & $\mathrm{X}$ & & & $X$ & & & $\mathrm{X}$ & & & $\mathrm{X}$ & & \\
\hline United States & $\mathrm{X}$ & $\mathrm{X}$ & & & $\mathrm{X}$ & & $\mathrm{X}$ & & $\mathrm{X}$ & & & $\mathrm{X}$ & & $\mathrm{X}$ & & & & $\mathrm{X}$ & \\
\hline
\end{tabular}




\begin{tabular}{|c|c|c|c|c|c|c|c|c|c|c|c|c|c|c|c|c|c|c|}
\hline & 2000 & 2001 & 2002 & 2003 & 2004 & 2005 & 2006 & 2007 & 2008 & 2009 & 2010 & 2011 & 2012 & 2013 & 2014 & 2015 & 2016 & 2017 \\
\hline Australia & & & & & $\mathrm{X}$ & & & & $\mathrm{X}$ & & & & & $\mathrm{X}$ & & & & \\
\hline Austria & & & & & $\mathrm{X}$ & & & & & $\mathrm{X}$ & & & & & $\mathrm{X}$ & & & \\
\hline Belgium & & $\mathrm{X}$ & & & & $\mathrm{X}$ & & & & & $\mathrm{X}$ & & & & & $\mathrm{X}$ & & \\
\hline Canada & & & $\mathrm{X}$ & & & & & $\mathrm{X}$ & & & & & $\mathrm{X}$ & & & & & \\
\hline Czech Republic & & & & & & & & & & & & & & & & & $\mathrm{X}$ & \\
\hline Denmark & & & & $\mathrm{X}$ & & & & $\mathrm{X}$ & & & & $\mathrm{X}$ & & & & & $\mathrm{X}$ & \\
\hline Finland & & & & $\mathrm{X}$ & & & & $\mathrm{X}$ & & & & & $\mathrm{X}$ & & & & & $\mathrm{X}$ \\
\hline France & $\mathrm{X}$ & & & & $\mathrm{X}$ & & & & $\mathrm{X}$ & & & & & $\mathrm{X}$ & & & & \\
\hline Germany & & $\mathrm{X}$ & & & & $\mathrm{X}$ & & & & & $\mathrm{X}$ & & & & & $\mathrm{X}$ & & \\
\hline Greece & & & $\mathrm{X}$ & & & & $\mathrm{X}$ & & & & & $\mathrm{X}$ & & & & & & \\
\hline Iceland & & & & & & & & & & & & & & & & & & $\mathrm{X}$ \\
\hline Ireland & & & & $\mathrm{X}$ & & & & & & $\mathrm{X}$ & & & & & $\mathrm{X}$ & & & \\
\hline Italy & $\mathrm{X}$ & & & & $\mathrm{X}$ & & & & & $\mathrm{X}$ & & & & & $\mathrm{X}$ & & & \\
\hline Japan & & & & $\mathrm{X}$ & & & & & & & $\mathrm{X}$ & & & & $\mathrm{X}$ & & & \\
\hline Korea & & & & & & & & & & & & & $\mathrm{X}$ & & & & & $\mathrm{X}$ \\
\hline Luxembourg & & & & $\mathrm{X}$ & & & & & $\mathrm{X}$ & & & & $\mathrm{X}$ & & & & & $\mathrm{X}$ \\
\hline Netherlands & & $\mathrm{X}$ & & & & & $\mathrm{X}$ & & & & & $\mathrm{X}$ & & & & & & $\mathrm{X}$ \\
\hline New Zealand & $\mathrm{X}$ & & & & & $\mathrm{X}$ & & & & & $\mathrm{X}$ & & & & & $\mathrm{X}$ & & \\
\hline Norway & & & & & $\mathrm{X}$ & & & & $\mathrm{X}$ & & & & & $\mathrm{X}$ & & & & \\
\hline Poland & & & & & & & & & & & & & & & & & $\mathrm{X}$ & \\
\hline Portugal & & $\mathrm{X}$ & & & & & $\mathrm{X}$ & & & & $\mathrm{X}$ & & & & & $\mathrm{X}$ & & \\
\hline $\begin{array}{l}\text { Slovak } \\
\text { Republic }\end{array}$ & & & & & & & & & & & & & & & & & & \\
\hline Slovenia & & & & & & & & & & & & & & & & & & $\mathrm{X}$ \\
\hline Spain & & & $\mathrm{X}$ & & & & & $\mathrm{X}$ & & & & $\mathrm{X}$ & & & & & $\mathrm{X}$ & \\
\hline Sweden & $\mathrm{X}$ & & & & & $\mathrm{X}$ & & & & $\mathrm{X}$ & & & & $\mathrm{X}$ & & & & \\
\hline Switzerland & $X$ & & & & & $\mathrm{X}$ & & & & $X$ & & & & $X$ & & & & \\
\hline $\begin{array}{l}\text { United } \\
\text { Kingdom }\end{array}$ & & $\mathrm{X}$ & & & & & $X$ & & & & $\mathrm{X}$ & & & & $\mathrm{X}$ & & & \\
\hline United States & & & $\mathrm{X}$ & & & & $\mathrm{X}$ & & & & & $\mathrm{X}$ & & & & & $\mathrm{X}$ & \\
\hline
\end{tabular}




\section{APPENDIX 4 - OECD-DAC Membership by Year}

\begin{tabular}{|c|c|}
\hline OECD-DAC Member & Year Joined \\
\hline Australia & 1966 \\
\hline Austria & 1965 \\
\hline Belgium & 1960 \\
\hline Canada & 1960 \\
\hline Czech Republic & 2013 \\
\hline Denmark & 1963 \\
\hline European Union & 1961 \\
\hline Finland & 1975 \\
\hline France & 1960 \\
\hline Germany & 1960 \\
\hline Greece & 1999 \\
\hline Iceland & 2013 \\
\hline Ireland & 1985 \\
\hline Italy & 1960 \\
\hline Japan & 1960 \\
\hline Korea & 2009 \\
\hline Luxembourg & 1992 \\
\hline The Netherlands & 1960 \\
\hline New Zealand & 1973 \\
\hline Norway & 1962 \\
\hline Poland & 2013 \\
\hline Portugal & $1960 / 1991$ \\
\hline Slovak Republic & 2013 \\
\hline Slovenia & 2013 \\
\hline Spain & 1991 \\
\hline Sweden & 1965 \\
\hline Switzerland & 1968 \\
\hline United Kingdom & 1961 \\
\hline United States & 1961 \\
\hline
\end{tabular}

All data was compiled from: OECD, "DAC in Dates: The History of OECD's Development Assistance Committee”, OECD: Paris, 2006. http://www.oecd.org/dac/1896808.pdf 


\begin{tabular}{|c|c|c|c|c|c|}
\hline & Model 1 & Model 2 & Model 3 & Model 4 & Model 5 \\
\hline$\%$ ODA to top $10 \mathrm{UN}$ voting partners & $\begin{array}{c}-0.063 * * * \\
(0.013)\end{array}$ & $\begin{array}{c}0.057 * * * \\
(0.014)\end{array}$ & $\begin{array}{c}0.005 \\
(0.019)\end{array}$ & $\begin{array}{l}0.013^{*} \\
(0.005)\end{array}$ & $\begin{array}{l}-0.013^{*} \\
(0.006)\end{array}$ \\
\hline$\%$ ODA to LDCs and LICs & $\begin{array}{c}-0.002 \\
(0.002)\end{array}$ & $\begin{array}{c}0.007 \\
(0.005)\end{array}$ & $\begin{array}{c}-0.009 \\
(0.006)\end{array}$ & $\begin{array}{l}0.006+ \\
(0.003)\end{array}$ & $\begin{array}{l}-0.003 \\
(0.002)\end{array}$ \\
\hline$\%$ ODA to top 10 trading partners & $\begin{array}{c}-0.008^{* *} \\
(0.003)\end{array}$ & $\begin{array}{c}0.000 \\
(0.004)\end{array}$ & $\begin{array}{c}0.001 \\
(0.004)\end{array}$ & $\begin{array}{c}0.011 * * * \\
(0.002)\end{array}$ & $\begin{array}{l}-0.003^{*} \\
(0.001)\end{array}$ \\
\hline Humanitarian as $\%$ of ODA & $\begin{array}{c}0.000 \\
(0.003)\end{array}$ & $\begin{array}{l}-0.009 \\
(0.011)\end{array}$ & $\begin{array}{c}0.026^{* *} \\
(0.010)\end{array}$ & $\begin{array}{c}-0.005 \\
(0.008)\end{array}$ & $\begin{array}{c}-0.012 * * \\
(0.004)\end{array}$ \\
\hline ODA as $\%$ of GNI & $\begin{array}{c}0.132 * * * \\
(0.019)\end{array}$ & $\begin{array}{l}-0.089 \\
(0.065)\end{array}$ & $\begin{array}{c}0.056 \\
(0.073)\end{array}$ & $\begin{array}{l}-0.082 * \\
(0.041)\end{array}$ & $\begin{array}{l}-0.017 \\
(0.033)\end{array}$ \\
\hline ODA (budget size) & $\begin{array}{l}-0.001 \\
(0.009)\end{array}$ & $\begin{array}{c}-0.131 * * * \\
(0.030)\end{array}$ & $\begin{array}{l}-0.064^{*} \\
(0.032)\end{array}$ & $\begin{array}{c}0.188 * * * \\
(0.023)\end{array}$ & $\begin{array}{c}0.008 \\
(0.013)\end{array}$ \\
\hline Ideology of Executive & $\begin{array}{c}0.000 \\
(0.001)\end{array}$ & $\begin{array}{c}0.008 * * \\
(0.003)\end{array}$ & $\begin{array}{l}-0.006^{*} \\
(0.003)\end{array}$ & $\begin{array}{c}-0.002 \\
(0.001)\end{array}$ & $\begin{array}{l}-0.001 \\
(0.001)\end{array}$ \\
\hline Admin as $\%$ of ODA & $\begin{array}{c}0.029 * * * \\
(0.008)\end{array}$ & $\begin{array}{c}-0.012 \\
(0.014)\end{array}$ & $\begin{array}{c}-0.015 \\
(0.020)\end{array}$ & $\begin{array}{c}0.012 \\
(0.008)\end{array}$ & $\begin{array}{l}-0.013 \\
(0.010)\end{array}$ \\
\hline Disbursements as $\%$ of commitments & $\begin{array}{c}-0.001+ \\
(0.001)\end{array}$ & $\begin{array}{l}-0.005+ \\
(0.003)\end{array}$ & $\begin{array}{l}0.004 * \\
(0.002)\end{array}$ & $\begin{array}{c}0.001 \\
(0.001)\end{array}$ & $\begin{array}{c}0.000 \\
(0.001)\end{array}$ \\
\hline Model Count & $\begin{array}{c}-0.004 * * * \\
(0.001)\end{array}$ & $\begin{array}{l}0.005+ \\
(0.003)\end{array}$ & $\begin{array}{c}-0.009 * * \\
(0.003)\end{array}$ & $\begin{array}{c}0.004 * * * \\
(0.001)\end{array}$ & $\begin{array}{l}0.004 * \\
(0.002)\end{array}$ \\
\hline Country Programming & $\begin{array}{l}0.391+ \\
(0.219)\end{array}$ & $\begin{array}{c}-0.267+ \\
(0.145)\end{array}$ & $\begin{array}{l}-0.294+ \\
(0.174)\end{array}$ & $\begin{array}{c}0.455^{* * *} \\
(0.078)\end{array}$ & $\begin{array}{c}-0.284 * * * \\
(0.056)\end{array}$ \\
\hline Presidential/Parliamentary & $\begin{array}{l}0.040+ \\
(0.024)\end{array}$ & $\begin{array}{l}-0.066 \\
(0.068)\end{array}$ & $\begin{array}{c}0.392 * * * \\
(0.069)\end{array}$ & $\begin{array}{c}-0.429 * * * \\
(0.052)\end{array}$ & $\begin{array}{c}0.063 \\
(0.049)\end{array}$ \\
\hline Unitary/Federal & $\begin{array}{c}-0.254 * * * \\
(0.053)\end{array}$ & $\begin{array}{l}-0.173^{*} \\
(0.069)\end{array}$ & $\begin{array}{l}0.209^{*} \\
(0.092)\end{array}$ & $\begin{array}{c}0.202 * * * \\
(0.049)\end{array}$ & $\begin{array}{c}0.016 \\
(0.044)\end{array}$ \\
\hline NPM & $\begin{array}{c}0.189 * * * \\
(0.054)\end{array}$ & $\begin{array}{l}-0.224^{*} \\
(0.091)\end{array}$ & $\begin{array}{l}-0.102 \\
(0.111)\end{array}$ & $\begin{array}{l}-0.023 \\
(0.020)\end{array}$ & $\begin{array}{c}0.160 * * * \\
(0.038)\end{array}$ \\
\hline Unemployment & $\begin{array}{c}0.007 \\
(0.005)\end{array}$ & $\begin{array}{l}0.018^{*} \\
(0.007)\end{array}$ & $\begin{array}{c}-0.029^{* *} \\
(0.010)\end{array}$ & $\begin{array}{c}0.005 \\
(0.004)\end{array}$ & $\begin{array}{l}-0.001 \\
(0.003)\end{array}$ \\
\hline Fiscal Balance (surplus, deficit) & $\begin{array}{c}-0.006 * * \\
(0.002)\end{array}$ & $\begin{array}{c}0.002 \\
(0.006)\end{array}$ & $\begin{array}{c}0.029 * * * \\
(0.008)\end{array}$ & $\begin{array}{c}-0.016^{* *} \\
(0.005)\end{array}$ & $\begin{array}{c}-0.010^{* *} \\
(0.004)\end{array}$ \\
\hline Observations & 665 & 665 & 665 & 665 & 665 \\
\hline
\end{tabular}




\section{APPENDIX 6: Estimation 3 - Annual Model, no outliers}

\begin{tabular}{|c|c|c|c|c|c|}
\hline & Model 1 & Model 2 & Model 3 & Model 4 & Model 5 \\
\hline$\%$ ODA to top $10 \mathrm{UN}$ voting partners & $\begin{array}{c}-0.028 * * \\
(0.011)\end{array}$ & $\begin{array}{c}0.017 * * \\
(0.006)\end{array}$ & $\begin{array}{c}0.002 \\
(0.010)\end{array}$ & $\begin{array}{c}0.014 * * \\
(0.004)\end{array}$ & $\begin{array}{c}-0.005 \\
(0.004)\end{array}$ \\
\hline$\%$ ODA to LDCs and LICs & $\begin{array}{c}-0.003 * * \\
(0.001)\end{array}$ & $\begin{array}{c}0.004 \\
(0.003)\end{array}$ & $\begin{array}{l}-0.002 \\
(0.004)\end{array}$ & $\begin{array}{c}0.002 \\
(0.002)\end{array}$ & $\begin{array}{c}0.000 \\
(0.001)\end{array}$ \\
\hline$\%$ ODA to top 10 trading partners & $\begin{array}{c}-0.011 * * * \\
(0.002)\end{array}$ & $\begin{array}{c}0.000 \\
(0.003)\end{array}$ & $\begin{array}{c}0.005 \\
(0.004)\end{array}$ & $\begin{array}{c}0.006^{* * *} \\
(0.002)\end{array}$ & $\begin{array}{c}0.001 \\
(0.001)\end{array}$ \\
\hline Humanitarian as $\%$ of ODA & $\begin{array}{c}0.002 \\
(0.001)\end{array}$ & $\begin{array}{c}0.006 \\
(0.009)\end{array}$ & $\begin{array}{l}0.021 * \\
(0.009)\end{array}$ & $\begin{array}{c}0.001 \\
(0.006)\end{array}$ & $\begin{array}{c}-0.030 * * * \\
(0.009)\end{array}$ \\
\hline ODA as $\%$ of GNI & $\begin{array}{c}0.187 * * * \\
(0.031)\end{array}$ & $\begin{array}{c}-0.067 \\
(0.067)\end{array}$ & $\begin{array}{c}0.022 \\
(0.083)\end{array}$ & $\begin{array}{c}-0.053 \\
(0.056)\end{array}$ & $\begin{array}{c}-0.090+ \\
(0.054)\end{array}$ \\
\hline ODA (budget size) & $\begin{array}{c}0.006 \\
(0.011)\end{array}$ & $\begin{array}{c}-0.116^{* * *} \\
(0.029)\end{array}$ & $\begin{array}{c}-0.031 \\
(0.044)\end{array}$ & $\begin{array}{c}0.127 * * * \\
(0.031)\end{array}$ & $\begin{array}{c}0.015 \\
(0.017)\end{array}$ \\
\hline Ideology of Executive & $\begin{array}{c}-0.001 * * \\
(0.000)\end{array}$ & $\begin{array}{c}0.009 * * * \\
(0.002)\end{array}$ & $\begin{array}{c}-0.005 * \\
(0.002)\end{array}$ & $\begin{array}{l}-0.002 \\
(0.002)\end{array}$ & $\begin{array}{c}0.000 \\
(0.001)\end{array}$ \\
\hline Admin as $\%$ of ODA & $\begin{array}{c}0.030 * * * \\
(0.007)\end{array}$ & $\begin{array}{c}-0.039 * * \\
(0.015)\end{array}$ & $\begin{array}{l}-0.008 \\
(0.020)\end{array}$ & $\begin{array}{c}0.020 \\
(0.012)\end{array}$ & $\begin{array}{c}-0.003 \\
(0.008)\end{array}$ \\
\hline Disbursements as $\%$ of commitments & $\begin{array}{c}-0.000 * \\
(0.000)\end{array}$ & $\begin{array}{c}-0.002+ \\
(0.001)\end{array}$ & $\begin{array}{c}0.001 \\
(0.001)\end{array}$ & $\begin{array}{c}0.001 \\
(0.001)\end{array}$ & $\begin{array}{c}0.000 \\
(0.000)\end{array}$ \\
\hline Model Count & $\begin{array}{c}-0.007 * * * \\
(0.001)\end{array}$ & $\begin{array}{l}0.007 * \\
(0.003)\end{array}$ & $\begin{array}{c}-0.007 * \\
(0.003)\end{array}$ & $\begin{array}{c}0.002 * * * \\
(0.001)\end{array}$ & $\begin{array}{l}0.005 * \\
(0.002)\end{array}$ \\
\hline Country Programming & $\begin{array}{c}0.193 * * \\
(0.074)\end{array}$ & $\begin{array}{c}-0.311 * * * \\
(0.078)\end{array}$ & $\begin{array}{c}0.076 \\
(0.113)\end{array}$ & $\begin{array}{c}0.218 * * * \\
(0.057)\end{array}$ & $\begin{array}{c}-0.176 * * * \\
(0.037)\end{array}$ \\
\hline Presidential/Parliamentary & $\begin{array}{c}0.105 * * * \\
(0.021)\end{array}$ & $\begin{array}{c}-0.119 \\
(0.078)\end{array}$ & $\begin{array}{c}0.347 * * * \\
(0.087)\end{array}$ & $\begin{array}{c}-0.355^{* * *} * \\
(0.068)\end{array}$ & $\begin{array}{c}0.022 \\
(0.039)\end{array}$ \\
\hline Unitary/Federal & $\begin{array}{c}-0.322 * * * \\
(0.050)\end{array}$ & $\begin{array}{l}-0.107 \\
(0.088)\end{array}$ & $\begin{array}{l}0.197 * \\
(0.084)\end{array}$ & $\begin{array}{c}0.216^{* * *} \\
(0.051)\end{array}$ & $\begin{array}{c}0.016 \\
(0.051)\end{array}$ \\
\hline NPM & $\begin{array}{c}0.300 * * * \\
(0.037)\end{array}$ & $\begin{array}{c}-0.161 * \\
(0.077)\end{array}$ & $\begin{array}{c}-0.044 \\
(0.093)\end{array}$ & $\begin{array}{c}-0.142 * * * \\
(0.039)\end{array}$ & $\begin{array}{c}0.047 \\
(0.032)\end{array}$ \\
\hline Unemployment & $\begin{array}{l}0.006+ \\
(0.003)\end{array}$ & $\begin{array}{l}0.012+ \\
(0.007)\end{array}$ & $\begin{array}{c}-0.014 \\
(0.008)\end{array}$ & $\begin{array}{c}-0.003 \\
(0.003)\end{array}$ & $\begin{array}{l}-0.001 \\
(0.004)\end{array}$ \\
\hline Fiscal Balance (surplus, deficit) & $\begin{array}{l}-0.004 * \\
(0.002)\end{array}$ & $\begin{array}{c}0.002 \\
(0.003)\end{array}$ & $\begin{array}{c}0.007 \\
(0.004)\end{array}$ & $\begin{array}{c}-0.006 * * \\
(0.002)\end{array}$ & $\begin{array}{c}0.000 \\
(0.003)\end{array}$ \\
\hline Observations & 674 & 674 & 674 & 674 & 674 \\
\hline
\end{tabular}


APPENDIX 7: Correlation of Variables for Multinomial Logit

\begin{tabular}{|c|c|c|c|c|c|c|c|c|c|c|c|c|c|c|c|c|}
\hline & GNI & ODA & Admin & Ideology & Vote & Poor & Trade & Humanitarian & Commitments & $\begin{array}{l}\text { Model } \\
\text { Count }\end{array}$ & President & Federal & $\begin{array}{l}\text { Country } \\
\text { program }\end{array}$ & NPM & $\begin{array}{l}\text { Unemploy } \\
\text { ment }\end{array}$ & $\begin{array}{l}\text { Debt- } \\
\text { to- } \\
\text { GDP }\end{array}$ \\
\hline GNI & 1.00 & & & & & & & & & & & & & & & \\
\hline ODA & 0.10 & 1.00 & & & & & & & & & & & & & & \\
\hline Admin & -0.06 & 0.08 & 1.00 & & & & & & & & & & & & & \\
\hline Ideology & -0.17 & 0.11 & 0.13 & 1.00 & & & & & & & & & & & & \\
\hline Vote & -0.16 & 0.06 & -0.07 & 0.08 & 1.00 & & & & & & & & & & & \\
\hline Poor & 0.34 & -0.12 & -0.00 & -0.07 & -0.23 & 1.00 & & & & & & & & & & \\
\hline Trade & -0.06 & -0.03 & -0.30 & -0.07 & 0.25 & -0.24 & 1.00 & & & & & & & & & \\
\hline $\begin{array}{l}\text { Humanita } \\
\text { rian }\end{array}$ & 0.08 & 0.02 & 0.31 & 0.06 & -0.15 & 0.24 & -0.35 & 1.00 & & & & & & & & \\
\hline $\begin{array}{l}\text { Commit } \\
\text { ments }\end{array}$ & 0.21 & -0.03 & -0.01 & $\begin{array}{l}-0.09 \\
\end{array}$ & -0.07 & 0.10 & 0.03 & -0.01 & 1.00 & & & & & & & \\
\hline $\begin{array}{l}\text { Model } \\
\text { Count }\end{array}$ & -0.08 & 0.25 & 0.23 & 0.07 & 0.05 & -0.00 & -0.19 & 0.21 & 0.00 & 1.00 & & & & & & \\
\hline President & -0.37 & 0.02 & -0.09 & -0.01 & 0.13 & -0.13 & 0.05 & -0.06 & -0.10 & 0.05 & 1.00 & & & & & \\
\hline Federal & -0.26 & 0.22 & -0.01 & 0.10 & 0.17 & -0.25 & 0.13 & -0.00 & -0.07 & 0.18 & 0.24 & 1.00 & & & & \\
\hline $\begin{array}{l}\text { Country } \\
\text { program }\end{array}$ & 0.22 & 0.24 & 0.25 & 0.05 & -0.15 & 0.14 & -0.46 & 0.25 & 0.03 & 0.16 & -0.09 & 0.04 & 1.00 & & & \\
\hline NPM & -0.06 & 0.07 & 0.24 & 0.13 & -0.18 & 0.02 & -0.19 & 0.22 & 0.18 & 0.24 & 0.07 & -0.04 & 0.26 & 1.00 & & \\
\hline $\begin{array}{l}\text { Unemplo } \\
\text { yment }\end{array}$ & -0.22 & -0.09 & -0.01 & 0.11 & -0.07 & -0.09 & -0.05 & -0.14 & 0.11 & -0.08 & -0.01 & 0.09 & -0.05 & 0.26 & 1.00 & \\
\hline $\begin{array}{l}\text { Debt-to- } \\
\text { GDP }\end{array}$ & -0.06 & 0.09 & 0.00 & 0.07 & -0.01 & -0.03 & 0.05 & -0.05 & -0.03 & -0.01 & 0.07 & -0.05 & -0.08 & 0.06 & 0.22 & 1.00 \\
\hline
\end{tabular}




\section{APPENDIX 8: Correlation of Variables for Rare-events Logit}

\begin{tabular}{|c|c|c|c|c|c|c|c|c|c|c|c|c|c|c|}
\hline & GNI & ODA & Admin & Ideology & Vote & Poor & Trade & Humanitarian & Commitments & $\begin{array}{l}\text { Country } \\
\text { program }\end{array}$ & NPM & Unemployment & $\begin{array}{l}\text { Debt- } \\
\text { to- } \\
\text { GDP }\end{array}$ & Structural \\
\hline GNI & 1.00 & & & & & & & & & & & & & \\
\hline ODA & 0.36 & 1.00 & & & & & & & & & & & & \\
\hline Admin & -0.43 & $\begin{array}{l}-0.33 \\
\end{array}$ & 1.00 & & & & & & & & & & & \\
\hline Ideology & 0.02 & $\begin{array}{l}-0.01 \\
\end{array}$ & 0.03 & 1.00 & & & & & & & & & & \\
\hline Vote & -0.14 & -0.05 & 0.00 & -0.00 & 1.00 & & & & & & & & & \\
\hline Poor & -0.04 & 0.00 & 0.15 & -0.02 & -0.00 & 1.00 & & & & & & & & \\
\hline Trade & 0.20 & 0.04 & -0.20 & -0.03 & 0.08 & -0.23 & 1.00 & & & & & & & \\
\hline Humanitarian & -0.02 & 0.01 & 0.04 & -0.05 & 0.01 & 0.05 & -0.04 & 1.00 & & & & & & \\
\hline Commitments & 0.15 & 0.14 & -0.23 & 0.06 & -0.04 & -0.04 & 0.03 & -0.12 & 1.00 & & & & & \\
\hline $\begin{array}{l}\text { Country } \\
\text { program }\end{array}$ & 0.01 & 0.00 & -0.00 & $\begin{array}{l}-0.00 \\
\end{array}$ & 0.01 & -0.04 & 0.08 & 0.00 & 0.03 & 1.00 & & & & \\
\hline NPM & $\begin{array}{l}-0.09 \\
\end{array}$ & 0.01 & 0.05 & 0.02 & 0.00 & 0.01 & 0.02 & 0.02 & 0.03 & 0.18 & 1.00 & & & \\
\hline Unemployment & 0.04 & 0.01 & 0.04 & 0.09 & -0.03 & 0.01 & -0.02 & -0.03 & 0.06 & -0.09 & -0.11 & 1.00 & & \\
\hline Debt-to-GDP & -0.01 & 0.02 & 0.01 & 0.01 & -0.01 & -0.03 & 0.03 & -0.02 & 0.01 & -0.09 & 0.07 & 0.43 & 1.00 & \\
\hline Structural & $\begin{array}{l}-0.03 \\
\end{array}$ & $\begin{array}{l}-0.03 \\
\end{array}$ & $\begin{array}{l}-0.00 \\
\end{array}$ & -0.07 & -0.00 & 0.04 & 0.01 & $\begin{array}{c}-0.03 \\
\end{array}$ & -0.00 & -0.06 & -0.09 & 0.06 & -0.02 & 1.00 \\
\hline
\end{tabular}

